University of Rhode Island

DigitalCommons@URI

Open Access Dissertations

1991

\title{
Modeling Vessel Mobility: The Gulf of Mexico Shrimp Fleet
}

John Michael Ward

University of Rhode Island

Follow this and additional works at: https://digitalcommons.uri.edu/oa_diss

\section{Recommended Citation}

Ward, John Michael, "Modeling Vessel Mobility: The Gulf of Mexico Shrimp Fleet" (1991). Open Access Dissertations. Paper 975.

https://digitalcommons.uri.edu/oa_diss/975

This Dissertation is brought to you for free and open access by DigitalCommons@URI. It has been accepted for inclusion in Open Access Dissertations by an authorized administrator of DigitalCommons@URI. For more information, please contact digitalcommons-group@uri.edu. 


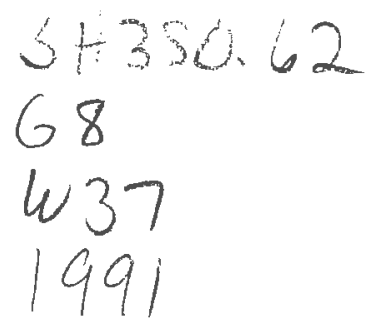

MODELLING VESSEL MOBILITY:

THE GULF OF MEXICO SHRIMP FLEET

BY

JOHN MICHAEL WARD

A DISSERTATION SUBMITTED IN PARTIAL FULFILLMENT OF THE REQUIREMENTS FOR THE DEGREE OF

DOCTOR OF PHILOSOPHY

IN

RESOURCE ECONOMICS

27202629

UNIVERSITY OF RHODE ISLAND 


\begin{abstract}
Given the heterogeneous nature of the fishing fleet and the complex behavior of vessels, the traditional marginalist supply models are not well suited for modelling vessel mobility. A discrete choice model is utilized in this analysis to predict the probability that a vessel will enter, exit, or remain in the Gulf of Mexico shrimp fishery based on a myopic profit maximization criteria. The multinomial logit model indicates that fisherman behavior in the Gulf of Mexico shrimp fishery is not influenced by stock variability. The crowding externality as represented by the size of the fishing fleet exhibited a strong negative impact on the probability of entry by fishing vessels independent of changes in abundance, exvessel prices, or harvesting costs. Lastly, the Gulf of Mexico shrimp fishery was not an autonomous system of fishing vessels as was initially believed.
\end{abstract}




\section{Acknowledgements}

A special thanks is accorded to Richard Raulerson for his help in completing and support of this project. Betty Guisinger, Guy Davenport, and J. Ernest snell were particularly helpful in setting up meetings with shrimp fishermen and dealers, explaining National Marine Fisheries Service (NMFS) data sets, and changes in collection methods that occurred over time. Without the assistance of Brett Schavey and Mary Anne Treadway in accessing the NMFS computer in Miami, FL and seattle, WA, this project never would have been completed. The credit for the original idea of studying fleet entry-exit dynamics belongs to Fred Prochaska of the University of Florida. I also feel a debt of gratitude to Virgil Norton who talked me into applying to the University of Rhode. Island. I particularly enjoyed working with Jon Sutinen on this dissertation and appreciate his interest, patience, and endurance; any credit derived from this dissertation is totally due to his influence. Beth Ward deserves much more than an acknowledgement for the help and support she gave me, for the lonely nights at home while I worked on this dissertation, and for raising my son which was no small task since he took after me. 
Preface

"Well, I mean, yes, idealism, yes the dignity of pure research, yes the pursuit of truth in all its forms, but there comes a point I'm afraid where you begin to suspect that if there's any real truth, its that the entire multidimensional infinity of the Universe is almost certainly run by a bunch of maniacs. And if it comes to a choice between spending yet another ten million years finding that out, and on the other hand just taking the money and running, then I for one could do with the exercise."1

Although bioeconomics has been in existence since Gordon wrote "the article" ${ }^{2}$, resistance to the idea that externalities could be the root cause of the fisheries management problem still exists. Managers have typically resorted to biologically based regulations such as total quotas, closed areas, fishing seasons, and prohibiting the use of efficient fishing gear. By concentrating on conserving the fish stock, the other resources used in the

'Douglas Adams, The Hitchhiker's Guide to the Galaxy, (New York: Crown Publishers, Inc., 1979), 200.

${ }^{2}$ H. S. Gordon, "The Economic Theory of a Common Property Resource: The Fishery," Journal of Political Economy 62 (1954): 124-142. The earliest reference belongs to J. Warming, "Om Grundrente af Fiskegrunde," Nationalфkonomisk Tidssdift 49 (1911): 499-505. 
fishery have not been allocated rationally; i.e. over capitalization has developed in the fleet, the fishery resource became overexploited, and the income levels of fishermen have beçome depressed. Unsophisticated bioeconomic models that demonstrate these results have not fazed fishery managers who often argue that fishermen behave irrationally and economics just does not work in this environment. The objective of this dissertation is to test the hypothesis that fishermen in the Gulf of Mexico shrimp fishery actually make an economically rational decision to enter, remain in, or exit the fishing fleet. This decision is based on a profit maximization motive in a highly competitive industry exploiting a commonly held fish resource.

A more practical application of this dissertation is the prediction of the change in fleet size that will result from the adoption of various management regulations and the length of time required to achieve the new equilibrium fleet size. By determining the long run impacts on fleet size and the change in net revenue, the benefits and costs of proposed management regulations can be estimated. Management regulations designed to correct or eliminate finfish bycatch are being developed for the Gulf of Mexico shrimp fishery. The impact of the proposed regulation on fleet size in the shrimp and related finfish fisheries could reduce or eliminate any benefits derived from correcting the 
problem in the shrimp fishery. Import restrictions on aquacultured and wild captured shrimp have been proposed time and again as a means of providing relief to the domestic shrimp industry. In conjunction with a model being developed at Louisiana State University that predicts dockside price changes due to import restrictions, the increase in fleet size could be predicted. Hopefully, both objectives of predicting changes in fleet size and that fishermen make economically rational decisions to enter, remain in, or exit the fishing fleet have been achieved. This dissertation follows the manuscript plan in developing a model of vessel entry-exit behavior for the Gulf of Mexico shrimp fishery using a multinomial logit specification. The shrimp fishery and the entry-exit behavior of vessels in the fleet is described first. Then, the relevant literature is reviewed. The model is presented next, followed by a discussion of the results. A summary of the relevant findings and results concludes the manuscript. The fishery is described in Appendix $\mathrm{A}$ and the literature is reviewed in Appendix B. Appendix C contains a description of the methods used to estimate the parameters of the indirect cost model. Appendix D contains the results from the estimation of the multinomial logit model. Appendix E provides a general discussion of policy, theory, and directions for future research. The bibliography follows these appendices. 
Táble of Contents

Modelling Vessel Mobility: The Gulf of Mexico Shrimp

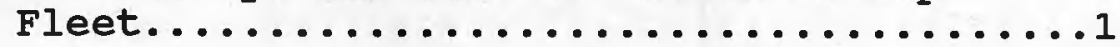

Appendix

Appendix A: Vessel Entry and Exit Behavior in the Gulf of Mexico Shrimp Fishery From 1965 - 1980...42

Appendix B: Literature Review.................... 70

Theoretical Entry-Exit Behavior........70

Gulf of Mexico Shrimp Fishery.........94

Qualitative Dependent Variables........113

Appendix C: An Indirect Total Cost Function for Vessels operating in the Southeast Region Shrimp Fishery......................147

Appendix D: Statistical Results of the Multinomial

Logit Procedure.................178

Introduction......................... 178

Statistical Result 1: Final Parameter

Estimates....................... 180

Statistical Result 2: Class Level Model Parameter

Estimates.............................

Statistical Result. 3: Length/Gross Tonnage Hypothesis

Test ...........................198

Statistical Result 4: Price/Cost Hypothesis Test...204

Statistical Result 5: Alternative Model Hypothesis

Test.........................11

Statistical Result 6: Nonconstant Stock Model.....218

Statistical Result 7: Rent Model............221

Appendix E: Directions for Future Research..........224

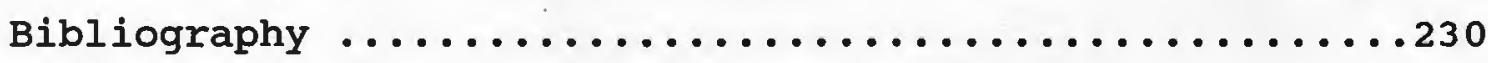




\section{List of Tables}

Table 1: Logit Procedure Results..................23

Table 2: Weighted. Frequency counts for the ordered

Response Categories.....................33

Appendix A

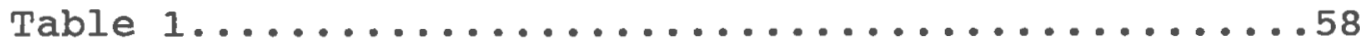

Appendix D

Table 1 Three-Stage Least Squares Estimation.......159

Table 2 Three-Stage Least Squares Estimation.......160

Table 3 ordinary Least Squares Estimation........161

Table 4 Variable Definitions................162 


\section{List of Figures}

Appendix A

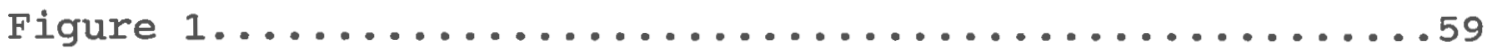

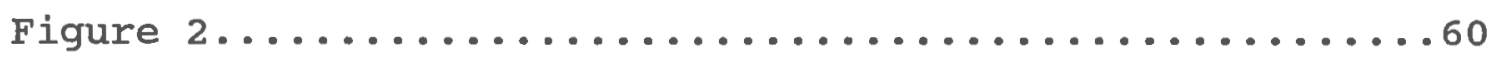

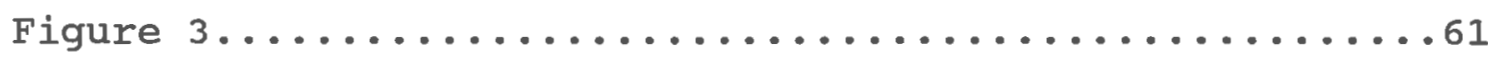

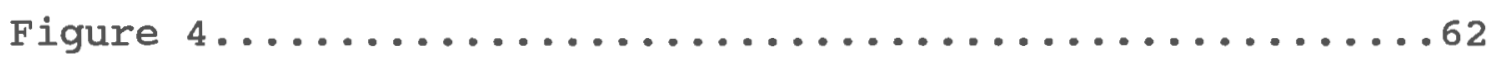

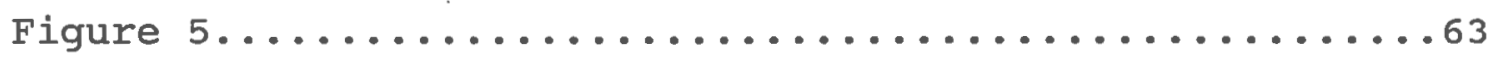

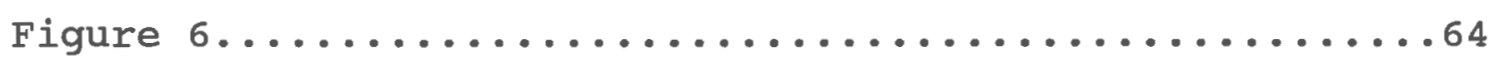

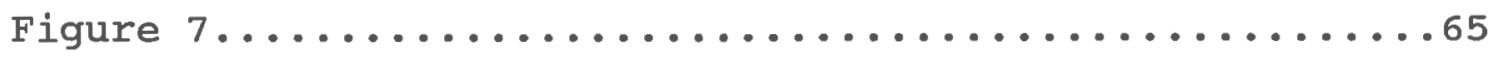

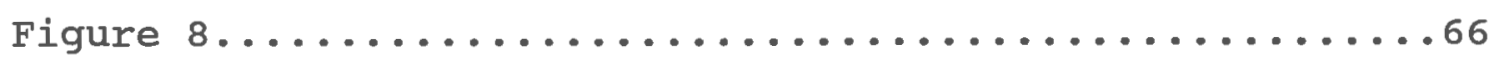

Figure $9 \ldots \ldots \ldots \ldots \ldots \ldots \ldots \ldots \ldots \ldots \ldots \ldots \ldots \ldots \ldots \ldots \ldots \ldots \ldots \ldots \ldots \ldots \ldots$

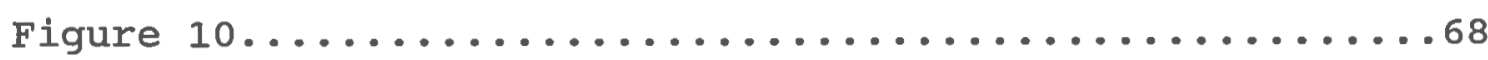

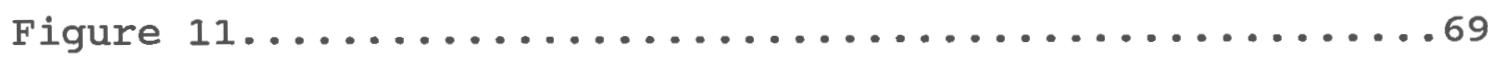




\section{Modelling Vessel Mobility: \\ The Gulf of Mexico shrimp Fleet}

\section{Introduction}

The common property shrimp fishery in the Gulf of Mexico is presently experiencing over capitalization in the harvesting sector (Nance, et. al., 1990), growth overfishing of the stock (Nichols, 1986), and the discarding of excessive amounts of bycatch. ${ }^{3}$ Fishery management regulations designed to correct these problems that fail to account for changing total effort levels often report benefits that are actually dissipated through increased participation in the fishery (Waters and Platt, 1990). Given the flexibility of the fishing fleet in responding to changing market and biological conditions in the shrimp and the related finfish fisheries and the general economy, determining the impacts of fishery management regulations on total effort levels requires an understanding of vessel entry-exit behavior.

${ }^{3}$ G.J. Pellegrin Jr., s.B. Drummond, and R.S. Ford, Jr., The Incidental Catch of Fish by the Northern Gulf of Mexico Shrimp Fleet. Draft Report, NOAA, NMFS, SEFC, Mississippi Laboratories, Pascagoula, MS, 1985 found finfish to shrimp ratios that ranged from $2: 1$ to $21.1: 1$. J.E. Powers, C.P. Goodyear, and G.P. Scott, The Potential Effect of Shrimp Fleet Bycatch on Fisheries Production of Selected Fish Stocks in the Gulf of Mexico, Draft Report, NOAA, NMFS, SEFC, Miami Laboratory, Miami, FL, 1987, for example, concluded that the elimination of red snapper from the shrimp bycatch would result in a ninety percent increase in this fish stock available to recreational and commercial finfish fishermen. 
The practical application of the theoretical

marginalist modelling approach is a problem when a heterogenous fleet with complex entry-exit behavior exists. Using aggregate data, models that determine total fleet size as some function of aggregate measures of explanatory variables (Ward, 1989b or Penson, et al., 1987) result in biased parameter estimates. ${ }^{4}$ The discrete choice model utilizes an econometric technique that resolves this problem by capturing the response of the individual firm to the many forces affecting its decision.

Although common in recreational fishery analyses (Milon, 1988 and Green, 1989), discrete choice models of commercial fishing activities are rare in the applied literature (Bockstael and Opaluch, 1983). A multinomial logit model utilizing the theory of the firm is used in this analysis to predict the probability that a vessel will enter, exit, or remain in the Gulf of Mexico shrimp fishery. The model assumes myopic profit maximization (stollery, 1987), a heterogeneous fleet operating in a highly competitive industry that faces a competitive processing industry, an externality caused by vessel crowding (Dasgupta and Heal, 1979 and Arnason, 1989), and highly variable

4The bias arises because the firm is assumed to respond to aggregate measures of the explanatory variables rather than to the actual values that the firm faces (N.E. Bockstael and J.J. Opaluch, "Discrete Modeling of Supply Response under Uncertainty: The Case of the Fishery," Journal of Environmental Economics and Management, 10 (1983): 125-137). 
recruitment that is representative of the Gulf of Mexico shrimp fishery (Anderson, 1989) with no stock-recruitment relationship (Garcia, 1988). Variability in the fishery is incorporated into the model using an approach suggested by McKelvey (1983) and Smith and McKelvey (1986) whereby a generalist fleet develops due to market or biological variability. The probability matrix estimated from the discrete choice model can be used to predict the number of vessels that will enter, remain in, or exit the shrimp fishery in response to changing biological and market conditions as well as proposed management scenarios.

\section{The Fishery}

Domestic shrimp landings in the Gulf of Mexico have ranged from 134 to 304 million pounds live weight between 1961 and 1990. Landings have gradually increased from an annual average of 193 million pounds between 1950 and 1980, to an average of 243 million pounds between 1980 and 1990 . The average real exvessel price of heads-off shrimp has declined forty-one percent during this thirty nine year period as imports increased 1,180 percent ${ }^{5}$.

With the gradual increase in the level of domestic landings, the number of vessels in the heterogenous Gulf of Mexico shrimp fishing fleet increased 102 percent between

${ }^{5}$ Personal Communication, Jon Vondruska as compiled from Fishery Statistics of the United states, 1950 to 1977 and Fisheries of the United States, 1978 to 1990, NOAA, NMFS, washington, D.C. 
1965 and $1988^{6}$ despite the decrease in the real exvessel price and increased harvesting capacity. While the fleet was expanding, approximately $20 \%$ of these vessels were engaged in some form of entry-exit behavior each year ${ }^{7}$. Between 1966 and 1979, an annual average of 515 vessels entered the shrimp fishery as new constructions or from other fisheries and 376 vessels exited the shrimp fishery, going to alternative fisheries or becoming inactive (Ward, 1989).

This entry-exit behavior is theorized to be partially the result of improved technology causing the displacement of the inefficient vessel, such as those with wood hulls, with the more efficient vessel possessing steel or fiberglass hulls. For example, vessels entering the fishery report higher average revenue and pounds landed per trip (averaging $\$ 3600$ and 2322 lbs) than vessels that are in the fishery ( $\$ 2556$ and 1680 . lbs.) while vessels exiting the 1988 .

${ }^{6}$ The last year for which reliable totals are available is

$7_{A}$ count of vessels in the vessel operating units files and the shrimp landings files by vessel documentation number for each year provides a list of vessels that access the Gulf of Mexico shrimp fishery. This list is then compared to a prior year and a subsequent year to determine the entries to and exits from the base year fishery. A vessel enters the base year fishery if it is not in the previous year's data file, but is in the base year and subsequent year files. A vessel exits the fishery if it appears in the previous and base year files, but not in the subsequent year file. A vessel that exits and then reenters the fishery two years later, for example, would be counted as an entry during that three year comparison. 
fishery have lower revenue and pounds per trip (averaging $\$ 1990$ and 1285 lbs.).8

Changes in market conditions could also have been responsible for the shift in fleet characteristics. Fuel cost increases, for example, tend to favor medium size vessel operations over large and small fishing craft. Although declining in absolute value, exvessel price has increased relative to shrimp harvesting costs and the prices of alternative finfish species. This increase in relative price may have increased the heterogeneity of the Gulf of Mexico shrimp fishing fleet by inducing vessels designed to operate in alternative fisheries to enter the shrimp fishery. These vessels increase the range of vessel characteristics found in the shrimp fishery. Management measures could be partially responsible for this entry-exit behavior. Reductions in the relative abundance of finfish stocks from overfishing, or because of management regulations, may encourage generalist fishermen to enter the

\footnotetext{
${ }^{8}$ Vessels in the fishery have the highest number of trips per vessel (averaging 17.9). Entering vessels average 9.9 trips and those that exit have 8.7 trips per vessel. The average number of annual trips per vessel for the vessels in the fishery of 17.9 is not that different from the estimate of 20 to 25 trips per vessel provided by the port agents. Personal communication, E. Snell, Supv. Survey statistician, Southeast Fishery Center, National Marine Fisheries Service, Miami, Fl.
} 
shrimp fishery forcing the specialized shrimp fisherman to exit the fishery. ${ }^{9}$

\section{Literature Review}

Models of fishing firm entry-exit behavior were first proposed by Smith $(1968,1969)$. Given homogeneous firms, fleet size is hypothesized to change proportionately to profits with entry faster than exit for specialist vessels and equal for generalist vessels. Clark, Clarke, and Munro (1979) incorporate capital cost, depreciation, and the degree of capital malleability into Smith's (1969) model and demonstrate that the fishery achieves the optimum sustained yield state in the long run when capital is perfectly malleable, but short run firm behavior is constrained by nonmalleable capital. McKelvey (1983) investigates the economic incentives that cause existing generalist vessels to enter a fishery and compete with specialist vessels in the harvest of a fishery resource. Smith and McKelvey (1986) cite case studies that support the contention that market and biological variability results in the development of a generalist fleet. Berck and Perloff (1982) demonstrate that Smith's (1969) entry-exit criteria is based on current profits (myopic expectations) and then extend it to include the discounted value of all future profits (rational expectations) derived from harvesting the resource. Both

${ }^{9}$ The vessels that exit the shrimp fishery may enter alternative finfish fisheries and further exacerbate their overcapitalization problems. 
the myopic and rational expectation models have the same equilibrium, but with the rational expectations model assuming perfect foresight entry will occur at lower levels of fish stock size and exit at higher levels than in the myopic model. Bjorndal and conrad (1987) found that current profits in the purse seine herring fishery were the primary basis of the investment decision that supported the myopic expectations model of Berck and Perloff (1982). After explicitly developing the myopic expectations model of Smith (1968), stollery (1987) extends the rational expectations approach of Berck and Perloff (1982) to study the effects of a monopsonistic processing sector on vessel entry and exit decisions in a competitive harvesting sector. Sutinen (1986) extends the theory by introducing the effect of seasonality or cyclical variation on the behavior of the fishing firm and industry.

Empirical estimates of the rate of capital investment in renewable resources have been derived for the fur seal industry and the Texas shrimp fishery. The fur seal industry (Paterson and wilen, 1977) was characterized by a stable spiral and, at the time of the international agreement to close the fishery, was experiencing a recovery of its stock because of economic conditions in the marketplace. The annual net investment model estimated by Penson, Tetty, and Griffin (1987) suggests that the low real interest rates designed to stimulate investment activities 
in the general economy increases capitalization in the shrimp fleet.

These theoretical and applied studies usually assume a homogeneous fishing fleet harvesting a homogeneous stock of fish. Changes in fleet size occur continuously and instantaneously as the optimal vessel enters or leaves the fishery with changing market conditions. While exhibiting many of the characteristics theoretically derived in the literature, actual fishing operations are characterized by heterogeneous fleets and multiple fish stocks. Bockstael and opaluch (1983) model the switching behavior of fisherman by employing a discrete choice approach because entry and exit occur simultaneously rather than being mutually exclusive actions. Utilizing a multinomial logit specification in a pooled coefficients model incorporating uncertainty and imperfect malleability of capital ${ }^{10}$ to predict choice of fishery, the authors found that increases in expected returns had a positive effect and variability in returns had a negative effect on the probability that fishermen would choose each feasible alternative.

In this analysis, a discrete choice model is utilized to predict the probability that a vessel will enter, exit,

${ }^{10}$ Inertia or imperfect malleability of capital in the Gulf of Mexico shrimp. fishery is not expected to be of concern since vessels have historically exhibited a high degree of mobility (Ward, 1989) and because $90 \%$ of the vessels in the southeastern region fisheries are capable of refitting and entering the shrimp fishery (Per. Comm., T. Allen, chief, Financial Services, NMFS). 
or remain in the Gulf of Mexico shrimp fishery. The model assumes that the individual firm uses myopic profit maximization as its entry-exit criteria (Stollery, 1987), that the heterogeneous fleet that operates in this highly competitive industry faces a competitive processing industry, an externality exists that is caused by vessel crowding (Dasgupta and Heal, 1979 and Arnason, 1989), and that the Gulf of Mexico shrimp fishery is characterized by highly variable recruitment (Anderson, 1989) with no stockrecruitment relationship (Garcia, 1988). Variability in the fishery is incorporated into the model using an approach suggested by McKelvey (1983) and Smith and McKelvey (1986) whereby a generalist fleet develops due to market or biological variability.

The Model

Shrimp in the Gulf of Mexico, unlike most fisheries that exploit multiple year classes, can be characterized as an annual crop, since being short lived they do not recruit into a second year class. Assuming that no growth or natural mortality occurs within the season, the shrimp stock declines according to

where

$$
\begin{aligned}
& \dot{B}_{i}(t)=-q \underset{v=1}{\sum_{i}^{N}} e_{i v} B_{i}(t) \\
& B_{i}(0)=R(A)
\end{aligned}
$$

$R(A)$ is the number of fish recruited annually into the fishery that varies over time due to environmental conditions, 
q is a proportionality constant that represents catchability of the fishing gear,

$B_{i}(t)$ is the total biomass of the fish stock in fishery $i$,

$\Sigma e_{i v}$ is the total fishing effort level of the vessels $v$ in the heterogeneous fleet for fishery $i$,

$N_{i}$ is the number of vessels $v$ in the active fleet for fishery $i$,

The individual shrimp fisherman acts to maximize the present value of profits (I) expressed as ${ }^{11}$

$$
\begin{aligned}
I=\operatorname{Max} & \int_{t=0}^{T} \cdot e^{-\delta t} \pi_{i} d t \\
\text { s.t. } & \dot{B}_{i}(t)=-\underset{v=1}{q \sum_{i v} e_{i} B_{i}(t)}
\end{aligned}
$$

where

$\pi_{i}$ is profit in the $i^{\text {th }}$ fishery,

$\delta$ is the discount rate,

$t=0$ is the time of recruitment into the

fishery; the time at which the fish

first become available to the fishing gear,

$T$ is the end of the fishing season.

Assuming shrimp in the Gulf of Mexico is a finite resource and the fishery is over-capitalized, a vessel crowding externality occurs in that the harvest accruing to an individual vessel depends on its own effort level as well as the level of fishing effort applied by all the other fishing firms. Following Dasgupta and Heal (1979), this

${ }^{11}$ Ragnar Arnason, "Minimum Information Management with the Help of Catch Quotas," in ed. P.A. Neher, et al. "Rights Based Fishing, (Kluwer Academic Publishers, 1989), 215-241 and P.S. Dasgupta and G.M. Heal, Economic Theory and Exhaustible Resources. (New York: Cambridge University Press, 1979) both recognize the firm's perception of a biomass growth constraint. 
effect due to the vessel crowding externality can be represented by

$$
\frac{B_{i}(t)}{\Sigma e_{i l}} \quad v \neq 1
$$

The individual shrimp fisherman's profit is the product of this average biomass per unit effort, his individual effort level, exvessel price, and catchability minus the cost of fishing effort; e.g.

$$
\pi_{i}=p_{i} q e_{v} \frac{B_{i}}{\Sigma e_{i l}}-c\left(e_{v}\right)
$$

where $p_{i}$ is the exvessel price per pound of fish in fishery $i$,

$e_{v}$ is the fishing effort level of fisherman

$c\left(e_{v}\right)$ is the cost of fishing effort used to

Individual firms in the Gulf of Mexico shrimp fishery do not necessarily exploit a single stock of fish. Fisheries that are gear dependent require firms to switch fishing gear to harvest the fish stock in an alternative directed fishery ${ }^{12}$ (Clark, 1985 p. 191-194). That is, firms can maximize profits by harvesting fish in one fishery or the other, but not both simultaneously during the fishing season, i.e.

${ }^{12} \mathrm{~A}$ fisherman could also leave the fishery for an alternative form of employment. In this case, the wages earned would have to be greater than the return to labor from fishing. 


$$
\begin{aligned}
I=\operatorname{Max} \int_{t=0}^{T} e^{-\delta t} \pi_{i} d t & \\
\text { s.t. } & \dot{B}_{i}(t)=-\underset{v=1}{\sum e_{i v} B_{i}(t)}
\end{aligned}
$$

or

$$
\begin{aligned}
J=\operatorname{Max} & \int_{t=0}^{T} \cdot e^{-\delta t} \pi_{j} d t \\
\text { s.t. } & \dot{B}_{j}(t)=-q \underset{v=1}{\sum_{j} e_{j v} B_{j}(t)}
\end{aligned}
$$

The implicit solution for this set of equations can be represented by

$$
z=Z\left(p_{z}, c^{\prime}\left(e_{z v}\right), B_{y}, q, \Sigma e_{z l}\right) \quad(Z=I, J ; z=i, j)
$$

This implies that individual firms will apply fishing effort to fishery i if

$$
I\left(p_{j}, c^{\prime}\left(e_{v}\right), B_{i}, q, \Sigma e_{i l}\right)>J\left(p_{j}, c^{\prime}\left(e_{j}\right), B_{j}, q, \Sigma e_{j l}\right)
$$

or to fishery $j$ if

$$
I\left(p_{i}, c^{\prime}\left(e_{v}\right), B_{i}, q, \Sigma e_{i l}\right)<J\left(p_{j}, c^{\prime}\left(e_{j}\right), B_{j}, q, \Sigma e_{j l}\right)
$$

and that firms will continue to switch between fisheries until, for marginal firms,

$$
I\left(p_{i}, c^{\prime}\left(e_{v}\right), B_{i}, q, \Sigma e_{i l}\right)=J\left(p_{j}, c^{\prime}\left(e_{j}\right), B_{j}, q, \Sigma e_{j l}\right)
$$

The problem of choosing which fishery to operate in can be transformed into a marginal framework by specifying the discrete choice probabilities as the dependent variable using a multinomial logit specification. ${ }^{13}$ That is, if

${ }^{13}$ N.E. Bockstael and J.J. Opaluch. "Discrete Modeling of Supply Response under Uncertainty: the Case of the Fishery," Journal of Environmental Economics and Management, (1983) 10:125-137, D. McFadden, "Conditional Logit Analysis of Qualitative Choice Behavior", in Frontiers in Econometrics, ed. P. Zarembka (New York: Academic Press, 1973), and R.D. Luce and P. Suppes, "Preference, Utility, and Subjective 
profits for the marginal firm are greater in the $i^{\text {th }}$ fishery, then fishing effort $e_{v}$ will be positive, e.g. $e_{v}>$ 0 if $I>J$. Alternatively, if profits are greater in the $j^{\text {th }}$ fishery, then fishing effort $e_{v}$ will be zero, e.g. $e_{v}=0$ if $I<J$. To model this behavior, assume that profits in the $i^{\text {th }}$ and $j^{\text {th }}$ fisheries can be approximated by an inherently linear function ${ }^{14}$ of exogenous variables $x, e . g$.

and

$$
I=\sum_{k=1}^{K} a_{k i} x_{k}+v_{i}
$$

$$
\mathrm{J}=\sum_{\mathrm{k}=1}^{\mathrm{K}} \mathbf{a}_{\mathrm{kj}} \mathrm{x}_{\mathrm{k}}+\mathrm{v}_{\mathrm{j}}
$$

where $j=1, \ldots, i, \ldots, n$ fisheries

$\mathrm{k}=1, \ldots, \mathrm{k}$ exogenous variables, and

$\mathrm{v}=$ error terms.

Then define

$$
\mathrm{Y}_{\mathrm{i}}^{*}=I-J=\sum_{\mathrm{k}=1}^{\mathrm{K}}\left(\mathrm{a}_{\mathrm{ki}}-\mathrm{a}_{\mathrm{kj}}\right) \mathrm{X}_{\mathrm{k}}+\left(\mathrm{v}_{\mathrm{i}}-\mathrm{v}_{\mathrm{j}}\right)
$$

which can be expressed as

$$
Y_{i}^{*}=\sum_{k=1}^{K} b_{i k} x_{k}-u_{i}
$$

where

$$
\begin{aligned}
& b_{i k}=\left(a_{k i}-a_{k j}\right) \\
& u_{i}=\left(v_{j}-v_{i}\right) \\
& Y_{i}^{*}=I-J>0\left(u_{i}<\Sigma b_{i k} X_{k}\right) \text { if fishery } i \text { is chosen and } \\
& Y_{i}^{*}=I-J<0\left(u_{i}>\Sigma b_{i k} X_{k}\right) \text { if fishery } j \text { is chosen. }
\end{aligned}
$$

This leads to the probabilistic statement that

Probability," in Handbook of Mathematical Psychology, Vol. 3, eds. R.D. Luce, R. Bush, and E. Galanter (New York: John Wiley, 1965).

${ }^{14}$ Inherently linear functions include functional forms that can be transformed into linear functions, such as logarithmic transformations. 


$$
P\left(Y_{i}=i\right)=P\left(Y_{i}^{*}>0\right)=P\left(u_{i}<\sum_{k=1}^{K} b_{i k} X_{k}\right)
$$

If $u_{i}$ is a continuous random variable and $Y_{i}$ is a polytomous ${ }^{15}$ variable, then this equation can be written as a multinomial logit model ${ }^{16}$

$$
P\left(Y_{i}=i\right)=\underset{k=1}{\exp }\left(\sum b_{i k} X_{k}\right) /\left[\sum_{j=1}^{m} \underset{k=1}{K} \underset{i k}{K}\left(\sum b_{i k} X_{k}\right)\right]
$$

where $i \neq j$,

$\mathrm{m}$ is the number of mutually exclusive alternatives available to the fisherman, b repressents the parameters estimated by the logit model, and

$\mathrm{X}_{\mathrm{k}}$ are the exogenous variables representing exvessel prices, operating costs, generalist versus specialist vessel operations, the fixed vessel characteristics, and other variables that: describe the firm's indirect profit function.

The probability that an individual firm will enter the $i^{\text {th }}$ fishery will :ncrease as profits in that fishery increase relative to the other employment alternatives available to the fisherman. The probability that an individual firm will exit the $i^{\text {th }}$ fishery will increase as profits in that fishery decreasse relative to the other alternatives available to the fishing firm. Inertia, imperfect capital malleability, or resistance to change observed in the

${ }^{15}$ Polytomous or multiple category variables represent more than two choices, such as travel by car, bus, or subway, where the numbering represents labels for the mutually exclusive and exhaustive categories, but do not indicate order or magnitude (Aldrich and Nelson (1984), p. 22).

${ }^{16}$ Where $b_{i k}=0$ for $k=1, \ldots, k$ in the denominator. 
Bockstael and Opaluch (1983) study ${ }^{17}$ can be tested for by comparing the estimated coefficients effect on entry and exit decisions for specific independent, exogenous variables. If fishermen are reluctant to leave a fishery, for example, the derivative of the probability of exit with respect to cost would be less than the derivative of the probability of entering the fishery with respect to the same cost variables, i.e.

$$
\partial \mathrm{P}_{\mathrm{i}} / \partial \mathrm{x}_{\mathrm{ik}}=\mathrm{f}\left(\Sigma \mathrm{b}_{\mathrm{ik}} \mathrm{x}_{\mathrm{k}}\right) \mathrm{b}_{\mathrm{ik}}<\mathrm{f}\left(\Sigma \mathrm{b}_{\mathrm{jk}} \mathrm{x}_{\mathrm{k}}\right) \mathrm{b}_{\mathrm{jk}}=\partial \mathrm{P}_{\mathrm{j}} / \partial \mathrm{x}_{\mathrm{jk}}
$$

where $f(*)$ is the probability density function. ${ }^{18}$ The statistical significance of the parameter estimate for a qualitative generalist-specialist variable ${ }^{19}$ can be used to test the hypothesis suggested by McKelvey (1983) and Smith and McKelvey (1986) that a generalist fleet develops due to market or biological variability.

The fishing firm has five mutually exclusive alternatives from which it can choose. It can 1) enter the shrimp fishery from some alternative fishery,

17"... some minimum threshold of expected gain is required to induce fishermen to change fishery. Because this threshold includes nonmonetary factors such as family tradition and pure inertia, it is not directly measurable. The only observable measure of the threshold is the fisherman's observed resistance to change." Bockstael and Opaluch, 133.

${ }^{18}$ T.B. Fomby, R.C. Hill, and S.R. Johnson, Advanced Econometric Methods, (New York: Springer-Verlag, 1984), 351.

${ }^{19}$ Specialist vessels harvest shrimp exclusively while generalist vessels use multiple gear types to access shrimp and other finfish and shellfish fisheries in the Gulf of Mexico. 
2) enter from outside the fishing industry (construct a new vessel),

3) remain in the Gulf of Mexico shrimp fishery,

4) exit this fishery for an alternative fishery, or

5) retire from the fishing industry.

The choice of a fishery as discussed in the above model depends on the profits derived from each alternative. Profits can be expressed in terms of the exvessel prices for alternative species of fish, the costs of harvesting the fish, and the physical characteristics of the vessel. ${ }^{20}$ The fishery chosen by the fishing firm is identified by the type of fishing gear the fishing vessel employs. The Gulf of Mexico shrimp fisherman employs the shrimp otter trawl in his directed shrimp fishing operation. A weighted exvessel price per pound from landings reported by gear type is computed for other fishery operations for this analysis. The costs of these different fishery operations are assumed to be the same as in the shrimp fishery since the National Marine Fisheries Service does not collect operating cost data. An additional exogenous, qualitative variable representing generalist or specialist fishing operations is incorporated into the model to determine if fishermen respond to market or biological variability. This approach decreases the number of dependent qualitative variable

\footnotetext{
${ }^{20}$ See the discussion of duality theory in $\mathrm{E}$. Silberberg, The Structure of Economics, (New York: McGraw-Hill, 1978).
} 
categories while still allowing the probabilities of entry and exit to reflect the specialist or generalist characteristic.

\section{Results}

Data

The data set used to estimate the model parameters is collected by the National Marine Fisheries Service and maintained in the Gulf of Mexico shrimp landings file 21 and the vessel operating units file for the southeast region by the U.S. Coast Guard vessel documentation number. The shrimp landings file contains information from 1964 to 1991 on the pounds, value, and, to a limited extent, fishing effort for vessels ${ }^{22}$ that harvest shrimp in the Gulf of Mexico. The vessel operating units file contains information about vessel characteristics from 1965 to 1983. Annual landings and value for the shrimp fishery are summarized on a per vessel basis using the shrimp landings file and then combined with vessel characteristics from the vessel operating units file.

${ }^{21}$ The shrimp landings files for the South Atlantic do not routinely record the individual vessel identification numbers preventing the application of this modelling approach to the South Atlantic shrimp fishery.

${ }^{22} \mathrm{~A}$ vessel is a fishing craft in excess of five gross tons. A complete explanation of these data sets is available in J. Ward, Feasibility study of Vessel Entry and Exit Behavior Using the Gulf of Mexico Shrimp Fishery Data set from 1965-80, NOAA Technical Memorandum, NMFS-SEFC-231, 1989. 
Entry-exit categories are determined by a three year comparison of vessel documentation numbers in the vessel operating units file. Vessels in the base year and the subsequent year's fishery, but not in the previous year are treated as an entering vessel. Vessels in the base year and the previous year's fishery, but not in the subsequent years fishery are treated as an exiting vessel. Vessels in the previous, base, and subsequent year's fishery are treated as a vessel in the shrimp fishery. Entry and exit categories are further divided to reflect entry from alternative fisheries or new constructions and exits to alternative fisheries or retirements. Additional categories of vessels that enter and exit the shrimp fishery, and exit and then reenter the shrimp fishery are excluded from the data set since these vessels are small in number and are not considered representative of vessel entry-exit behavior.

The model's independent variables include a qualitative or dummy variable reflecting a change in ownership that is identified by a change in the vessel name but not its documentation number. Specialist vessels are distinguished from generalist vessels by the number and type of different fishing gears reported in the vessel operating units file. Specialists operate exclusively in the shrimp fishery using the shrimp otter trawl. Generalist vessels employ both the shrimp otter trawl and alternative gear types over the course of the fishing year. The qualitative variable 
representing generalist - specialist fishing behaviors is coded as a one if multiple gear types are reported and zero if only the shrimp otter trawl is employed by the vessel. Vessel mobility is a qualitative variable representing one state of landing (coded as a one) or multiple states of landing (coded as a zero) as reported in the shrimp landings files. This variable accounts for shrimp vessels that diversify their fishing activities to alternative shrimp fishing grounds rather than to alternative fisheries.

The model's continuous independent variables include a price per pound variable that is the annual exvessel price of shrimp that the vessel reported in the shrimp landings files and deflated to the base year of $1982 .{ }^{23}$ A shrimp abundance index is used to control for seasonal variation in recruitment. ${ }^{24}$ An average price per pound weighted by the level of finfish landings is calculated for each alternative gear type used by the vessel. The fleet size based on a count of vessels in the vessel operating units file for each year is used to control for the vessel crowding externality because total effort data, such as days fished, is not available. A multiplicative dummy variable for pre and post 1967 fleet size is created by multiplying a qualitative variable, that is coded as a zero prior to 1967 and as an

\footnotetext{
${ }^{23}$ Producer Price Index for unprocessed fish is used to deflate the price per pound variable.

${ }^{24}$ The shrimp abundance index was developed by the NMFS, Galveston Laboratory, Galveston, Texas.
} 
one after 1967, with the continuous fleet size variable. This variable acts as an adjustment to the coefficient of the fleet size variable after 1967. Two vessel characteristics from the vessel operating units file, vessel length and gross tonnage, are included in the model to account for the heterogeneous nature of the fishing fleet. Although cost and return surveys have been conducted for the southeastern region shrimp fishery and budget simulators exist for the Texas shrimp fleet, cost information for the Gulf of Mexico shrimp fishery is not routinely collected by federal, state, or local government agencies. Without this theoretically important harvesting cost information, the estimated coefficients and the probabilities of entry, remaining in, or exit from the shrimp fishery would be biased. To reduce this bias, the stock constant harvest cost per pound variable is calculated from the indirect cost function estimated in Appendix c. This model uses economic theory in conjunction with cost and returns data collected by the National Marine Fisheries Service for the 1982 fishing year and conforms with the requirements of duality theory. The cost estimates are combined with the shrimp abundance index to create a stock constant harvest cost per pound variable that reduces the bias that would exist if this information were not available for the estimation of the coefficients in the multinomial logit model. 
The data set that results from merging the shrimp landings and vessel operating units files is too large to use in the estimation of the multinomial logit model parameters since between 2,000 and 7,000 vessels participate in the fishery in any given year. A random sample ${ }^{25}$ of approximately 300 observations is taken for each year data is available. ${ }^{26}$ The resulting data set for the years 1965 to 1975 and 1981 to 1983 contain approximately 2650 observations. This random sample represents approximately 8 percent of the vessels in the data set and provides sufficient degrees of freedom for the estimation of the model parameters. ${ }^{27}$

Model Estimation

The probability model represented by equation (2) is based on a Cobb-Douglas functional form conforming to the indirect cost model used to estimate harvest costs in the

${ }^{25}$ The random sample without replacement was selected using the ranuni function provided by SAS version 6.03 for the personal computer. SAS Institute Inc., SAS Applications Guide, 1987 Edition, (Cary, NC: SAS Institute Inc., 1987), $226-235$.

${ }^{26}$ The years 1975 to 1980 are not included in this data set because of a change in data collection procedures used by the Southeast Fisheries Center, National Marine Fisheries Service that result in the loss of the vessel identification numbers. The data from 1984 to present is not available for this analysis, but is being developed by the Washington, D.C. office of the National Marine Fisheries Service in conjunction with the Beaufort Laboratory.

${ }^{27}$ Personnel communication, Edward Burgess, Statistician, National Marine Fisheries Service, Southeast Regional office, St. Petersburg, Fl., 1989. 
fishery and to the long run shrimp yield curve that is assumed to be logarithmic in effort (Nance and Nichols, 1987), i.e.

$$
\log \left(\mathrm{P}_{\mathrm{i}} / \Sigma \mathrm{P}_{\mathrm{j}}\right)=\Sigma \mathrm{b}_{\mathrm{ik}} \mathrm{x}_{\mathrm{k}}+\mathrm{u}
$$

where $\log \left(P_{i} / \Sigma P_{j}\right)$ is the $\log$ ratio of the odds,

$\mathrm{x}_{\mathrm{k}}$ are the independent variables in Table 1 expressed in terms of their natural logarithms, and

$u$ is the error term.

Table 1 presents the multinomial logit results for vessel entry-exit behavior in the Gulf of Mexico shrimp fishery based on this model specification. The log likelihood ratio chi-square test statistic for the null hypothesis that the estimated coefficients are equal to zero had a calculated value of 1,643 with over 10,000 degrees of freedom. This result indicates that the null hypothesis could be rejected and is the best fit of the different model specifications considered. The estimated coefficients of the independent variables are consistent and have an asymptotic normal distribution ${ }^{28}$ and are statistically significant at the $\dot{\alpha}=$ 0.05 level except for the generalist and mobility variables.

\section{Discussion}

The results of the pooled coefficient multinomial logit estimation procedure are presented in Table 1 . The variable Intercept. 0 represents the base case of entry into the shrimp fishery from outside the southeastern region or by

${ }^{28}$ See the Appendix B Qualitative Dependent Variables Iiterature Review for a complete discussion of the statistical properties of discrete choice model coefficients. 
Table 1

Logit Procedure Results

\begin{tabular}{|c|c|c|c|c|c|}
\hline $\begin{array}{l}\text { Variable } \\
\text { Intercept. } 0^{29}\end{array}$ & $\begin{array}{l}\text { DF } \\
1\end{array}$ & $\begin{array}{c}\text { Estimate } \\
44.43\end{array}$ & $\begin{array}{l}\text { Std } \operatorname{Err} \\
20.56\end{array}$ & $\begin{array}{c}\text { Chisquare } \\
4.67\end{array}$ & $\begin{array}{l}\text { Pr }>\text { Chi } \\
0.0307\end{array}$ \\
\hline Price Per Pound & 1 & 2.18 & 0.22 & 99.57 & 0.0001 \\
\hline $\begin{array}{l}\text { Stock Constant } \\
\text { Harvest Cost Per }\end{array}$ & & & & & \\
\hline Pound & 1 & -2.03 & 0.34 & 35.64 & 0.0001 \\
\hline Fleet Size & 1 & -5.96 & 2.53 & 5.56 & 0.0184 \\
\hline $\begin{array}{l}\text { Post-67 Fleet } \\
\text { Size }\end{array}$ & 1 & 0.12 & 0.04 & 6.76 & 0.0093 \\
\hline Vessel Length & 1 & -1.05 & 0.20 & 28.38 & 0.0001 \\
\hline $\begin{array}{l}\text { Vessel Gross } \\
\text { Tonnage }\end{array}$ & 1 & 0.67 & 0.19 & 12.93 & 0.0003 \\
\hline $\begin{array}{l}\text { Generalist } \\
\text { Vessel }\end{array}$ & 1 & -0.11 & 0.34 & 0.10 & 0.7529 \\
\hline Shrimp Abundance & 1 & 2.22 & 0.41 & 29.38 & 0.0001 \\
\hline $\begin{array}{l}\text { Vessel } \\
\text { Bought/sold }\end{array}$ & 1 & $-1 \cdot 10$ & 0.33 & 11.04 & 0.0009 \\
\hline Vessel Mobility & 1 & -0.31 & 0.16 & 3.57 & 0.0587 \\
\hline Intercept. $1^{30}$ & 1 & 0.05 & 0.02 & & \\
\hline Intercept. $2^{31}$ & 1 & 7.43 & 0.20 & & \\
\hline Intercept. $3^{32}$ & 1 & 7.56 & 0.20 & & \\
\hline
\end{tabular}

${ }^{29}$ Entry into the shrimp fishery from outside the southeastern region or the construction of a new vessel.

${ }^{30}$ Entry from an alternative fishery within the southeastern region.

${ }^{31}$ Remain in the Gulf of Mexico shrimp fishery.

${ }^{32}$ Exit the shrimp fishery for another fishery within the southeastern region. The fifth case of exiting the shrimp fishery for another region or the retirement of the vessel is represented by the difference between the sum of the first 
the construction of a new vessel. Intercept. 1 represents entry from an alternative fishery within the southeastern region. Intercept. 2 represents the case of vessels that remain in the Gulf of Mexico shrimp fishery. Intercept. 3 represents the exit of vessels from the shrimp fishery for another fishery within the southeastern region. Lastly, the fifth case representing the exit from the shrimp fishery to another region or the retirement of the vessel is represented by the difference between the sum of the first four cases and the total probability of one.

Theoretically, changes in total effort are proportional to profits (Smith, 1968 and 1969). Based on the price per pound and stock constant harvest cost per pound parameters estimated in Table 1 , the probability of entry increases more with a price increase than it declines with a cost increase. Given the standard errors of the parameter estimates, however, this difference is not statistically significant. That is, the null hypothesis that the coefficient of price per pound equals the negative of the coefficient of harvest cost per pound cannot be rejected. ${ }^{33}$ Based on these two variables, the probability of entry and exit of vessels in the Gulf of Mexico shrimp fishery is

four cases and the total probability of one.

${ }^{33}$ The calculated likelihood ratio test value of 0.5186 is not greater than the critical value of 3.84 found in the chisquared statistic table with one degree of freedom at the $\alpha=0.05$ confidence level. 
equally affected by changes in harvesting costs and exvessel price.

While the sign of the coefficient indicates the direction of the change in the probability of an event, the magnitude of the change. depends on where the derivative is evaluated on the cumulative probability distribution function. ${ }^{34}$ In this analysis a comparison of the derivative of the probability of entry and the derivative of the probability of exit with respect to the stock constant harvest cost per pound variable determines if entry and exit are equally likely to occur. Using the mean values of the independent variables from the sample data, these derivatives are evaluated using the estimated coefficients in Table 1. Vessels are found to be more willing to enter the fishery when profits increase than exit the fishery when profits decline. ${ }^{35}$ since a specific reason for this result is not modelled, these results cannot be explicitly compared to the estimated resistance to change coefficient in the Bockstael and Opaluch (1983) model. However, the finding that a threshold exists due to monetary conversion costs,

34 The derivative of the probability of an event with respect to an independent variable is a function of the probability density function. T.B. Fomby, R.C. Hill, and S.R. Johnson, Advanced Econometric Methods, (New York: SpringerVerlag, 1984), 351 .

${ }^{35} \mathrm{~A} t$ test of the null hypothesis that the derivative of the probability of entry with respect to a cost decline is equal to the derivative of the probability of exit with respect to a cost increase is rejected with a calculated $t$ value of 2.43 at the $\alpha=0.05$ level of significance. 
nonmonetary factors, and personal preferences found in Bockstael and opaluch (1983) is supported by this analysis. If a crowding externality exists in the Gulf of Mexico shrimp fishery, then the probability of entry should be negatively related to the size of the fishing fleet (Fleet size) in time $t$. In a common property resource, this externality manifests itself in terms of the size of the fishing fleet (Dasgupta and Heal, 1979) ${ }^{36}$. As the fleet grows in size, average landings and revenue per vessel decline with biomass per unit effort (equation (1)), fishing effort costs remain the same, and rents to the resource are dissipated. In equilibrium, the total stock of capital remains at the same level with depreciation and retirement of vessels offset by new investment ${ }^{37}$. The tendency to enter (exit) the fishery is mitigated (enhanced) by the size of the fishing fleet. As fleet size increases, the probability of entry will decline. Declines in the fleet size result in increased probability of vessel entry and reduced probability of exit, ceteris paribus. As predicted, the parameter estimate for fleet size in Table 1 is negative and highly significant.

${ }^{36}$ Number of vessels is used as a proxy for a total effort variable. Days fished as a measure of tow time is available for only a ten percent sample of vessels in the fleet.

${ }^{37}$ This is similar to a stock of fish where natural mortality and recruitment and growth are in balance. 
The multiplicative dummy variable for fleet size since $1967^{38}$ (Post-67 Fleet Size) indicates that the influence of fleet size on the probability of entry into the shrimp fishery declined. This variable was instrumental in generating a statistically significant fit for the individual variables as well as for the overall model structure. A fishery independent measure of shrimp abundance increased 43.7 percent between the six year average before 1967 and the six year average after $1967^{39}$. Landings of shrimp in the Gulf of Mexico rarely exceeded 200 million pounds prior to 1967 and since then have rarely been below 200 million pounds. ${ }^{40}$. This increase in total landings and shrimp abundance has been attributed to increased marsh land due to coastal sinking (Browder, et al 1989 and Klima, 1987). Others have attributed the increase

${ }^{38} \mathrm{~A}$ multiplicative dummy variable for pre and post 1967 fleet size is created by multiplying a qualitative variable, that is coded as a zero prior to 1967 and as an one after 1967, with the continuous fleet size variable and acts as an adjustment to the coefficient of the fleet size variable after 1967.

${ }^{39}$ NMFS, Galveston Laboratory, Galveston, Texas shrimp index values from 1960-1989.

${ }^{40}$ National Fishery Statistics Program, Fishery Statistics of the United States, U.S. Department of Commerce, National Oceanic and Atmospheric Administration, National Marine Fisheries Service, 1951 to 1977 and Fisheries Statistics Division, Fisheries of the United States, U.S. Department of Commerce, National Oceanic and Atmospheric Administration, National Marine Fisheries Service, 1978 to 1990 indicate that between 1950 and 1966 shrimp landings exceeded 200 million pounds on only five occasions. In the 22 years since 1967, landings have been above 200 million pounds all but four times. 
in landings to improved gear efficiency due to the adoption of quad rigs by vessels operating in the Gulf of Mexico and the increase in exvessel price relative to operating cost ${ }^{41}$. Regardless of its cause, the increase in the available stock has led to an increase in landings, reduced the relative congestion on the fishing grounds, and resulted in an increase in the size of the fishing fleet.

Multicollinearity exists between the fleet size (FLSZ) variable, the multiplicative dummy variable for fleet size since 1967 (Post-67 Fleet Size), and the intercept term for the case of entry into the shrimp fishery from outside the southeastern region or the new construction of a vessel ( $r=$ -0.99 and $r=0.69$, respectively). The reason for the multicollinearity is difficult to determine since the intercept variables for the other cases of entry, remain in, or exit from the fishery are not strongly correlated with the fleet size variable. However, correcting this problem would not improve the ability of the model to predict the probabilities of entry or exit from the shrimp fishery, since multicollinearity does not affect the predicted value of the dependent variable.

${ }^{41}$ Personal Communications, w. Keithly, Center for Marine Studies, Louisiana State University, Baton Rouge, La. and J.E. Snell, Supv. Survey statistician, Statistics Operation Team, Statistics and Data Management office, southeast Fisheries center, National Marine Fisheries Service, National Oceanic and Atmospheric Administration, U.S. Department of Commerce, Miami, Fl. 
Variables representing vessel length and vessel gross tonnage are included in the model to account for the fixed factors in the profit function that determine entry and exit behavior. With growth overfishing, the relative abundance of large shrimp offshore has declined relative to the smaller size classes of shrimp near shore ${ }^{42}$. Medium length vessels are better able to operate near shore as well as offshore than are the smaller and larger vessel size classes and their larger carrying capacity allows the medium size vessels to trawl for longer periods of time per trip. Over the time period of this analysis, average gross tonnage as a measure of carrying capacity increased 33 percent while the average vessel length increased approximately 12 percent (see Appendix B). The estimated parameters indicate that the probability of entry into the fishing fleet declines with increases in vessel length and increases with gross tonnage reflecting this trend. ${ }^{43}$

The variable shrimp abundance is included in the model to account for annual variability in the shrimp stock. Theoretically, increased abundance should cause vessels to

\section{${ }^{42}$ Hence the need for a Texas closure regulation.}

43 This trend also results in a strong negative correlation coefficient $(r=-0.97)$ between vessel length (LLEN) and vessel gross tonnage (LGTON). One solution to this biased parameter problem is to reestimate the model using a ratio of vessel length to gross tonnage as the independent variable. However, correcting this problem would not improve the predictability of the model, since multicollinearity does not affect the predicted value of the dependent variable. 
enter the shrimp fishery by increasing catch per unit effort and decreasing the harvesting cost per pound of shrimp. As a result, the profitability of the fishing operation should increase resulting in new entry into the fishery. The coefficient of this abundance variable is positive and highly significant, indicating that capital flows rapidly into and out of the shrimp fishery in response to changes in abundance.

Anecdotal information indicates that most fishermen entering the Gulf of Mexico shrimp fishery first crew on an existing shrimp fishing vessel and then purchase their own vessel. The variable reflecting the recent purchase or sale of a vessel (Vessel Bought/Sold) is negatively related to the probability of entry, contradicting this anecdotal information. This indicates that the probability of entry is greater for vessels that have not been recently purchased, and exit is greater for recently purchased vessels. This suggests that entry is more likely to occur with experienced fishermen than with novices and that novice fishermen are more likely to fail after entering the fishery than experienced fishermen.

To account for variability in the fishery, variables reflecting the mobility of the vessel (Vessel Mobility) and whether it is a generalist or specialist vessel (Generalist Vessel) are included in the model. With highly variable conditions, fishermen are expected to diversify harvest 
operations between fishing grounds (increase mobility) and between fisheries (generalist versus specialist fishing operations). Neither variable is significant at the $\alpha=0.05$ significance level, but-both had the theoretically correct sign. Since the time period of the analysis is characterized by higher than normal landings, specialist vessels (fish exclusively with the shrimp otter trawl) would have been favored.in the fishery according to Smith and McKelvey (1986). Vessels that harvested from one fishing ground (reported landings in one state) did positively affect the probability of entering the fishery and this variable is only marginally insignificant. The statistical insignificance of the estimated coefficients indicates that during the time period of the analysis Gulf of Mexico shrimp fishermen did not act as if variability causes them to diversify their fishing operations into other fisheries or on to other fishing grounds.

Lastly, variables representing exvessel prices for fish species harvested in alternative fisheries are excluded from the model. These variables represent the opportunity cost of remaining in the shrimp fishery. As the exvessel price of an alternative fish species increases relative to the price of shrimp, for example, the probability that a vessels would exit the shrimp fishery should increase. However, the estimated coefficients for the alternative species price variables are statistically insignificant and excluding them 
from the estimated equation did not affect the values of the other independent variable coefficients. The composite price variable created from the reported finfish landings and value for each alternative gear type reported by the vessel apparently does not reflect the actual values the firm faces when it makes its decision to enter, remain in, or exit the shrimp fishery. A better approach would have been to use the actual price per pound values that the vessel receives in the alternative fishery. ${ }^{44}$

The three year comparison of vessel documentation numbers indicates that most entries to and exits from the shrimp fishery involve movements outside the southeastern region that consists of the Gulf of Mexico and South Atlantic regions (Table 2). Information concerning the regions these vessels migrate to or from, what fisheries they enter or leave, the costs associated with these harvesting activities, and the prices they receive for their landings is unavailable for the individual vessel.

\section{Conclusions}

Bockstael and opaluch (1983) first investigated fisherman behavior using discrete choice models. Employing a utility theoretic approach, their analysis indicates that fishermen tend to be risk adverse in their intermediate run

\footnotetext{
${ }^{44}$ Unfortunately, this information is not available on a per vessel basis for the finfish landings data bases maintained in the southeastern region.
} 
Table 2

Weighted Frequency Counts for the ordered Response categories

Label

New Construction or Entered from Outside the Region

Entered from an Alternative Fishery

Remained in the Shrimp Fishery

Exited to an Alternative Fishery

Exited to another Region or Retired
Level count

$0 \quad 109$

1

4

2

427

3

12

4

95 
fishery participation choice, have a bias to remain with the same fishery over time, and that price controls tend to "be relatively ineffectual compared to quantity controls"45. This study differs from the Bockstael and Opaluch (1983) study in that the pooled coefficients, multinomial logit model is based on the theory of the firm to study fisherman entry-exit behavior. Cross sectional data covering a ten year time period is used to determine entry-exit behavior. This analysis tests for the existence of a crowding externality, the development of generalist-specialist, firms caused by variable conditions, as well as the resistance to change found in the Bockstael and opaluch study.

No statistically significant difference is found that would indicate that generalist vessels are favored relative to specialist vessels or that more mobile vessels are favored over less mobile vessels. Although the magnitudes of the exvessel price and the stock constant unit harvesting cost coefficients are not statistically different, the derivatives of the probabilities of entry and exit with respect to a change in the stock constant unit harvesting cost variable indicate that vessels are more willing to enter the fishery than to exit it. While not directly comparable, this result supports the resistance to change result found in the Bockstael and opaluch (1983) study.

${ }^{45}$ Bockstael and opaluch, 136. 
Testing for the existence of a crowding externality is an extension of the Bockstael and Opaluch (1983) model. Since property rights do not exist in the Gulf of Mexico shrimp fishery, free access to the fishing grounds manifests itself in terms of the size of the fishing fleet. In a fishery characterized by property rights, the fishing fleet size would not influence the entry-exit decision of fishermen. Instead, the value of the property rights would reflect the capitalized value of the shrimp resource and be captured as a component of the variable costs of operating in the fishery. As a result, the expected value of the estimated coefficient would be zero. The divergence between the expected value and the estimated value of the parameter is an indication of the extent of overcapitalization that has occurred in the fishery. The fleet size variable is statistically different from zero and has a strong negative impact on the probability of entry and by implication a positive impact on the exit probability. In addition, the improvement in shrimp landings that occurred since 1966 reduces the impact of the crowding externality on entry and exit probabilities according to the post-67 fleet size multiplicative dummy variable.

In this analysis, shrimp abundance and exvessel price are positively related to the probability of entry. Gulf 
wide closure regulations similar to the Texas closure ${ }^{46}$ have been considered to reduce the incidence of bycatch of commercially and recreationally valuable finfish species in the shrimp fishery. Small inshore shrimp that would have been harvested without a closure grow into larger size categories as they migrate offshore and are harvested at higher exvessel prices. The shift in the size distribution would result in a higher average price per pound and increase the abundance of shrimp for the offshore component of the shrimp fishing fleet while the inshore fleet would experience a decline in shrimp availability due to the offshore migration. This regulation would affect the probability of vessel entry such that the offshore fleet would increase and the inshore fleet would decline in size. The increase in offshore fleet size would reduce and could eliminate the benefits derived from the reduction in bycatch.

Fishery management regulations for the Gulf of Mexico shrimp fishery that either directly or indirectly affect exvessel prices or harvesting costs can have a significant impact on fleet size. For example, tariff or quota

${ }^{46}$ James N. Nance, Edward F. Klima, et.al., Review of the 1987 Texas Closure for the Shrimp Fishery off Texas and Louisiana, Presented at the Gulf of Mexico Fishery Management Council Shrimp Advisory Panel Meeting, Tampa, Florida, January, 1988. The Texas closure regulation closes the state controlled territorial sea and the fishery conservation zone to shrimp fishing for approximately six weeks in May and June of each year. 
restrictions on shrimp imports would tend to increase price as supply contracted relative to a fixed demand and lead to a larger fishing fleet from an increased probability of entry and reduced probability of exit. In this case, the model supports the theoretical hypothesis and provides a means of measuring impacts and determining the length of time required to reach a new equilibrium. 
Arnason, Ragnar. "Minimum Information Management with the Help of Catch Quotas." in Rights Based Fishing, ed. P.A. Neher, et al., Kluwer Academic Publishers, 1989, 215-241.

Berck, P. and J.M. Perloff. "An Open-Access Fishery with Rational Expectations." Econometrica 52 (2) (1984): 489-506.

Bjorndal, Trond and Jon M. Conrad. "Capital Dynamics in the North Sea Herring Fishery." Marine Resource Economics 4 (1987): 63-74.

Bockstael, N.E. and J.J. Opaluch. "Discrete Modeling of Supply Response under Uncertainty: The Case of the Fishery." Journal of Environmental Economics and Management 10 (1983): 125-137.

Browder, J.A., I.N. May, Jr., A. Rosenthal, J.G. Gosselink, and R.H. Baumann. "Modeling Future Trends in Wetland Loss and Brown Shrimp Production in Louisiana Using Thematic Mapper Imagery." Remote Sens. Environ. 28 (1989): 45-59.

Clark, C. Bioeconomic Modelling and Fisheries Management. New York: John Wiley and Sons, Inc., 1985

Clark, C.W., F.H. Clarke, and G.R. Munro, "The optimal Exploitation of Renewable Resource Stocks: Problems of Irreversible Investment." Econometrica $47(1) \cdot(1979): 25-47$.

Dasgupta, P.S. and G.M. Heal. Economic Theory and Exhaustible Resources. New York: Cambridge University Press, 1979.

Fomby, Thomas B., R. Carter Hill, and Stanley R. Johnson. Advanced Econometric Methods. New York: Springer-Verlag, 1984 .

Green, T. The Economic Value and Policy Implications of Recreational Red Drum Success Rate in the Gulf of Mexico. Marine Fisheries Initiative contract No. NA87WC-H-06146 prepared for SERO, NMFS, NOAA, st. Petersburg, Fl., July, 1989.

Griffin, W.L., N.J. Wardlaw, and J.P. Nichols. "Cost and Return Analysis by Selected Vessel Characteristics: Gulf of Mexico Shrimp Fishery, 
1971-75." Tex. Agric. Exper. Sta., Tex. A\&M Univ., Rep. MP-1253C, 1976.

Klima, E. "Shrimp Habitat Considerations." Report presented to the Gulf of Mexico Fishery Management Council, Shrimp Advisory Panel, Tampa, Florida, Jan., 1988.

Luce, R.D. and P. Suppes. "Preference, Utility, and Subjective Probability." in Handbook of

Mathematical Psychology, Vol.3., ed. R.D. Luce, R. Bush, and E. Galanter, New York: John Wiley, 1965.

McKelvey, R. "The Fishery in a Fluctuating Environment: Coexistence of Specialist and Generalist Fishing Vessels in a Multipurpose Fleet." Journal of Environmental Economics and Management 10 (1983): 287-309.

McFadden, D. "Conditional Logit Analysis of Qualitative Choice Behavior. in Frontiers in Econometrics, ed. P. Zarembka. New York: Academic Press, 1973.

Milon, J.W. Estimating Recreational Angler Participation and Economic Impact in the Gulf of Mexico Mackerel Fishery. Marine Fisheries Initiative Contract No. NA86WC-H-06116 prepared for SERO, NMFS, NOAA, st. Petersburg, Fl., July, 1988.

Nance, J. and S. Nichols. "Stock Assessment for Brown, White and Pink Shrimp in the U.S. Gulf of Mexico, 1960-1986," Report presented to the Gulf of Mexico Fishery Management Council, Shrimp Advisory Panel, Tampa, Florida, Jan., 1988.

Nance, James N., Edward F. Klima, Peter F. Sheridan, K. Neal Baxter, Frank J. Patella, and Dennis B. Koi, Review of the 1987 Texas Closure for the Shrimp Fishery off Texas and Louisiana, Presented at the Gulf of Mexico Fishery Management Council shrimp Advisory Panel Meeting, Tampa, Florida, January, 1988 .

Paterson, D.G. and J. Wilen. "Depletion and Diplomacy: the North Pacific Seal Hunt." Research in Economic History 2 (1977): 81-139.

Penson, John B., Jr., Ernest O. Tetty, and Wade I. Griffin. "An Econometric Analysis of Net Investment in Gulf Shrimp Fishing Vessels." Technical Article No. TA-20803 of the Texas 
Agricultural Experiment Station, Texas A\&M University, 1987.

Silberberg, E. The Structure of Economics: A Mathematical Analysis. New York: McGraw-Hill, 1978 .

Smith, V.L. "Economics of Production from Natural Resources." American Economic Review 58 (1968): 409-431.

Smith, V.L. "On Models of Commercial Fishing." Journal of Political Economy 77 (1969): 181-198.

Smith, C. and R. McKelvey. "Specialist and Generalists: Roles for Coping with Variability," North American Journal of Fisheries Management 6 (1986): 88-99.

Stollery, K.R. "Monopsony Processing in an open-Access Fishery." Marine Resource Economics 3(4) (1987): $331-351$.

Sutinen, J.G. "Seasonality in Renewable Resource Models." Presented at the annual meeting of the Allied Social Science Association, New orleans, La., Dec., pp. 28-31, 1986.

Ward, J.M. "Feasibility Study of Vessel Entry and Exit Behavior Using the Gulf of Mexico Shrimp Fishery Data set from 1965-80." NOAA Technical Memorandum NMFS-SEFC-231, National Marine Fisheries Service, Southeast Regional office, 9450 Koger Blvd., st. Petersburg, FL 33702, 1989.

Ward, J.M. "Modeling fleet size in the Gulf of Mexico shrimp fishery, 1988-1979." NOAA Technical Memorandum NMFS-SEFC-229. National Marine Fisheries Service, Southeast Regional office, 9450 Koger Blvd., St. Petersburg, FL 33702, 1989b.

Ward, J.M. "Vessel Entry and Exit Behavior in the Gulf of Mexico Shrimp Fishery." Draft Report. National Oceanic and Atmospheric Administration, National Marine Fisheries Service, southeast Regional Office, 9450 Koger Blvd., St. Petersburg, FL 33702,1990

Waters, J. and J. Platt: "Economic Analyses of Alternative Management options for the Red Snapper Fishery in the Gulf of Mexico." Report prepared for the Gulf of Mexico Fishery Management council. 
Southeast Regional office, National Marine Fisheries Service. July, 1990. 


\author{
Appendix A \\ Vessel Entry - Exit Behavior in \\ the Gulf of Mexico Shrimp Fishery \\ From 1965 - 1980
}

\title{
Introduction
}

A data set that describes the changes in the size and structure of the fleet caused by vessel entry-exit behavior has been assembled from information collected by the National Marine Fisheries Service (NMFS). Specifically, the NMFS vessel operating units file (VOUF), the shrimp landings file (SLF) for the Gulf of Mexico shrimp fishery, and a cost and returns survey (CNR) conducted by Centaur Associates and Danville Research Associates under contract to NMFS in 1983 for the 1982 shrimp fishing year have been merged for this purpose. The results indicate that combining the existing data sets provides sufficient information to track trends in the size and structure of the fleet and to model vessel entry-exit behavior.

\section{Description of the Available Data}

Data collected by the NMFS or at its direction by contractors is used for this analysis. The vouf contains information about individual vessel characteristics indexed by the United States Coast Guard (USCG) vessel documentation number. This data set contains information about the universe of vessels that operate in the fisheries of the 
southeastern region of the United States. The SLF contains information on the pounds, value, and to a limited extent fishing effort for those vessels that land shrimp in the Gulf of Mexico by USCG vessel documentation number. The CNR data set contains input cost and behavior information by USCG vessel documentation number for a sample of shrimp vessels operating in the southeastern region in 1982. Other sources of data for this analysis include published information from Fisheries Abstract of the United states, Fishery Statistics of the United States, the Statistical Abstract of the United States, and the Survey of current Business.

The VOUF contains information on vessel characteristics from 1965 through $1982 .{ }^{47}$ A vessel is defined according to the USCG to be any craft in excess of five gross tons. The vessel characteristics that are included in this data set are the vessel's name and USCG documentation number, the amount of full and part time crew, the hull material, the gross tonnage, the length of the hull, the year the vessel was construction, the engine type and its horsepower, the gear type, number and quantity of gear the vessel used, the state, county, and region where the vessel operated, and the number of auxiliary boats with and without motors used by the vessel.

${ }^{47}$ The VOUF covering the 1983 to 1988 time period do not include vessel characteristics, such as length, gross tonnage, or horse power, and could not be included in this analysis. 
The SLF contains information on the landings and value of vessels operating in the Gulf of Mexico from 1964 to 1991. Information in this data set includes the vessel documentation number, the port where the vessel landed its catch, the date of the landing and the trip, the number of trips the catch represents, whether the shrimp are machine or box graded for size, whether the information is collected as part of the dealer census or as a fisherman interview, the species and size of the shrimp, the pounds and value of the catch, whether it is reported in heads-off or heads-on weight (landings type), and fishing effort data such as the water, area, and depth where the shrimp are caught and the number of hours of actual fishing time in 24 hour units (days fished).

These data sets contain multiple records for an individual vessel documentation number. An entry is made in the vouf data file for each port that the vessel was observed landing a catch, for each type of gear the vessel used, for each time its crew size changed, etc. for a particular year. The SLF's multiple records correspond to the size distribution, species, and landings type of shrimp caught, the size grading method, and the port of landing on a per trip basis ${ }^{48}$. This file also contains a large number of consolidated records that exclude individual vessel

${ }^{48}$ Some entries in this file contain information on multiple trips for a particular vessel documentation number. 
documentation numbers ${ }^{49}$. The exclusion of unique vessel documentation numbers, however, prevents comparisons between the SLF and the VOUF data sets for a particular vessel. Since the consolidated records capture some of the trips made by a vessel, for example, comparisons of total catch by vessels of different lengths are made difficult. Also, using the SLF to make comparisons of different years to determine vessel entry-exit patterns may exclude vessels from their proper behavior categories because they are represented in the consolidated records.

The data contained in the VOUF and the SLF are collected by NMFS fishery reporting specialists. For the VOUF, each time a new vessel enters a port they record its characteristics such as crew size, gear type, and length. For the SLF, the fishery reporting specialists collect census data from the fish dealers in each port and interview approximately a ten percent sample of fishermen for effort related information. As a result, the portion of the SLF pertaining to dealer census records does not contain fishing effort information such as days fished or the water, area, and depth codes.

Changes in the data collection method have occurred over the time period of the analysis. From 1964 to 1975 and from 1981 to present, the data collection method for the SLF

${ }^{49}$ The consolidated record number discriminates landings between the vessel and boats classes and between states. 
uses a dealer census and a random survey of fishermen. A trip interview approach is used for the data collected between 1976 and 1980. Individual vessels are sampled for fishing effort and catch data and dealers are interviewed for price data. These data are then combined and expanded to represent the total catch of shrimp in the Gulf of Mexico shrimp fishery. Unfortunately, the individual vessel documentation numbers are lost in the expansion algorithm. The original data, available from NMFs in washington, D.C., is used in this descriptive analysis by combining the vessel interview files with the dealer files to generate the missing ex-vessel price, and value information by vessel documentation number.

Although information on fishing effort in the form of vessel characteristics, harvest levels, and market exvessel prices are available from the VOUF and SLF data sets, input cost information is not routinely collected by the NMFS or state/local government agencies. In 1983, the NMFS did collect cost and returns (CNR) information from fishermen operating in the Gulf of Mexico and the southern Atlantic states shrimp fisheries for the 1982 fishing year. This stratified random sample based on port, ownership, mobility, state, vessel size, bycatch utilization and non-shrimp participation level was collected through personal interviews with fishermen, vessel owners, and accountants by 
a private contractor ${ }^{50}$. The resulting data set contains detailed information on the fishing firm's name and USCG documentation number, input costs (groceries, fuel, share for crew, vessel, and captain, ice, etc.), factors of production (numbers of trips and days fished inshore and offshore, vessel tonnage and length, type of hull, gallons of fuel, pounds of ice, engine horsepower, crew size, and type of gear), fixed costs (insurance, depreciation, and maintenance and repair), the output mix of species harvested as bycatch and from other fishing operations, and exvessel prices. Of the 193 interviews conducted, 21 came from Texas, 60 from Louisiana, 20 from Alabama, 9 from the east coast of Florida, 24 from Georgia, and 59 from South Carolina.

The resulting data set assembled from the CNR, VOUF, and SLF provides information on nearly all aspects of the shrimp fishing industry. Contained within it are data on pounds landed, value of the catch, fishing effort, input costs, USCG vessel documentation numbers, and vessel characteristics for this fishery resource. Although this data set is not collected explicitly for economic research and the cost data associated with operating in this fishery had to be approximated, sufficient information is available to study the causes of vessel entry-exit behavior.

${ }^{50} \mathrm{DRA} /$ Centaur Assoc. Contract No. NA82-GA-C-000421. 


\section{Descriptive Analysis of Entry/Exit Behavior}

in the Gulf of Mexico shrimp Fishery

Vessel entry-exit behavior is determined by first comparing the trends in and the correlations between different entry-exit categories created using the vessel operating units file (VOUF) and the Gulf of Mexico shrimp landings file (SLF). The data sets are then combined on a per vessel basis to generate a data set from which entryexit behavior can be modelled.

\section{SLF - VOUF Comparison}

The trends in and the correlations between different entry-exit classifications as determined by the vouf (according to the gear and region codes) and by the SLF are compared. A count of the vessels in the respective data files by vessel documentation number for each year provides a list of vessels that access the Gulf of Mexico shrimp fishery. This list is then compared to a prior year and a subsequent year to determine the entries to and exits from the base year fishery. A vessel enters the base year fishery if it is not in the previous year's data file, but is in the base year file. A vessel exits the fishery if it appears in the base year file, but not in the subsequent year file. One additional category is established for vessels that enter and exit the shrimp fishery; it is in the base year file, but not in either the previous or subsequent year files. The trends found in the vouf are then compared to those contained in the SLF for the Gulf of Mexico. 
The pattern of entry-exit behavior found in the two data sets differ significantly on a yearly basis. Table 1 presents the number of vessels that enter, exit, and remain in the Gulf of Mexico shrimp fishery according to the VOUF and SLF for 1966 to 1979. Between 29.8 and 98.7 percent of those vessels reported to be operating in this fishery by the VOUF can be found in the SLF; between 3.9 and 83.5 percent of entering vessels; and between 10.5 and 90.0 percent of exiting vessels. On average, 72.8 percent of the vessels in the fishery, 50.1 percent of the entering vessels, and 48.1 percent of the exiting vessels as determined by the VOUF can be matched with vessel documentation numbers found in the SLF between 1966 and 1979 .

A comparison of the VOUF and SLF vessel behavior trends indicates a poor relationship over time for the categories of vessels in the fishery (Figure 1) and vessels entering the fishery (Figure 2). While the number of vessels in the shrimp fishery has increased according to the VOUF, the SLF indicates a downward trend in Figure 1. The correlation coefficient $(r=-0.612)$ indicates that as vessels in the fishery increase according to the Vouf, vessels in the fishery according to the SLF decline. The correlation coefficient $(r=-0.182)$ for vessels entering the fishery (Figure 2) indicates a similar though much weaker relationship between the time trends in the two sets of data 
files. In Figure 3 , the relationship between the time trend for the vessel exiting the fishery was stronger and in the right direction $(r=0.670)$. That is, changes in the number of vessels exiting the fishery tend to move in the same direction at the same time in both data sets.

Figures 1 through 3 suggest a closer correlation between the time trends observed in the two data sets, if the 1976 to 1980 data are excluded. For vessels in the fishery, the correlation coefficient increases from -0.612 to 0.285 ; from -0.182 to 0.827 for vessels entering the fishery; and from 0.670 to 0.911 for vessels exiting the fishery. This suggests that the SLF data collection method used from 1976 to 1980 may be responsible for the poor overall correlation between the time trends in the two data sets when used for this. type of economic analysis.

These figures and the reported correlation coefficients indicate that the SLF alone does not accurately represent the vessel entry-exit patterns in this fishery. The consolidated records conceal information about individual vessel operations. Since only an average of 72.8 percent of the vessels reported operating in the shrimp fishery by the VOUF are reported catching shrimp in the SLF, 27.2 percent of the vessels in the shrimp fishery are not consistently identified by either data set. Eliminating the 1976 through 1980 SLF data would result in an improvement in the quality of this data set, but information about changes in vessel 
behavior during this five year period would be lost. If VOUF and SLF data do not accurately reflect actual entryexit behavior, the economic models built using this data will not provide insight into the causes of the observe vessel behavior.

\section{Combined Data set}

Combining the VOUF and SLF on a per vessel basis results in a data set from which entry-exit behavior can be modeled. The consolidated records in the SLF and the change in the method of data collection prevent an accurate determination of the entry-exit behavior patterns. However, the economic data in the SLF on a per vessel basis appears to be well behaved. The trends in vessel entry-exit behavior can be determined from the Vouf as well as the short and long run trends in vessel characteristics and the economic information for a subset of each group can be drawn from the SLF. Combining this information generates a data set capable of explaining the short and long run fluctuations in the structure and size of the fleet from vessel entry-exit behavior caused by changing economic and biological conditions.

Figures 4 through 6 present the revenue and pounds landed per trip and trips per vessel information from the SLF organized by vessel behavior category as determined by the VOUF. Vessels that enter the fishery generate a higher revenue per trip (averaging $\$ 3600$ ) and pounds per trip 
(averaging 2322 lbs.) than vessels that are in the fishery (\$2556 and 1680 lbs.); Figures 4 and 5, respectively. This could reflect the increased fishing power of newer vessels. Vessels that exit, the fishery have lower revenue (averaging $\$ 1990$ ) and pounds per trip (averaging 1285 lbs.) than vessels that remain in the fishery. This should reflect their relatively poorer financial performance that would cause them to search for better opportunities elsewhere. The last group of vessels, those that enter and exit the fishery, generally report slightly higher pounds (averaging 1413 lbs.) and lower revenue (averaging $\$ 1,267$ ) per trip than those vessels in the exit the fishery category. Since the correlation coefficient for this behavior category was positive for above average fishing years $(r=0.209)$ and negative for below average years $(r=-0.112)$, this behavior may represent opportunistic behavior by vessels that operate primarily in other fisheries but perceive potential profits for short periods in the shrimp fishery.

The trips per vessel by behavior category in Figure 6 also exhibit an interesting pattern. Vessels in the fishery have the highest number of trips per vessel (averaging 17.9). This is followed by vessels in the entering category with 9.9 trips per vessel, vessels in the exiting category with 8.7, and lastly by vessels in the entering and exiting 
category with 5.3 trips per vessel. One explanation ${ }^{51}$ for this observed behavior is that vessels in the fishery would be making trips from the beginning to the end of the fishing season. Entering or exiting vessels would not be in the fishery as long and vessels that both enter and exit in the same year would be in the fishery the least amount of time. Once the vessel behavior categories are accounted for, the average number of annual trips per vessel for the vessels in the fishery of 17.9 is not that different from the estimate of 20 to 25 trips per vessel provided by the port agents ${ }^{52}$. If the years 1976 to 1979 are excluded, the annual average in this vessel behavior category would rise to 21.8 trips per vessel. The 1976 to 1979 time period indicates a significant decline in the trips per vessel by behavior category. The change in the data collection method is more likely responsible for this decline than is a change in economic conditions. Also, the consolidated records contained in the SLF apparently conceal some of the trip information for each vessel identified by an unique USCG documentation number.

${ }^{51}$ Alternative explanations, including multispecies fishing operations, seasonality in the shrimp fishery, region where fishing activities occurred, etc., could also account for this observed behavior. Personal communication, Richard Raulerson, Industry Economist, Southeast Regional office, National Marine Fisheries Service, St. Petersburg, Fl.

52Personal communication, E. Snell, Supv. Survey Statistician, southeast Fishery Center, National Marine Fisheries Service, Miami, Fl. 
Figures 7 through 11 present trends in vessel

characteristics for the shrimp fishing fleet derived from the VOUF. Except for crew size, a general upward trend exists for each of these vessel characteristics. The average gross tonnage of a vessel (Figure 7) has risen from approximately 45 tons in 1965 to 69 tons in 1980. A general increase in fishing effort has, therefore, been occurring over this time period presumably caused by improving economic or biological conditions in the fishery. The standard errors ${ }^{53}$ presented in Figure 7 through 11 have been increasing and fluctuating around their mean values for each vessel characteristic. Vessel length in Figure 8 increased from a mean value of about 52 feet with an one standard error range of 43 to 62 feet in 1965 to a mean value of 56 feet in 1980 with an one standard error range of 43 to 69 feet. This implies that the fishing fleet has become more heterogenous over time. These two trends imply that newer and more powerful vessels have been entering the fishery and the characteristics of these vessels have become increasingly diverse. As a result, vessels may be specializing in the characteristics that allow them to catch a specific size range of shrimp more efficiently; e.g. a

${ }^{53}$ Figures 7 through 11 are only intended to illustrate how trends in vessel characteristics have fluctuated over time. The data represented by these figures do not follow a normal distribution and cannot to be used in statistical tests of significance. 
large vessel, offshore fleet and a small vessel, inshore fleet.

The fluctuations exhibited in Figures 7 through 11 probably reflect the fleet response to short run changes in the economic and biological conditions in the fishery. In Figure 9, the steady increase in mean horsepower is accompanied in 1969 to 1973 by an increase and then a decline in the range of horsepower found in the fleet. In Figure 10, peaks in crew size occur in 1967 and in 1977. A peak also occurs in 1976 for the year the vessel was constructed (Figure 11). Vessels in other fisheries may be entering the shrimp fishery to take advantage of what is perceived to be a particularly good fishing year and then exit the fishery in the following year. The fluctuation in horsepower may be caused by an increase in price and decline in availability of fuel during this period of time. Changes in fishing strategy may increase the variability of vessel characteristics in below average fishing years with unsuccessful vessels exiting the fishery and reducing the variability in future years. Whatever their causes, these short run fluctuations affect the structure of the fishing fleet through vessel entry-exit activity.

\section{CNR Data}

The previous discussion of vessel entry-exit behavior using the SLF and the VOUF data sets did not include shrimp vessel operating cost information. The lack of vessel 
operating cost information would seriously handicap any economic analysis of the Gulf of Mexico shrimp fishery, especially an analysis of vessel entry-exit behavior. Fortunately, vessel operating costs are estimated in Appendix D using the 1982 survey data collected under contract to the NMFS in 1983. Since the operating behavior of a vessel is revealed in its cost and revenue structure, operating costs can be interpolated and extrapolated for other vessels exhibiting the same behavior using economic theory.

\section{Conclusions}

Combining information from the VOUF and the SLF creates a data set from which the effects of changing economic and biological conditions on fleet size in the Gulf of Mexico shrimp fishery can be modeled. The vessel entry-exit behavior patterns found in the vouf can be explained using the economic, biological, and effort information contained in the combined data set. Although the vessel entry-exit behavior patterns found in the two data files are inconsistent, the economic and biological data in the SLF on a per vessel basis is consistent with the trends found in the Vouf.

The comparison of the VOUF and the SLF indicates that a viable data set can be generated from combining these data sets on an individual vessel basis. Using the VOUF, vessel entry-exit behavior and vessel characteristics can be 
determined based on the USCG vessel documentation number. The SLF can provide information on vessel landings, trips, exvessel prices, and pounds landed for those vessels identified in the vOUF by their USCG documentation number. Information from this combined set of data can be used in conjunction with the estimated cost equations from the 1982 CNR survey to estimate vessel operating costs. This combined data set can then be used to determine the causal factors that underlie the observed vessel entry-exit behavior patterns. 


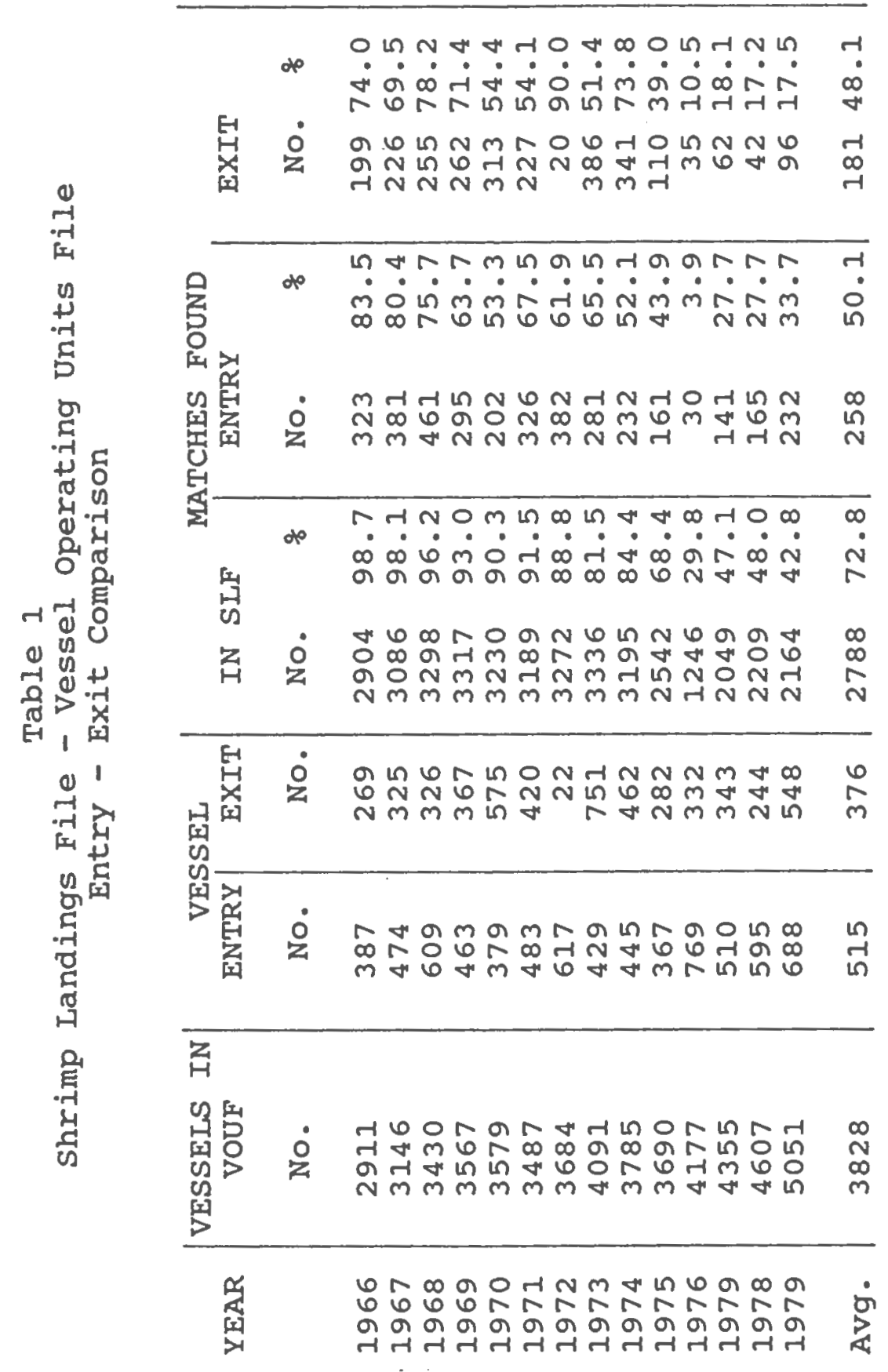


Figure 1

VOUF AND SHRIMP LANDINGS FILE VESSELS

Thousands $1966-1979$

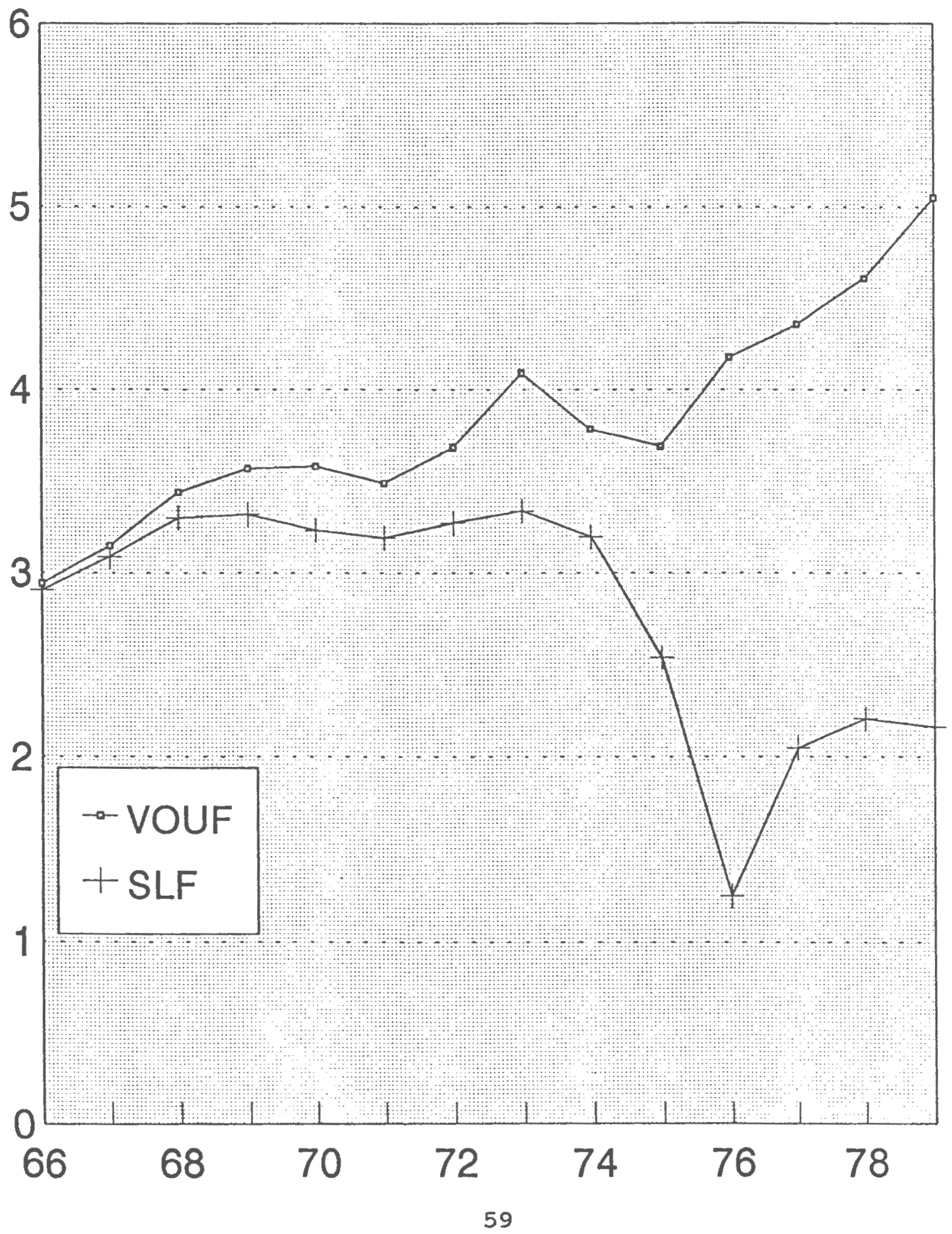


Figure 2

VOUF VS SLF VESSEL ENTRY

$1966-1979$

NUMBER OF VESSELS

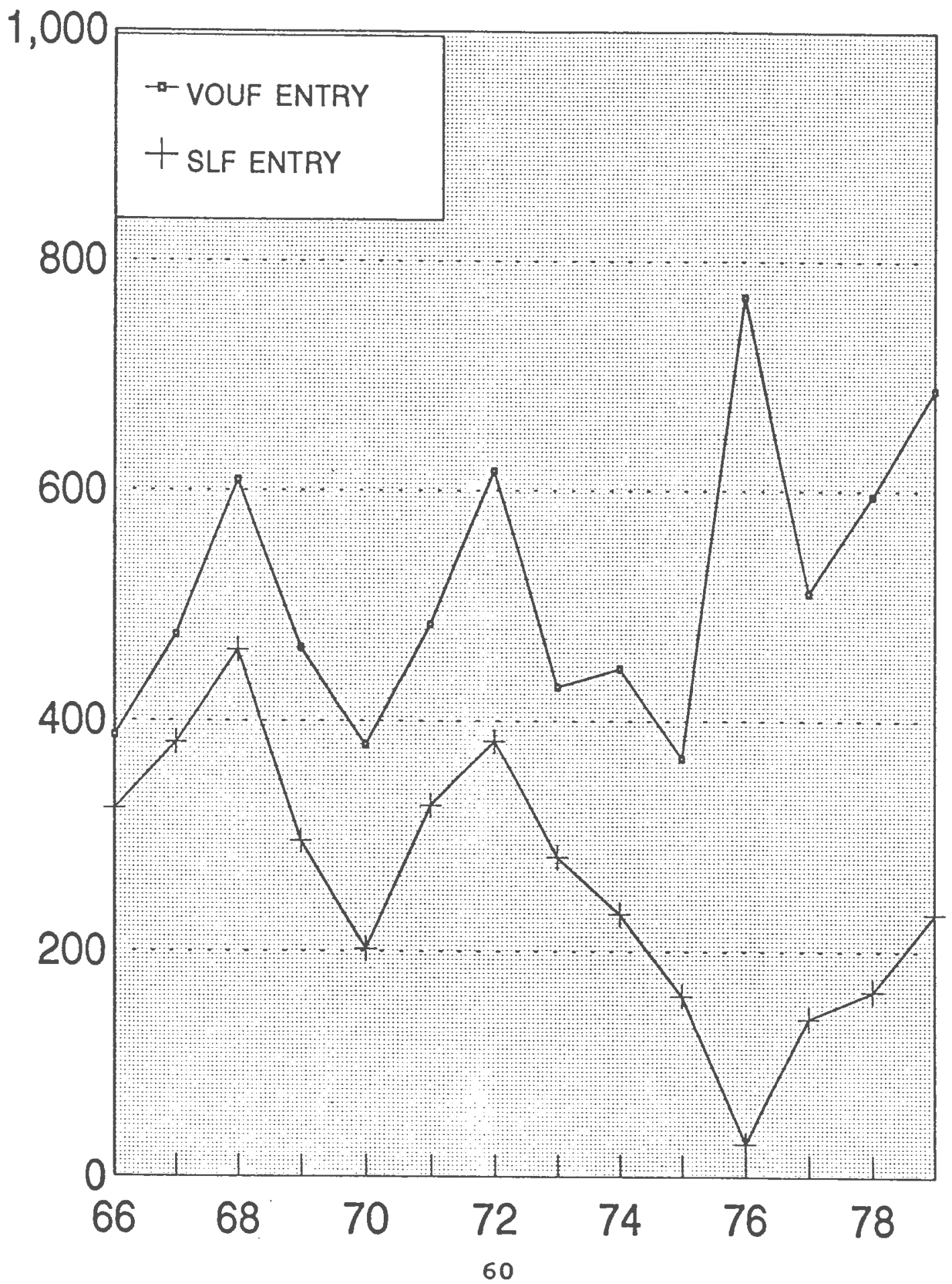


Figure 3

VOUF AND SLF VESSEL EXITS

$1966 \cdot 1979$

NUMBER OF VESSELS

800

$$
\begin{aligned}
& \text { a- VOUF EXITS } \\
& + \text { SLF EXITS }
\end{aligned}
$$

600

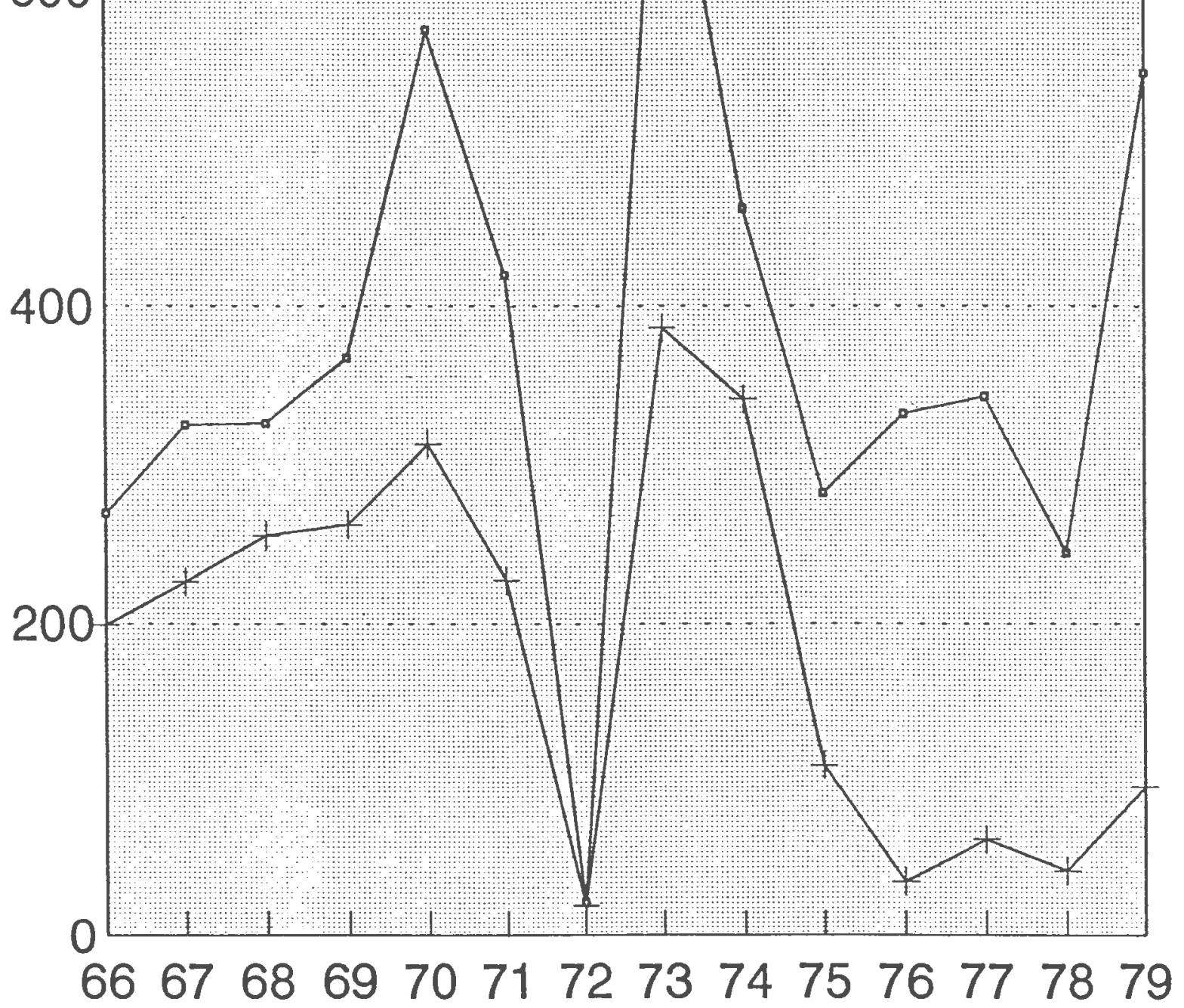


Figure 4

REVENUE PER TRIP BY BEHAVIOR CATEGORY 1966.1979

DOLLARS (THOUSANDS)

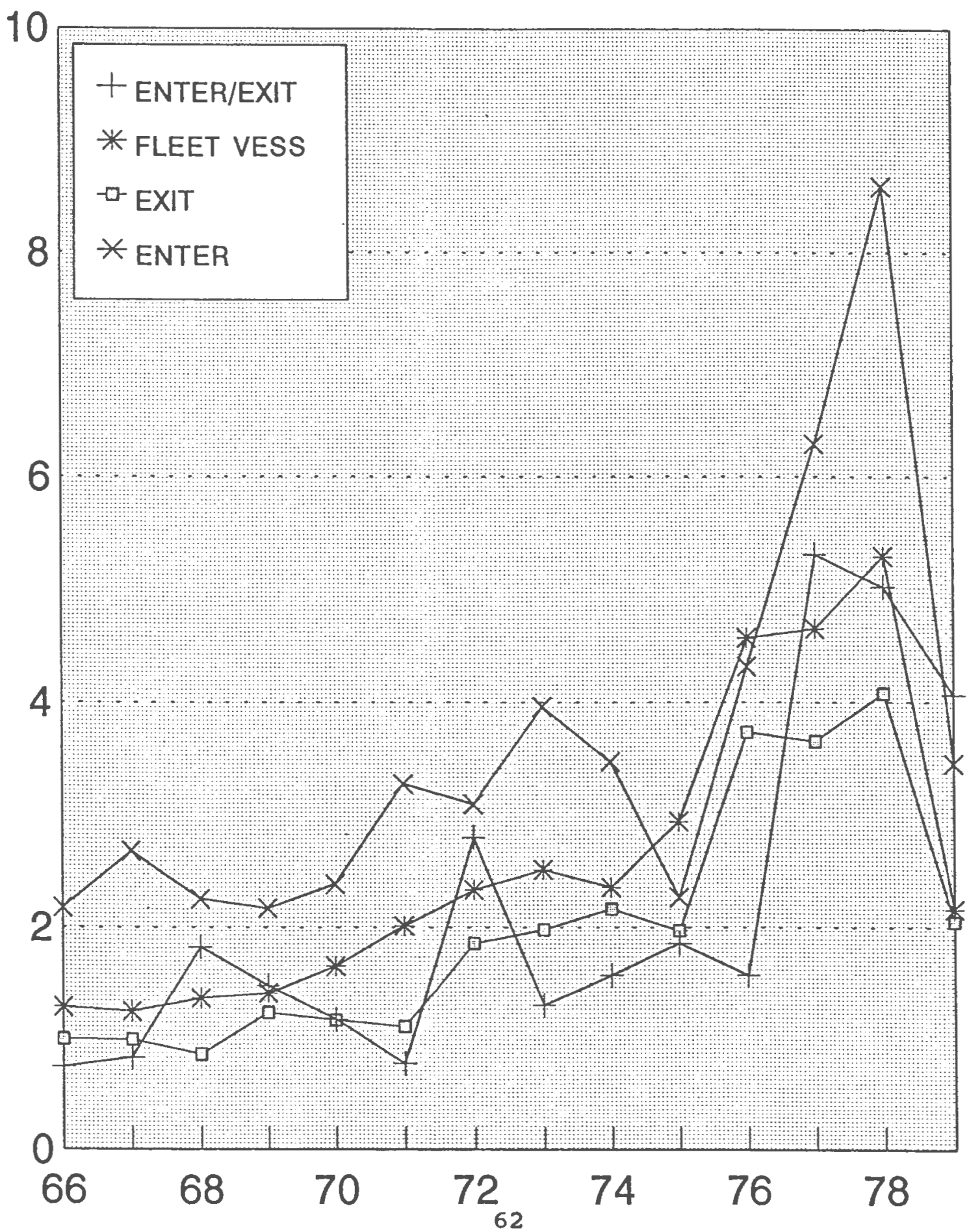




\section{POUNDS BY BE BEHÁE 5 VIOR CATEGORY POUNDS 1966-1979}

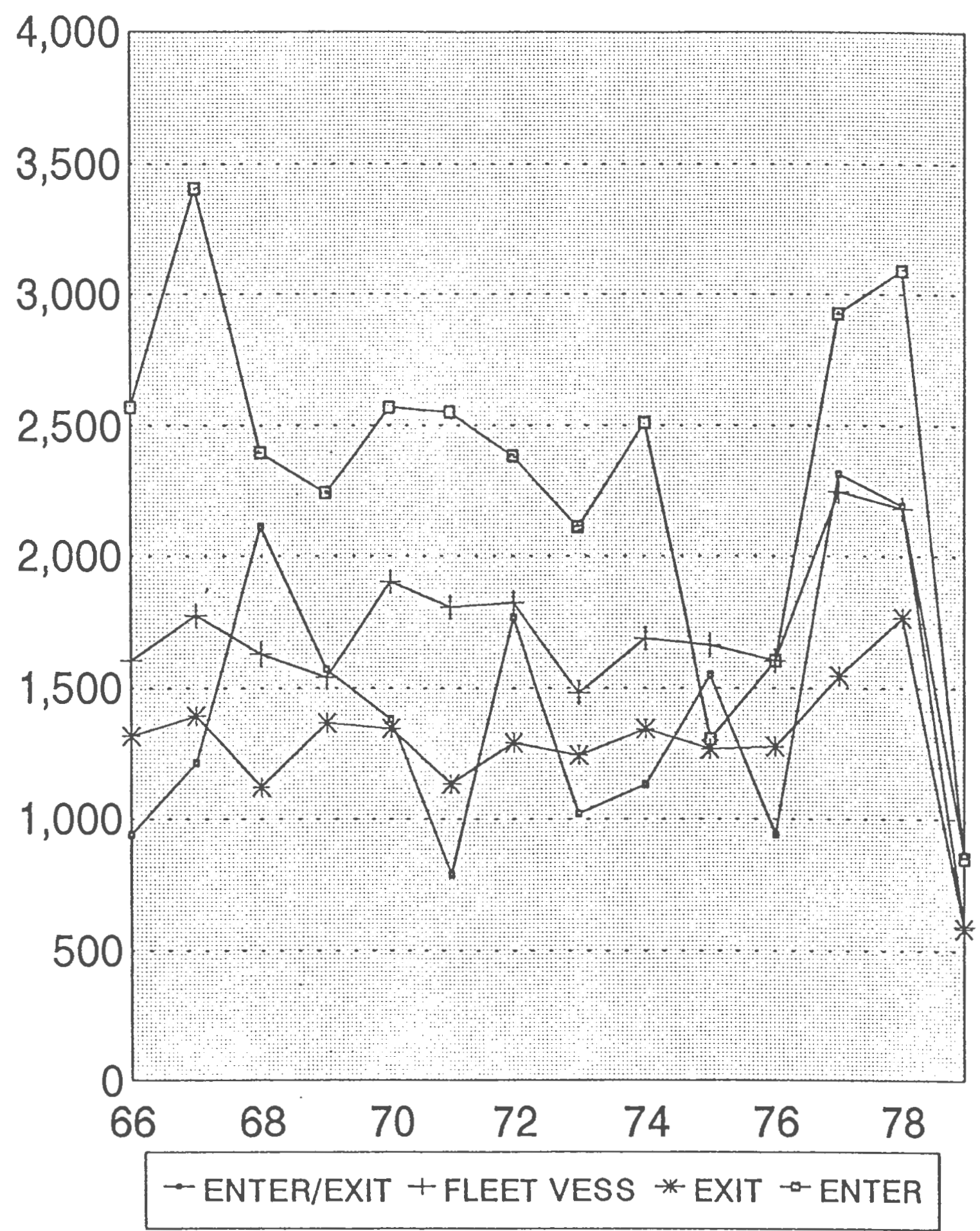


Figure 6

\section{VESSEL TRIPS BY BEHAVIOR CATEGORY $1966-1979$}

NUMBER OF TRIPS

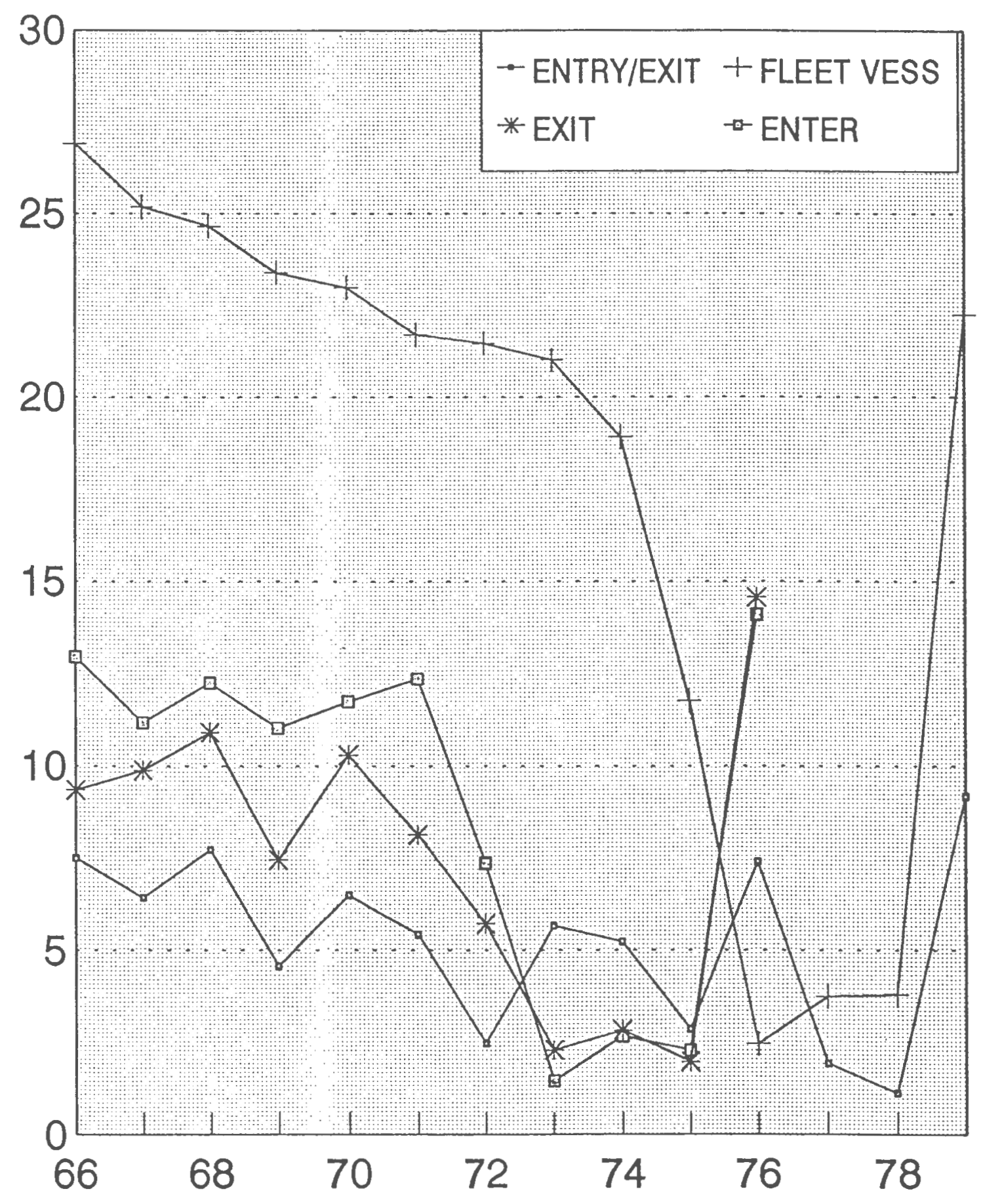


Figure 7

VESSEL GROSS TONNAGE $1965-1980$

AVG GROSS TONS

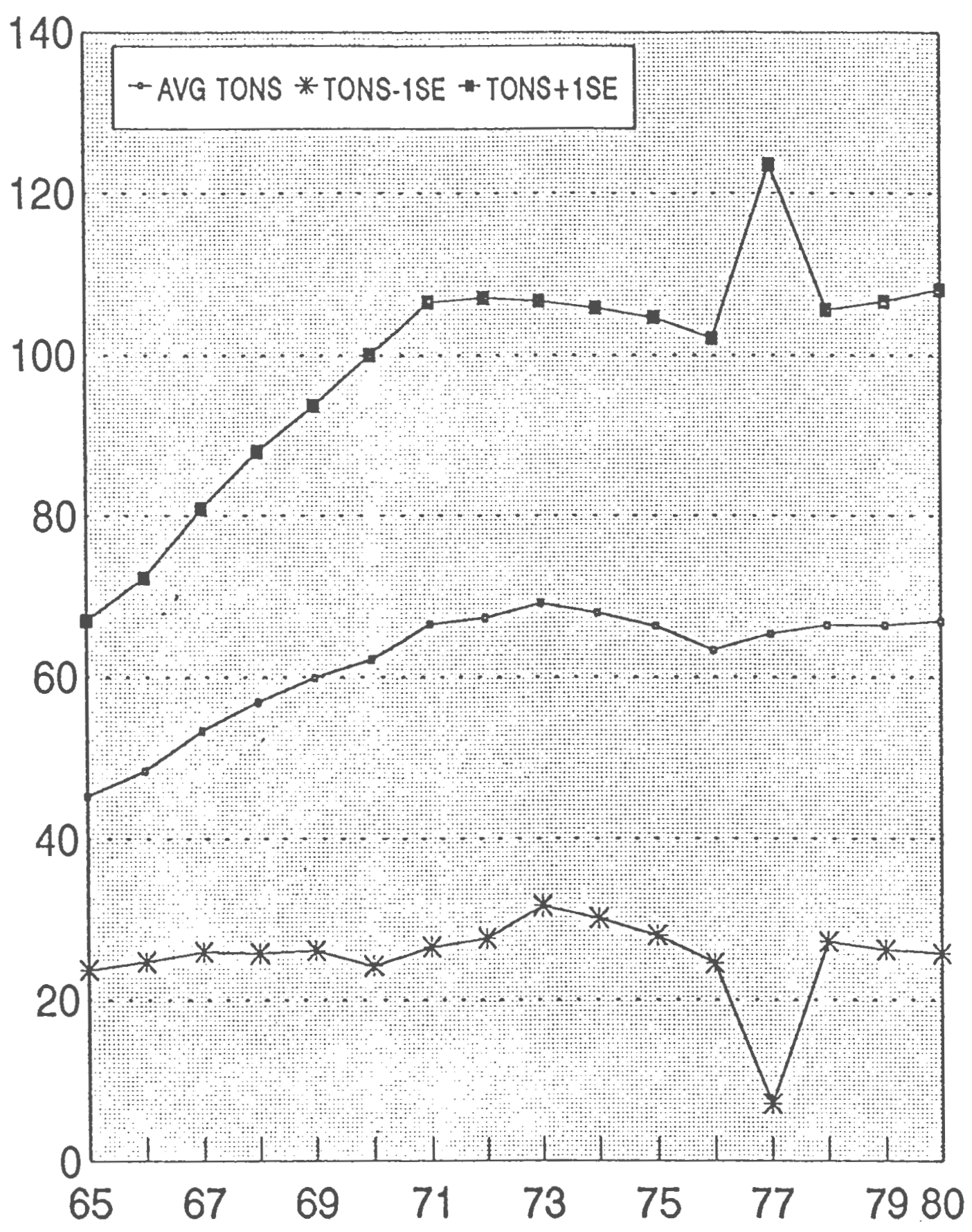




\section{Figure 8 \\ VESSEL LENGTH}

\section{VESSEL LENGTH (FEET)}

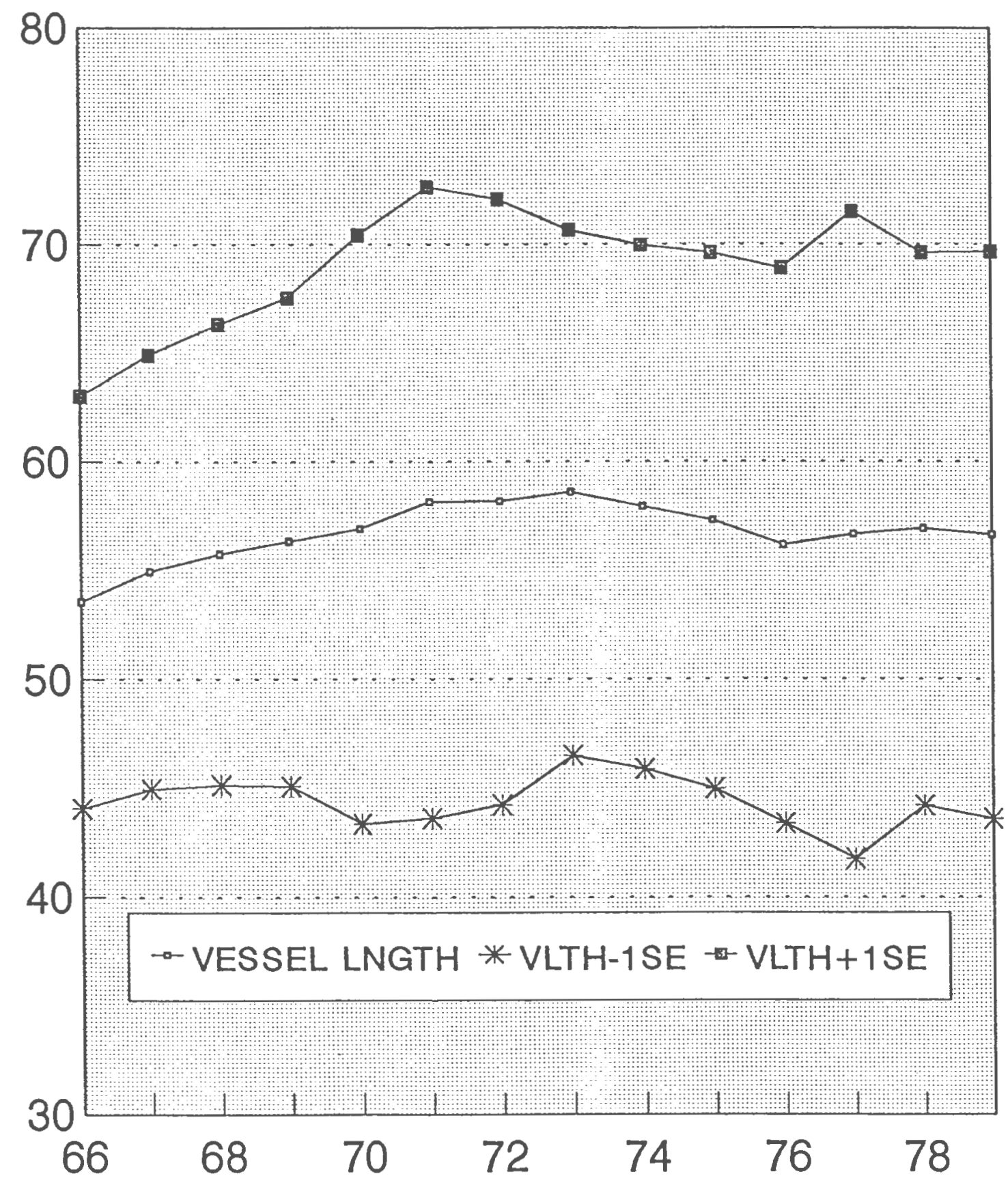




\section{VESSEL HORSEROPOWER 1966 - 1979}

HORSEPOWER

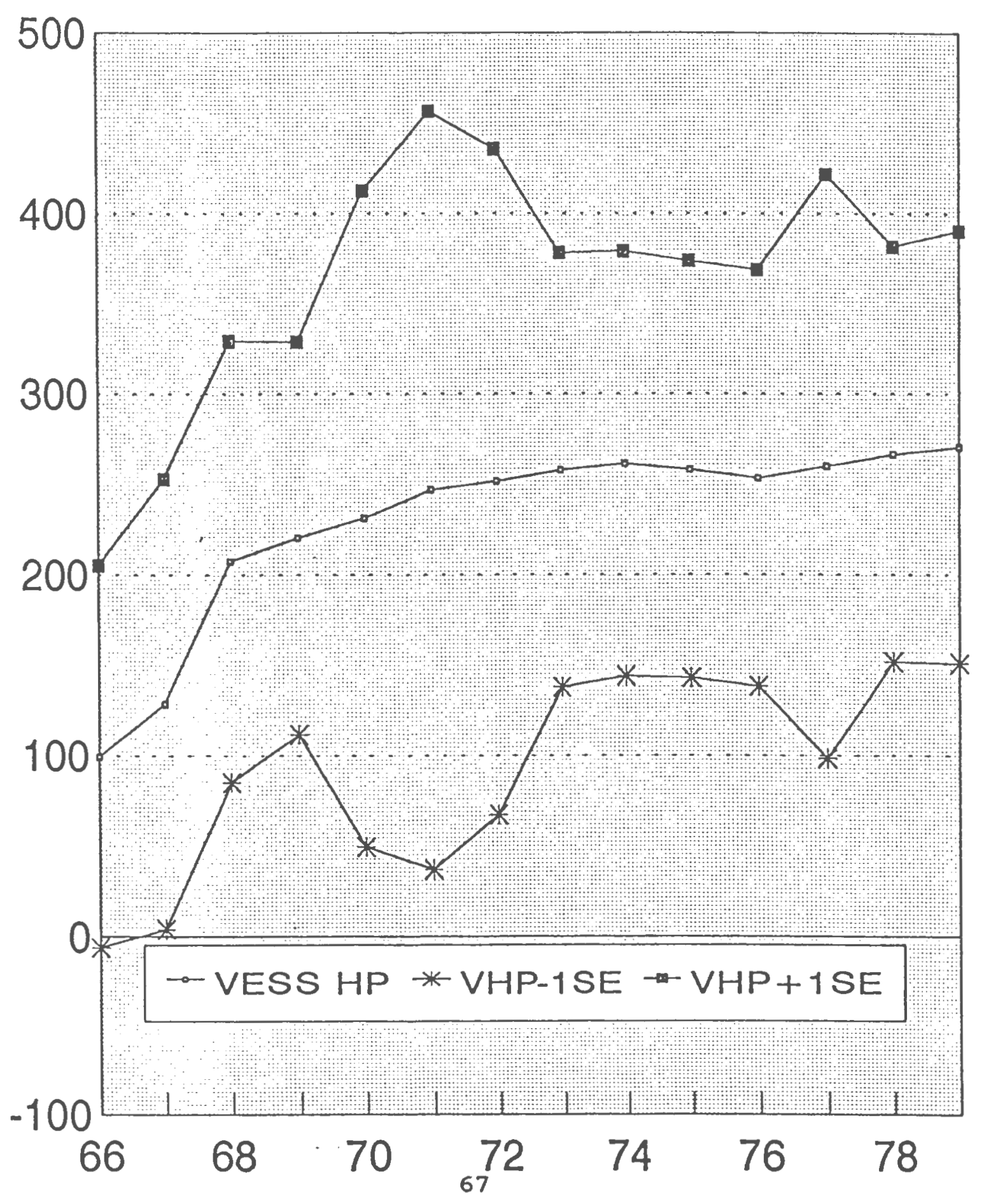


Figure 10

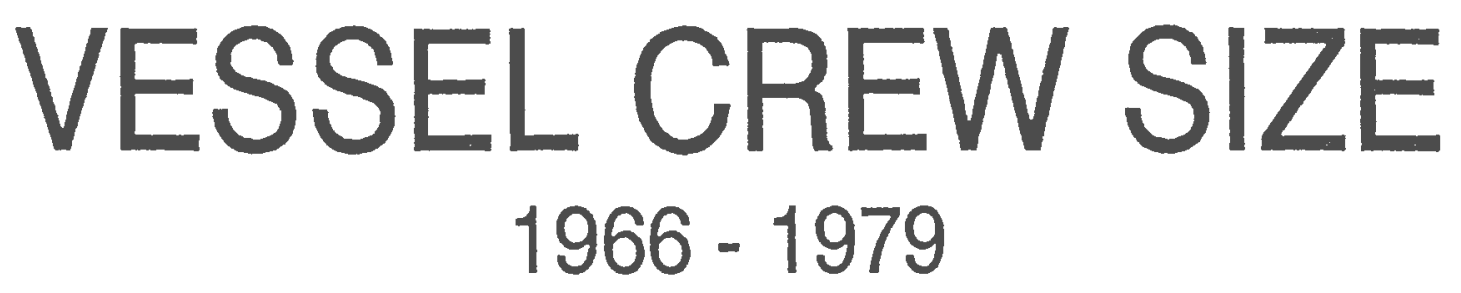

CREW SIZE

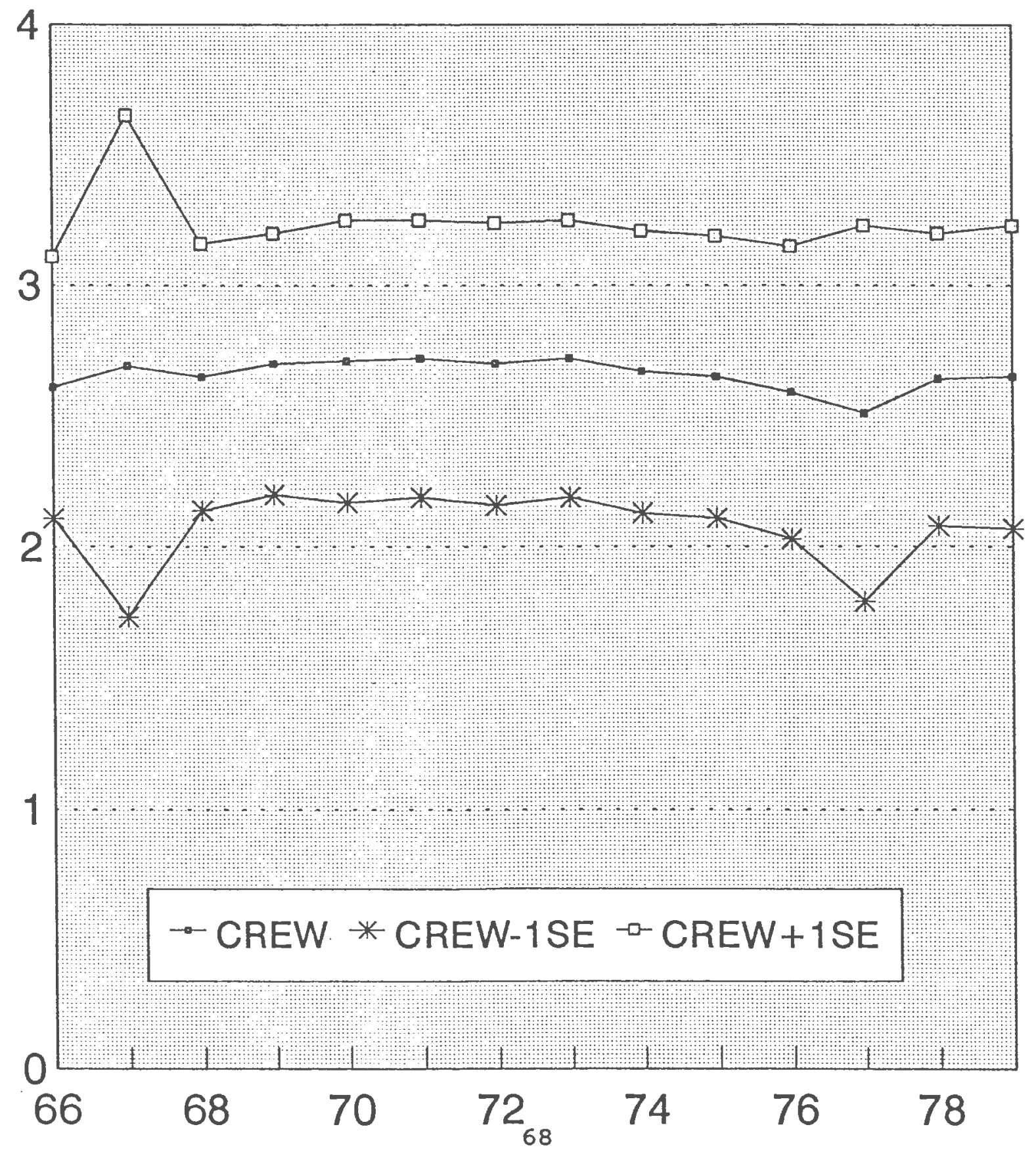


Figure 11

VESSEL YEAR BUILT

AVG YEAR BUILT

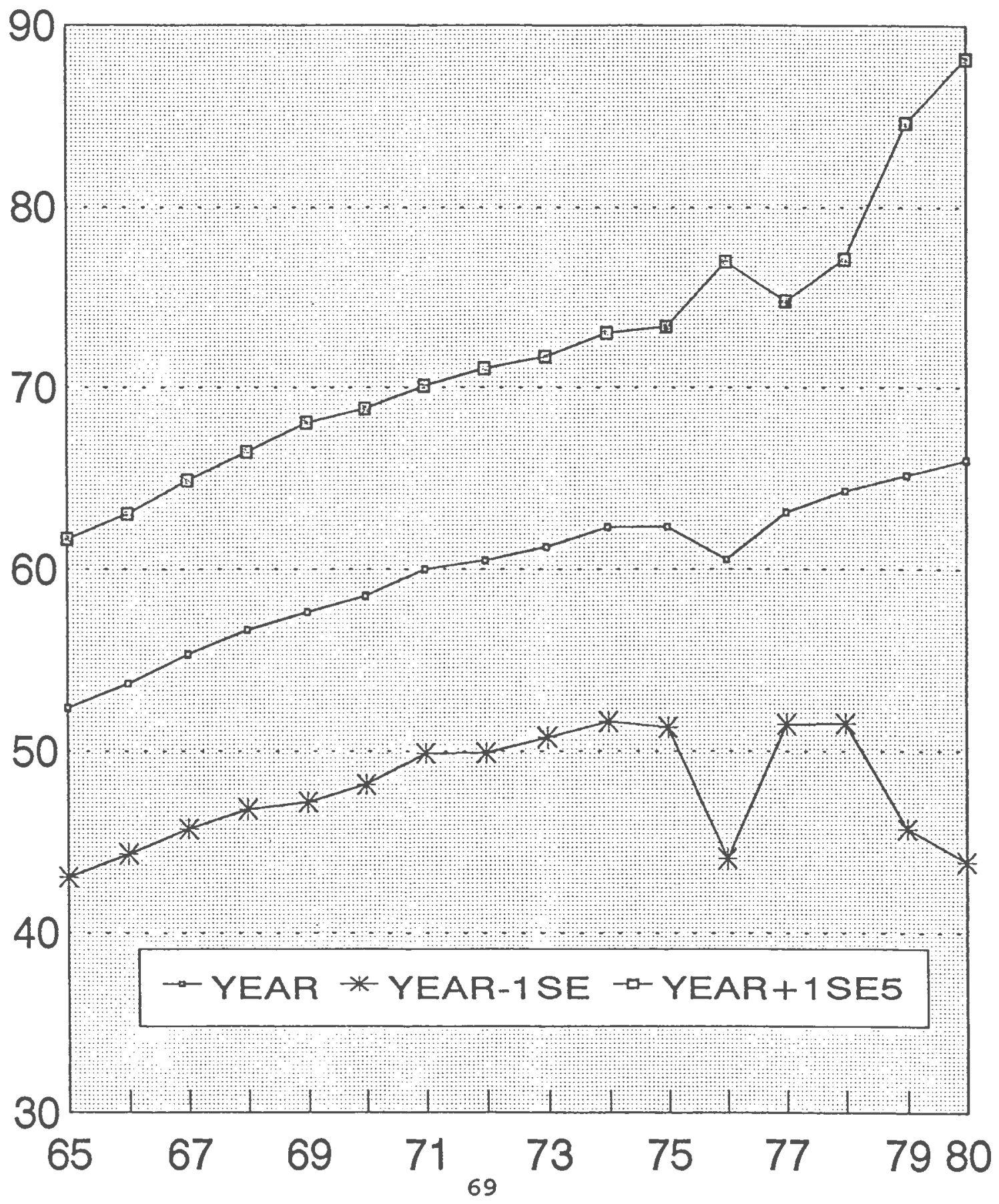




\section{Appendix B}

\section{Iiterature Review}

\section{Introduction}

This appendix first summarizes the applied and theoretical literature on fleet entry-exit behavior. This is followed by a general review of the literature pertaining to the Gulf of Mexico shrimp fishery that includes the literature pertaining to shrimp fishing vessel entry-exit behavior or fleet size change. The appendix is completed with a review of the qualitative dependent variable literature that is used to formulate and estimate the multinomial logit shrimp entry-exit model.

\section{Theoretical Entry-Exit Behavior}

Assuming homogeneous firms, Smith (1968, 1969)

hypothesizes that fleet size changes proportionately to profits with entry faster than exit for specialized vessels and equal for generalist vessels. In developing a model of a competitive recovery process in any natural resource extractive industry, Smith (1968) proposes that the flow of capital is proportional to profit. Extending this result to the fishing industry, Smith (1969) develops a model incorporating a stock externality where an increase in stock size reduces the total harvesting costs such that

$$
\partial c(x, x, m, K) / \partial x<0,
$$


a mesh externality where the gear affects the private

fishermen costs and revenues and the growth behavior of the fish stock such that

$$
\partial c(x, x, m, K) / \partial m>0,
$$

and a crowding externality where vessel congestion increases vessel operating costs such that

$$
\partial c(x, x, m, k) / \partial K>0
$$

where

$K$ is the number of identical homogeneous fishing firms,

$x$ is the catch rate in pounds per unit time,

$m$ is the mesh size, and

$\mathrm{X}$ is the population size.

The growth function of the fish stock is given by

where

$$
\partial x / \partial t=\dot{x}=F(X, m, K x)
$$

$F(\underline{X})=F(X)=0$;

$F^{\prime}\left(X^{0}\right)=0$

$F^{\prime \prime}(X)<0$

$\mathrm{X} \geq 0$

$0 \leq \underline{x}<x^{0}<\bar{x}$

$\underline{x}$ is the population size below which the species is not

viable,

$\bar{x}$ is the equilibrium population mass in the natural state; the environmental carrying capacity,

$\mathrm{Kx}$ is the total harvest rate, and

$\partial \mathrm{F} / \partial \mathrm{Kx}<0$ indicates that net recruitment

(instantaneous growth) declines with increased harvest.

Total cost per unit time can be expressed as

where

$$
\mathrm{C}=\mathrm{C}(\mathrm{x}, \mathrm{x}, \mathrm{m}, \mathrm{K})+\pi
$$

$$
\begin{aligned}
& \pi=\text { the minimum profit required for the } \\
& \text { vessel to operate in the fishery; rate } \\
& \text { of return on capital investment, } \\
& c \text { is the total cost per unit of time, } \\
& \partial c / \partial x>0 \text {, } \\
& \partial c / \partial x \leq 0 \text {, and } \\
& \partial c / \partial m>0 \text {, and }
\end{aligned}
$$




$$
\partial \mathrm{C} / \partial \mathrm{K}>0
$$

The profit function is expressed as

$$
\Pi=p(m) x-c(x, x, m, K)
$$

where

$$
\begin{aligned}
& \mathrm{p}(\mathrm{m})=\mathrm{R}(\mathrm{Kx}, \mathrm{m}) / \mathrm{Kx} \text { is the exvessel price } \\
& \text { (marginal revenue equals average revenue } \\
& \text { implies that demand is perfectly } \\
& \text { elastic) that increases with mesh size } \\
& \text { reflecting the size of fish landed; } \\
& \text { larger fish are assumed to be more } \\
& \text { valuable, } \\
& \mathrm{R}(\mathrm{Kx}, \mathrm{m}) \text { is industry revenue, and } \\
& \mathrm{R}(\mathrm{Kx}, \mathrm{m}) / \mathrm{Kx} \text { is average revenue. }
\end{aligned}
$$

Solving the first order conditions of the profit function subject to the control variables mesh size $\mathrm{m}$ and rate of harvest $x$ results in

$$
\mathrm{p}(\mathrm{m}) \equiv \mathrm{R}(\mathrm{Kx}, \mathrm{m}) / \mathrm{Kx}=\mathrm{C}_{\mathrm{x}}(\mathrm{x}, \mathrm{x}, \mathrm{m}, \mathrm{K})
$$

price equals marginal cost and

$$
p^{\prime}(m) x \equiv R_{x}(K x, m) / K \leq c_{m}(x, x, m, K) \text { if }<m=\underline{m}
$$

marginal revenue from varying mesh size equals its marginal cost. Free entry and exit in proportion to profit is assumed

$$
\partial \mathrm{K} / \partial \mathrm{t}=\dot{\mathrm{K}}=\left[\begin{array}{ll}
\delta_{1} \Pi, & \text { if } \Pi \geq 0 \\
\delta_{2} \Pi, & \text { if } \Pi<0
\end{array}\right]
$$

where

$\delta_{1}$ is the entry speed coefficient and

$\delta_{2}$ is the exit speed coefficient such that if

$$
\delta_{1}>\delta_{2}
$$

entry occurs faster than exit for durable vessels specialized in the harvest of one species of fish, or

$$
\delta_{1}=\delta_{2}
$$


entry occurs at the same rate as exit for generalist vessels capable of harvesting other species or for use in nonfishing activities.

Since equations (2) and (3) determine equilibrium values for harvest rate $\mathrm{x}$ and mesh size $\mathrm{m}$, then equations (1) and (4) reduce to

where

$$
\begin{aligned}
& \dot{\mathrm{X}}=F(X, K) \\
& \dot{\mathrm{K}}=I(X, K)
\end{aligned}
$$

$$
\begin{aligned}
& \dot{\mathrm{X}}=0 \text { for ecological equilibrium and } \\
& \dot{\mathrm{K}}=0 \text { for equilibrium in the exploiting } \\
& \text { industry and alternative uses of } \\
& \text { capital. }
\end{aligned}
$$

These two first order nonlinear equations define the equilibrium conditions between the exploiting industry and the fish population.

Smith (1969) also develops a sole owner model of a commercial fishery for comparison purposes:

$$
\begin{gathered}
\operatorname{Max} \Phi=p(m) K x-K C(x, x, m, K) \\
x, m, X, K=F(x, m, K x)
\end{gathered}
$$

where the first order conditions determine equilibrium values for the control variables. Specifically for fleet size

$$
\partial \Phi / \partial \mathrm{K}=\mathrm{p}(\mathrm{m}) \mathrm{x}-\mathrm{c}=\mathrm{KC}_{\mathrm{K}}-\mu \mathrm{F}_{\mathrm{Kx}} \mathrm{x}
$$

where $\mu$ is the marginal profitability of recruitment.

Clark, Clarke, and Munro (1979) further develop the sole owner model proposed by Smith (1969). The authors use 
a sole owner, bioeconomic model of a commercial fishery with a general production (Schaefer) model as the biological basis. The discounted net cash flow is the objective function:

$$
J=\int e^{-\delta t}[\operatorname{Ph}(t)-\operatorname{cE}(t)-\Pi I(t)] d t
$$

where

$\delta$ is the instantaneous discount rate; a constant,

$P$ is the price of landed fish; a constant,

$c$ is the operating cost per unit effort; a constant, and

II is the purchase or replacement price of capital; a constant,

subject to the population dynamics given by

where

$$
\begin{aligned}
& \dot{X}=F(X)-q E X \\
& X(0)=x^{0} \\
& X(t) \geq 0
\end{aligned}
$$

$X(t)$ is the population biomass at time $(t)$,

$F(X)$ is the natural growth function,

$q$ is the catchability coefficient (constant),

$E(t)$ is the fishing effort level at time ( $t)$,

$\mathrm{F}(\mathrm{X})>0$,

$F(0)=F(\bar{X})=0$,

$F^{\prime \prime}(X)<0$ for $0^{\prime}<x<\bar{X}$, and

$h(t)=q E(t) X(t)$ is the harvest rate in period $(t)$; a cobb-Douglas production function.

Equation (6) assumes that no harvest-stock interaction affect exists in this model of the fishery.

Fishing effort $E(t)$ is defined to fall within the range

$$
0 \leq \mathrm{E}(\mathrm{t}) \leq \mathrm{E}_{\max }=\mathrm{K}(\mathrm{t})
$$

where

$E_{\max }$ is maximum fishing effort capacity and

$\mathrm{K}(t)$ is the amount of capital invested in the fishery; i.e. standardized fishing vessels. 
Equation (7) asserts that the maximum effort capacity equals the number of vessels available and that the actual effort level employed at any point in time cannot exceed $\mathrm{E}_{\max }$.

Equation (5) is also constrained by the rate of capital adjustment. Capital adjustment in this model of the sole owner fishery differs from Smith (1969) model in that it is determined by

with

$$
\dot{K}=I(t)-\gamma K
$$

$$
\begin{aligned}
& K(0)=K^{0} \\
& K(t) \geq 0 \\
& 0 \leq I(T) \leq+\infty
\end{aligned}
$$

where

$I(t)$ is the gross physical investment at time $(t)$ and $\gamma$ is a constant depreciation rate with $\gamma=0$ for perfect non-malleability of capital and $\gamma=+\infty$ for perfect malleability of capital.

The non-malleability of capital assumption is embodied in the investment constraint; equation (8). The case of $I(t)=+\infty$ allows instantaneous discrete increases in the level of capital, but no disinvestment, to occur.

Disinvestment can be included by modifying equation (5) to include a scrap value of capital.

$$
\begin{gathered}
J=\int e^{-\delta t}[P h(t)-C E(t)-\Phi I(t)] d t \\
\text { subject to } \dot{X}=F(X)-q E X \\
\dot{X}=I-\gamma K \\
-\infty \leq I(t) \leq+\infty \\
X(t) \geq 0 \\
K(t) \geq 0 \\
0 \leq E(t) \leq E_{\max }=K(t)
\end{gathered}
$$




$$
\Phi I(t)=\left[\begin{array}{ll}
\Pi I & \text { if } I>0 \\
\Pi_{s}=I & \text { if } I=0 \\
\Pi_{s} I & \text { if } I<0
\end{array}\right.
$$

where

$I_{s}$ is the unit scrap value of capital; a constant $0<\Pi_{s}<\Pi$ in the case of perfectly malleable capital.

Clark, Clarke, and Munro (1979) investigate a model of new vessel entry and exit in a single species, sole owner fishery. Their model analyzes the effect of new investment in the fleet and disinvestment and depreciation of the fishing fleet on the optimal path of investment and effort that results in three possible scenarios:

(1) Non-malleable capital where

$$
\begin{aligned}
& \gamma=0 \text { and } \\
& 0 \leq I(t) \leq+\infty .
\end{aligned}
$$

(2) Quasi-malleable capital where

$$
\begin{aligned}
& 0 \leq I(t) \leq+\infty \text { and } \\
& 0 \leq \Pi_{s} \leq I
\end{aligned}
$$

(3) Perfectly malleable capital where

$$
\Pi_{s}=\Pi
$$

The non-malleability of capital assumption in the dynamic model of an optimally controlled fishery corresponds to the short run behavior of the firm. In the long run when capital is perfectly malleable, the fishery reaches the optimum sustained yield state where the cost function includes both the operating and the capital costs of fishing. 
McKelvey (1983) introduces two classes of vessels into the analysis and then investigates the conditions underlying the entry of existing generalist vessels into a fishery where existing specialist vessels are already exploiting the stock within a fishing season.

within a season, the population dynamics of a fish stock are determined by:

$$
\begin{array}{ll}
\dot{x}=-f(t) x & \text { for } 0 \leq t \leq T \\
x(0)=R &
\end{array}
$$

where $X(t)$ is the stock biomass,

$f(t)=f_{\alpha}(t)+f_{\beta}(t)$ is the total harvesting

$f_{\alpha}(t)$ is the harvesting effort of the

specialist fleet, and

$f_{\beta}(t)$ is the harvesting effort of the generalist fleet.

Equation (9) assumes that no growth or natural mortality occurs within the fishing season.

The subfleet fishing intensities are constrained by overall capacity:

$$
\begin{aligned}
& f_{\alpha}(t) \leq \Phi_{\alpha} \leq K \\
& f_{\beta}(t) \leq \Phi_{\beta}
\end{aligned}
$$

where

$\Phi_{\alpha}$ is the total capacity of vessels that have committed themselves to the seasonal start up costs and

$\Phi_{\beta}$ is a rental fleet that is drawn upon as needed.

The social return to the fleet is given by

where

$$
V=\int_{0}^{T}\left[P h(t)-C_{\alpha} f_{\alpha}(t)-C_{\beta} f_{\beta}(t)\right] d t-K_{\alpha} \Phi_{\alpha}-K_{\beta} \Phi_{\beta}
$$

$h(t)=f(t) X(t)$ is the rate of harvest by the fleet, $P$ is the unit price of landed fish that varies between years,

$C_{\alpha}$ and $C_{\beta}$ are constant unit operating costs of effort, 
$\mathrm{K}_{\alpha}$ and $\mathrm{K}_{\beta}$ are the unit start up costs of capacity. Since specialist vessels are assumed to be more efficient than generalist vessels and generalist vessels face an opportunity cost from neglecting the alternative fishery, then

$$
\mathrm{C}_{\alpha}<\mathrm{C}_{\beta}
$$

Also,

$$
\mathrm{K}_{\alpha}>\mathrm{K}_{\beta}
$$

since $K_{\beta}$ is the switching cost for vessels already actively engaged in an alternative fishery.

$$
\begin{aligned}
& \text { Let } \rho=P R \text { be the total value of the stock and } \\
& V(\rho, K) \text { be the maximum of the social } \\
& \text { return to the fleet } V \text { where the optimal } \\
& \text { fleet capacities of } \Phi_{\alpha} \text { and } \Phi_{\beta} \text { have been } \\
& \text { chosen. }
\end{aligned}
$$

Then the long run objective is to maximize the expected present value of

$$
\sum_{n=1}^{\infty}\left[V(\rho, K)-\Pi\left(I_{n}\right)\right]
$$

the sequence of annual investments that determines the sequence of annual $\alpha$ fleet capital levels $k_{n}(n=1,2, \ldots)$ according to

$$
K_{n+1}=(1-\gamma) K_{n}+I_{n}
$$

where $\mathrm{K}$ is the capital level,

$\gamma$ is the depreciation rate,

$I$ is investment,

$\Pi\left(I_{n}\right)$ is the nonlinear annual cost of investment, $\beta=1 /(1+r)$ is the annual discount rate, and $R$ is recruitment.

The objective is to find an investment policy for responding to the generally stochastic $R_{n}$ and $P_{n}$ levels. The nature of 
this policy is fundamentally affected by the degree of nonmalleability present in fleet capital investment;

modelled using cost penalties or prohibitions of excessive levels of investment or disinvestment.

In season optimization occurs when

$$
\begin{aligned}
& f_{\alpha}=\int_{0}^{T} f_{\alpha}(t) d t, \\
& f_{\beta}=\int_{0}^{T} f_{\beta}(t) d t
\end{aligned}
$$

where $f_{\alpha}, f_{\beta}$ are total seasonal effort.

The seasonal return is given by

$$
\operatorname{Max} V=\rho\left(1-e^{-f}\right)-\hat{C}_{\alpha} f_{\alpha}-\hat{C}_{\beta} f_{\beta}
$$

where $f=f_{\alpha}+f_{\beta}$ which implies that as $f$ increases $e^{-f}$ approaches 0 and $\mathrm{V}$ goes to $\rho$ if $\mathrm{C}_{\alpha}=\mathrm{C}_{\beta}=0$.

This results in the break even effort levels that determine the optimal levels of fleet size in a fishing season

$$
\begin{aligned}
& \rho e^{-f+}=\hat{C}_{\alpha} \text { or } f_{+}=\ln \rho / \hat{C}_{\alpha} \text { for specialist vessels } \\
& \rho e^{-f} f_{-} \hat{C}_{\beta} \text { or } f_{-}=\ln \rho / \hat{C}_{\beta} \text { for generalist vessels }
\end{aligned}
$$

and since

$$
\hat{C}_{\alpha}<\hat{C}_{\beta} \text {, }
$$

then

$$
f_{+}(p)>f_{-}(p)
$$

To substantiate these results, Smith and McKelvey (1986) extend the specialist-generalist framework to multispecies models as a means of demonstrating how society copes with stochastic variability. Specialists develop 
technical skills over their environment to reduce variability. Generalist maintain low switching costs to allow them to move to the fishery generating the best potential return. As fluctuating environmental and market conditions increase revenue variability, the optimal fleet will consist of a mix of these vessel types.

The authors use behavioral descriptions of actual fisheries to determine the validity of their theoretical hypothesis. Actual tests cannot be performed because of data limitations. The Australian prawn and rock lobster fishery vessels behave as theory predicts with reduced stochastic variability favoring specialist vessels and phasing out rock lobster vessels. Increased variability favored generalist vessels. Also, annual variability in catch tends to affect the generalist vessels (brine trawlers) much more then specialist (freezer trawlers) in their decision to enter or remain in the prawn fishery. Territoriality tends to support specialists by restricting the entry of generalists to the fishery; Maine lobster on Matenicus Island and the diver gill nets for Columbia river salmon are examples of a perimeter-defended fishery. Market price variability supports the generalist strategy of baymen in Shoal Harbor, New Jersey.

The authors conclude that the generalist vessels gain from shorten seasons and catch quotas. Specialist vessels gain from limited entry programs that tend to lengthen the 
fishing season and allows their catch effectiveness to work to their best advantage.

Berck and Perloff (1982) demonstrate that smith's (1969) entry and exit criteria is based on current profits (myopic expectations) and then extend it to include the discounted value of all future profits (rational expectations) derived from harvesting the resource. Dynamic fisheries theory assumes vessel entry and exit behavior is proportional to current profits. The general expectations fishery model is:

where

$$
\begin{aligned}
& Y=\int_{t=0}^{\infty} e^{-r(z-t)} \prod^{e}(z) d s \\
& \text { s.t. } \quad \dot{X}=f(X)-\alpha s X \\
& \dot{s}=\delta Y
\end{aligned}
$$

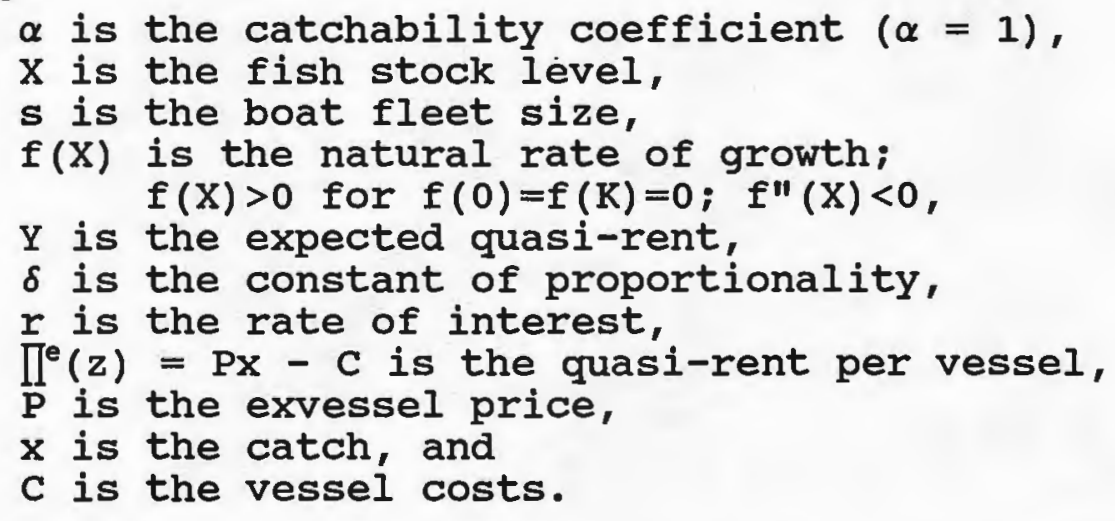

In the standard model, potential entrants base their entry decision on the present value of profits where current profits are a myopic estimate of future profits; e.g.

$$
\pi^{e}(z)=\pi(t) \text { for all } z>t \text {. }
$$

Then

$$
Y=\pi(t) / r=(P X-C) / r
$$


and

$$
\dot{S}(t)=\frac{\delta}{r}(P x-C)
$$

Entry, therefore, is proportional to instantaneous profits.

Berck and Perloff assume that potential entrants base their decision on an estimate of all future quasi-rents (profits). In the rational expectations model with perfect foresight the entry decision is based on the present value of the future quasi-rent where

$$
\pi^{e}(z)=\pi(z)
$$

and the quasi-rents are measured as

$$
\int_{t}^{\infty} e^{-r(z-t)}[\operatorname{Px}(z)-c] d z
$$

and

$$
\dot{\mathrm{S}}=\delta \mathrm{Y}
$$

Entry is proportional to the expected present value of the quasi-rents. Without perfect foresight

$$
\pi^{\mathrm{e}}(\mathrm{z})=\Delta \pi(\mathrm{z})
$$

where

$E(\Delta)=1$

$\Delta$ is a probability distribution to account for uncertainty about future quasirents.

This approach could account for the reluctance of vessels to exit the fishery as current profit levels decline in a particular time period ( $t$ ) resulting in asymmetric entry and exit behavior. Firms would be more likely to enter in above average years based on the standard model $\left(\pi^{e}(z)=\pi(z)\right)$ but less likely to exit the fishery during below average years $\left(\pi^{\mathrm{e}}(\mathrm{z})=\Delta \pi(z)\right)$. 
Bjorndal and Conrad (1987) found that current profits in the purse seine herring fishery were the primary basis for the investment decision. These results support the myopic expectations model of Berck and Perloff (1982). The authors estimate the size of the adjustment parameter ( $n$ ) of capital to changes in industry profits $\left(\pi_{t}\right)$ for the North Sea Herring fishery using a discrete time model:

$$
\mathrm{K}_{\mathrm{t}+1}-\mathrm{K}_{\mathrm{t}}=\mathrm{n} \pi_{\mathrm{t}}
$$

where $k_{t}$ is the level of capital invested in the fishery. The empirical results support the adjustment hypothesis although the lower rate of exit was found to be statistically insignificant. Measures of opportunity cost such as the relative price of mackerel, an alternative fishery, are included in an ad hoc manner and improve the fit of the model. Lagged profit variables also improve the fit of the model which indicates the adjustment time necessary to construct new vessels. However, the results indicate that current period profits are the primary cause of entry-exit and that opportunity costs depend on returns in alternative fisheries. This might also indicate that vessels behave as generalists (McKelvey, 1983) moving between fisheries depending on the relative net return in a multispecies fishing environment.

stollery (1987) adapt the rational expectations approach of Berck and Perloff (1982) to study the effects of a monopsonistic processing sector on vessel entry-exit 
decisions in a competitive harvesting sector. The assumption of perfect competition in the processing and harvesting sectors of the fishing industry is replaced by assuming that the perfectly competitive harvesting sector faces a monopsonistic processing sector. The ability of the monopsonist to depress the price paid to the fishermen depends on the slope of long run fishing supply that is a function of the ease of entry and exit in the competitive fishery. With perfect entry and exit, the monopsonist is only able to collect the resource rent in the fishery. When entry is blocked, the monopsonist can collect the monopsony rents from the harvesting sector. The competitive harvesting sector maximizes the present value of expected future profits net of entry costs:

$$
J_{c}(t)=\int_{t}^{\infty} e^{-p(z-t)}\left(n \pi_{f}^{e}-\left[C_{k}(\dot{n})^{2}\right] / 2\right) d z
$$

where $\pi_{f}^{e}=P_{f} h x e-C_{f}(e)$ is the expected short run profits of a vessel,

$P_{f}$ is the exvessel price of unprocessed fish,

$\mathrm{h}$ is a parameter; harvest rate,

$X$ is the stock size,

$e$ is the per vessel level of effort,

$C_{f}(e)$ is the cost of fishing effort,

$\mathrm{n}$ is the number of identical fishing vessels,

$\left[c_{k}(\dot{n})^{2}\right] / 2$ is the total industry cost of adjusting capacity,

$C_{k}$ is the slope of the new capacity (n) supply curve, $p$ is the social rate of discount, and

$\mathrm{Z}$ is a time period greater than $t_{;}$in the future.

From this model, investment or the entry and exit of vessels is given by: 


$$
\dot{n}(t)=\frac{\pi_{f}(t)}{p c_{k}}=\alpha \pi_{f}(t)
$$

where $\alpha=1 / p c_{k}$ is the accelerator; the speed of entry or exit is inversely related to the discount rate $(p)$ and the slope of the new capacity supply curve $\left(c_{k}\right)$.

Perfectly elastic supply $\left(C_{k}=0\right)$ implies instantaneous entry or exit $(\alpha=\infty)$ until MC $=\min$ ATC for each homogenous firm and therefore $\pi_{f}=0$.

Sutinen (1986) extends the theory by introducing the effect of seasonality or cyclical variation on the behavior of the firm. Seasonal variation in resource availability is the major source of seasonality in most fisheries. Equilibrium output, price, and the number of firms are derived for each season, the year, and for full bioeconomic equilibrium based on a logistic growth function for the fish stock and a production function that is related to the season of the year.

$$
q_{s}=f^{s}(v, k, x)
$$

where $q_{s}$ is the vessel catch or firm output each season $(s=1,2, \ldots, s)$,

$\mathrm{v}$ is a vector of variable inputs,

$\mathrm{k}$ is a vector of fixed inputs, and

$x$ is the size of the fish stock.

A firm's net operating revenue is given by

$$
\Omega^{s}=p q-c^{s}(q, k, x)
$$

where $P$ is price and $c^{s}(q, k, x)$ is variable cost.

Annual profits are given by

$$
\Sigma \Omega^{s}-\beta k
$$


where $k$ are the fixed factor inputs and

$\beta$ are the costs of the fixed factor inputs.

Firms enter the heterogeneous fleet until the marginal firm's annual profits equal zero.

$$
\mathrm{p}=\frac{\Sigma \mathrm{c}^{\mathrm{s}}(\mathrm{q}, \mathrm{k}, \mathrm{x})+\beta \mathrm{k}}{\Sigma \mathrm{q}^{\mathrm{s}}}=\operatorname{ATC}
$$

since the number of firms (N) is considered a constant initially, industry seasonal output can be determined from

$$
p=c_{q}^{s}\left(q, k, x^{s}\right)=M C=A T C \text { in open access }
$$

where $\mathrm{x}^{\mathrm{s}}$ is seasonal biomass.

The fixed inputs ( $k$ ) are chosen optimally each year and can be subsumed as an argument in

$$
c_{q}^{*}(*) \text {. }
$$

which implies

$$
q^{s}=q^{s}\left(p, x^{s}\right)
$$

and seasonal output is

$$
Q^{s}=Q^{s}\left(p, x^{s}\right)=\sum_{j=1}^{N} q_{j}^{s}\left(p, x^{s}\right)
$$

However, $\mathrm{N}$ can change with the bettering or worsening of seasonal conditions based on the stock dynamics of the fishery. The industry supply curve becomes

$$
Q_{t}\left(p, R_{t}\right)=Q_{t}\left(p, x_{t}^{\prime}\right)=\underset{s}{\Sigma} Q_{t}^{s}\left(p, x^{s}\right)
$$

where $R_{t}=x_{t}^{\prime}$ is recruitment into the fishery.

The model is then extended to account for variable prices and multispecies fisheries. The firm in multispecies setting chooses the fishery that yields the highest net operating revenue in a season. The single fishery's 
seasonal supply curve becomes:

$$
Q^{m s}=\sum_{j=1}^{N} q_{j}^{m s}\left(p^{m s}, x^{m s}\right)
$$

where $\mathrm{m}$ is the particular fishery chosen by the firm for the season.

Instead of the number of firms $\mathrm{N}$ being fixed, $\mathrm{N}$ depends on the profitability of this fishery relative to the other m-1 fisheries. While $\mathrm{N}$ is not determined explicitly in the model, $\mathrm{N}$ and $\mathrm{Q}$ are directly related through the production functions of the individual firms and should be easily derivable.

Two articles that derive empirical estimates of the rate of capital investment in renewable resources are for the fur seal industry (Paterson and wilen, 1977) and the Texas shrimp fishery (Penson, Tetty, and Griffin, 1987). Paterson and wilen (1977) conduct an empirical study of the impact of joint harvest of north Pacific fur seals by the U.S. in their rookeries and by Canada as a common property, open ocean resource and found that the herd was driven to near extinction. Dynamic theories predict that the declining harvesting sector would collapse due to the economic pressures of reduced herd size and prices. This theoretical result is supported by a descriptive discussion of the economic trends in the seal industry and by the estimation of equations measuring the time rate of change in stock size and capital investment in the industry. of particular interest is the empirical estimation and 
statistical significance of capital investment as a function of profits in the industry:

$$
\dot{\mathrm{K}}=\delta[\mathrm{PAX}-\mathrm{C}-\pi]
$$

where $\dot{\mathrm{K}}=\partial \mathrm{K} / \partial \mathrm{t}$ is the time rate of change in capital investment,

$P$ is the market price of fur seal skins,

$C$ is the cost of harvesting capital,

$\pi$ is the unit return required on capital

(opportunity cost of capital), and

$\delta$ is a response parameter indicating the rate of change in capital due to changes in the level of profits.

When combined with the estimated time rate of change in stock size, a stable spiral results that is borne out by the observed data. The model indicates that capital is declining in the industry (exit) and stock size is recovering as the dynamic system approaches a steady state equilibrium. Therefore, the fur seal industry, characterized by a stable spiral, at the time of the international agreement to close the fishery was already experiencing a recovery of its stock because of economic conditions in the marketplace.

Both Bjorndal and Conrad (1987) and Peterson and wilen (1977) have relatively simplistic models of capital investment in their harvesting industries. Limitations in the size of the available data bases are probably the primary explanation for these model specifications. Both sets of authors are restricted to annual data covering relatively short periods of time. This limits the degrees 
of freedom available to estimate more sophisticated models. It is also likely that little cross sectional data is available to incorporate into the models again limiting the model specifications that could be estimated.

Penson, Tetty, and Griffin (1987) estimate an econometric model of annual net investment in fishing vessels based on the neoclassical theory of aggregate investment behavior. Assuming homogeneous firms within the categories of wood, steel, and fiberglass hull vessels, an adaptive expectations hypothesis, and that competitive firms add to their existing capital stock provided the present value of the periodic net cash flows generated by an additional unit of capital exceeds its net purchase price can be expressed as $\mathrm{N}_{\mathrm{jt}}=\mathrm{b}_{\mathrm{j} 0}+\mathrm{b}_{\mathrm{j} 1}\left(\mathrm{pX} / \mathrm{c}_{\mathrm{j}}\right)_{\mathrm{t}}+\mathrm{b}_{\mathrm{j} 2} \mathrm{~K}_{\mathrm{jt}-1}+\mathrm{b}_{\mathrm{j} 3} \mathrm{~N}_{\mathrm{jt}-1}+\mu_{\mathrm{jt}}$ where $b_{j 0}$ is the intercept,

$\mathrm{b}_{\mathrm{j} 1}=\Theta \beta \lambda$,

$\mathrm{b}_{\mathrm{j} 2}=-\Theta \lambda$,

$\mathrm{b}_{\mathrm{j3}}=(1-\lambda)(1-\theta)$,

$\Theta$ is the partial adjustment coefficient,

$\beta$ is the partial production elasticity of vessel category (j),

$\lambda$ is the adaptive expectations coefficient,

$p$ is the real exvessel price of shrimp,

$\mathrm{X}$ is the shrimp harvest level,

$c_{j}$ is the implicit rental price of vessel category (j),

$\mathbf{K}_{\mathrm{jt}-1}$ is the productive capital stock in year $t-1$,

$\mathrm{N}_{\mathrm{jt}-1}$ is the net investment in year $t-1$.

$\mu_{\mathrm{jt}}$ is a random disturbance term.

The econometric results are statistically significant, comply with economic theory, and indicate that low real interest rates designed to stimulate investment activities 
in the general economy actually increase capitalization in the shrimp fleet.

These theoretical and applied studies usually assume a homogeneous fishing fleet harvesting a homogeneous stock of fish. Changes in fleet size occur continuously and instantaneously as the optimal vessel enters or leaves the fishery with changing market conditions. While exhibiting many of the characteristics theoretically derived in the literature, actual fishing operations are characterized by heterogeneous fleets.

Bockstael and Opaluch (1983) model fishermen or vessel behavior utilizing the discrete choice approach. Since managers do not have complete control over effort and because fishermen face discrete, not marginal, decisions when choosing a fishery in which to participate, the usual bioeconomic modelling approach to fisheries management is inappropriate. Alternatively, behavioral modelling to predict firms response to regulation policies is proposed as a basis for rational management.

The intermediate run choice ${ }^{54}$ of which fishery the fisherman's capital will be employed in is constrained by imperfect malleability of capital and fishery specific knowledge and by uncertainty about economic returns from the

${ }^{54} \mathrm{Utilizing}$ a different theoretical model based on myopic expectations, the same econometric technique can be used to predict the probability of entry, exit, or remaining in the shrimp fishing fleet. 
fishery. A logit specification incorporating uncertainty based on fishermen's utility is utilized to predict the choice of fishery. This is accomplished by defining the expected utility of each alternative in terms of the moments of the distribution of random returns:

$$
E[U(W)]=U\left(W_{0}+E(R)\right)+1 / 2 U^{\prime \prime}\left(W_{0}+E(R)\right) * \operatorname{Var}(R)
$$

where $\mathrm{W}$ is wealth,

$\mathrm{U}(\mathrm{W})$ is utility derived from wealth, and

$R$ is the random return from a fishery.

Substituting $U+\ln (W)$ into this expression and assuming differences in the costs of switching between fisheries results in a probability of individual ( $n$ ) choosing fishery(i) as:

$$
P_{n i}=\frac{\exp \left[\theta_{1} \ln \left(W_{o n}+E\left(R_{n i}\right)\right)+\theta_{2}\left[\begin{array}{c}
\frac{1}{2} \operatorname{Var}\left(R_{n i}\right) \\
-\left(W_{o n}+E\left(R_{n i}\right)\right)^{2}
\end{array}\right]+\theta_{3} T_{i}\right]}{\sum \exp \left[\theta_{1} \ln \left(W_{o n}+E\left(R_{n j}\right)\right)+\theta_{2}\left[\begin{array}{c}
\frac{3}{2} \operatorname{Var}\left(R_{n j}\right) \\
\left(W_{o n}+E\left(R_{n j}\right)\right)^{2}
\end{array}\right]+\theta_{3} T_{j}\right]}
$$

where

$$
\begin{aligned}
& T_{j}=I \text { when the fisherman previously } \\
& \text { participated in fishery } j \text { and }=0 \\
& \text { otherwise, } \\
& \theta_{i}, i=1,2,3 \text { are consistent and } \\
& \text { asymptotically efficient estimates of } \\
& \text { the centering parameters } \alpha_{i} \text { that reflect } \\
& \text { the monetary and psychic costs of } \\
& \text { switching fisheries. }
\end{aligned}
$$

This logit model is applied to the quasi-investment decision of the New England fishing firm choosing a fishery in which to participate. The probability $P_{n i}$ that fisherman (n) chooses to participate in fishery (i) is a function of 
the expected returns and variability of returns in each of his alternative fisheries and of a threshold reflecting the costs of conversion.

The predicted probabilities are a function of the characteristics of the individual (vessel size, port of landing, etc.) and indicate the proportion of each group of fishermen that would choose each feasible alternative. Fishermen are found to exhibit a positive response to increases in expected returns and a negative response to variability in returns (risk averse). Since the structure of the utility function ( $\ln (W)$ ) assumes risk aversion, the statistical results support the risk aversion conclusion.

\section{Conclusions}

Capital investment in the harvesting sector of the fishing industry represents a long term viewpoint by fishermen. The usual open access assumption of an infinite individual or firm discount rate would imply a low level of capital investment in the fishery because future discounted benefits would not be sufficient to offset the initial capital costs of entering the fishery. A more appropriate assumption of a finite but positive discount rate in conjunction with a resource scarcity rent equal to zero under open access allows fishermen to make long run capital investment decisions while harvesting a common property resource where resource rents are dissipated through excessive effort levels. 
Given the heterogeneous nature of the fishing fleet and the complex entry-exit behavior, the traditional marginalist supply models are not well suited for modelling vessel behavior. This modelling approach assumes that small changes in the cost of inputs or the relative prices of outputs cause unit increases or decreases in the size of the fishing fleet. The practical application of this modelling approach is a problem when a heterogenous fleet with complex entry-exit behavior exists. Using aggregate data, models that determine total fleet size as some function of aggregate measures of explanatory variables (Ward, 1989b or Penson, et al., 1987) result in biased parameter estimates. ${ }^{55}$ The discrete choice model utilizes an econometric technique that resolves this problem by capturing the response of the individual firm to the many forces affecting its decision.

${ }^{55}$ The bias arises because the firm is assumed to respond to aggregate measures of the explanatory variables rather than to the actual values that the firm faces (N.E. Bockstael and J.J. Opaluch, "Discrete Modeling of supply Response under Uncertainty: The case of the Fishery," Journal of Environmental Economics and Management, 10 (1983): 125-137). 


\section{Gulf of Mexico shrimp Fishery}

\section{Introduction}

Because of the high value and relative size of the shrimp fishery, a great many applied studies have been conducted. Cost and return studies for the Gulf of Mexico shrimp fishery have been conducted in the 1970's and early 1980's (Griffin, et al., 1974). The remainder of the 1980's are dominated by analyses of the Texas Closure regulation impacts (Conroy and Poffenberger, 1986). The analysis of the Texas closure regulation by the National Marine Fisheries Service concentrates on measuring its impact on optimal yield from the resource. Reallocations of existing effort levels or increases in fishing effort levels from the entry or exit of firms are not part of these analyses.

Additional analyses range from demand studies of domestic consumption (Adams, 1984), imports and aquaculture (Keithly and Roberts, 1991), vessel mobility (Browder, 1983), and bioeconomic simulation models (Griffin et al., 1991 and Tse and Khilnani, 1989). Few of these applied research efforts explicitly consider the impact of the common property nature of the resource on long run fishing effort levels, fleet size, or firm profitability. In part, this seems to be the result of the belief that little biological harm can be done to the shrimp resource stock with the present harvesting technology because it is an annual crop without a stock recruitment relationship 
(Garcia, 1983, 1988). In recent years, the distortions this management philosophy has caused in resource markets has resulted in bycatch and discard rates impacting the commercial and recreational finfish fisheries (Nichols, et al. 1987) and excessive capitalization in the shrimp harvesting industry.

The biological literature deals with the life history of the various species of shrimp and their population dynamics ${ }^{56}$. The economic literature that is pertinent to entry-exit modelling is divided into three groups reflecting cost and return surveys, simulation modelling, fleet size modelling, and fisheries management.

\section{Cost and Return surveys}

The change in operating costs relative to revenues creates an economic incentive for fishermen to alter their levels of fishing effort. The cumulative effect of individual fishermen responding to fluctuating market conditions is a change in both the number and the fishing

${ }^{56}$ See S. Garcia, S. and L. Le Reste, "Life Cycles, Dynamics, Exploitation and Management of coastal Penaeid Shrimp stocks." FAO Fish. Tec. Pap., 203, 1981 and S. Garcia, "The stock-Recruitment Relationship in Penaeid Shrimp: Reality or Artefact and Misinterpretations." Oceanogr. Trop., 18 (1983): 25-48, S. Garcia, "Environmental Aspects of Penaeid Shrimp Biology and Dynamics." In Penaeid Shrimps- Their Biology and Management, eds. J.A. Gulland and B.J. Rothschild (Farnham, UK: Fishing News Books, 1984)., and S. Garcia, "Reproduction, stock Assessment Models and Population Parameters in Exploited Penaeid Shrimp Populations." In Second Australian National Prawn Seminar, eds. P.C. Rothlisberg, B.J. Hill, and D.J. Staples (Eds), (Queensland, Australia: NPS2, Cleveland, 1985) for a review of the existing biological literature on tropical shrimp species. 
power of vessels in the fleet. Monitoring the impacts of long run trends in relative costs on fleet size has been difficult because a comprehensive time series of cost data has not been routinely collected for vessels operating in any of the U.S. southeast region fisheries. To meet this need, cost and return surveys have been conducted for the fisheries in the southeast region.

In the case of the shrimp fishery a number of cost and revenue survey studies have been conducted under the auspices of the National Marine Fisheries Service (NMFS), Sea Grant, and other public and private institutions and organizations. The studies by Warren and Griffin (1978), Duffy and Johnson, 1979), Griffin et al. (1974), (1975) and (1976), Swartz and Adams (1979), Roberts and Sass (1979), Blomo and Griffin (1978), and Tettey, Pardy, and Griffin (1982), for example, are designed to meet specific shortterm objectives that prevent direct comparisons of survey results. Each report surveys a particular and in some cases distinct subset of vessels in the shrimp fleet, resulting in different sample variances. The magnitude of these differences can be seen in the range of the reported means, variances, standard deviations, and other descriptive statistics. For example, mean total revenue for surveyed vessels is reported as $\$ 60,142$ (Warren and Griffin, 1978) and $\$ 9,214$ (Duffy and Johnson, 1979). In addition, the sample sizes of the surveys range from 1 (Anonymous, 1977) 
to 115 vessels (Griffin, et al., 1976). Vessel

characteristics also vary between reports. Vessel length ranges from less than 24 feet (Duffy and Johnson, 1979) to greater than 70 feet (Griffin, et al., 1974). Vessels operate out of Texas (Swartz and Adams, 1979), Louisiana (Roberts and Sass, 1979 and Keithly and Baron-Mounce, 1990), and Florida (Blomo and Griffin, 1978). Some surveys concentrate on inshore areas of operation while others study offshore fisheries for a particular state. Generally, the analyses are restricted to a single year, however, three studies of cost and returns by Griffin and Nichols (1976), Griffin, Nichols, and Smith (1975), and Griffin, Wardlaw, and Nichols (1976) did analyze time trends in profitability for the Texas shrimp fleet. One survey of cost and returns conducted under contract for the National Marine Fisheries Service did cover the entire southeastern region shrimp fishery (DRA, 1982).

Another cause of variation in the reports is the exclusion of information on vessel ownership. The cost structure of a single vessel, owner-operated firm could conceivably be different from the cost structures of vertically integrated, horizontally integrated, or nonowner operated firms. The single vessel, owner-operated fishing firm may maximize the income of a fisherman while the vertically integrated fịshing firm may operate at a loss to ensure a continuous supply of fish to the parent company or 
to maximize profits at some other level within the firm. Most reports do not provide information on the quantity of factor inputs used in the production process such as gallons of fuel or trawl size, and the survey results are reported in current rather than constant or real dollars.

As a result, comparisons of these studies do not provide any information on long-term trends in costs relative to revenues in the shrimp fishery. As an example, consider the comparison of 66-72 foot vessels operating off the coast of Texas (Griffin, et al., 1974) with vessels 24 feet or less in length operating in the bays and rivers of Louisiana (Duffy and Johnson, 1977). Although both studies report costs and revenues for shrimp vessels, meaningful conclusions cannot be drawn about the long-term trends in the fishery because no common denominator exists between the two reports.

Cost and revenue trends, however, are contained implicitly in the survey data. For example, changes in the cost and revenue structure of the firm from the utilization of a new production technology would have been implicitly represented in the published survey results for that point in time. If these changes are assumed to affect the cost and revenue structures of all firms similarly, then these trends can be used as the common denominator to estimate costs and revenues based on historical data, to interpolate missing values, and extrapolate future values. Ward (1988) 
develops a weighted relative cost index for the offshore fleet and compares it to the number of vessels operating in the Gulf of Mexico shrimp fishery as a measure of fishing effort. Declines in the relative costs of fishing are usually accompanied in the next year by an increase in the number of vessels operating in the fishery. Increases in the relative cost index are followed in the next year by declines in the number of vessels ${ }^{57}$

\section{Simulation Modelling}

Simulation models of the shrimp fishery in the southeastern region have been restricted to the Fisheries System Management Model (FYSIS) developed by Stanford University under contract to NMFS (Tse and Khilnani, 1989a and Tse and Khilnani, 1989b), General Bioeconomic Fishery Simulation Model (GBFSM) developed at Texas A\&M University (Griffin and Grant, 1991), and a recent population dynamics bioeconomic model developed at the NMFS Galveston Laboratory primarily for the analysis of fishery management scenarios (Nance, et al., 1990).

The FYSIS model is designed for the Gulf of Mexico shrimp fishery beginning with the Tortugas fishery, then adding the Texas fishery, and finally the entire Gulf of Mexico. The model is modular and adapts to a specific fishery problem via module selection and modification. The dynamic structure of the shrimp population is based on the

${ }^{57}$ The correlation coefficient is $(-0.46)$. 
published estimates for mortality, growth rate, recruitment, etc. The shrimp harvesting model assumes fishermen allocate their fishing activities based on availability of fish and the price response in the dockside market. A dockside demand model is incorporated into the model that determines equilibrium prices and quantities for large and small shrimp.

FYSIS is essentially a macro model of the shrimp harvesting industry. Nominal days fished per vessel class, characterized by variable cost per nominal day fished and vessel characteristics such as horse power and footrope length of the average vessel, are estimated by the model to determine an aggregate total days fished in response to various management scenarios. From these estimates, changes in the size and composition of total shrimp landings and predictions of total revenues, total costs, and industry profits or losses can be determined. Fleet size or individual vessel behavior are not incorporated into the model.

About the same time the FYSIS model was being developed, Grant and Griffin (1977 and 1979) began to develop a simulation model of the Texas shrimp harvesting industry. Using simple economic assumptions such as homogeneous vessel and boat fleets and a biological growth model, the resulting bioeconomic model of the brown shrimp fishery in Galveston Bay, Texas and adjacent offshore waters 
accurately predicts the general trends in the seasonality of shrimp harvest and the distribution of the harvest in relation to size of shrimp and water depth. Blomo, stokes, Griffin, Grant, and Nichols (1978) incorporate a nonlinear optimization procedure into the simulation model. The biological and economic aspects are interrelated through effort and landings. Supply and demand equations determine equilibrium price which when combined with unit cost determine the amount of nominal days fished and the total fishing effort expended on the Gulf of Mexico shrimp resource. Both price and fleet characteristics are held constant and nominal days fished are allowed to vary to determine the new equilibrium conditions in the market under various management scenarios.

Basic dynamics of the model result from changes in the number of organisms in the fishery over time, which can be summarized as a set of difference equations of the general form

$$
\mathrm{CN} / \mathrm{Ct}=\mathrm{R}+\mathrm{I}-\mathrm{E}-\mathrm{M}-\mathrm{F}
$$

where CN/Ct is the net change in number of

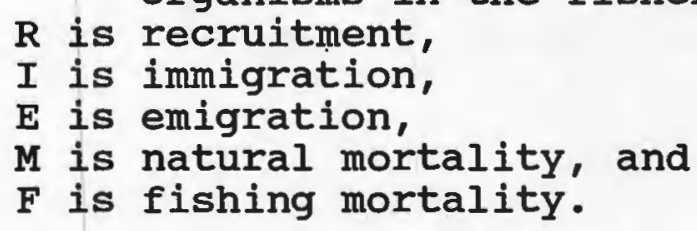

The driving variable is recruitment $R$ whereas immigration $I$, emigration $E$, natural mortality $M$, and fishing mortality $F$ 
are functions of the state of the system at any given point in time.

Over time, this short run model has developed into the GBFSM model (Griffin and Grant, 1991). The model has been adapted to the northwest African cephalopod fishery (Grant, Griffin, and Warren, 1981 and Griffin, Warren, and Grant, 1979) and to Ivory Coast shrimp (Griffin and Grant, 1981). A general bioeconomic simulation model for annual crop fisheries developed from the modelling effort on cephalopod and Gulf of Mexico shrimp fisheries (Grant, Isakson, and Griffin, 1981).

Blomo, et al. (1982) expands the model to the eastern Gulf of Mexico shrimp fishery. Fishing regulations are analyzed in the simulation model by incorporating intraseasonal shrimp growth rates, differences in demand for shrimp by size, and a heterogenous fishing fleet with consumer and producer surplus techniques. Although recognizing that fishing effort is usually assumed to be a function of shrimp prices, expected and lagged catches, operating costs, and work preferences by the captain and crew, no behavioral relationship is estimated and fishing effort is exogenously manipulated in the model.

This model is used to analyzing the impacts of the Texas closure regulation in Griffin, Warren, Nichols, Grant, and Pardy (1983). Six management alternatives are evaluated in terms of their impact on total landings, amount of 
discards, cost and returns, and fishing effort levels. Management alternatives consist of specified area closures for particular periods of time, changes in count size regulations, or both. The General Bioeconomic Fishery Simulation Model is designed to represent the important biological and economic processes of the Texas shrimp fishery. Impacts are estimated both for the first year and for a long run situation, which give the industry time to adjust by increasing or decreasing the number of bay boats and Gulf vessels. Although fishing effort could reallocate itself between inshore and offshore areas of operation in the long run, total fleet size is fixed. Impacts are measured as changes in the rent that accrue to the average vessel in the shrimp fishing fleet.

The GBFSM model (Griffin and Grant, 1991) incorporates a long run analysis into the simulation model by adjusting fishing effort, days fished, and fleet size according to the economic and biological conditions generated in the simulation model. Two fleet size strategies are available within the GBFSM model. The first sets the rate of change of fleet size within a vessel class equal to the ratio of total revenue to total cost after adjusting for asset fixity. This approach assumes that each vessel class consists of homogeneous. vessels that is in equilibrium when total revenue equals the adjusted total cost. The second option employs the multinomial logit model estimated in this 
dissertation to estimate a fleet size based on the probability that an individual vessel will enter, remain in, or exit the fishery based on economic and biological conditions.

\section{Fleet size Models}

Prochaska orchestrated the first efforts to research firm entry-exit behavior in the shrimp fisheries of the southeastern region. Prochaska and Andrew (1974) investigate the shrimp processing industry to determine if a growing deficit in shrimp landings relative to processing needs in the southeast region of the United States has encouraged structural changes in the shrimp industry. Assuming that the supply deficit would not ease, further concentration in the shrimp processing industry is expected with the successful small firm vertically and horizontally integrating into other seafoods and production of specialty products.

Although not concerned with fishing fleet size, Alvarey, Andrew, and Prochaska (1976) analyze stability, entry, exit, and mobility patterns for six size categories of firms in the Florida shrimp processing industry for the 1959-71 time period using a Markov Chain technique. A dual equilibrium resulting in fewer medium size firms and more small and large firms can be explained by the tendency for small firms to develop a specialty product and/or services to differentiate their markets from those of the very large 
firm. Medium size firms tend to expand or decline in size moving toward specialty products and services or exiting from the industry.

The historical economic conditions that contributed to the severe financial conditions existing in the domestic shrimp fishery during 1980 and early 1981 such as rapidly falling consumer demand and lower shrimp prices, increased competition from within the fishery from the entry of new boats and vessels, competition from foreign imports, and rapidly increasing fuel costs are reviewed in Prochaska and cato (1981). The number of boats and vessels that enter the fishery are noted and the relationship of this entry pattern to price movements is analyzed. The effect of prices and quantity landed on the number of vessels and boats is determined from:

$$
\text { Craft }_{t}=a+b_{1} \text { Price }_{t-1}+b_{2} \text { Quantity }_{t-1}
$$

where $a=5,416$

$b_{1}=2049.4$

$b_{2}=6.7$

craft $_{t}$ is the annual number of craft (boats plus vessels) in the Gulf of Mexico shrimp fishery in year $t$,

Price $_{t-1}$ is the annual average ex-vessel shrimp price in the Gulf of Mexico in the previous year in dollars per pound, and

Quantity $y_{t-1}$ is the average annual landings per craft (boats plus vessels) in the previous year in thousands of pounds.

Prices are discussed with respect to consumer demand and imports and their impact on fleet size determined. Using interpolated and extrapolated data based on cost and returns 
studies conducted for the Gulf of Mexico shrimp fishery, Ward (1988) found that fleet size and relative operating costs are correlated. Ward (1989) extends the fleet size model of Prochaska by incorporating the physical characteristics of the fleet and fleet capital cost in the estimation of fleet size:

FS $=-b_{1} / b_{6}+b_{6} / b_{6} \quad p q x / r_{6}-b_{2} / b_{6} T-b_{3} / b_{6} G T-b_{4} / b_{6} c-b_{5} / b_{6}$ VL where FS is the fleet size, $p$ is exvessel price of shrimp, $q$ is the catchability coefficient, $x$ is the biomass level, $r_{6}$ is the capital cost of the fleet, $T$ is the number of trips, GT is the gross tonnage of a vessel, $C$ is the crew size, and $\mathrm{VL}$ is the vessel length. $b_{1} / b_{6}=17,670.1$

$b_{6} / b_{6}=3.14$ $\mathrm{b}_{2} / \mathrm{b}_{6}=355.9$ $\mathrm{b}_{3} / \mathrm{b}_{6}=300.8$ $b_{4} / b_{6}=89.6$ $b_{5} / b_{6}=712$

While both models are statistically significant and explain much of the variation in fleet size over time, neither is firmly based in economic theory. In addition, biased parameter estimates result when aggregated firms that choose a particular fishery to participate in are regressed against aggregate explanatory variables rather than the actual values these firms face in making the decision. The bias arises because the firm is assumed to respond to aggregate measures of the explanatory variables rather than to the actual values that the firm faces (Bockstael and 
Opaluch, 1983). As a result, neither model can be used to determine the impacts of shrimp fishery management policy. Penson, Tetty, and Griffin (1987) estimate an econometric model of annual net investment in fishing vessels based on the neoclassical theory of aggregate investment behavior. The model is presented and discussed in the previous section. The econometric results comply with economic theory and indicate that low real interest rates designed to stimulate investment activities in the general economy increase capitalization in the shrimp fleet. Fishery Management

The Magnuson Fishery Conservation and Management Act $^{58}$ (MFCMA) grants the federal government the authority to manage fishery resources in the fishery conservation zone; the area that extends seaward from the territorial sea to a point 200 miles from shore ${ }^{59}$. The shrimp resource consists of six species that include brown shrimp (Penaeus aztecus Ives), white shrimp (Penaeus setiferus Linnaeus), pink shrimp (Penaeus duorarum Burkenroad), royal red shrimp (Hymenopenaeus robustus Smith), seabobs (Xiphopenaeus kroyeri Heller), and rock shrimp (Sicyonia brevirostris Stimpton). Jurisdiction over the shrimp resource is shared by the Gulf of Mexico Fishery Management Council, the

${ }^{58}$ Public Law 94-265.

${ }^{59}$ The territorial sea is three nautical miles for the states of Louisiana, Mississippi, and Alabama and nine nautical miles for the Texas and west coast of Florida. 
National Marine Fisheries Service, the Florida Department of Natural Resources, The Alabama Department of Conservation and Natural Resources, the Mississippi Marine Conservation Commission, the Louisiana Wildlife and Fisheries Commission, and the Texas Parks and Wildlife Commission. The user groups that exploit the shrimp stocks include a large commercial fleet fishing the inshore, nearshore, and open waters, a large but undetermined number of recreational shrimpers mainly fishing the inshore and nearshore waters, and a substantial number of bait shrimpers mainly fishing the inshore waters. Management problems in the fishery include conflicts among user groups concerning the area and size at which shrimp are to be harvested, discards of culled shrimp, finfish, and the incidental take of marine turtles and mammals, the decline in the quality and quantity of estuarine and inland habitats, and the loss of gear and trawling grounds to man-made underwater obstructions. Management objectives include optimizing the yield from shrimp recruited into the fishery, habitat protection, and minimizing the incidental capture of finfish, conflicts between user groups, and the adverse effects of underwater man-made obstructions.

The passage of the MFCMA eliminated foreign fishing in the Gulf of Mexico fishery conservation zone. Mexican, Cuban, and Panamanian vessels had harvested shrimp off U.S. shores prior to the implementation of the Magnuson Act. The 
annual harvest by Mexican vessels off Texas ranged from zero to 2.8 million pounds for the years 1971-1976. Cuban vessels operating off Texas during the peak brown shrimp season took approximately half a million pounds per month heads-off. During the winter season off Florida, Cuban vessels annually took 135 thousand pounds.

The passage of the Magnuson Act also eliminated U.S. fishing in foreign waters of the Gulf of Mexico. A treaty between the U.S. and Mexico was signed November, 1976 that phased out U.S. shrimp fishing in Mexican waters over a three year period. As a result, all U.S. shrimp fishing within Mexico's 200 mile offshore fishing zone was terminated by January, 1980. Landings from Mexican waters ranged from 18 to 10 million pounds per year from 1962-1974 and were valued at $\$ 13$ million. Griffin and Beattie (1978) estimate the present value of the negative rent stream to range from 4.6 to 27.4 million dollars depending on the adjustment period and the exvessel price.

In the 1970's, various species of marine turtles were declared endangered or threaten under the endangered species act. The domestic turtle fishery was eliminated. However, the bycatch of endangered marine turtles resulted in regulations requiring the adoption of turtle excluder devices (TEDs) in shrimp trawls. This conflict between shrimp fishermen, conservation organizations, and the NMFS 
was not resolved until the late $1980^{\prime}$ 's when mandatory regulations were imposed under the endangered species act. In addition to the bycatch of marine turtles, a substantial amount of finfish bycatch and discards occur in shrimp fishing operations. Some estimates place the ratio of finfish to shrimp as high as 21.1 pounds of finfish to each pound of shrimp (Pellegrin, et. al., 1985). The decline in stocks of red snapper have been attributed to the bycatch of juveniles in the Gulf of Mexico shrimp fishery (Waters and Platt, 1990). Future regulations proposed to correct this problem include closed areas and fishing seasons and bycatch reduction devices.

The regulation closing the Federal Economic Zone adopted by the Gulf of Mexico Fisheries Management Council in cooperation with the Texas closure of its territorial sea and inshore waters is designed to increase the size and implicitly the value of brown shrimp landed in Texas. A number of seriously flawed economic studies have been conducted by the Southeast Fisheries Center of the National Marine Fisheries service. In a series of reports by Poffenberger (1982a, 1982b, 1986a, 1986b, and 1987) and Conroy and Poffenberger (1986) the impact of the closure regulation on the price of shrimp is used to estimate a change in the value of the resource that ranges from $\$ 21.5$ million increase (Poffenberger, 1982) to a $\$ 5.06$ million decline (Poffenberger, 1987). Ward and Sinha (1988) drop 
the single equation, price dependent model approach used in the previous studies as unrealistic and use reported market prices to estimate the change in value of the Texas closure regulation to be approximately $\$ 10$ million. This result is well within the natural variation of shrimp landings and is probably statistically insignificant. Unfortunately, the biological model these value estimates are based on did not generate statistical tests of significant.

A cooperative effort developed between the Galveston Laboratory and Texas A\&M University in 1990 to study the impacts of the Texas closure regulation on the shrimp fishing fleet (Nance, Klima, and Martinez, 1990). This model predicts the change in net revenue that occurs on an individual vessel basis with and without the closure being in effect. The analysis concludes with the warning that Gulf of Mexico wide closures designed to reduce finfish bycatch in shrimp trawls could greatly increase offshore fishing effort and fleet $\mathrm{size}^{60}$. Additional studies (Griffin, et al., 1981) support this conclusion. summary

The theoretical and applied fisheries economics literature pertaining to the shrimp fishery of the southeast region does not explicitly address the problem of modelling

${ }^{60}$ Personal communication, Dr. Edward Klima, Director, Galveston Laboratory, SEFC, NMFS, at the Gulf of Mexico Fishery Management Council, Shrimp Committee Meeting, New Orleans, January, 1991. 
changes in fleet size. This is partially due to the nature of the problem; a heterogeneous fleet, the lack of the appropriate statistical tools (multinomial logit), and limited cost data. Tettey, et al. (1986) models aggregate net investment in Gulf of Mexico shrimp fishing vessels in a discrete time context. Net investment in the fishing fleet is hypothesized to be a function of shrimp price, expected landings, the implicit rental price of vessels, the existing real stock of vessels at the beginning of the time period, and net investment lagged one time period. This model avoids the discrete choice and heterogenous fleet problems by using total net investment in the fleet as the dependent variable. Although useful for analysis of tax policy on industry investment levels, determining the economic impacts caused by management regulations on various components of the fleet is not possible. The decision to enter or exit the fishery is made at the individual vessel or firm level. In a heterogeneous fleet with entry and exit occurring simultaneously, this decision is not mutually exclusive. That is, net investment could increase even if more old, small vessels are exiting then new vessels are entering in response to market conditions. The discrete choice approach models the individual firms decision making process and better reflects real world behavior than aggregate industry models using continuous dependent variables. 


\section{Qualitative Dependent Variables}

\section{Introduction}

In the economics literature, the question of how much to produce or consume results in the traditional econometric models where the dependent variable is assumed to be continuous and normally distributed. In models that address the question of whether to produce or consume, the dependent variable takes on discrete values. That is, individuals choose from a set of alternatives based on their descriptive characteristics. Numerous applications of discrete choice models that quantify the effects of these characteristics exist in the literature. Labor force participation is studied by Gronau (1976), Gunderson (1974), Heckman and Willis (1977), Kahn and Morimune (1979), Long and Jones (1980), Medoff (1979), Nickell (1979), Parsons (1980a,b), Pencavel (1979), Schiller and Weiss (1979), and Smith (1979). Boskin (1974) and Schmidt and Strauss (1975) investigate the factors determining the choice of occupation. Job and firm location decisions are studied by Duncan (1980), Osten (1979), and Wilensky and Rossiter (1978). The decision to join a union is analyzed by Duncan and Stafford (1980), Lee (1978), Scmidt and Strauss (1976), and Warren and Strauss (1979). Choice of geographic location and migration is investigated by Akin, Guilkey, and Sickles (1979), Bartel (1979), Da Vanzo (1978), Fields (1979), and Hughes (1980). Transportation choice is 
analyzed by Domencich and McFadden (1975), Hausman and Wise (1978), Lave (1970), Lee (1977), McGillivray (1972), Quandt (1968), Talvitie (1972), Warner (1962), Watson and Westin (1975), and Westin (1974). The decision to purchase consumer durables is investigated by Cragg and Unler (1970), Dubin and McFadden (1980), Hausman (1979), Parks (1980), and Wu (1965). The housing market is researched by David and Legg (1975), Li (1977), Rosen and Rosen (1980), and Uhler (1968). Family size and birth rates are studied by BenPorath (1976), Heckman and willis (1975), Powers, Marsh, Huckfeldt, and Johnson (1978). Education is examined by Hill (1979), Kohn, Manski, and Mundel (1976), Radner and Miller (1970), Spector and Mazzeo (1980), and Willis and Rosen (1979). Legislation and voting are analyzed by Deacon and Shaprio (1975), Fair (1978), Heckman (1976), Kau and Rubin (1978), Moore, Newman, and Thomas (1974), Siblerman and Durden (1976), Tollefson and Pichler (1974), and Weisberg (1978). Criminology is investigated by Goldberg and Nold (1980) and Witte and Schmidt (1979). Discrete choice models are adapted to fishery problems by Bockstael and Opaluch (1983), Green (1989), and Milon (1988). This survey reviews the economic foundations of discrete choice models, their mathematical/statistical properties in relationship to linear models, and develops a multinomial logit model of firm entry and exit behavior for 
use in estimating fleet size in the Gulf of Mexico shrimp fishery.

\section{Theoretical Foundations}

The rational choice perspective on behavior (Luce and Suppes, 1965) is developed into an econometric model based on utility theory by McFadden (1973). Aldrich and Nelson (1984) determine that this rational while sufficient is not necessary to justify the use of these models. That is, these models may still be utilized without assuming that their nonlinear specifications arise from utility theory. ${ }^{61}$

An individual is faced with the choice of selecting between two alternatives, such as driving his car to work or traveling on mass transit. The rational choice approach assumes that the individual will choose the most preferred alternative. The utility $\mathrm{U}_{\mathrm{ij}}$ that individual $i$ derives from alternative $j$ is a function of the characteristics of the different alternatives and the individual's socio-economic characteristics $x_{i}$ plus an additive error term $v$. Individual $i$ would choose alternative $j$ if

$$
U_{i j}>U_{i m} \quad j \neq m
$$

and would choose alternative $\mathrm{m}$ if

$$
U_{i j}<U_{i m} \quad j \neq m
$$

There is indecision when

$$
\mathrm{U}_{\mathrm{ij}}=\mathrm{U}_{\mathrm{im}} \quad \mathrm{j} \neq \mathrm{m}
$$

${ }^{61}$ Profit maximization will be utilized as the basis of a multinomial logit model in a later section of this survey. 
This happens with zero probability according to Amemiya (1981) if $v_{i j}$ and $v_{i m}$ are continuous random variables. This choice can be modelled if utility is assumed to be an inherently linear function of the exogenous variables:

$$
\begin{aligned}
& \mathrm{u}_{\mathrm{ij}}=\Sigma \mathrm{a}_{\mathrm{kj}} \mathrm{x}_{\mathrm{ik}}+\mathrm{v}_{\mathrm{ij}} \\
& \mathrm{u}_{\mathrm{im} .}=\Sigma \mathrm{a}_{\mathrm{km}} \mathrm{x}_{\mathrm{ik}}+\mathrm{v}_{\mathrm{im}}
\end{aligned}
$$

and the error terms $v_{i}$ represent random aspects of behavior. If utility from alternative $j$ is greater than from alternative $\mathrm{m}$, then

$$
U_{i j}-U_{i m}>0 \quad j \neq m
$$

or alternatively

$$
U_{i j}-U_{i m}<0 \quad j \neq m
$$

Letting $\mathrm{Y}_{i}{ }^{*}$ represent this difference,

$$
\mathrm{Y}_{\mathrm{i}}^{*} \equiv \mathrm{U}_{\mathrm{ij}}-\mathrm{U}_{\mathrm{im}}=\Sigma\left(\mathrm{a}_{\mathrm{kj}}-\mathrm{a}_{\mathrm{km}}\right) \mathrm{X}_{\mathrm{ik}}+\left(\mathrm{v}_{\mathrm{ij}}-\mathrm{v}_{\mathrm{im}}\right)
$$

This reduces to

$$
\mathrm{Y}_{\mathrm{i}}^{*}=\Sigma \mathrm{b}_{\mathrm{k}} \mathrm{x}_{\mathrm{ik}}+\mathrm{u}_{\mathrm{i}}
$$

where $b_{k}=\left(a_{k j}-a_{k m}\right)$

$$
u_{i}=\left(v_{i j}-v_{i m}\right)
$$

Individual $i$ chooses alternative $j$ if $Y_{i}{ }^{*}>0$ which implies that

$$
u_{i}<\Sigma b_{k} x_{i k}
$$

or alternative $m$ if $Y_{i}^{*}<0$. This leads to the probabilistic statement that

$$
P\left(Y_{i}=j\right)=P\left(Y_{i}^{*}>0\right)=P\left(u_{i}<\Sigma b_{k} x_{i k}\right)
$$

where

$Y_{i}=$ the observed event and

$u_{i}=a$ continuous, random variable. 
The probability that event $j$ occurs $P\left(Y_{i}=1\right)$ can be expressed as

where

$$
P\left(u_{i}<\Sigma b_{k} x_{i k}\right)=F\left(b_{k} x_{i k}\right)=\int_{-\infty}^{\Sigma b_{k} x_{i k}} f(u) d u
$$

$F\left(b_{k} x_{i k}\right)$ is the cumulative distribution function, $f(u)$ is the probability density function, and $u_{i}$ is the random variable.

Assuming that the probability distribution of $u_{i}$ follows the logistic or normal ${ }^{62}$ distribution, then $F\left(b_{k} x_{i k}\right)$ is 0 at negative infinity and increases monotonically until it reaches 1 at positive infinity.

Utility theory therefore provides a rational for the qualitative choice model. Based on this model, a particular nonlinear specification of the probability model can be derived. Quandt (1968) applied stochastic utility theory to a modal choice model of the form

$$
U_{i j}=\alpha H_{i j}^{\beta} C_{i j}^{\gamma}
$$

where

$\mathrm{U}_{\mathrm{ij}}$ is utility,

$H_{i j}$ is time of the $j^{\text {th }}$ mode for the $i^{\text {th }}$ person,

$C_{i j}$ is the cost of the $j^{\text {th }}$ mode for the $i^{\text {th }}$ person,

$\alpha, \beta$, and $\gamma$ are parameters that represent random taste variation among individuals.

Assuming a normal distribution for these parameters would lead to a probit model similar to that used by Hausman and Wise (1978), Daganzo (1979), McFadden (1974 and 1976a), or Domencich and McFadden (1975). The error term in this

${ }^{62}$ For the probit model. 
specification represents alternative and individual socioeconomic characteristics that are unobservable to the researcher; the omitted variables interpretation in econometrics. Although this suggests a non-zero correlation between the random error terms $v_{i j}$ and $v_{i m}$, the existence of this correlation is of no consequence since the probability function depends on the difference between the error terms as in equation (4). The utilities of different individuals $\left(U_{h j}\right.$ and $\left.U_{i j}\right)$ are usually. assumed to be independently distributed to avoid the necessity of constructing a correlation matrix.

The utility theoretic specification of equations (1) and (2) depends on the characteristics or attributes of the alternative. Specific physical entities such as mode of travel can be ignored and a abstract mode (Quandt and Baumol, 1966) that recognizes a bundle of services such as time, cost, and comfort that each alternative offers to the individual can instead be employed. The impact of unknown alternatives whose characteristics can be described can as a result be determined.

The coefficients on the socio-economic characteristics of the individual in equation (3) are represented by their differences $\left(a_{k j}-a_{k m}\right)$. A socio-economic characteristic variable should not appear in the final model specification if its coefficient is the same for the different alternatives. If an individual has a choice between car and 
bus to commute to work, as in Domencich and McFadden (1975, page 159), the income of that individual would not be significantly different in a statistical sense from zero in the estimated model because the coefficient is the same for each alternative.

\section{Model Choice}

The traditional regression model does not restrict the exogenous variables; they may be continuous, interval level (net worth of a company), positive or zero (multiplicative dummy variables or percentages), integers (family size), or dichotomous (dummy variables). The dependent variable is assumed to be continuous from negative to positive infinity.

In qualitative choice models, restricting the dependent variable to $j$ values affects the assumptions about the error term $v_{i}$. Let the dependent variable $Y_{i}$ take two values; 0 or 1 . The expected value of $Y_{i}$ reduces to the probability that $Y_{i}$ equals one; i.e.

$$
E\left(Y_{i}\right)=1 * P\left(Y_{i}=1\right)+0 * P\left(Y_{i}=0\right)=P\left(Y_{i}=1\right) \text {. }
$$

Since the linear regression model assumes

$$
E\left(Y_{i}\right)=\Sigma b_{k} X_{i k}
$$

then

$$
E\left(Y_{i}\right)=P\left(Y_{i}=1\right)=\Sigma b_{k} X_{i k}
$$

referred to as the linear probability model (Amemiya, 1981). In this model specification the error term $v_{i}$ takes on two values for any given $x_{i k}$ :

$$
\text { if } Y_{i}=0 \text { then } v_{i}=-\Sigma b_{k} x_{i k}
$$


if $Y_{i}=1$ then $v_{i}=1-\Sigma b_{k} X_{i k}$.

The assumption of regression analysis that the expected value of the error term be equal to zero still holds, i.e.

$$
\begin{aligned}
E\left(v_{i}\right) & =P\left(Y_{i}=0\right)\left[-\Sigma b_{k} X_{i k}\right]+P\left(Y_{i}=1\right)\left[1-\Sigma b_{k} X_{i k}\right] \\
& =-\left[1-P\left(Y_{i}=1\right)\right] P\left(Y_{i}=1\right)+P\left(Y_{i}=1\right)\left[1-P\left(Y_{i}=1\right)\right]=0
\end{aligned}
$$

Therefore, the estimates of $b_{k}$ are unbiased. However, the assumption of constant variance is violated:

$$
\begin{aligned}
\operatorname{Var}\left(v_{i}\right) & =E\left(v_{i}{ }^{2}\right)=P\left(Y_{i}=0\right)\left[-\Sigma b_{k} X_{i k}\right]^{2}+P\left(Y_{i}=1\right)\left[1-\Sigma b_{k} X_{i k}\right]^{2} \\
& =\left[1-P\left(Y_{i}=1\right)\right]\left[P\left(Y_{i}=1\right)\right]^{2}+P\left(Y_{i}=1\right)\left[1-P\left(Y_{i}=1\right)\right]^{2} \\
& =P\left(Y_{i}=1\right)\left[1-P\left(Y_{i}=1\right)\right] \\
& =\left[\Sigma b_{k} X_{i k}\right]\left[1-\Sigma b_{k} X_{i k}\right]
\end{aligned}
$$

The variance of the error term varies systematically with the values of the independent variables (Aldrich and Nelson, 1984 ) and any hypothesis tests based on the $t$ or $F$ test or confidence intervals based on these sampling variances will be invalid even for very large samples. The estimated parameters $b_{k}$ are best but do not have the smallest sampling variance.

Goldberger (1964) develops a weighted least squares estimator to correct this variance problem with the linear probability model. The estimate of the weighted coefficient is unbiased, has the smallest possible constant, sampling variance, and can be used for hypothesis testing. However, the estimated probabilities of both the weighted least squares and ordinary least squares linear probability model can exceed the zero and one range. 
One solution to the problem of exceeding the zero to one range in the linear probability model is to truncate the estimate of $\Sigma b_{k} x_{i k}$ in the first stage to a value close to one or zero. At values of zero or one, the denominator of the weighting factor

$$
w_{i}=1 /\left(\Sigma b_{k} x_{i k}\right)\left(1-\Sigma b_{k} x_{i k}\right)^{1 / 2}
$$

equals zero creating an undefined weight that approaches infinity at the limit. The second stage estimate of the probability that an event occurs can still exceed one or be less than zero. In the polytomous case, the probabilities may not sum to one after the second stage of estimation.

Two additional problems with the linear probability model exist. First, the assumption that the model is linear imposes constraints on the values of the regression coefficients $b_{k}$ that are not taken into account by the least squares estimation procedure. That is, the marginal effects of exogenous variables are restricted. In a bivariate case:

$$
P\left(Y_{i}=1\right)=E\left(Y_{i}\right)=b_{0}+b_{1} X_{i}
$$

then

$$
0 \leq b_{0}+b_{1} x_{l}<b_{0}+b_{1} x_{u} \leq 1
$$

That is, the constraints imposed by the linear probability model require that the smallest value assumed by the exogenous variable $x_{l}$ must yield a predicted probability that is greater than or equal to zero. Alternatively, the largest value it assumes $x_{u}$ must yield a probability no larger than one. Reestimating the linear probability model 
with additional data that exceeded $x_{u}$ would cause the estimated relationships to become less steep. Secondly, the marginal effect of the exogenous variables on the dependent variable is constant. That is, the first unit change in the independent variable has as much impact on the probability that an event will occur as the last unit change in the dependent variable.

A specification that expresses $P\left(Y_{i}=1\right)$ as a nonlinear function of $x_{i}$ that approached zero and one asymptotically avoids these problems of unknown distributional properties, data range sensitivity, understatement of the magnitudes of the true effects, probability predictions that exceed the 0,1 range, and the deterioration of the estimates when standard statistical practices for their improvement are employed. One approach to avoid the 0,1 constraint is to employ the logistic function which is the natural logarithm of the ratio of the odds ${ }^{63}$, i.e.

$$
\log \left[P_{i} /\left(1-P_{i}\right)\right]
$$

which takes any value from negative to positive infinite. Assuming that the transformed dependent variable is a linear function of $\mathrm{x}$ :

$$
\log \left[P_{i} /\left(1-P_{i}\right)\right]=\Sigma b_{k} x_{i k}=z_{i}
$$

Solving for $P_{i}$

${ }^{63}$ Alternative distribution functions include the normal and Urban if symmetry and both positive and negative values of $\mathrm{z}$ exist, Burr if $\mathrm{z}$ is restricted to the positive range, and Gompertz if asymmetries are involved. 


$$
\begin{gathered}
e^{\log \left[P_{i} /\left(1-P_{i}\right)\right]}=e^{Z_{i}} \\
P_{i} /\left(1-P_{i}\right)=e^{Z_{i}} \\
\log P_{i}-\log \left(1-P_{i}\right)=z_{i} \\
P_{i}=z_{i}+\log \left(1-P_{i}\right) \\
P_{i}=e^{z_{i}}\left(1-P_{i}\right) \\
P_{i}=e^{z_{i}}-e^{z_{i}} P_{i} \\
P_{i}+e^{z_{i} P_{i}}=e^{Z_{i}} \\
P_{i}\left[1+e^{z_{i}}\right]=e^{z_{i}} \\
P_{i}=-1 e^{z_{i}} \\
{\left[1+e^{Z_{i}}\right]}
\end{gathered}
$$

The multinomial logit specification is a generalization of this dichotomous dependent variable logit model (Fomby, Hill, and Johnson, 1984):

$$
P_{i}=\frac{e^{K b_{i k} x_{i j}}}{\sum\left[e^{\Sigma b_{j k} x_{i k}}\right]} \quad \text { for all } j \text { events }(j=1, \ldots, J)
$$

where

$$
b_{j k}=0 \text { for } k=1, \ldots, k
$$


The multinomial logit model can be developed from the utility theoretic framework assuming that the error terms are independently and identically distributed with Weibull density functions (McFadden, 1974)64.

Although the multinomial logit model works well when the alternatives are dissimilar, the assumption of independence of the error terms makes it impossible to take into account similarities among alternatives (Debreu, 1960). That is, the relative odds of one alternative being chosen over a second should be independent of the presence or absence of unchosen third alternatives. McFadden (1974) illustrates this point by proposing a population that faces the alternative of travel by auto or bus with $2 / 3$ of the population preferring auto. If a second type of bus is introduced (blue versus red) that is essentially identical to the first, then intuitively $2 / 3$ of the population would still choose auto. However, only half the population will choose auto when the second bus is introduced to maintain the odds between bus and auto at two to one. In the multinomial logit model, the relative probabilities between a pair of alternatives are specified without consideration of the nature of the third alternative. This independence of irrelevant alternatives (MCFadden, 1974) suggests that the model should be utilized in situations where the

${ }^{64} \mathrm{Multinomial}$ probit assumes that the errors have a multivariate normal distribution. 
alternatives can be assumed to be distinct and weighted independently of each other. ${ }^{65}$

\section{Shrimp Fishery Model}

Shrimp in the Gulf of Mexico unlike most fisheries that exploit multiple year classes can be characterized as a annual crop since being short lived they do not recruit into a second year class. Assuming that no growth or natural mortality occurs within the season, the shrimp stock declines according to

$$
\begin{aligned}
& \dot{B}_{i}(t)=-q \underset{v=1}{N_{i}} e_{i v} B_{i}(t) \\
& B_{i}(0)=R(A)
\end{aligned}
$$

where $R(A)$ is the number of fish recruited annually into the fishery which varies over time due to environmental conditions,

q is a proportionality constant that represents catchability of the fishing gear,

$B_{i}(t)$ is the total biomass of the fish stock in fishery $i$,

$\Sigma e_{i v}$ is the total fishing effort level of the vessels $v$ in the heterogeneous fleet for fishery $i$,

$\mathrm{N}_{\mathrm{i}}$ is the number of vessels $\mathrm{v}$ in the active fleet for fishery $i$,

The individual shrimp fisherman acts to maximize the present value of profits (I) expressed as

$$
I=\operatorname{Max} \int_{t=0}^{T} e^{-\delta t} \pi_{i} d t
$$

${ }^{65}$ McFadden (1977) suggests a bivariate distribution to account for the correlation between the error terms also known as nonindependent logit (Amemiya, 1981). 


$$
\text { s.t. } \quad \dot{B}_{i}(t)=-q \sum_{i=1}^{N_{i}} e_{v i} B_{i}(t)
$$

where $\pi_{i}$ is profit in the $i^{\text {th }}$ fishery,

$\delta$ is the discount rate,

$t=0$ is the time of recruitment into the

fishery; the time at which the fish

first become available to the fishing

$T$ is the end of the fishing season,

Assuming shrimp in the Gulf of Mexico is a finite

resource and the fishery is over-capitalized, a vessel

crowding externality occurs in that the harvest accruing to an individual vessel depends on its own effort level as well as the level of fishing effort applied by all the other fishing firms. Following Dasgupta and Heal (1979), this effect due to the vessel crowding externality can be represented by

$$
\frac{B_{i}(t)}{\Sigma e_{i l}} \quad v \neq 1
$$

The individual shrimp fisherman's profit is the product of this average biomass per unit effort, his individual effort level, exvessel price, and catchability minus the cost of fishing effort; e.g.

$$
\pi_{i}=p_{i} q e_{v} \frac{B_{i}}{\Sigma e_{i l}}-c\left(e_{v}\right)
$$

$p_{i} \quad$ is the exvessel price per pound of fish

in fishery $i$,

$e_{v}$ is the fishing effort level of fisherman

$c\left(e_{v}\right)$ is the cost of fishing effort used to harvest shrimp.

Individual firms in the Gulf of Mexico shrimp fishery do not necessarily exploit a single stock of fish. 
Fisheries that are gear independent require firms to switch fishing gears to harvest the fish stock in an alternative directed fishery ${ }^{66}$ (Clark, 1985 p. 191-194). That is, firms can maximize profits by harvesting fish in one fishery or the other, but not both simultaneously during the fishing season, i.e.

$$
\begin{aligned}
I=\operatorname{Max} & \int_{t=0}^{T} e^{-\delta t} \pi_{i} d t \\
\text { s.t. } & \dot{B}_{i}(t)=-q \underset{v=1}{N_{i} e_{i v} B_{i}}(t)
\end{aligned}
$$

or

$$
\begin{aligned}
& J=\operatorname{Max} \int_{t=0}^{T} e^{-\delta t} \pi_{j} d t \\
& \text { s.t. } \quad \dot{B}_{j}(t)=-q \underset{v=1}{\sum} e_{j v} B_{j}(t)
\end{aligned}
$$

The implicit solution for this set of equations assuming rational expectations can be represented by

$$
z=I\left(p_{y}, c^{\prime}\left(e_{y w}\right), B_{y}, q, \Sigma e_{y l}\right) \quad(Z=I, J y=i, j)
$$

This implies that individual firms will apply fishing effort to fishery $i$ if

$$
I\left(p_{i}, c^{\prime}\left(e_{v}\right), B_{i}, q, \Sigma e_{i l}\right)>J\left(p_{j}, c^{\prime}\left(e_{j}\right), B_{j}, q, \Sigma e_{j l}\right)
$$

or to fishery $j$ if

$$
I\left(p_{i}, c^{\prime}\left(e_{v}\right), B_{i}, q, \Sigma e_{i l}\right)<J\left(p_{j}, c^{\prime}\left(e_{j}\right), B_{j}, q, \Sigma e_{j l}\right)
$$

and that firms will continue to switch between fisheries until

${ }^{66} \mathrm{~A}$ fisherman could also leave the fishery for an alternative form of employment. In this case, the wages earned would have to be greater than the return to labor from fishing. 


$$
I\left(p_{i}, c^{\prime}\left(e_{v}\right), B_{i}, q, \Sigma e_{i l}\right)=J\left(p_{j}, c^{\prime}\left(e_{j}\right), B_{j}, q, \Sigma e_{j l}\right)
$$

The problem of choosing in which fishery to operate can be transformed into a marginal framework by specifying the probabilities of a discrete choice as the dependent variable using a multinomial logit specification ${ }^{67}$. That is, if profits are greater in the $i^{\text {th }}$ fishery, then fishing effort $e_{v}$ will be positive, e.g. $e_{v}>0$ if $E[I]>E[J]$. If profits are greater in the $j^{\text {th }}$ fishery, then fishing effort $e_{v}$ will be zero, e.g. $e_{v}=0$ if $E[I]<E[J]$. To model this behavior, assume that the expected value of profits $E[*]$ in the $i^{\text {th }}$ and $j^{\text {th }}$ fisheries are an inherently linear function of exogenous variables $\mathrm{x}$, e.g.

and

$$
\begin{aligned}
& E[I]=\sum_{k=1}^{K} a_{k i} X_{k}+v_{i} \\
& E[J]=\sum_{k=1}^{K} a_{k j} X_{k}+v_{j}
\end{aligned}
$$

where $j=1, \ldots, i, \ldots, n$ fisheries

$\mathrm{k}=1, \ldots, \mathrm{K}$ exogenous variables, and

$\mathrm{v}=$ error terms.

Then

$$
Y_{i}^{*}=I-J=\sum_{k=1}^{K}\left(a_{k i}-a_{k j}\right) X_{k}+\left(v_{i}-v_{j}\right)
$$

which can be expressed as

${ }^{67}$ N.E. Bockstael and J.J. Opaluch (1983), D. McFadden, "Conditional Logit Analysis of Qualitative Choice Behavior," in Frontiers of Econometrics, ed P. Zarembka (New York: Academic Press, 1973), and R.D. Luce and P.Suppes, "Preference, Utility, and Subjective Probability," in Handbook of Mathematical Psychology, vol. 3, eds. R.D. Luce, R. Bush, and E. Galanter (New York: John Wiley, 1965). 
where $b_{i k}=\left(a_{k i}-a_{k j}\right)$

$$
Y_{i}^{*}=\sum_{k=1}^{K} b_{i k} X_{k}-u_{i}
$$

$$
\begin{aligned}
& u_{i_{*}}=\left(v_{j}-v_{i}\right) \\
& Y_{i}=I-J>0\left(u_{i}<\Sigma b_{i k} X_{k}\right) \text { if fishery } i \text { is } \\
& Y_{i}{ }^{*}=\begin{array}{l}
I-J<0 \text { and } \\
\text { chosen. }
\end{array}
\end{aligned}
$$

This leads to the probabilistic statement that

$$
P\left(Y_{i}=i\right)=P\left(Y_{i}^{*}>0\right)=P\left(u_{i}<\sum_{k=1}^{K} b_{i k} X_{k}\right)
$$

If $u_{i}$ is a continuous random variable and $v_{i}$ is a polytomous variable, then this equation can be written as a multinomial logit $\operatorname{model}^{68}$

$$
P\left(Y_{i}=i\right)=\underset{k=1}{\exp }\left(\sum b_{i k} X_{k}\right) /\left[\sum_{j=1}^{m} \underset{k=1}{K} \underset{\left.\left(\sum b_{i k} X_{k}\right)\right]}{K}\right.
$$

where $i \neq j$,

$m$ is the number of mutually exclusive

alternatives available to the fisherman,

b represent the parameters estimated by the logit model.

$\mathrm{x}_{\mathrm{k}}$ are the exogenous variables representing exvessel prices, operating costs, generalist versus specialist vessel operations, the fixed vessel

characteristics, and other variables

that describe the firms indirect profit function.

The probability that an individual firm will enter the $i^{\text {th }}$ fishery will increase as profits in that fishery increase relative to the other employment alternatives available to the fisherman. The probability that an individual firm will exit the $i^{\text {th }}$ fishery will increase as profits in that

${ }^{68}$ Where $b_{i k}=0$ for $k=1, \ldots, k$ in the denominator. 
fishery decrease relative to the other employment alternatives available to the fisherman. Inertia, imperfect capital malleability, or observed resistance to change observed in the Bockstael and Opaluch (1983, p. 133) study $^{69}$ can be tested for by comparing the estimated coefficients effect on entry and exit decisions for specific independent, exogenous variables. For example, if fishermen are reluctant to leave a fishery the derivative of the probability of exit with respect to cost would be less than the derivative of the probability of entering the fishery with respect to the same cost variables, i.e.

$$
\partial \mathrm{P}_{\mathrm{i}} / \partial \mathrm{x}_{\mathrm{ik}}=\mathrm{f}\left(\Sigma \mathrm{b}_{\mathrm{ik}} \mathrm{x}_{\mathrm{k}}\right) \mathrm{b}_{\mathrm{ik}}<\mathrm{f}\left(\Sigma \mathrm{b}_{\mathrm{jk}} \mathrm{x}_{\mathrm{k}}\right) \mathrm{b}_{\mathrm{jk}}=\partial \mathrm{P}_{\mathrm{j}} / \partial \mathrm{x}_{\mathrm{jk}}
$$

where $f(*)$ is the probability density function. ${ }^{70}$

The hypothesis of independence from irrelevant alternatives could be tested for by a method proposed by McFadden (1976b). If this hypothesis is true, estimates obtained from a full set of alternatives should be close to estimates obtained by randomly eliminating some unchosen alternatives. Testing the coefficients simultaneously, the difference between each estimate should be statistically insignificant so that the null hypothesis of independence

${ }^{69}$ N.E. Bockstael and J.J. Opaluch (1983). "... some minimum threshold of expected gain is required to induce fishermen to change fishery. Because this threshold includes nonmonetary factors such as family tradition and pure inertia, it is not directly measurable. The only observable measure of the threshold is the fisherman's observed resistance to change."

${ }^{70}$ T.B. Fomby, R.C. Hill, and S.R. Johnson (1984) p. 351. 
from irrelevant alternatives cannot be rejected. ${ }^{11}$ Given the significant differences between the shrimp otter trawl fishery and the available alternatives in terms of gear type, bottom conditions, and population dynamics of the fish stocks, there is little reason for concern that this assumption is violated in the entry-exit model for shrimp fishing vessels.

\section{Conclusions}

Discrete choice or qualitative response models are those in which the endogenous variable takes discrete values reflecting choices rather than being a continuously observable variable. The choice of a statistical procedure to estimate these models depends on theoretical questions first, then on the assumption that the model is a reasonably close approximation to the way the data are generated, and finally on the ability of the technique to make inferences of interest. If only two alternatives or choices exist and sufficient data are available to adequately estimate selection probabilities using relative frequencies, then generalized least squares versions of the linear probability model, logit, or probit may be used. Maximum likelihood approaches to the estimation of probit and logit functions are recommended when only a few observations for each

${ }^{71} \mathrm{~J} . \mathrm{A}$. Hausman and D.MCFadden, "A Specification Test for the Independence of Irrelevant Alternatives in Logit Models," Unpublished paper given at the European Workshop on Discrete Choice Models, 1981 develop the procedure to perform this test. 
experimental cell are available. If more than two alternatives exist, the choice between generalized logit and probit models becomes more important regardless of the number of observations for each experimental cell. The advantage of the logit model is its computational ease relative to that of the probit model, but it is based on assumptions that may be violated if some of the alternatives are close substitutes. The probit model is more flexible in that it does not suffer from this logit model weakness termed the independence of irrelevant alternatives. The entry and exit model for vessel behavior in the Gulf of Mexico shrimp fishery is estimated using an unordered, independent, multinomial logit model specification. Alternative specifications such as ordered, nonindependent, or multivariate multinomial logit or multinomial probit as discussed in Amemiya (1981) or systems of simultaneous equations, models with continuous and discrete endogenous variables, and multinomial probit as presented in Judge, et. al. (1985) do not fit the theoretical model or the manner in which the data are estimated. Also the independence of the irrelevant alternatives assumption is not violated since no close alternatives to shrimp fishing in the Gulf of Mexico exist. 
Adams, C.M. "Price Dynamics in the U.S. Shrimp Market." Dissertation, Department of Agricultural

Economics, University of Florida, Gainesville, FL., 1984 .

Akin, J.S., D.K. Guilkey, and R. Sickles. "A Random Coefficient Probit Model with an Application to a study of Migration." J. Econometrics (1979): 23346.

Aldrich, J.H. and R.D. Nelson. Linear Probability, Logit, and Probit Models. Sage University Paper series on Quantitative Applications in the social Sciences, 07-045. Beverly Hills and London: Sage Pubs., 1984

Alvarey, J., C.O. Andrew, and F.J. Prochaska. "Dual structure Equilibrium in the Florida Shrimp Processing Industry." Fishery Bulletin 74(4) (1976) : 879-883.

Amemiya, T. "Qualitative Response Models: A Survey." Journal of Economic Literature 19 (1981): 14831536.

Anonymous. "Revenues, Costs, and Returns from Vessel Operations in Major U.S. Fisheries." U.S. Dep. Commer., NOAA., NMFS. Rep. NTIS PB-265275, Wash., D.C., Feb., 1977.

Bartel, A. "The Migration Decision: What Role Does Job Mobility Play?" Amer. Econ. Rev., Dec. (1979): 775-86.

Ben-Porath, Y. "Fertility Response to Child Mortality: Mirco Data from Israel." J. Polit. Econ., Aug. (1976): 163-78.

Berck, P. and J.M. Perloff. "An Open-Access Fishery with Rational Expectations." Econometrica 52 (2) $(1984): 489-506$.

Bjorndal, T. and J. Conrad. "Capital Dynamics in the North Sea Herring Fishery," Marine Resource

Economics $4(1)(1987): 63-74$.

Bockstael, N.E. and J.J: Opaluch. "Discrete Modeling of Supply Response Under Uncertainty: The Case of the 
Fishery." Journal of Environmental Economics and Management 10 (1983): 127 .

Blomo, V., and W.L. Griffin. "Cost and Returns Data Florida Based Gulf of Mexico Shrimp Trawlers, 1977." Tex. A\&M univ. Sea Grant Rep. TAMU-SG-79$604,1978$.

Blomo, V.J., J.P. Nichols, W.L. Griffin, and W.E. Grant. "Dynamic Modeling of the Eastern Gulf of Mexico Shrimp Fishery." American Agricultural Economics Association. August (1982): 475-482.

Blomo, V., J. Nichols, w.L. Griffin, and W. Grant. "Dynamic Modeling of a Natural Resource Problem: Eastern Gulf of Mexico Shrimp Fishery." American Journal of Agricultural Economics 64(3) (1982): 475-482.

Blomo, V., K. Stokes, W.L. Griffin, W. Grant, and J. Nichols. "Bioeconomic Modeling of the Gulf Shrimp Fishery: An Application to Galveston Bay and Adjacent offshore Areas." Southern Journal of Agricultural Economics July (1978): 119-125.

Boskin, M.J. "A Conditional Logit Model of occupational Choice." J. Polit. Econ. Mar.-Apr. (1974) : 389-98.

Browder, J.A. "Vessel Activity Relative to the Texas Closure, 1981 and 1982." NOAA Technical Memorandum NMFS-SEFC-118, 1983.

Clark, C.W., F.H. Clarke, and G.R. Munro. "The optimal Exploitation of Renewable Resource Stocks: Problems of Irreversible Investment," Econometrica 47 (1). (1979): 25-47.

Conroy, P.D. and J.R. Poffenberger. "Estimated Impacts of Texas Closure Regulation on Ex-Vessel Prices and Value of Shrimp, 1983 and 1984." NOAA Technical Memorandum NMFS-SEFC-171, 1986.

Cragg, J.G. and R.S. Unler. "The Demand for Automobiles." Can. J.Econ. Aug. (1970): 386-406.

Daganzo,C. Multinomial Probit. New York: Academic Press, 1979 .

Danville Research Associates, Inc. "Work Plan for the Development of Cost, Revenue and Income Profiles 
for the Gulf and South Atlantic Shrimp Fleet." Prepared for the SEFC, NMFS, Dec., 1982.

David, J.M. and W.E. Legg. "An Application of Multivariate. Probit Analysis to the Demand for Housing: A Contribution to the Improvement of the Predictive Performance of Demand Theory, Preliminary Results." Amer. Statist. Assoc. Proceedings of the Bus. and Econ. Statist. Section Aug. (1975): 295-300.

Da Vanzo, J. "Does Unemployment Affect Migration? Evidence from Micro Data." Rev. Econ. Statist., Nov. (1978): 504-14.

Deacon, R. and P. Shaprio. "Private Preference for Collective Goods Revealed Through Voting and Referenda." Amer. Econ. Rev. March (1975): 18688.

Debreu, G. "Review of 'Individual Choice Behavior' by R. Luce," Amer. Econ. Rev. Dec. (1975) : 943-55.

Domencich, T.A. and D. McFadden. Urban Travel Demand. Amsterdam: North-Holland, 1975.

Dubin, J.A. and D. McFadden. "An Econometric Analysis of Residential Electric Appliance Holdings and Consumption." Draft report, Feb., 1980.

Duffy, J., Jr. and D.B. Johnson. "study of Costs and Earnings of Bay Shrimp Fishermen in Louisiana." SEFC, NMFS, La. State Univ., Baton Rouge, 1977.

Duncan, G.M. "Formulation and Statistical Analysis of the Mixed, Continuous/Discrete Dependent Variable Model in Classical Production Theory."

Econometrica Mar. (1980): 839-52.

Duncan, G.M. and F. Stafford. "Do Union Members Receive Compensating Wage Differentials." Amer. Econ. Rev. June (1980): 355-71.

Fair, R.C. "The Effect of Economic Events on Votes for President." Rev. Econ. Statist. May (1978): 15973.

Fields, G.S. "Place to Place Migration: some New Evidence." Rev. Econ. Statist. Feb. (1979): 2132. 
Fomby, T.B., R.C. Hill, and S.R. Johnson. Advanced Econometric Methods. New York:Springer-Verlag, 1984 .

Garcia, S. "The Stock-Recruitment Relationship in Penaeid Shrimp: Reality or Artefact and Misinterpretations." Oceanogr. Trop. 18 (1983): 25-48.

Garcia, S. "Environmental Aspects of Penaeid Shrimp Biology and Dynamics." In Penaeid shrimps-their biology and management, eds. J.A. Gulland and B.J. Rothschild. Farnham, UK: Fishing New Books, 1984.

Garcia, S. "Reproduction, Stock Assessment Models and Population Parameters in Exploited Penaeid Shrimp Populations." In Second Australian National Prawn Seminar, eds. P.C. Rothlisberg, B.J. Hill, and D.J. Staples. NPS2, Cleveland, Queensland, Australia, 1985.

Garcia, S. "Tropical Penaeid Prawns." In Fish Population Dynamics, ed. J.A. Gulland. New York: John Wiley \& Sons, 1988.

Garcia, S. and L. Le Reste. "Life Cycles, Dynamics, Exploitation and Management of Coastal Penaeid Shrimp stocks." FAO Fish. Tec. Pap., 203, 1981.

Goldberg, I. and F.C. Nold. "Does Reporting Deter Burglars? - An Empirical Analysis of Risk and Return in Crime." Rev. Econ. Statist. Aug. $(1980): 424-31$.

Goldberger, A.S. Econometric Theory. New York: John Wiley, 1964 .

Grant, W. and W.L. Griffin. "Bioeconomic Model of the Gulf of Mexico Shrimp Resources." Transactions of American Fisheries Society, Annual Meeting, Vancouver, British Columbia, Sept., 1977.

Grant, W.E. and W.L. Griffin. "A Bioeconomic Model of the Gulf of Mexico Shrimp Fishery." Transactions of the American Fisheries Society 108(1) (1979): $1-13$.

Grant, W., W.L. Griffin, and J.P. Warren. "A Management Model of the Northwest African Cephalopod Fishery." Marine Fisheries Review 43(11) (1981) : 1-10. 
Grant, W.E., K.G. Isakson, and W.L. Griffin. "A General Bioeconomic Simulation Model for Annual Crop Marine Fisheries." Ecological Modelling 13 (1981): 195-219.

Green, T. The Economic Value and Policy Implications of Recreational Red Drum Success Rate in the Gulf of Mexico. Marine Fisheries Initiative contract No. NA87WC-H-06146 prepared for SERO, NMFS, NOAA, st. Petersburg, Fl., July, 1989.

Griffin, W.L. and B. Beattie. "Economic Impact of Mexico's 200-mile offshore Fishing Zone on the U.S. Gulf of Mexico Shrimp Fishery." Land Economics 54 (1978):27-38.

Griffin, W.L. and W.E. Grant. "A Bioeconomic Analysis of the Ivory Coast Shrimp Fishery." CECAF/TECH/82/41 (En). United Nations Development Programme, Food and Agricultural Organization of the United Nations, 1981.

Griffin, W.L. and W.E. Grant. "General Bioeconomic Fisheries Simulation Model." Draft report, Department of Agricultural Economics, Texas A\&M University, College Station, Texas, 1991.

Griffin, W.L., R.D. Lacewell, and W. Hayenga. "Estimated Costs and Returns and Financial Analysis: Gulf of Mexico Shrimp Vessels." Mar. Fish. Rev. 36(12) (1974):1-4.

Griffin, W.L., R.D. Lacewell, and J.B. Smith. "Economic Analysis of Returns to Gulf of Mexico Shrimp Vessel Owners for the Period 1971 - 1975." Tex. A\&M Univ. Staff Pap. Dir 75-1, Sp-4, 1975.

Griffin, W., J.P. Nichols, W.E. Grant, and J.P. Warren. "Analysis of Management Alternatives for the Texas Shrimp Fishery." DIR 81-1, staff Paper No. 1, Department of Agricultural Economics, Texas Agricultural Experiment Station, Texas A\&M University, February, 1981.

Griffin, W.L., J.P. Nichols, and J.B. Smith. "Economic Analysis of Returns to Gulf of Mexico Shrimp Vessel Owners for the Period 1971-75." Tex. A\&M Univ. Staff Pap. DIR 75-1, SP-4, 1975.

Griffin, W.L., N.J. Wardlaw, and J.P. Nichols. "Cost and Return Analysis by Selected Vessel Characteristics: Gulf of Mexico Shrimp Fishery, 
1971-75." Tex. Agric. Exper. Sta., Tex. A\&M Univ., Rep. MP-1253C, 1976.

Griffin, W.L., J.P. Warren, and W. Grant. "A Bioeconomic Model for Fish stock Management: The Cephalopod Fishery of Northwest Africa." CECAF/TECH/79/16 (En). United Nations Development Programme, Food and Agricultural Organization of the United Nations, 1979.

Griffin, W., J. Warren, J. Nichols, W. Grant, and C. Pardy. "The Texas Shrimp Fishery: Analysis of Six Management Alternatives Using the General

Bioeconomic Fishery Simulation Model (GBFSM)." TAMU-SG-84-202, Sea Grant College Program, Texas A\&M University, College Station Texas, Oct., 1983.

Gronau, R. "The Allocation of Time of Israeli Women." J. Polit. Econ. Aug. (1976): 201-20.

Gunderson, M. "Retention of Trainees: A study With Dichotomous Dependent Variables." J. Econometrics May (1974): 79-93.

Hausman, J.A. "Individual Discount Rates and The Purchase and Utilization of Energy-Using Durables." Bell J. Econ. Manage. Sci. Spring $(1979): 33-54$.

Hausman, J.A. and D, MCFadden. "A Specification Test for the Independence of Irrelevant Alternatives in Logit Models." Unpublished paper given at the European Workshop on Discrete Choice Models, 1981.

Hausman, J.A. and D.A. Wise. "A Conditional Probit Model for Qualitative Choice: Discrete Decisions Recognizing Interdependence and Heterogeneous Preferences." Econometrica Mar. (1978): 403-26.

Heckman, J.J. "Simultaneous Equations Models with Continuous and Discrete Endogenous Variables and structural shifts." in studies in nonlinear estimation, ed. S.M. Goldfeld and R.E. Quandt. Cambridge, Mass.: Ballinger, 1976.

Heckman, J.J. and R.J. Willis. "Estimation of a Stochastic Model of Reproduction: An Econometric Approach." In Household Production and Consumption, ed. N.E. Terleckyj. New York: NBER, 1975. 
Heckman, J.J. and R.J. Willis. "A Beta-Logistic Model for the Analysis of Sequential Labor Force Participation by Married Women." J.Polit. Econ. Feb. (1977): 27-58.

Hill, C.R. "Capacities, Opportunities, and Educational Investments: The Case of the High School Dropout." Rev. Econ. Statist. Feb. (1979): 9-20.

Hughes, G.A. "On the Estimation of Migration Equations." . Draft report. Faculty of Economics Cambridge University, 1980.

Judge, G.G., W.E. Griffiths, R.C. Hill, H. Lutkepohl, and T. Lee. The Theory and Practice of Econometrics. New York: John Wiley and Sons, 1985.

Kahn, L.M. and K. Morimune. "Unions and Employment Stability: A Sequential Logit Approach." Int. Econ. Rev. Feb. (1979): 217-36.

Kau, J.B. and P.H. Rubin. "Voting on Minimum Wages: A Time Series Approach." J. Polit. Econ. Apr. $(1978): 337-42$.

Keithly, W.R., Jr. and Liz Baron-Mounce. "An Economic Assessment of the Louisiana Shrimp Fishery." Final Report to National Marine Fisheries Service, NA88WC-H-MF179, Oct., 1990.

Keithly, W.R., Jr. and Liz Baron-Mounce. "Louisiana Shrimp Fishery: An Economic Perspective with Emphasis on the 1987 Inshore Fleet." Submitted to NOAA Technical Report, NMFS, 1991.

Keithly, W.R., Jr. and K.J. Roberts. "An Economic Analysis of U.S. Shrimp Imports and Dockside Prices with Policy Implications." Draft Report, Center for Wetland Resources, Louisiana State University, Baton Rouge, LA, 1991.

Kohn, M.G., C.F. Manski, and D.S. Mundel. "An Empirical Investigation of Factors Which Influence College-Going Behavior." Ann. Econ. Soc. Measure. Fall (1976): 391-420.

Lave, C.A. "The Demand for Urban Mass Transportation." Rev. Econ. Statist. Aug. (1970): 320-23.

Lee, L.F. "Estimation of a Modal Choice Model for the Work Journey with Incomplete Observations." Draft 
Report. Dept. of Economics, University of Minnesota, 1977.

Lee, L.F. "Unionism and Wage Rates: A Simultaneous Equations Model with Qualitative and Limited Dependent Variables." Int. Econ. Rev. June (1978): 415-34.

Li, M.M. "A Logit Model of Home Ownership." Econometrica July (1977): 1081-98.

Long, J.E. and E.B. Jones. "Labor Force Entry and Exit by Married Women: A Longitudinal Analysis." Rev. Econ. Statist. Feb. (1980): 1-6.

Luce, R.D. and P. Suppes. "Preference, Utility, and Subjective Probability." In Handbook of Mathematical. Psychology, Vol. 3. eds. R.D. Luce, R. Bush, and E. Galanter. New York: John Wiley, 1965 .

McFadden, D. "Conditional Logit Analysis of Qualitative Choice Behavior." In Frontiers of Econometrics, eds. P. Zarembka. New York: Academic Press, 1974.

McFadden, D. "Quantal Choice Analysis: A Survey." Ann. Econ. Soc. Measure. Fall (1976a): 363-90.

McFadden, D. "The Revealed Preferences of a Government Bureaucracy: Empirical Evidence." Bell J. Econ. Manage. Sci. Spring (1976b): 55-72.

McFadden, D. "Qualitative Methods for Analyzing Travel Behavior of Individuals: Some Recent Developments." Cowles Foundation Discussion Paper No. 474, Nov., 1977. In Behavioral Travel Modeling. Ed. D. Hensher and P. Stopher. London: Croom-Helm, 1979.

McGillivray, R.G." "Binary Choice of Urban Transport Mode in the San Francisco Bay Region." Econometrica Sept. (1972): 827-48.

McKelvey, R. "The Fishery in a Fluctuating Environment: Coexistence of Specialist and Generalist Fishing Vessels in a Multipurpose Fleet," Journal of Environmental Economics and Management 10 (1983): 287-309. 
Medoff, J.L.. "Layoffs and Alternatives Under Trade Unions in U.S. Manufacturing. Amer. Econ. Rev. June (1979): 380-95.

Milon, J.W. Estimating Recreational Angler Participation and Economic Impact in the Gulf of Mexico Mackerel Fishery. Marine Fisheries Initiative Contract No. NA86WC-H-06116 prepared for SERO, NMFS, NOAA, St. Petersburg, Fl., July, 1988 .

Montegut, R.S. "Planning to Buy a Shrimp Boat? Some Things to Consider First." La. State Univ. Sea Grant Publ. LSU-TL-79-005, 1979.

Moore, W.J., R.J. Newman, and R.W. Thomas. "Determinants of the Passage of Right-to-Work Laws: An Alternative Interpretation." J. Law Econ. Apr. (1974): 197-211.

Nance, J.M., E.F. Klima, and E.X. Martinez. "Impacts of Proposed Brown Shrimp Fishery Management Closures in the Gulf of Mexico." Report for the Gulf of Mexico Fishery Management Council, Dec., 1990 .

Nichols, S., A. Shad, and G. Pellegrin, Jr. "Estimates of Annual Shrimp Fleet Bycatch for Thirteen Finfish Species in the offshore Waters of the Gulf of Mexico." Draft report, National Marine Fisheries Service, Southeast Fisheries Center Mississippi Laboratories, Pascagoula Facility, Pascagoula, Ms, Oct., 1987.

Nickell, S. "Education and Lifetime Patterns of Unemployment. J. Polit. Econ. Oct. (1979): 11731.

Osten, s. "Industrial Search for New Locations: An Empirical Analysis." Rev. Econ. Statist. May (1979): 288-92.

Parks, R.W. "On the Estimation of Multinomial Logit Models from Relative Frequency Data." J. Econometrics Aug. (1980): 293-304.

Parsons, D.O. "The Decline in Male Labor Force Participation. J. Polit. Econ. Feb. (1980a): 11734. 
Parsons, D.O. "Racial Trends in Male Labor Force Participation." Amer. Econ. Rev. Dec. (1980b) : 911-20.

Paterson, D.G. and J. Wilen. "Depletion and Diplomacy: the North Pacific Seal Hunt," Research in Economic History Vol. 2. (1977).

Pellegrin, G.J., Jr., S.B. Drummond, and R.S. Ford, Jr. The Incidental Catch of Fish by the Northern Gulf of Mexico Shrimp Fleet. Draft Report, NOAA, NMFS, SEFC, Mississippi Laboratories, Pascagoula, MS., 1985 .

Pencavel, J.H. "Market Work Decisions and Unemployment of Husbands and wives in the Seattle and Denver Income Maintenance Experiments." Draft Report. Apri1, 1979.

Penson, John B., Jr., Ernest o. Tetty, and wade L. Griffin. "An Econometric Analysis of Net Investment in Gulf Shrimp Fishing Vessels." Technical Article No. TA-20803 of the Texas Agricultural Experiment Station, Texas A\&M University, 1987.

Poffenberger, J.R. "Estimated Impacts on Ex-Vessel Brown Shrimp Prices and Value as a Result of the Texas Closure Regulation." Mar. Fish. Rev. 44(910) (1982a): 38-43.

Poffenberger, J.R. "Estimated Impacts of Texas Closure Regulation on Ex-Vessel Prices and Value, 1981 and 1982." NOAA Technical Memorandum NMFS-SEFC-111, $1982 \mathrm{~b}$.

Poffenberger, J.R. "Economic Impacts of the Texas Closure Regulation on Ex-Vessel Prices and Value, 1984 and 1985." NOAA Technical Memorandum, NMFS SEFC - 184, Oct., 1986a.

Poffenberger, J.R. "Economic Impacts of the Texas Closure, 1981 - 1985." Draft report prepared for the Gulf of Mexico Fishery Management Council, December, $1986 \mathrm{~b}$.

Poffenberger, J.R. "Economic Impacts of the Texas Closure, 1985 - 1986." Draft report prepared for the Gulf of Mexico Fishery Management Council, 1987. 
Powers, J.A., L.C. Marsh, R.R. Huckfeldt, and Johnson. "A Comparison of Logit, Probit, and Discriminant Analysis in Predicting Family size." Amer.

statist. Assoc. Proceedings of the Soc. Statist. Section Aug. (1978): 693-97.

Prochaska, F.J. and C.O. Andrew. "Shrimp Processing in the Southeast: Supply Problems and structural Change." Southern Journal of Agricultural Economics July (1974): 247-252.

Prochaska, F.J. and J.C. Cato. "Economic Conditions in the Gulf of Mexico Shrimp Industry: 1960 - 1981." Staff Paper 180, Food and Resource Economics Department, Institute of Food and Agricultural Sciences, University of Florida, Gainesville, April, 1981.

Quandt, R.E. "Estimation of Modal Splits." Transp. Res. (1968): 41-50.

Quandt, R.E. and W.J. Baumol. "The Demand for Abstract Transport Modes: Theory and Measurement." J.Reg. Sci. Winter (1966): 13-26.

Radner, R. and L.S. Miller. "Demand and Supply in U.S. Higher Education: A Progress Report." Amer. Econ. Rev., Papers and Proceedings May (1970): 326-34.

Roberts, K.J. and M.E. Sass. "Financial Aspects of Louisiana Shrimp Vessels, 1978." La. State Univ. Sea Grant Rep. LSU-TL-79-007, 1979.

Rosen, H.S. and K.T. Rosen. "Federal Taxes and Home Ownership: Evidence from Time Series." J. Polit. Econ. Feb. (1980): 59-75.

Schiller, B.R. and R.D. Weiss. "The Impact of Private Pensions on Firm Attachment." Rev. Econ. Statist. Aug. (1979): 369-80.

Schmidt, P. and R.P. strauss. "The Prediction of Occupation Using Multiple Logit Models." Int. Econ. Rev. June (1975): 471-86.

Schmidt, P. and R.P. Strauss. "The Effects of Unions on Earnings and Earnings on Unions: A Mixed Logit Analysis." Int. Econ. Rev. Feb. (1976): 204-12.

Siblerman, J.I. and G.C. Durden. "Determining Legislative Preferences on the Minimum Wage: An 
Economic Approach." J. Polit. Econ. Apr. (1976): 317-29.

Smith, C. and R. McKelvey. "Specialist and Generalists: Roles for Coping with Variability," North American Journal of Fisheries Management 6 (1986): 88-99.

Smith, J.P. "The Distribution of Family Earnings." J. Polit. Econ. Oct. (1979): 163-92.

Smith, V.L. "Economics of Production from Natural Resources." American Economic Review 58 (1968): 409-431.

Smith, V.L. "On Models of Commercial Fishing." Journal of Political Economy 77 (1969): 181-198.

Spector, L. and M. Mazzeo. "Probit Analysis and Economic Education." Journal of Economic Education 11 (1980): 37-44.

Stollery, K.R. "Monopsony Processing in an open-Access Fishery." Marine Resource Economics 3 (4) (1987): $331-351$.

Sutinen, J.G. "Seasonality in Renewable Resource Models," Presented at the Annual Meeting of the Allied Social Science Association, New orleans, LA, Dec., 1986.

Swartz, A.M. and C.M. Adams. "The Economics of Rockport Bay Texas Shrimping Vessels." Rep. DIR 79-1, SP-6 Dep. Agric. Econ., Tex. A\&M Univ., 1979.

Talvitie, A. "Comparison of Probabilistic Modal Choice Models: Estimation Methods and System Inputs." National Academy of Science, National Research Council, Highway Research Board, Record, No. 392, 1972 .

Tettey, E.O., W.L. Griffin, J.B. Penson, and J.R. Stoll. "Implications of Tax Policy on Investment in a Common-Property Resource." North American Journal of Fisheries Management 6 (1986): 100-104.

Tettey, E., C. Pardy, and W. Griffin. "Economic analysis of investment alternatives for the Gulf of Mexico shrimp vessels." Draft rep., Tex. A\&M Univ., 1982 . 
Tollefson, J.O. and J.A. Pichler. "A Comment on RightTo-Work Laws: A Suggested Economic Rationale." J. Law Econ. Apr. (1974): 193-96.

Tse, E. and A. Khilnani. "An Integrated System Model for a Fishery Management Process-I." Computers Math. Applic. $17(8 / 9)$ (1989a): 1329-1343.

Tse, E. and A. Khilnani. "An Integrated System Model for a Fishery Management Process-II. A Case Study." Computers Math. Applic. $17(6 / 7)$ (1989b): 675-690.

Uhler, R.S. "The Demand for Housing: An Inverse Probability Approach." Rev. Econ. Statist. Feb. (1968): 129-34.

Ward, J.M. "A Synthesis of Cost and Revenue Surveys for Gulf of Mexico Shrimp Vessels." Marine Fisheries Review 50(1) (1988): 47 - 52 .

Ward, J.M. "Modelling Fleet Size in the Gulf of Mexico Shrimp Fishery, 1966 - 1979." NOAA Technical Memorandum NMFS-SEFC-229. National Marine Fisheries Service, Southeast Regional office, 9450 Koger Blvd., St. Petersburg, FL, 1989.

Ward, J.M. and S. Sinha. "Resource Value Impacts of the Texas Closure for 1986-1987." Report prepared for the Gulf of Mexico Fishery Management Council, Jan., 1988.

Warner, S.L. Stochastic Choice of Mode in Urban

Travel-A Study in Binary Choice. Evanston, Ill.: Northwestern University Press, 1962.

Warren, J.P., and W.L. Griffin. "Cost and Return Trends for Gulf of Mexico Shrimp Vessels." Tex. A\&M Univ., Staff Pap. Ser. Dir 78-1, SP-4, 1978.

Warren, J.P., W.L. Griffin, and R.D. Lacewell. "Applying an Index of Fishing Effort to Estimated 1971 Costs and Returns for Gulf of Mexico Shrimp Vessels." Dep. Agric. Econ., Tex. A\&M Univ. Sea Grant rep. TAMU-SG-74-217, 1974.

Warren, R.S. and R.P. Strauss. "A Mixed Logit Model of the Relationship Between Unionization and RightTo-Work Legislation." J. Polit. Econ. June $(1979): 648-55$. 
Watson, P.L. and R.B. Westin. "Transferability of Disaggregate Mode Choice Models." Reg. Sci. and Urban Econ. May (1975): 227-49.

Weisberg, H.W. "Evaluating Theories of Congressional Roll-call Voting." American Journal of Political Science 22 (1978): 554-557.

Westin, R.B. "Predictions from Binary Choice Models." J. Econometrics May (1974): 1-16.

Wilensky, G.R. and L.F. Rossiter. "OLS and Logit Estimation in a Physician Location study." Amer. Statis. Assoc. Proceedings of the soc. Statist. Section Aug. (1978): 260-65.

Willis, R.J. and S. Rosen. "Education and SelfSelection." J. Polit. Econ. Oct. (1979): 7-36.

Witte, A.D. and P. Schmidt. "An Analysis of the Type of Criminal Activity Using the Logit Model." J.Res, in Crime and Delinquency Jan. (1979): 16479 .

Wu, D.M. "An Empirical Analysis of Household Durable Goods Expenditure." Econometrica Oct. (1965): 761-80. 


\section{Appendix c \\ An Indirect Total cost Function \\ for Vessels operating in \\ the southeast Region Shrimp Fishery}

\section{Introduction}

According to economic theory, a change in operating costs relative to revenues creates an incentive for fishermen to alter their levels of fishing effort. The cumulative effect of individual fishermen responding to fluctuating market conditions and stock abundance is a change in both the number and the fishing power of vessels in the fleet. Monitoring the impacts on fleet size caused by the long-run trends in costs relative to revenues is difficult because comprehensive time series cost data are not routinely collected for vessels operating in any of the southeast region fisheries.

Numerous southeastern region shrimp fishery cost and returns surveys have been conducted under the auspices of the National Marine Fisheries Service (NMFS), Sea Grant, and other public and private institutions and organizations. Designed to meet different specific short-term objectives, the results of these studies are not directly comparable. Each report surveys a distinct subset of vessels in the shrimp fleet, resulting in different sample variances. The magnitude of these differences can be seen in the range of reported means, variances, standard deviations, and other descriptive statistics. For example, mean total revenue for surveyed vessels was reported as $\$ 60,142$ (Warren and 
Griffin, 1978) and $\$ 9,214$ (Duffy and Johnson, 1977). In addition, the sample sizes of the surveys ranged from 1 (Anonymous, 1977) to 115 vessels (Griffin et al., 1976).

Vessel characteristics also varied between reports. Vessel length ranged from less than 24 feet (Duffy and Johnson, 1977) to greater than 70 feet (Griffin et al., 1974). Vessels operated out of Texas (Swartz and Adams, 1979), Louisiana (roberts and Sass, 1979), and Florida (Blomo and Griffin, 1978). the surveys concentrated on different areas of operation (inshore versus offshore fisheries) and were generally restricted to a single year. Another cause of variation in the reports is the exclusion of information on vessel ownership. The cost structure of a single vessel, owner operated firm could conceivable be different from that of vertically integrated, horizontally integrated, or nonowner operated firms. The single vessel, owner operated fishing firms may operate as cost minimizers while the vertically integrated fishing firm may operate at a loss to ensure a continuous supply of fish to the parent company or to maximize profits at some other level within the firm. The reports also did not provide information on the quantity of factor inputs used in the production process such as gallons of fuel or trawl size, and the survey results were reported in current rather than constant or real dollars. 
As a result, comparisons of these studies do not provide any information on long run trends in costs relative to revenues in the shrimp fishery. As an example, consider the comparison of 66 to 72 foot vessels operating off the coast of Texas (Griffin, et al., 1974) with vessels 24 feet or less in length operating in the bays and rivers of Louisiana (Duffy and Johnson, 1977). Although both studies reported costs and revenues for shrimp vessels, meaningful conclusions cannot be drawn about the long run trends in the fishery because no common denominator exists between the two reports. These disassociated studies are used in a hedonic analysis of shrimp costs and returns for the Gulf of Mexico shrimp fishery (Ward, 1988). The results from this study, while indicating that fleet size responds to changes in profitability, are not designed to determine the impacts of fishery management regulations or changing market conditions on vessel operating behavior or on fleet size and structure.

A budget simulator model would allow the evaluation of private and public management decisions and changes in market forces upon the operating costs and net earnings of vessels operating in the Gulf of Mexico shrimp fishery. Budget simulators have been developed in other regions of the United States, such as the otter trawl fleet in New England developed by the University of Rhode Island (Crutchfield, 1986), the paying passenger fleet at the University of Florida (Prochaska, Cato, and Taylor, 1982), 
the New England otter trawl and sea scallop fleets by NMFS, NERO (Kurkle, 1986), and the Alaskan Salmon Fishery by the Alaska Limited Entry Commission. In the southeastern region, a budget simulator model (FLEETSIM) exists only for the Texas shrimp fishery (Griffin, 1988). FLEETSIM combines the hedonic approach, where cost and revenue estimates are a function of vessel characteristics and effort levels derived from statistical surveys, with the engineering approach, in which costs are estimated from the technical specifications provided by the manufacturer of the component ${ }^{72}$, to determine vessel operating costs and net revenue under various proposed management scenarios over time.

Without an existing time series of vessel operating cost data or a budget simulator model such as FLEETSIM, vessel entry-exit behavior in the Gulf of Mexico shrimp fishery cannot be modelled without first estimating a vessel operating cost model. This appendix develops an indirect cost function utilizing the economic theory of the firm, the 1982 cost and returns survey conducted by National Marine Fisheries Service, and duality theory. The assumption that firms operate where costs are minimized subject to an output constraint is incorporated into the economic model. An appropriate functional form for the production function is

${ }^{72}$ For example, the fuel consumption rate for vessels of various horsepowers and engine types can be converted to a quantity of fuel and to a cost once fuel prices are determined. 
adopted that can be used to determine the derived demand and output supply functions of the vessel. Using duality theory, the indirect cost function is based on the physical characteristics of the vessel, the unit costs of the variable factor inputs, and the reported level of landings. The estimated model is statistically significant and the estimated coefficients comply with economic theory. Relationships between estimated parameters are compared statistically and indicate that the underlying assumptions are appropriate.

Using the estimated equations, information from the vessel operating units file (VOUF) on vessel characteristics and the shrimp landings file (SLF) on landings and mobility, and the producer price index to deflate factor costs over time, reasonable estimates of vessel operating costs can be predicted and used in an analysis of entry-exit behavior. These cost estimates derived from the indirect cost model are statistically significance and conform to the economic theory of the firm, fisheries economics, and knowledge of the industry.

Theoretical Model

Primal Approach

The output supply and factor input demand equations are derived using the theory of the firm under the assumption that firms behave as if they are minimizing costs subject to a constraint on production (Gordon, 1954). In the case of 
the fishing firm, this model is further complicated in that production is also constrained by the size of the naturally occurring, renewable, common property resource stock.

In the southeastern region shrimp fishery, firms are assumed to minimize the following direct total cost function subject to an output constraint ${ }^{73}$ :

$$
\begin{aligned}
\mathrm{TC}= & \mathrm{TC}\left(\mathrm{p}_{1}, \ldots, \mathrm{p}_{n}, \mathrm{x}_{1}, \ldots, \mathrm{x}_{n}\right)=\sum_{i=1}^{n} \mathrm{p}_{i} x_{i} \\
& \text { s.t. } \quad \overline{\mathrm{Y}}=\mathrm{qXE}
\end{aligned}
$$

where $\bar{Y}$ is the harvest level of the fishing firm or vessel,

$p_{i}$ is the unit price of a factor input $(i=1, \ldots, n)$,

$x_{i}$ is the physical quantity of the factor input $(i=1, \ldots, n)$,

$q$ is the catchability coefficient,

$\mathrm{x}$ is the stock size of the shrimp resource, and

$E$ is the level of fishing effort applied by the vessel.

Fishing effort (E) is a function of factor inputs employed by the firm in the production process:

$$
E=f\left(x_{1}, \ldots, x_{n}\right)
$$

Substituting equation (2) into equation ( 1 ) and forming the Lagrangian results in :

$$
L=\Sigma p_{i} x_{i}+\bar{\mu}\left[y-q x f\left(x_{1}, \ldots, x_{n}\right)\right]
$$

The first order conditions (FOC) for cost minimization subject to an output constraint are:

$$
\begin{aligned}
\partial \mathrm{L} / \partial \mathrm{x}_{\mathrm{i}} & =\mathrm{p}_{\mathrm{i}}-\mu \mathrm{qX} \partial f(*) / \partial \mathrm{x}_{\mathrm{i}}=0 \quad(\mathrm{i}=1, \ldots, \mathrm{n}) \\
\partial \mathrm{L} / \partial \mu & =\mathrm{Y}^{-}-\mathrm{qX} f\left(\mathrm{x}_{1}, \ldots, \mathrm{x}_{\mathrm{n}}\right)=0
\end{aligned}
$$

${ }^{73}$ This assumption is the dual of profit maximization subject to a constraint on production. 
Simultaneously solving the set of equations represented by (4) and (5) results in the derived demand equations for the factor inputs $\left(x_{i}\right)$ as a function of the fixed harvest levels and input prices, i.e.:

$$
x_{i}=f\left(\bar{Y}, p_{1}, \ldots, p_{n}\right)
$$

since

$$
\left[\mu q X \partial f(*) / \partial x_{i} / \mu q X \partial f(*) / \partial x_{j}\right]=\left[\partial f(*) / \partial x_{i} / \partial f(*) / \partial x_{j}\right]
$$

and the level of harvest $(Y)$ is fixed. That is, the demand for each factor input used in the production process is a function of the fixed level of output and the unit costs of the factor inputs. If some of the factor inputs are fixed in the short run, then equation (6) can be represented as:

$$
\mathrm{x}_{\mathrm{i}}=f\left(\overline{\mathrm{Y}}, \mathrm{p}_{1}, \ldots, \mathrm{p}_{\mathrm{m}}, \mathrm{x}_{\mathrm{m}+1}, \ldots, \mathrm{x}_{\mathrm{n}}\right)
$$

where $x_{m+1}, \ldots, x_{n}$ are the fixed factors of production ${ }^{74}$.

\section{Dual Approach}

The envelope theorem is used to directly derive a factor demand or output supply equation from the indirect cost function using Shepherd's Lemma. The derived demand equation (6) for $x_{i}$ and the firm's supply equation are substituted into the direct cost function, equation (1), to yield the indirect cost function.

$\operatorname{TC}=\operatorname{TC}\left[Y\left(P, p_{1}, \ldots, p_{n}\right), x_{1}\left(\bar{Y}, p_{1}, \ldots, p_{n}\right), \ldots, x_{n}\left(\bar{Y}, p_{1}, \ldots, p_{n}\right)\right]$

${ }^{74}$ B.R. Beattie and C.R. Taylor. The Economics of Production. (New York: John wiley \& Sons, 1985), 225. "An indirect profit function can accommodate fixed factor quantities." This is also true for indirect cost functions. 
Shepherd's Lemma states that the first derivative of the indirect cost function with respect to the unit price of the input is the derived demand for that factor of production, i.e.

$$
\partial \mathrm{TC} / \partial \mathrm{p}_{\mathrm{i}}=\mathrm{x}_{\mathrm{i}}\left(\overline{\mathrm{Y}}, \mathrm{p}_{1}, \ldots, \mathrm{p}_{\mathrm{n}}\right) \quad(\mathrm{i}=1, \ldots, \mathrm{n}),
$$

provided equations ( 8 ) and (9) meet the following conditions: ${ }^{75}$

(1) $\operatorname{TC}\left(Y, p_{i}\right) \geq 0$ for $p_{i} \geq 0$ and $Y>0$,

(2) $\operatorname{TC}\left(Y, p_{i}{ }^{1}\right) \geq \operatorname{TC}\left(Y, p_{i}{ }^{0}\right)$ for $p_{i}{ }^{1} \geq p_{i}{ }^{0}$,

(3) $\mathrm{TC}\left(\mathrm{Y}, \mathrm{P}_{i}\right)$ is homogeneous of degree one in all prices,

(4) $\partial \mathrm{TC}(*) / \partial \mathrm{p}_{\mathrm{i}}$ is homogeneous of degree zero in all prices,

(5) $T C\left(Y, p_{i}\right)$ is weakly concave in all prices if the explicit production function, $\mathrm{Y}=\mathrm{qX} f\left(\mathrm{x}_{1}, \ldots, \mathrm{x}_{\mathrm{n}}\right)$, where $x_{j}$ are the variable factor inputs, is strictly quasi-concave in the variable factors or the implicit production function is strictly quasi-convex, and

(6) $\operatorname{TC}\left(Y, p_{i}\right)=Y^{(1 / E)} A\left(p_{i}\right)$ if the production function is homogeneous of degree $\mathrm{E}$ in variable factors; if $\mathrm{E}$ $=1$, then $A\left(p_{i}\right)$ is the average variable cost function.

Additional information about the institutions that exist in the southeast region shrimp fishery must be included in the development of an applied model from this theoretical framework. For example, the proper functional form must be chosen for the production function that reflects the actual behavior of shrimp fishermen. The relationships that exist between the explanatory variables

${ }^{75}$ Beattie and Taylor, The Economics of Production, 242. 
must be understood so that the estimation technique chosen results in the best linear unbiased estimators. The resulting estimated coefficients will then conform to both economic theory and the actual behavior of fishermen. Applied Model

The functional form of equations (8) and (9) depends on the functional form chosen to represent the production function constraint; i.e. the effort function in equation (2). A Cobb-Douglas production function of the form:

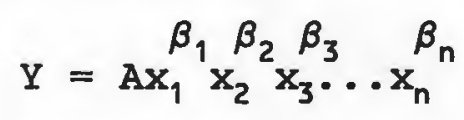

is adopted to represent the relationship between fishing effort and the level of landings. ${ }^{76}$

${ }^{76} \mathrm{M}$. Nerlove, "Recent Empirical studies on the CES and Related Production Functions," in The Theory and Empirical Analysis of Production, National Bureau of Economic Research, ed. M. Brown (New York: Columbia University Press, 1967) found conflicting estimates of the substitution elasticities in 40 papers surveyed and concluded that the estimates were sensitive to the period of time under consideration and the concepts employed. T.H. Mayor, Some Theoretical Difficulties in the Estimation of the Elasticity of Substitution from Cross-Sectional Data," Western Economic Journal, 7 (1969): 153-163 found in another survey that studies using crosssectional data obtained substitution elasticity estimates close to unity and time series based studies resulted in estimates grouped around one half. The difference in elasticity estimates between cross sectional and time series studies according to $L$. Johansen, Production Functions (Amsterdam: North-Holland Publishing Co. 1972) is the reduced substitution possibilities that exist once investment has occurred and capital is in place. Time series estimates reveal ex-post substitution possibilities after capital is in place and so are relatively low while cross sectional data reveal ex-ante substitution possibilities before capital is in place and have relatively high elasticities of substitution. Alternative functional forms for the production function have been investigated with the Cobb-Douglas specification best suited to describe the operation of vessels in the shrimp 
Having chosen a functional form that reflects the vessel's production behavior, the indirect cost function is estimated using a two step approach. In the first step, the level of harvest ( $\mathrm{Y}$ ) is estimated as a function of output price, input costs, and the fixed factors of production since output $(Y)$ is fixed for any set of prices and factor inputs in the short run, but is adjusted in the long run to maximize profits; e.g.

$$
\partial \mathrm{TC} / \partial \mathrm{p}_{\mathbf{i}}=\partial \mathrm{TC} /\left.\partial \mathrm{p}_{\mathbf{i}}\right|_{\mathrm{Y}=\overline{\mathrm{Y}}}+\partial \mathrm{TC} / \partial \mathrm{Y} \partial \mathrm{Y} / \partial \mathrm{p}_{\mathbf{i}}
$$

where $\partial \mathrm{TC} / \partial \mathrm{p}_{i}$ is the coefficient on $\mathrm{p}_{i}$ in $\mathrm{TC}\left(\mathrm{p}_{1}, \ldots, \mathrm{p}_{n}, \mathrm{Y}(*)\right)$ given a fixed output level $(Y)$ (the short run effect), $\partial T C / \partial Y$ is the coefficient on $Y$, and $\partial Y / \partial p_{i}$ is the coefficient on $p_{i}$ in $Y(*)=Y\left(P, p_{1}, \ldots, p_{n}\right)$; the supply equation (the long run effect).

In addition, the crew cost in the shrimp fishery is a function of the level of output. The crew of the shrimp vessel receives a share of the total trip revenue at the end of each trip. As a result, the level of landings in part determines the crew cost and the crew cost in part determines the level of landings. Harvest and crew cost must, therefore, be estimated simultaneously. The predicted values of harvest and crew cost are then used in the second step estimation of the indirect cost function.

The indirect cost function, equation (8), using a cobbDouglas production function, equation (10), takes the form:

fishery using this cross sectional data set. 


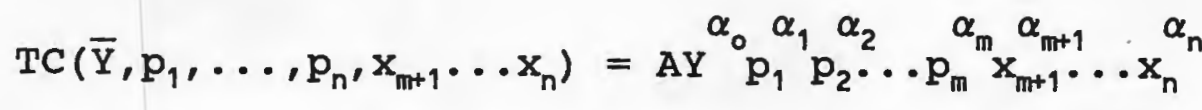

where the variables $x_{m+1} \ldots x_{n}$ indicate factors of production that are not variable for the period of time covered by this cross sectional data set. Provided the six conditions outlined earlier are met, this equation reflects the total cost associated with the given level of harvest and input costs. The indirect cost function is then used to estimate vessel profitability resulting from different management scenarios or changes in market conditions. Alternatively, the appropriate derivatives can be taken according to Shepherd's Lemma to determine changes in factor demand and create vessel cost and return profiles.

\section{Data set}

In 1983, the NMFS collected cost and returns (CNR) information from fishermen operating in the Gulf of Mexico and the southern Atlantic states shrimp fisheries for the 1982 fishing year. A random sample stratified by port, ownership, mobility, state, vessel size, bycatch utilization, and alternative fishery participation level was collected through personal.interviews with fishermen, vessel owners, and accountants by a private contractor ${ }^{77}$. The resulting data set contains detailed information on each fishing firm's input costs (groceries, fuel, ice, share for crew, vessel, and captain, etc), factors of production

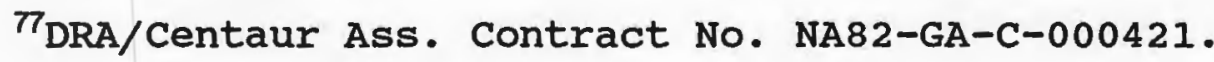


(numbers of trips and days fished inshore and offshore, vessel tonnage and length, type of hull, gallons of fuel, pounds of ice, engine horsepower, crew size, and type of gear), fixed costs (insurance, depreciation, and maintenance and repair), the output mix of species harvested as bycatch and from other fishing operations, and exvessel prices. of the 193 interviews conducted, 21 came from Texas, 60 from Louisiana, 20 from Alabama, 9 from the east coast of Florida, 24 from Georgia, and 59 from South Carolina. Results $^{78}$

Using these theoretical results and the cost and returns survey data, the indirect cost function is estimated in two steps using three-stage least squares and ordinary least squares estimation techniques. In the first step of the estimation procedure, three stage least squares ${ }^{79}$ is employed to estimate the landings and crew income models since these endogenous variables are simultaneously determined. Tables 1 and 2 provide the three-stage least squares results for landings (LY) and crew income (LC) and indicate that a good statistical fit exists for the cross

${ }^{78}$ The statistical significance of the estimated coefficients is determined using an $\alpha=0.10$ or a 90 percent confidence interval for this cross sectional data set.

${ }^{79}$ Estimated coefficients using three stage least squares are asymptotically more efficient than two stage least squares because the covariance matrix is estimated from the residuals of the two stage least squares estimates (M. Intriligator, Econometric Models, Techniques, and Applications (New Jersey: Prentice-Hall, 1978), page 409). 
Table 1

SYSLIN Procedure

Three-Stage Least Squares Estimation

Dependent variable: LY

Sum of

Squares

Model 16

Error 155

C Total 171
42.09

22.46

73.84

Analysis of Variance

\begin{abstract}
Root MSE
Dep Mean

c.V.
\end{abstract}

Mean

Square

$$
2.63
$$

0.14

F Value Prob $>$ F

$18.16 \quad 0.0001$

R-Square

0.65

Adj R-SQ

0.62

\section{Parameter Estimates}

Parameter standard $T$ for $\mathrm{HO}$ :

$\begin{array}{lrrrrr}\text { Variable } & \text { DF } & \text { Estimate } & \begin{array}{c}\text { Error } \\ \text { Parameter }=0\end{array} & \text { Prob>|T } \\ \text { INTERCEP } & 1 & 8.37 & 2.05 & 4.09 & 0.0001 \\ \text { LC } & 1 & 0.28 & 0.16 & 1.74 & 0.0835 \\ \text { LSHPDINT } & 1 & -3.22 & 1.42 & -2.27 & 0.0245 \\ \text { LSHPDOFT } & 1 & -0.10 & 0.05 & -1.86 & 0.0650 \\ \text { DINT } & 1 & 3.02 & 1.59 & 1.90 & 0.0591 \\ \text { LFP } & 1 & -9.97 & 2.30 & -4.33 & 0.0001 \\ \text { LLBICE } & 1 & 0.06 & 0.02 & 2.25 & 0.0260 \\ \text { LCEPT } & 1 & 0.04 & 0.01 & 2.91 & 0.0041 \\ \text { LHP1 } & 1 & 0.37 & 0.11 & 3.25 & 0.0014 \\ \text { LHP2 } & 1 & 0.02 & 0.01 & 2.21 & 0.0289 \\ \text { DRD } & 1 & -2.47 & 0.77 & -3.21 & 0.0016 \\ \text { DRQ } & 1 & -2.32 & 0.77 & -3.00 & 0.0032 \\ \text { DRDQ } & 1 & -2.42 & 0.73 & -3.30 & 0.0012 \\ \text { DRDS } & 1 & -2.20 & 0.81 & -2.70 & 0.0076 \\ \text { DMOB2 } & 1 & 0.07 & 0.07 & 1.02 & 0.3113 \\ \text { DMOB3 } & 1 & 0.23 & 0.12 & 1.90 & 0.0595 \\ \text { DMOB4 } & 1 & 0.35 & 0.15 & 2.25 & 0.0261\end{array}$


Table 2

SYSLIN Procedure

Three-Stage Least Squares Estimation

Dependent variable: LC

$$
\text { Analysis of Variance }
$$

$\begin{array}{lrcccc}\text { Source } & \text { DF } & \begin{array}{c}\text { Sum of } \\ \text { Squares }\end{array} & \begin{array}{l}\text { Mean } \\ \text { Square }\end{array} & \text { F Value } & \text { Prob }>\text { F } \\ \text { Model } & 6 & 26.64 & 4.44 & 35.74 & 0.0001 \\ \text { Error } & 165 & 20.50 & 0.12 & & \\ \text { C Total } 171 & 68.21 & & & \end{array}$

$\begin{array}{llll}\text { Root MSE } & 0.35 & \text { R-Square } & 0.57 \\ \text { Dep Mean } & 9.44 & \text { Adj R-SQ } & 0.55 \\ \text { C.V. } & 3.73 & & \end{array}$

Parameter Estimates

$\begin{array}{lccccc}\text { Variable } & \text { DF } & \begin{array}{c}\text { Parameter } \\ \text { Estimate }\end{array} & \begin{array}{c}\text { Standard } \\ \text { Error }\end{array} & \begin{array}{c}\text { T for HO: } \\ \text { Parameter=0 }\end{array} & \text { Prob>|T| } \\ \text { INTERCEP } & 1 & 0.47 & 0.85 & 0.56 & 0.5762 \\ \text { LY } & 1 & 0.88 & 0.08 & 10.98 & 0.0001 \\ \text { LSHP } & 1 & 0.34 & 0.15 & 2.29 & 0.0232 \\ \text { LPH } & 1 & -0.03 & 0.01 & -2.01 & 0.0461 \\ \text { LNC } & 1 & -0.63 & 0.10 & -6.52 & 0.0001 \\ \text { DFUEL } & 1 & -0.35 & 0.07 & -4.95 & 0.0001 \\ \text { DICE } & 1 & -0.12 & 0.07 & -1.70 & 0.0910\end{array}$




$$
\begin{gathered}
\text { Table } 3 \\
\text { SYsLIN Procedure } \\
\text { ordinary Least Squares Estimation }
\end{gathered}
$$

Model :

Dependent variable: LTC

$$
\text { Analysis of Variance }
$$

$\begin{array}{lrrcrl}\text { Source } & \text { DF } & \begin{array}{r}\text { Sum of } \\ \text { Squares }\end{array} & \begin{array}{l}\text { Mean } \\ \text { Square }\end{array} & \text { F Value } & \text { Prob>F } \\ \text { Model } & 8 & 65.26 & 8.16 & 104.35 & 0.0001 \\ \text { Error } & 159 & 12.43 & 0.08 & & \\ \text { C Total } 167 & 77.69 & & & \\ & & & & \\ \text { Root MSE } & 0.28 & \text { R-Square } & 0.84 \\ \text { Dep Mean } & 11.33 & \text { Adj R-SQ } & 0.83 \\ \text { C.V. } & 2.47 & & & \end{array}$

\section{Parameter Estimates}

$\begin{array}{lrrrrr}\text { Variable } & \text { DF } \begin{array}{r}\text { Parameter } \\ \text { Estimate }\end{array} & \begin{array}{c}\text { Standard } \\ \text { Error }\end{array} & \begin{array}{c}\text { T for HO: } \\ \text { Parameter=0 }\end{array} & \text { Prob>|T| } \\ \text { INTERCEP } & 1 & -3.49 & 1.16 & -3.01 & 0.0030 \\ \text { LYHAT } & 1 & 0.67 & 0.10 & 6.49 & 0.0001 \\ \text { LIP } & 1 & 0.72 & 0.40 & 1.80 & 0.0746 \\ \text { LCHAT } & 1 & 0.30 & 0.08 & 3.86 & 0.0002 \\ \text { LB } & 1 & 1.02 & 0.14 & 7.48 & 0.0001 \\ \text { LAGE } & 1 & -0.13 & 0.03 & -4.58 & 0.0001 \\ \text { LFPDGMA } & 1 & 0.12 & 1.18 & 0.11 & 0.9166 \\ \text { LFPDSA } & 1 & 0.96 & 1.08 & 0.90 & 0.3718 \\ \text { DOO } & 1 & -0.13 & 0.05 & -2.66 & 0.0086\end{array}$

Test: $\mathrm{H}_{0}:$ LIP + LFPDGMA + LFPDSA $=1$ Numerator: 0.011176 DF: 1 F value: 0.1430 Denominator: 0.078174 DF: 159 Prob>F: 0.7059 
Variable INTERCEP

LTC

LFPDGMA

LFPDSA

LSHP

LSHPDINT

ISHPDOFT

LIP

LLBICE

LC

LCHAT

LNC

LY

LYHAT

LB

LAGE

LHP1

LHP2

LCEPT

LPH

DFUEL

DICE

DMOB2

DMOB3

DMOB4

DINT

DRD

DRQ

DRDS

DRDQ

DOO
Table 4

Definition

Variable Definitions
Total cost

Fuel Price in the Gulf of Mexico

Fuel Price in the southern Atlantic

Exvessel Shrimp Price

Inshore Exvessel Shrimp Price

Offshore Exvessel Shrimp Price

Ice Price

Blocks of Ice

Per Crew Member Income

Predicted per Crew Member Income

Number of crew

Annual Level of Harvest

Predicted Annual Level of Harvest; fishing

effort index

Vessel Length in Feet

Vessel Age

Horse Power of the Vessels Power Plant

Horse Power of the Vessels Secondary Engine

Engine Repair Cost Per Trip

Packing and Heading Costs

Dummy Variable for Fuel Cost Deducted from Total Revenue

Dummy Variable for Ice Cost Deducted from Total Revenue

Landed shrimp in two adjacent or non-adjacent states

Landed shrimp in three states

Landed shrimp in four or more states

Dummy Variable for Inshore Trips

Double otter trawl fishing gear

Quad otter trawl fishing gear

Double and single otter trawl fishing gear

Double and quad otter trawl fishing gear

Owner operator 
sectional data used in the analysis. The second stage of the estimation procedure uses the predicted values of landings (LYHAT) and crew income (LCHAT) to estimate the indirect cost function (Table 3) using ordinary least squares.

The landings (LY) equation in Table 1 indicates a positive statistically significant relationship between landings and crew cost (LC). Theoretically, increases in the cost of a factor input in the production process should result in a decline in the level of output. In the shrimp fishery, crew costs are proportionate to total revenue which is a function of landings and prices. Increases in the level of landings or exvessel prices, given a fixed crew share ${ }^{80}$, result in increased crew costs. Increased crew costs imply increases in landings given the fixed crew share. As a result, a positive relationship between crew cost and landings exists.

The inshore (lshpdint) and offshore (lshpdoft) shrimp price variables in Table 1 are negatively related to the

${ }^{80}$ The crew share is the percent of total revenue that the crew of the shrimp fishing vessel receives at the end of a trip. The crew share remains constant during the shrimp fishing season. After the dramatic fuel price increase during the late 1970's and early 1980's, the crew share did change with fuel costs deducted from total revenue before the crew cost is calculated. Inclusion of the percent crew share in the landings and total cost equations results in statistically insignificant estimated coefficients, unstable parameter estimates for the other independent variables, reduced explanatory power of the models, and a poorer overall statistical fit. 
level of landings. Theoretically, output should increase with increases in the level of output prices. The estimated negative relationship occurs because the data set consists of annual landings and value for vessels operating in a fully developed, common property resource. At the beginning of the fishing season, vessels harvest large amounts of small, low value shrimp that have just been recruited into the fishery from the nursery areas. Fewer and fewer shrimp survive to grow into the larger, relatively higher valued shrimp size classes that are harvested as the season progresses. An individual vessel cannot preclude other vessels from harvesting the shrimp until its growth rate equals some internal rate of return because of the common property nature of the resource. As a result, individual vessels land fewer large, high value shrimp than small, low value shrimp. The price per pound used in this analysis is calculated by dividing reported value by reported pounds landed. Vessels that land predominately larger sizes of shrimp have lower annual landings but higher values and as a result a higher average price per pound than vessels that land smaller sizes of shrimp ${ }^{81}$.

${ }^{81}$ Personal communication, walter Keithly, ISU. This explanation of the inverse relationship between exvessel price and annual landings is confirmed by the 1982 shrimp landings file maintained by NMFS. The average annual pounds of shrimp landed by size class for a vessel in the Gulf of Mexico fishery declines as size class increases from greater than 68 count per pound to less than 15 count per pound. Total revenue tends to increase with size class which implies exvessel price compensates for the decline in landings. 
The inshore/offshore vessel operation variable (dint) was included in the model to account for inshore shrimp fishing operations that land large amounts of predominately small, low value shrimp relative to offshore shrimp operations that land smaller amounts of large, high value shrimp. The positive, statistically significant, relatively large in magnitude, estimated coefficient indicates that larger landings of shrimp occur in inshore waters. Although the magnitudes of the estimated inshore and offshore shrimp price coefficients declines with the inclusion of this variable in the model, their negative relationship with landings persists.

Fuel is the major component used by fishing vessels in the production of shrimp. Other studies for various areas of the Gulf of Mexico and southern Atlantic states fisheries and for different time periods have indicated fuel costs can exceed sixty percent of total variable costs ${ }^{82}$. The estimated coefficient for fuel price (lfp) is large in magnitude, statistically significant, and had the theoretically correct sign. Small increases in the

\footnotetext{
${ }^{82}$ W.L. Griffin, R.D. Lacewell, and W. Hayenga, "Estimated Costs and Returns and Financial Analysis: Gulf of Mexico Shrimp Vessels," Marine Fisheries Review $36(12)$ (1974): 1-4 for Texas, D.S. Liao, "An Economic Analysis of Mobility of Shrimp Vessels in the South Atlantic states," South Carolina Marine Research Center Technical Report No. 35, 1979 for North Carolina, and F. Prochaska, J. Cato, and J. Taylor, "Economic Returns in Operating Atlantic Coast Charter and Party Boats." University of Florida, Sea-Grant, MAP-28, Aug., 1982.
} 
exogenously determined fuel price result in large declines in shrimp landings.

Ice (1lbice) is used to chill the harvested shrimp to maintain its freshness until it can be unloaded at the processors/dealers dock. Increases in the level of landings should have resulted in increased demand for ice and increases in ice price should have reduced demand for ice by fishermen. Information provided by shrimp fishermen suggests that the amount of ice used during a shrimp fishing season is determined by the size and carrying capacity of the vessel, not the amount of shrimp landed. Ice melts at a constant rate and must be replaced at the end of a trip whether or not shrimp are harvested. The storage of ice on board the vessel reduces the carrying capacity available for shrimp. Since the level of landings for the next trip is relatively uncertain, the amount of ice remains relatively fixed per trip. As a result, the value of the coefficient in Table 1, while statistically significant, is close to zero implying a low marginal productivity of the ice input in the production of shrimp.

The coefficient for the cost of engine repair on a per trip basis (lcept) is positive and statistically significant in Table 1. This counter-intuitive result occurs because the cost and returns survey neglects to collect information on the number of times engine repair and maintenance is required for a particular vessel. Since engine repair and 
maintenance are a function of engine operation hours, trips are used as a proxy to approximate a unit cost. However, trips are not uniform for vessels in the Gulf of Mexico shrimp fishery. Vessels that made fewer trips of longer duration tend to have higher landings of shrimp than vessels that made more trips of shorter duration. As a result, vessels that had the same total annual days fished and engine repair and maintenance cost but fewer trips have a higher cost per trip and landings than vessels that made more trips for less shrimp landings. ${ }^{83}$

The estimated coefficients for the horsepower of the primary (lhpl) and auxiliary (lhp2) vessel engines were positive in sign and statistically significant in Table 1. In addition, the relative magnitude of the primary engine coefficient is much greater than the coefficient for the secondary engine. Since the primary engine powers the vessel, a higher horsepower allows it to trawl longer and land more shrimp than a vessel with lower horsepower ${ }^{84}$. The secondary engine usually provides electrical power to operate vessel lights and equipment such as winches.

\footnotetext{
${ }^{83}$ Engine repair and maintenance cost per fishing day was also used as an explanatory variable, but was not statistically significant and had the incorrect sign.

${ }^{84}$ Vessels trawl for shrimp at a speed of approximately 4 knots. As the trawl fills with shrimp and bycatch, the engine rpm's increase to maintain the same trawling speed. Eventually, the rpm's rise to a point where the fisherman has to back off. This point occurs sooner for a vessel of the same size with lower horsepower engines than with higher horsepower engines.
} 
Increases in this horsepower have less effect on total fishing effort of the vessel and on vessel landings.

The type of gear the vessel uses in the harvest of shrimp has a significant impact on the level of landings. Vessels tend to move inshore and offshore in response to fishing conditions and adapt their gear to suit the bottom conditions. Three types of gear were used in the shrimp fishery; single trawl (represented by the base case), double trawl (drd), and the quad trawl (drq). Some vessels used two types of gear in a single season; double and single trawls (drds) and double and quad trawls (drdq). Single trawls are used primarily in inshore and near shore waters where most shrimp are harvested. Double and single trawl vessels operate inshore and offshore at different times of the fishing season and have slightly lower total pounds landed than the base case. Quad trawls are primarily an offshore gear and have slightly smaller landings of shrimp, but because their trawls have 4 nets they land more shrimp than the double trawl that operates offshore as well but uses only 2 nets. ${ }^{85}$ Vessels that use both double and quad trawls had landings lower than vessels that used only quad trawls and higher than vessels that only used double trawls. The last set of variables represent the mobility of the vessel, i.e. the number of states in which it reported

${ }^{85}$ Since 1982 , the quad trawl has tended to dominate the offshore shrimp fishery. 
landing shrimp. More mobile vessels were expected to access a greater number of fishing grounds and land more shrimp than less mobile vessels. Vessels that reported landing shrimp in 4 or more states (dmob4) had higher landings than vessels that landed in 3 states (dmob3), in 2 states (dmob2), or in only one state (the base case). Although the estimated coefficient for dmob2 was statistically insignificant, these results do tend to support the contention that more mobile vessels harvest more shrimp than less mobile vessels.

Table 2 provides the three-stage least squares parameter estimates for the crew income (lc) model that is determined simultaneously with landings (ly) in Table 1. Crew income is proportionate to total revenue (exvessel shrimp price (lshp) times the level of landings (ly)) after deductions are made for fuel (dfuel) and ice (dice) purchased for the fishing trip. Packing and heading charges (lph) are included in the model since these are deducted from the exvessel shrimp price on a per pound basis before the crew share is applied to total revenue to calculate income. Size of crew (lnc) is included to determine if larger crews that received more total income received less on a per crew member basis.

The estimated coefficients in Table 2 are statistically significant and had the appropriate sign. Crew income increases with landings and the price of shrimp. That is, 
crew income increases with total revenue. Also, crew income declines when deductions are made for fuel and ice costs and packing and heading charges for each trip. Lastly, as the size of the crew increases, the income of the crew declines. Table 3 presents the ordinary least squares parameter estimates for the total cost (Itc) equation. Overall, the equation explains $83 \%$ of the variation in total costs of operating a vessel in the southeastern region (adjusted $r$ squared of 0.832 ). The model, significant at the $\alpha=0.0001$ level with 159 error degrees of freedom, has a good statistical fit. All but two of the estimated coefficients are statistically significant at the $\alpha=0.10$ level of confidence and these are retained in the model because their sign and magnitudes are correct and they are theoretically important variables.

The predicted values of landings (lyhat) and crew income (lchat) from the simultaneous equation model are used in the estimation of total cost. The estimated coefficients for both variables are positive and statistically significant. The unit cost of ice (lip) coefficient is positive and statistically significant. The coefficients for fuel price in the Gulf of Mexico (lfpdgma) and for the south Atlantic (lfpdsa) are statistically insignificant, but had the correct sign and magnitudes (between 0 and 1 ). These two multiplicative dummy variables are included in the model to account for differences in total costs due to the 
different operating behaviors of vessels in the Gulf of Mexico and in the south Atlantic. Had these coefficients been statistically significant, they would indicate that vessel operating costs in the south Atlantic are more sensitive to increases in fuel prices than vessels in the Gulf of Mexico. These two variables are left in the model because they are important theoretical variables.

of the remaining variables in the equation, total costs increase with vessel length (1b), decline with the age of the vessel (lage), and are lower for owner operated vessels (doo) than for fleet vessels or vessels operating under partnerships, nonowner operators, corporations, etc. As vessel length increases, the construction costs and the interest payments on the construction loan increase, the cost of insurance increases, the maintenance and repair costs increase, and the fuel cost increases. As the vessel ages, the costs of construction and interest payments are lower than for a newer vessel as are the interest rates on the construction loans. Owner operated vessels may have lower costs because the rents accrue to the operator of the vessel. Non-owner operated vessels may have higher costs because the operator of the vessel could have different objectives. Non-owner operated vessels that use a captain's share system, for example, may have revenue maximization as an operating objective function. 
The estimated indirect total cost function conforms to the six conditions required by duality theory. A test of the null hypothesis that the coefficients on fuel and ice prices summed to one was not rejected at the $\alpha=0.10$ confidence level indicating that the estimated total cost equation is homogeneous of the first degree as required by duality theory. This implies that the derived demand equations would be homogeneous of degree zero. ${ }^{86}$ Although the estimation of the firm supply equation in part one of the procedure resulted in some counter intuitive results, the estimation of the indirect total cost function in part two of the procedure did conform to duality theory.

\section{Conclusions}

The estimated indirect total cost function does conform to the six conditions required by duality theory. Total costs are positive for positive prices and output levels; condition (1). Total costs are greater for higher input prices than for lower input prices; condition (2). The indirect total cost function is homogeneous of degree one in all prices; condition (3). The derived demand functions are homogeneous of degree zero in all prices; condition (4). The indirect cost function is weakly concave in all prices; condition (5). Lastly, total cost is equal to output times

${ }^{86} \mathrm{~A} F$ test of the null hypothesis that one minus the ice price coefficient plus the fuel price coefficients equaled zero failed to be rejected at the $\alpha=0.10$ level. 
average variable cost given that the production function is homogeneous of degree one; condition (6).

The indirect. total cost model indicates that highly mobile vessels land more shrimp than vessels that are less mobile. Since higher landings indicate increased total costs, more mobile vessels also have higher operating costs. Owner operated vessels are found to have lower total costs than non-owner operated vessels which implies that non-owner operated vessels have different objectives in harvesting shrimp such as revenue maximization or to act as tax shelters. Lastly, quad nets that have come to dominate the offshore shrimp fishery since 1982 have higher levels of landings than the double nets that dominated the offshore fishery before 1982 .

Cost estimates for vessels operating in the shrimp fishery can be determined using this cost model, the landings data in the shrimp landings files, and the vessel operating units files maintained by the National Marine Fisheries Service. The effect on vessel profitability of management regulations affecting the southeastern region shrimp fisheries can be determined through their effect on vessel landings. Changes in market conditions on vessel profitability can be determined through the fuel and ice cost coefficients. Shifts in the structure of the fleet on vessel costs can be determined through the age and length variables. Most importantly, cost estimates exist from 
which the probabilities of vessel entry and exit behavior in the shrimp fishery can be estimated. 


\section{Literature cited}

Anonymous. "Revenues, Costs, and Returns from Vessel Operations in Major U.S. fisheries." U.S. Dep. Commer., NOAA, NMFS, NTIS PB-265275, Wash., D.C., Feb., 1977.

Beattie, B.R. and C.R. Taylor. The Economics of production. New York: John Wiley \& Sons, 1985.

Blomo, V. and W.L. Griffin: "Cost and Returns Data Florida Based Gulf of Mexico Shrimp Trawlers, 1977." Texas A\&M University Sea Grant Report TAMU-SG-79-604, 1978.

Crutchfield, S. "Personal Computer simulation of Two New England Trawl Fisheries." Fisheries Research 4 (2) (1986): 157-165.

Duffy, J., Jr. and D.B. Johnson. "Study of Costs and Earnings of Bay Shrimp Fishermen in Louisiana." SEFC, NMFS. La. State Univ., Baton Rouge, 1977.

Gordon, H.S. "The Economic Theory of a common Property Resource: The Fishery." Journal of Political

Economy 62 (1954): 124-142.

Griffin, W.L. "Fleetsim: A General Fleet Level Policy Simulation Model." Texas A\&M University, 1988.

Griffin, W.L., R.D. Lacewell, and W. Hayenga . "Estimated Costs and Returns and Financial Analysis: Gulf of Mexico Shrimp Vessels." Marine Fisheries Review 36(12) (1974): 1-4.

Griffin, W.L. and J.P. Nichols. "An Analysis of Increasing Costs to Gulf of Mexico Shrimp Vessel Owners, 1971-75." Marine Fisheries Review 38(3) $(1976): 8-12$.

Griffin, W.L., J.P. Nichols, and J.B. Smith. "Economic Analysis of Returns to Gulf of Mexico Shrimp Vessel Owners for the Period 1971-75." Texas A\&M University Staff Paper DIR 75-1, SP-4, 1975.

Griffin, W.L., N.J. Wardlaw, and J.P. Nichols. "Cost and Return Analysis by Selected Vessel Characteristics: Gulf of Mexico Shrimp Fishery, 1971-75." Texas Agricultural Experiment station. Texas A\&M University, Report MP-1253C, 1976. 
Gulland, J.A. and B.J. Rothschild. Penaeid Shrimps Their Biology and Management. Norwich, Norfolk, Great Britain: Fishing News Books Limited, 1984.

Intriligator, M. Econometric Models, Techniques, and Applications. New Jersey: Prentice-Hall, 1978.

Johansen, L. Production Functions. Amsterdam: NorthHolland Publishing Co., 1972.

Liao, D.S. "An Economic Analysis of Mobility of Shrimp Vessels in the South Atlantic States." South Carolina Marine Research Center Technical Report No. $35,1979$.

Kurkle, P. "Northeast Region Financial Information System." Draft Working Paper, NMFS, NERO, 1986.

Mayor, T.H. "Some Theoretical Difficulties in the Estimation of the Elasticity of Substitution from Cross-Sectional Data." Western Economic Journal 7 (1969) : 153-163.

Montegut, R.S. "Planning to Buy a Shrimp Boat? Some Things to Consider First." La. State Univ. Sea Grant Publ. LSU-TL-79-005, 1979.

Nerlove, M. "Recent Empirical studies of the CES and Related Production Functions." in The Theory and Empirical Analysis of Production, National Bureau of Economic Research, ed. M. Brown. New York: Columbia University Press, 1967.

Nichols, S. "Stock Assessments for Brown, White, and Pink Shrimp in the U.S. Gulf of Mexico, 1960 1985." USDOC, NOAA, NMFS, Miami Laboratory, 1986.

Prochaska, F., J. Cato, and J. Taylor. "Economic Returns in Operating Atlantic coast Charter and Party Boats." University of Florida, Sea Grant, MAP-28, Aug., 1982.

Roberts, K.J. and M.E. Sass. "Financial Aspects of Louisiana Shrimp Vessels, 1978." La. State Univ. Sea Grant Rep. LSU-TL-79-007, 1979.

Swartz, A.M. and C.M. Adams. "The Economics of Rockport Bay Texas Bay Shrimping Vessels." Rep. DIR 79-1, SP-6, Department Agricultural Economics, Texas A\&M University, 1979. 
Tettey, E., c. Pardy, and W. Griffin. "Economic Analysis of Investment Alternatives for the Gulf of Mexico Shrimp Vessels." Draft Report, Texas A\&M University, 1982.

Ward; J. "A Synthesis of Cost and Revenue Surveys for Gulf of Mexico Shrimp Vessels." Marine Fisheries Review 50(1) (1988): 47-52.

Warren, J.P. and W.L. Griffin. "Cost and Return Trends for Gulf of Mexico Shrimp Vessels." Staff Paper Series DIR 78-1, SP-4, Texas A\&M University, 1978.

Warren, J.P., W.L. Griffin, and R.D. Lacewell. "Applying an Index of Fishing Effort to Estimated 1971 Costs and Returns for Gulf of Mexico Shrimp Vessels." Department Agricultural Economics, Texas A\&M University, Sea Grant Report TAMU-SG-74217, 1974 . 


\section{Appendix D \\ statistical Results of the Multinomial Logit Procedure Introduction}

This appendix reports the statistical results of the multinomial logit model cited in the manuscript titled "Modelling Vessel Mobility: The Gulf of Mexico Shrimp Fleet." Included in this appendix are examples of model specifications that have been rejected and examples of hypothesis tests that have been evaluated during the analysis of the data set. The first set of results are for the model reported in Table 1 of the manuscript. The second set of results are for a model specification that uses class levels. The third set of results tests the null hypothesis that the coefficients for the length and gross tonnage variables are equal to zero. The fourth set of results tests the hypothesis that the negative of the exvessel price coefficient is equal to. the value of the stock constant harvesting cost coefficient. The fifth set of results tests the hypothesis that the negative of the exvessel price coefficient is equal to the value of the stock constant harvesting cost coefficient when vessel length and gross tonnage are excluded from the model specification. The sixth set of results presents an alternative model specification that does not employ a stock constant unit harvesting cost as an independent variable. In the seventh set of results, the specification is altered to estimate the model using rent as the independent variable rather than the 
ratio of exvessel price and stock constant harvesting cost. All model results are estimated using the proc probit procedure with the logistic distribution option that is contained in the SAS computer software for the personal computer (Ver, 6). 
statistical Results 1: Final Parameter Estimates

The results of the statistical analysis that are reported in Table 1 of the manuscript are presented in this section of the appendix. This model specification conforms to economic theory, the biology of the shrimp resource, and provides the best fit to the sample data as indicated by the value of the log likelihood ratio. Initially, the output from the logit procedure is calculated using class level variables represented by PROB for the probability of entering, remaining in, or exiting the fishery, GEN for whether the vessel is a generalist vessel or a specialist vessel, BGH for whether it has been recently purchased, and the variable DMOB2 to represent the mobility of the vessel. The continuous independent variables include exvessel price, the stock constant harvesting cost, vessel length, gross tonnage, and fleet size. One multiplicative dummy variable is used to represent the post 1967 fleet size.

When class levels are used in the analysis, however, the interpretation of the estimated coefficients for the qualitative variables is misleading. The results below use qualitative independent variables to represent generalist or specialist vessel operations, when a vessel is bought or sold, and the level of vessel mobility in the estimation procedure rather than class levels. This approach differs from the class level specification only in the sign of the qualitative variable coefficients and a slight shift in the 
intercept term. The value of the log likelihood function did not change from that in found in the class level specifications.

Multicollinearity appears to exist for two pairs of parameter estimates. Vessel length (LLEN) and vessel gross tonnage (LGTON) are strongly correlated $(r=-0.97)$. During the time period of this analysis, medium size vessels have been replacing larger and smaller class vessels in the shrimp fishery because of their relative advantage in operating in near and offshore waters. Also, gross tonnage per vessel has been increasing, allowing the vessel to operate away from port longer per trip. These two trends over time result in the negative sign for the correlation coefficient. One solution to this biased parameter problem is to reestimate the model using a ratio of vessel length to gross tonnage as the independent variable. However, since multicollinearity does not affect the predicted value of the dependent variable such a remedy is not required here as the point of the analysis is to predict the probability of entry, remain in, or exit from the shrimp fishing fleet. The second pair of parameters suffering form multicollinearity are fleet size (FLSZ) and the intercept term for the case of entry into the shrimp fishery from outside the southeastern region or the new construction of a vessel $(r=-0.99)$. The reason for this result is difficult to determine since the intercept variables for the other 
cases of entry, remain in, or exit from the fishery were not correlated strongly with the fleet size variable. Again, since the analysis is designed to predict the probabilities of an event, correcting this multicollinearity problem is not required. 


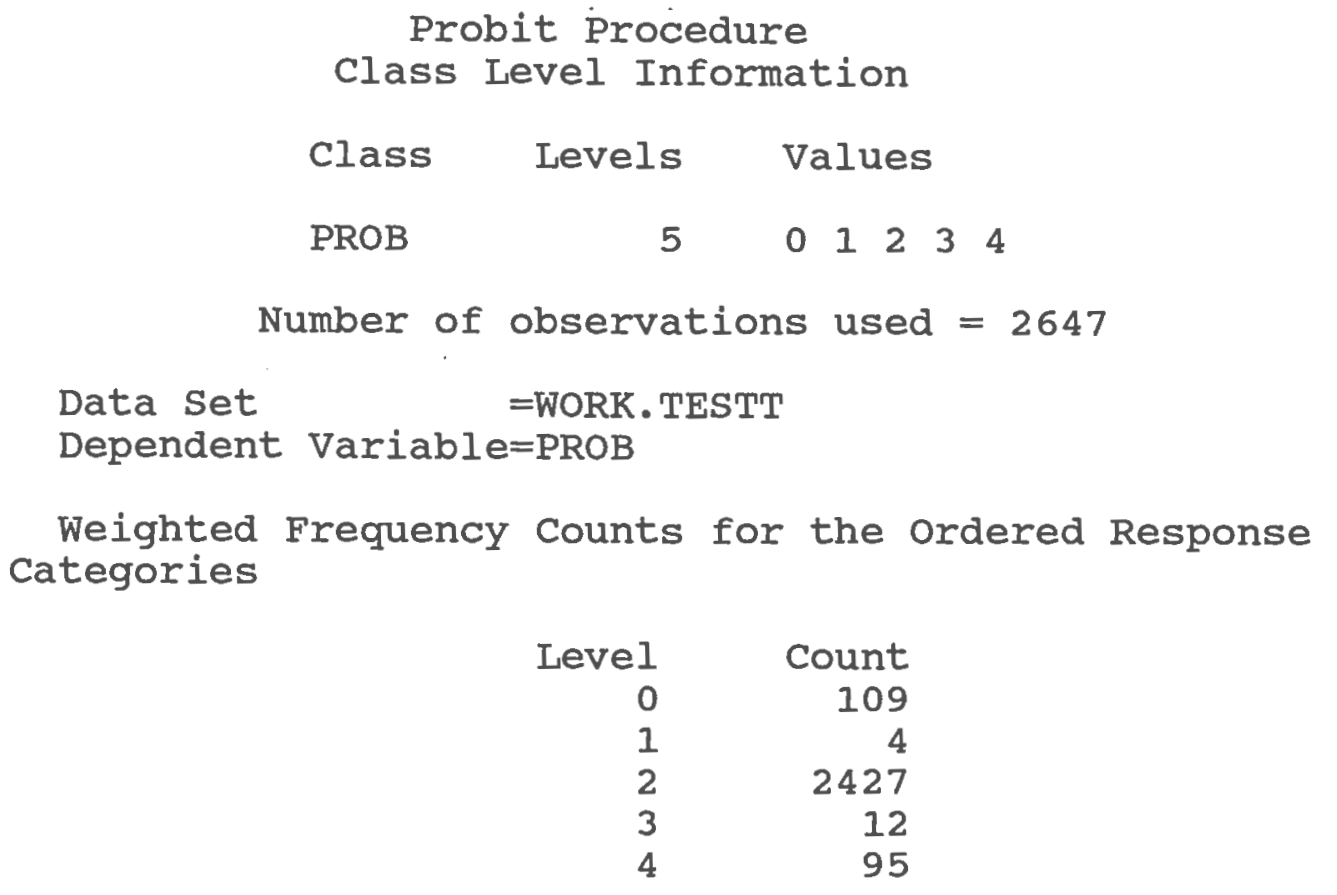

Observations with Missing Values= 4

Log Likelihood for LOGISTIC -821.5801996

Goodness-of-Fit Tests

Statistic
Pearson Chi-Square
L.R. Chi-square

Response Levels: 5 Number of Covariate Values: 2647

NOTE: Since the chi-square is small $(p>0.1000)$, fiducial limits will be calculated using a $t$ value of 1.96 . 
Probit Procedure

Variable DF Estimate std Err Chisquare Pr>Chi Label/Value

\begin{tabular}{|c|c|c|c|c|c|}
\hline INTERCPT & 44.43 & 20.56 & 4.67 & 0.0307 & Intercept. 0 \\
\hline LPLB & 2.18 & 0.22 & 99.57 & 0.0001 & $\begin{array}{l}\text { Price Per } \\
\text { Pound }\end{array}$ \\
\hline LCLBSC & $1-2.03$ & 0.34 & 35.64 & 0.0001 & $\begin{array}{l}\text { Stock Constant } \\
\text { Harvest Cost } \\
\text { Per Pound }\end{array}$ \\
\hline LFLSZ & $1-5.96$ & 2.53 & 5.56 & 0.0184 & Fleet Size \\
\hline DYRFLSZ & 10.12 & 0.04 & 6.76 & 0.0093 & $\begin{array}{l}\text { Post- } 67 \text { Fleet } \\
\text { Size }\end{array}$ \\
\hline LLEN & $1-1.05$ & 0.20 & 28.38 & 0.0001 & Vessel Length \\
\hline LGTON & 10.67 & 0.19 & 12.93 & 0.0003 & $\begin{array}{l}\text { Vessel Gross } \\
\text { Tonnage }\end{array}$ \\
\hline GEN & $1-0.11$ & 0.34 & 0.10 & 0.7529 & $\begin{array}{l}\text { Generalist } \\
\text { Vessel }\end{array}$ \\
\hline I.ABUN & 12.22 & 0.41 & 29.38 & 0.0001 & $\begin{array}{l}\text { Shrimp } \\
\text { Abundance }\end{array}$ \\
\hline BGH & $1-1.10$ & $0: 33$ & 11.04 & 0.0009 & $\begin{array}{l}\text { Vessel } \\
\text { Bought/Sold }\end{array}$ \\
\hline DMOB2 & $1-0.31$ & 0.16 & 3.57 & 0.0587 & $\begin{array}{l}\text { Vessel } \\
\text { Mobility }\end{array}$ \\
\hline INTER. 2 & 10.05 & 0.02 & & & Intercept. 1 \\
\hline INTER. 3 & 17.43 & 0.20 & & & Intercept. 2 \\
\hline INTER. 4 & 17.56 & 0.20 & & & Intercept. 3 \\
\hline
\end{tabular}


Estimated Covariance Matrix

INTERCPT

LPLB

LCLBSC

LFLSZ

INTERCPT

LPLB

LCLBSC

LFLSZ

DYRFLSZ

LLEN

LGTON

GEN

LABUN

BGH

DMOB2

INTER. 2

INTER. 3

INTER. 4

INTERCPT

LPLB

LCLBSC

LFLSZ

DYRFLSZ

LLEN

LGTON

GEN

LABUN

BGH

DMOB2

INTER. 2

INTER. 3

INTER . 4

INTERCPT

LPLB

LCLBSC

LFLSZ

DYRFLSZ

LLEN

LGTON

GEN

LABUN

BGH

DMOB2

INTER . 2

INTER. 3

INTER . 4
422.86

$-0.00$

3.05

$-51.98$

0.63

1.15

$-1.31$

0.00

$-4.43$

0.14

0.11

0.00

0.60

0.59

DYRFLSZ

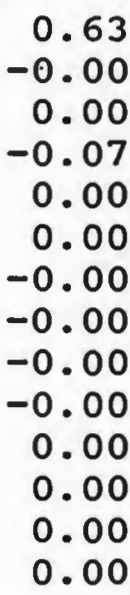

LABBUN

$\begin{array}{rr}-4.43 & 0.14 \\ 0.06 & -0.00 \\ -0.12 & 0.00 \\ 0.52 & -0.01 \\ -0.00 & -0.00 \\ -0.03 & 0.00 \\ 0.02 & -0.00 \\ 0.00 & 0.00 \\ 0.16 & -0.00 \\ -0.00 & 0.10 \\ -0.00 & 0.00 \\ -0.00 & -0.00 \\ 0.02 & -0.01 \\ 0.02 & -0.01\end{array}$

$-0.00$

0.04

$-0.05$

$-0.00$

$-0.00$

$-0.00$

0.00

0.00

0.06

$-0.00$

$-0.00$

0.00

0.02

0.02

LLEN

$$
\begin{array}{r}
1.15 \\
-0.00 \\
0.03 \\
-0.14 \\
0.00 \\
0.03 \\
-0.03 \\
-0.01 \\
-0.03 \\
0.00 \\
0.00 \\
-0.00 \\
-0.00 \\
-0.00
\end{array}
$$

BGH

$-1.31$

0.00

$-0.02$

0.16

$-0.00$

$-0.03$

0.03

0.01

0.02

$-0.00$

$-0.00$

0.00

0.00

0.00

DMOB2

0.11

$-0.00$

0.00

$-0.01$

0.00

0.00

$-0.00$

0.00

$-0.00$

0.00

0.02

$-0.00$

$-0.00$

$-0.00$
-51.98
-0.00
-0.36
6.39
-0.07
-0.14
0.16
-0.00
0.52
-0.01
-0.01
-0.00
-0.07
-0.07

GEN

0.00

0.00

$-0.00$

$-0.00$

$-0.00$

$-0.01$

0.01

0.11

0.00

0.00

0.00

$-0.00$

$-0.00$

$-0.00$

INTER. 2

0.00

0.00

0.00

$-0.00$

0.00

$-0.00$

0.00

$-0.00$

$-0.00$

$-0.00$

$-0.00$

0.00

0.00

0.00 
Estimated Covariance Matrix

INTER. 3

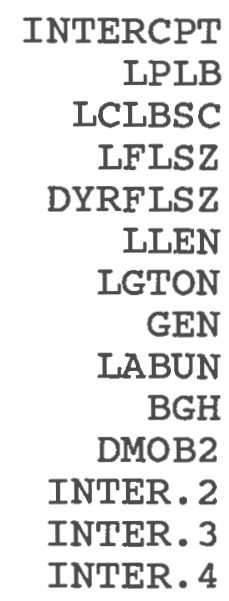

$$
\begin{array}{r}
0.60 \\
0.02 \\
-0.01 \\
-0.07 \\
0.00 \\
-0.00 \\
0.00 \\
-0.00 \\
0.02 \\
-0.01 \\
-0.00 \\
0.00 \\
0.04 \\
0.04
\end{array}
$$

INTER . 4

$$
\begin{array}{r}
0.59 \\
0.02 \\
-0.02 \\
-0.07 \\
0.00 \\
-0.00 \\
0.00 \\
-0.00 \\
0.02 \\
-0.01 \\
-0.00 \\
0.00 \\
0.04 \\
0.04
\end{array}
$$

Estimated Correlation Matrix

INTERCPT

$$
\begin{array}{r}
\text { INTERCPT } \\
\text { LPLB } \\
\text { LCLBSC } \\
\text { LFLSZ } \\
\text { DYRFLSZ } \\
\text { LLEN } \\
\text { LGTON } \\
\text { GEN } \\
\text { LABUN } \\
\text { BGH } \\
\text { DMOB2 } \\
\text { INTER.2 } \\
\text { INTER. } 3 \\
\text { INTER.4 }
\end{array}
$$

$$
\begin{array}{r}
1.00 \\
-0.00 \\
0.43 \\
-0.99 \\
0.69 \\
0.28 \\
-0.34 \\
0.00 \\
-0.52 \\
0.02 \\
0.03 \\
0.00 \\
0.14 \\
0.14
\end{array}
$$

LPLB

$-0.00$

1.00

$-0.78$

$-0.01$

$-0.01$

$-0.15$

0.12

0.07

0.74

$-0.06$

$-0.05$

0.00

0.53

0.53
LCLBSC

$$
\begin{array}{r}
0.43 \\
-0.78 \\
1.00 \\
-0.43 \\
0.26 \\
0.46 \\
-0.44 \\
-0.06 \\
-0.91 \\
0.04 \\
0.06 \\
0.00 \\
-0.29 \\
-0.28
\end{array}
$$

LFLSZ

$-0.99$

$-0.01$

$-0.43$

1.00

$-0.70$

$-0.28$

0.34

$-0.00$

0.51

$-0.02$

$-0.03$

$-0.00$

$-0.15$

$-0.15$ 
Estimated Correlation Matrix

DYRFLSZ

INTERCPT
LPLB
LCLBSC
LFLSZ
DYRFLSZ
LLEN
LGTON
GEN
LABUN
BGH
DMOB2
INTER. 2
INTER. 3
INTER. 4

INTERCPT

LPLB

LCLBSC

LFLSZ

DYRFLSZ

LLEN

LGTON

GEN

LABUN

BGH

DMOB2

INTER . 2

INTER. 3

INTER. 4
LLEN

0.69

$-0.01$

0.26

$-0.70$

1.00

0.19

$-0.24$

$-0.03$

$-0.32$

$-0.00$

0.02

0.00

0.17

0.17

LABUN

$-0.52$

0.74

$-0.91$

0.51

$-0.32$

$-0.40$

0.39

0.05

1.00

$-0.03$

$-0.06$

$-0.00$

0.26

0.25
0.28

$-0.15$

0.46

$-0.28$

0.19

1.00

$-0.97$

$-0.18$

$-0.40$

0.04

0.13

$-0.00$

$-0.17$

$-0.17$

BGH

0.02

$-0.06$

0.04

$-0.02$

$-0.00$

0.04

$-0.03$

0.05

$-0.03$

1.00

0.04

$-0.00$

$-0.15$

$-0.15$
LGTON

GEN

$-0.34$

0.12

$-0.44$

0.34

$-0.24$

$-0.97$

1.00

0.20

0.39

$-0.03$

$-0.14$

0.00

0.14

0.14

DMOB2

0.03

$-0.05$

0.06

$-0.03$

0.02

0.13

$-0.14$

0.02

$-0.06$

0.04

1.00

$-0.00$

$-0.10$

$-0.10$
0.00

0.07

$-0.06$

$-0.00$

$-0.03$

$-0.18$

0.20

1.00

0.05

0.05

0.02

$-0.00$

$-0.00$

$-0.00$

INTER . 2

$$
\begin{array}{r}
0.00 \\
0.00 \\
0.00 \\
-0.00 \\
0.00 \\
-0.00 \\
0.00 \\
-0.00 \\
-0.00 \\
-0.00 \\
-0.00 \\
1.00 \\
0.10 \\
0.10
\end{array}
$$


Estimated Correlation Matrix

INTER. 3

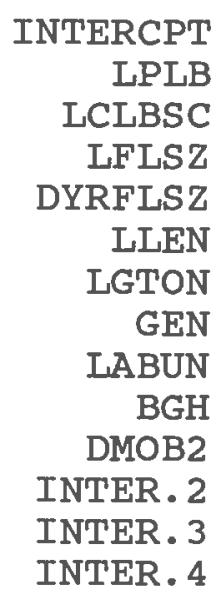

0.53

$-0.29$

$-0.15$

0.17

$-0.17$

0.14

$-0.00$

0.26

$-0.15$

$-0.10$

0.10

1.00

0.98
0.14
INTER . 4

0.14

0.53

$-0.28$

$-0.15$

0.17

$-0.17$

0.14

$-0.00$

0.25

$-0.15$

$-0.10$

0.10

0.98

1.00 
Plot of Fitted Probabilities Plot of PHAT*XBETA. Symbol used is 'P' .

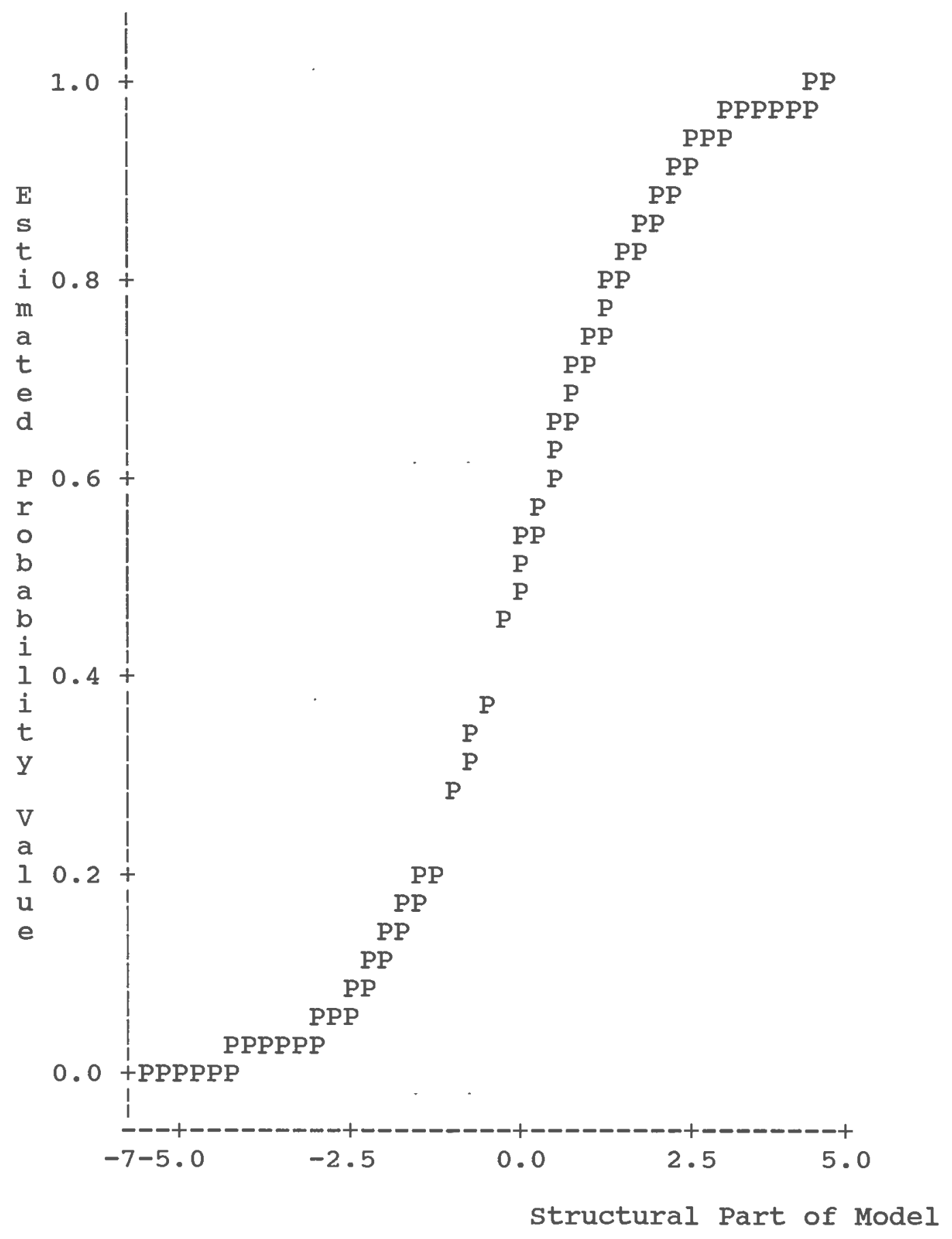

NOTE: 16 obs had missing values. 10495 obs hidden. 


\section{Statistical Results 2: Class Level Model Parameter Estimates}

The output from the logit procedure is calculated using class variables for the probability of entering, remaining in, or exiting the fishery, represented by the variable PROB, whether the vessel is a generalist vessel or a specialist vessel using the variable GEN, whether it has been recently, purchased using the variable $\mathrm{BGH}$, and the mobility of the vessel as represented by the variable DMOB2. The continuous independent variables include exvessel price, the stock constant harvesting cost, vessel length, gross tonnage, and fleet size. One multiplicative dummy variable is used to represent post 1967 fleet size. This approach generates the results presented below. 
Probit Procedure

Class Level Information

\begin{tabular}{|c|c|c|}
\hline Class & Levels & Values \\
\hline PROB & 5 & $\begin{array}{llll}0 & 1 & 2 & 3\end{array}$ \\
\hline GEN & 2 & 01 \\
\hline BGH & 2 & 01 \\
\hline DMOB2 & 2 & 01 \\
\hline
\end{tabular}

Number of observations used $=2647$

Data set $=$ WORK.TESTT

Dependent Variable $=$ PROB

Weighted Frequency Counts for the ordered Response Categories

$\begin{array}{rr}\text { Level } & \text { Count } \\ 0 & 109 \\ 1 & 4 \\ 2 & 2427 \\ 3 & 12 \\ 4 & 95\end{array}$

Observations with Missing Values $=4$

Log Likelihood for LOGISTIC -821.5801996

Goodness-of-Fit Tests

\begin{tabular}{|c|c|c|c|c|}
\hline Statist & & Value & $\mathrm{DF}$ & Prob $>$ Chi-Sq \\
\hline & & 83 & 105 & \\
\hline L.R. & $\mathrm{Ch}$ & 1643.1604 & 10574 & 1.0000 \\
\hline
\end{tabular}

Response Levels: 5 Number of Covariate Values: 2647

NOTE: Since the chi-square is small ( $p>0.1000)$, fiducial limits will be calculated using a $t$ value of 1.96 . 
Probit Procedure

\begin{tabular}{|c|c|c|c|c|c|c|}
\hline $\begin{array}{l}\text { Variable } \\
\text { INTERCPT }\end{array}$ & $\begin{array}{r}\mathrm{DF} \\
1\end{array}$ & $\begin{array}{l}\text { Estimate } \\
42.91\end{array}$ & $\begin{array}{l}\text { Std Err } \\
20.58\end{array}$ & $\begin{array}{c}\text { Chisquare } \\
4.35\end{array}$ & $\begin{array}{l}\mathrm{Pr}>\mathrm{Chi} \\
0.0371\end{array}$ & $\begin{array}{l}\text { i Label/Value } \\
1 \text { Intercept }\end{array}$ \\
\hline LPLB & 1 & 2.18 & 0.22 & 99.57 & 0.0001 & Price Per Pound \\
\hline LCLBSC & 1 & -2.03 & 0.34 & 35.64 & 0.0001 & $\begin{array}{l}1 \text { stock Constant } \\
\text { Harvest Cost Per } \\
\text { Pound }\end{array}$ \\
\hline LFLSZ & 1 & -5.96 & 2.53 & 5.56 & 0.0184 & 4 Fleet Size \\
\hline DYRFLSZ & 1 & 0.12 & 0.04 & 6.76 & 0.0093 & $\begin{array}{l}3 \text { Post-67 Fleet } \\
\text { Size }\end{array}$ \\
\hline LLEN & 1 & -1.05 & 0.20 & 28.38 & 0.0001 & 1 Vessel Length \\
\hline LGTON & 1 & 0.67 & 0.19 & 12.93 & 0.0003 & $\begin{array}{l}3 \text { Vessel Gross } \\
\text { Tonnage }\end{array}$ \\
\hline GEN & 1 & 0.11 & 0.34 & 0.10 & 0.7529 & $\begin{array}{l}\text { Generalist } \\
\text { Vessel }\end{array}$ \\
\hline L.ABUN & 1 & 2.22 & 0.41 & 29.38 & $0.0001 \mathrm{~s}$ & Shrimp Abundance \\
\hline $\mathrm{BGH}$ & 1 & 1.10 & 0.33 & 11.04 & 0.0009 & $\begin{array}{l}\text { Vessel } \\
\text { Bought/Sold }\end{array}$ \\
\hline DMOB2 & 1 & 0.31 & 0.16 & 3.57 & 0.0587 & Vessel Mobility \\
\hline INTER. 2 & 1 & 0.05 & 0.02 & & & Intercept. 1 \\
\hline INTER. 3 & 1 & 7.43 & 0.20 & & & Intercept. 2 \\
\hline INTER . 4 & 1 & 7.56 & 0.20 & & & Intercept. 3 \\
\hline
\end{tabular}


Estimated Covariance Matrix

\section{INTERCPT \\ LPLB \\ LCLBSC \\ LFLSZ \\ DYRFLSZ \\ LLEN \\ LGTON \\ GEN . 1 \\ LABUN \\ BGH. 1 \\ DMOB2 . 1 \\ INTER . 2 \\ INTER. 3 \\ INTER. 4}

\section{INTERCPT \\ LPLB \\ LCLBSC \\ LFLSZ \\ DYRFLSZ \\ LLEN \\ LGTON \\ GEN . 1 \\ IABUN \\ BGH . 1 \\ DMOB2 . 1 \\ INTER. 2 \\ INTER. 3 \\ INTER . 4}

\section{INTERCPT \\ LPLB \\ LCLBSC \\ LFLSZ \\ DYRFLSZ \\ LLEN \\ LGTON \\ GEN . 1 \\ LABUN \\ BGH. 1 \\ DMOB2 . 1 \\ INTER . 2 \\ INTER. 3 \\ INTER . 4}

$$
\begin{array}{r}
\text { INTERCPT } \\
423.64 \\
-0.00 \\
3.05 \\
-52.01 \\
0.63 \\
1.14 \\
-1.30 \\
-0.12 \\
-4.44 \\
-0.26 \\
-0.14 \\
0.00 \\
0.58 \\
0.58
\end{array}
$$

DYRFLSZ

0.63
-0.00
0.00
-0.07
0.00
0.00
-0.00
0.00
-0.00
0.00
-0.00
0.00
0.00
0.00

LABUN

$$
\begin{array}{r}
-4.44 \\
0.06 \\
-0.12 \\
0.52 \\
-0.00 \\
-0.03 \\
0.02 \\
-0.00 \\
0.16 \\
0.00 \\
0.00 \\
-0.00 \\
0.02 \\
0.02
\end{array}
$$

$$
\begin{array}{r}
\text { LPLB } \\
-0.00 \\
0.04 \\
-0.05 \\
-0.00 \\
-0.00 \\
-0.00 \\
0.00 \\
-0.00 \\
0.06 \\
0.00 \\
0.00 \\
0.00 \\
0.02 \\
0.02
\end{array}
$$

LLEN

1.14

$-0.00$

0.03

$-0.14$

0.00

0.03

$-0.03$

0.01

$-0.03$

$-0.00$

$-0.00$

$-0.00$

$-0.00$

$-0.00$

BGH. 1

$-0.26$

0.00

$-0.00$

0.01

0.00

$-0.00$

0.00

0.00

0.00

0.10

0.00

0.00

0.01

0.01
LCLBSC

3.05

$-0.05$

0.11

$-0.36$

0.00

0.03

$-0.02$

0.00

$-0.12$

$-0.00$

$-0.00$

0.00

$-0.01$

$-0.02$

LGTON

$-1.30$

$-0.02$

0.16

$-0.00$

$-0.03$

0.03

$-0.01$

0.02

0.00

0.00

0.00

0.00

0.00

DMOB2 . 1

-0.14
0.00
-0.00
0.01
-0.00
-0.00
0.00
0.00
0.00
0.00
0.02
0.00
0.00
0.00
LFLSZ

$-52.01$

$-0.00$

$-0.36$

6.39

$-0.07$

$-0.14$

0.16

0.00

0.52

0.01

0.01

$-0.00$

$-0.07$

$-0.07$

GEN . 1

$-0.12$

$-0.00$

0.00

0.00

0.00

0.01

$-0.01$

0.11

$-0.00$

0.00

0.00

0.00

0.00

0.00008

INTER . 2

0.00

0.00

0.00

$-0.00$

0.00

$-0.00$

0.00

0.00

$-0.00$

0.00

0.00

0.00

0.00

0.00 
Estimated Covariance Matrix

INTER. 3

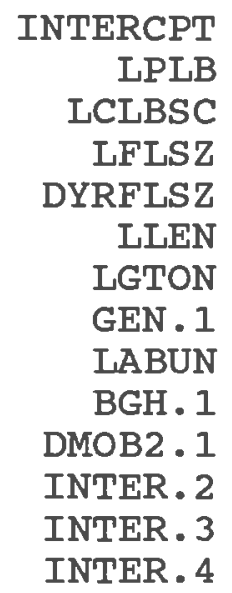

0.58
0.02
-0.01
-0.07
0.00
-0.00
0.00
0.00
0.02
0.01
0.00
0.00
0.04
0.04

INTER . 4

$$
\begin{array}{r}
0.58 \\
0.02 \\
-0.02 \\
-0.07 \\
0.00 \\
-0.00 \\
0.00 \\
0.00008 \\
0.02 \\
0.01 \\
0.00 \\
0.00 \\
0.04 \\
0.04
\end{array}
$$

Estimated Correlation Matrix INTERCPT LPLB LCLBSC

LFLSZ

INTERCPT
LPLB
LCLBSC
LFLSZ
DYRFLSZ
LLEN
LGTON
GEN. I
LABUN
BGH. 1
DMOB2 . 1
INTER. 2
INTER. 3
INTER. 4
$-0.00$
1.00
$-0.78$
$-0.01$
$-0.01$
$-0.15$
0.12
$-0.07$
0.74
0.06
0.05
0.00
0.53
0.53

0.43

$-0.78$

1.00

$-0.43$

0.26

0.46

$-0.44$

0.06

$-0.91$

$-0.04$

$-0.06$

0.00

$-0.29$

$-0.28$
$-0.99$

$-0.01$

$-0.43$

1.00

$-0.70$

$-0.28$

0.34

0.00

0.51

0.02

0.03

$-0.00$

$-0.15$

$-0.15$ 


\section{Estimated Correlation Matrix}

DYRFLSZ

\section{INTERCPT \\ LPLB \\ LCLBSC \\ LFLSZ \\ DYRFLSZ \\ LLEN \\ LGTON \\ GEN. 1 \\ LABUN \\ BGH . 1 \\ DMOB2 . 1 \\ INTER. 2 \\ INTER. 3 \\ INTER. 4}

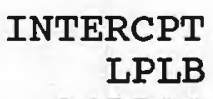

LCLBSC

LFLSZ

DYRFLSZ

LLEN

LGTON

GEN . 1

LABUN

BGH. 1

DMOB2 . 1

INTER . 2

INTER . 3

INTER . 4
LLEN

0.69

$-0.01$

0.26

$-0.70$

1.00

0.19

$-0.24$

0.03

$-0.32$

0.00

$-0.02$

0.00

0.17

0.17

LABUN

$-0.52$

0.74

$-0.91$

0.51

$-0.32$

$-0.40$

0.39

$-0.05$

1.00

0.03

0.06

$-0.00$

0.26

0.25
0.28

$-0.15$

0.46

$-0.28$

0.19

1.00

$-0.97$

0.18

$-0.40$

$-0.04$

$-0.13$

$-0.00$

$-0.17$

$-0.17$

BGH . 1

$-0.03$

0.06

$-0.04$

0.02

0.00

$-0.04$

0.03

0.05

0.03

1.00

0.04

0.00

0.15

0.15
LGTON

$-0.34$

0.12

$-0.44$

0.34

$-0.24$

$-0.97$

1.00

$-0.20$

0.39

0.03

0.14

0.00

0.14

0.14

DMOB2 . 1

$-0.04$

0.05

$-0.06$

0.03

$-0.02$

$-0.13$

0.14

0.02

0.06

0.04

1.00

0.00

0.10

0.10
GEN . 1

$-0.01$

$-0.07$

0.06

0.00

0.03

0.18

$-0.20$

1.00

$-0.05$

0.05

0.02

0.00

0.00

0.00

INTER . 2

0.00

0.00

0.00

$-0.00$

0.00

$-0.00$

0.00

0.00

$-0.00$

0.00

0.00

1.00

0.10

0.10 
Estimated Correlation Matrix

INTER. 3 INTER. 4

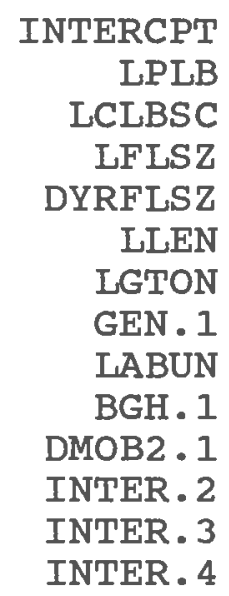

$$
\begin{array}{r}
0.14 \\
0.53 \\
-0.29 \\
-0.15 \\
0.17 \\
-0.17 \\
0.14 \\
0.00 \\
0.26 \\
0.15 \\
0.10 \\
0.10 \\
1.00 \\
0.98
\end{array}
$$$$
0.13
$$$$
0.53
$$$$
-0.28
$$$$
-0.15
$$$$
0.17
$$$$
-0.17
$$$$
0.14
$$$$
0.00
$$$$
0.25
$$$$
0.15
$$$$
0.10
$$$$
0.10
$$$$
0.98
$$

1.00 
Plot of Fitted Probabilities

Plot of PHAT*XBETA. Symbol used is 'P'.

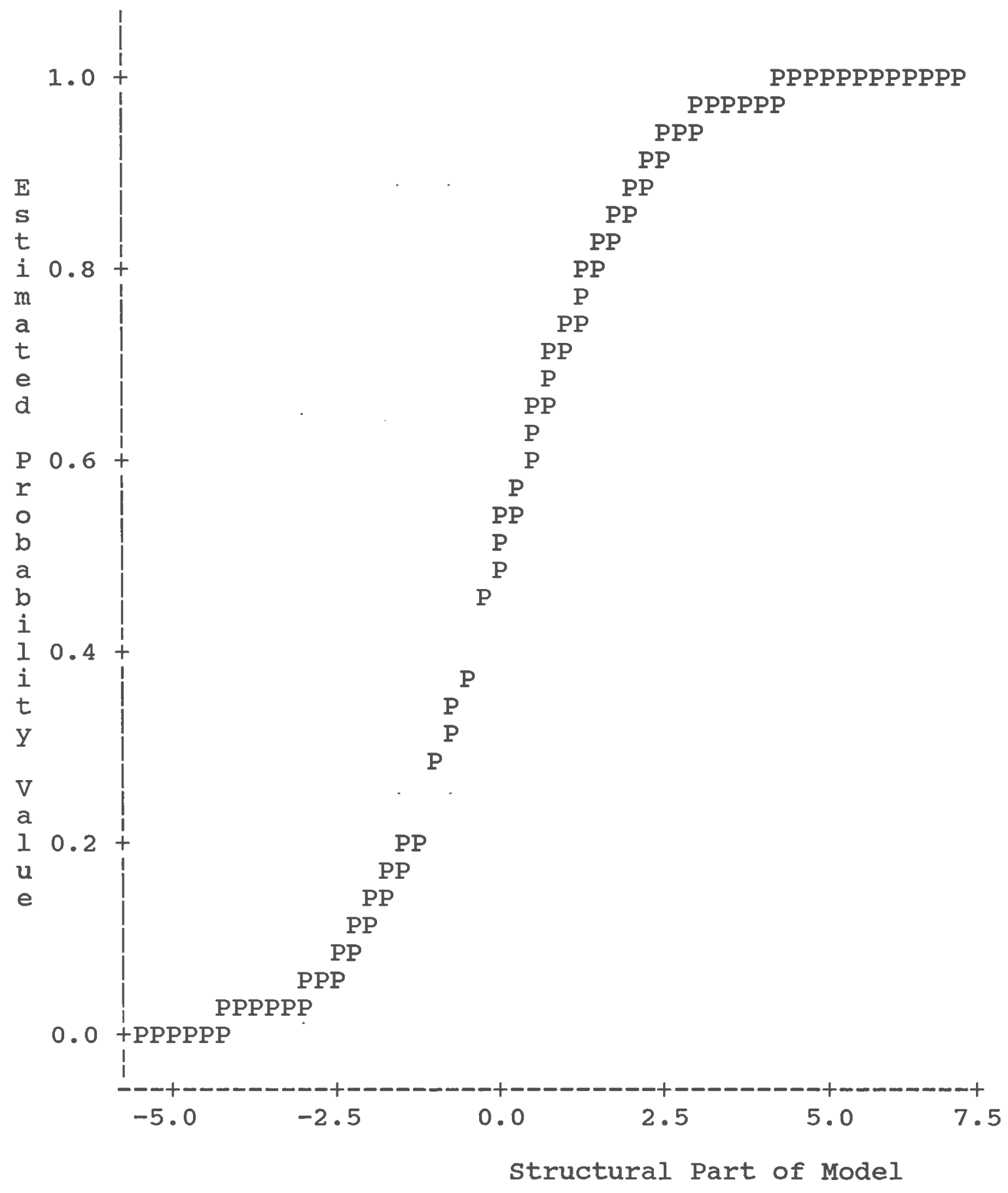

NOTE: 16 obs had missing values. 10495 obs hidden. 


\section{Statistical Results 3: Length/Gross Tonnage Hypothesis Test}

The model is modified to test the importance of vessel length and gross tonnage in determining the probability that an individual vessel would enter, remain in, or exit the shrimp fishery. The null hypothesis that these two coefficients are equal to zero is tested by dropping both variables from the model and comparing the value of the log likelihood function to its value when the model includes both variables. The likelihood ratio test rejects the null hypothesis at the $\alpha=0.05$ level with two degrees of freedom with a calculated value of 102.94 against a critical value of 5.99 from the Chi-square table.

The exclusion of these variables reduces the value of the stock constant harvesting cost, implying that the probability of entry declines with increases in costs less than by a decline in exvessel price; the calculated value of the likelihood ratio was 90.4232 . However, shrimp is not harvested by a homogeneous fishing fleet. The vessel length and gross tonnage variables hold constant the change in the physical characteristics of the fleet that effect the probability of entering, exiting, or remaining in the fishing fleet. 


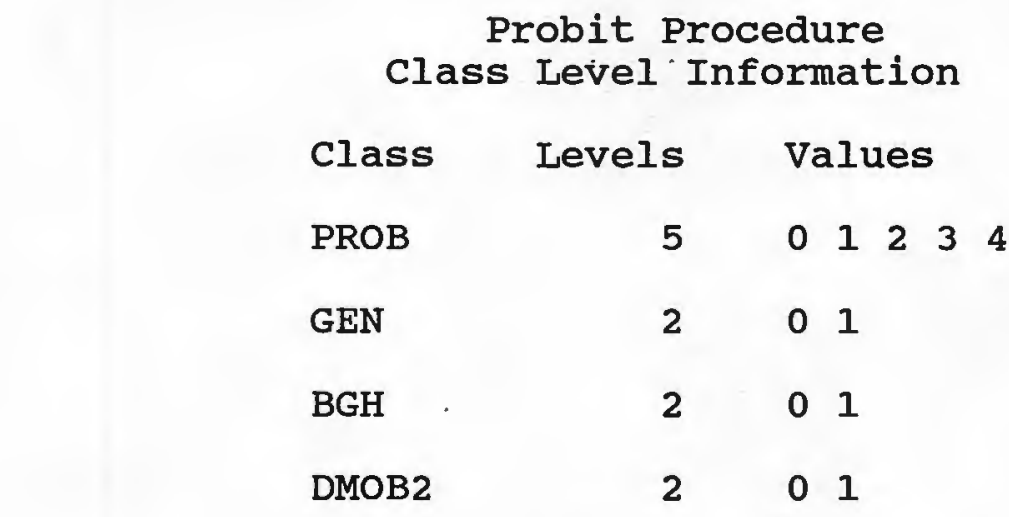

Number of observations used $=2647$

Data set =WORK.TESTT

Dependent Variable=PROB

Weighted Frequency Counts for the ordered Response Categories

$\begin{array}{rr}\text { Level } & \text { Count } \\ 0 & 109 \\ 1 & 4 \\ 2 & 2427 \\ 3 & 12 \\ 4 & 95\end{array}$

Observations with Missing Values= 4

Log Likelihood for LOGISTIC -873.0516064

\section{Goodness-of-Fit Tests}

statistic

Pearson Chi-Square

L.R. Chi-square

Response Levels: 5 Number of Covariate Values: 2647

NOTE: Since the chi-square is small ( $p>0.1000)$, fiducial limits will be calculated using a $t$ value of 1.96 . 
Probit Procedure

\begin{tabular}{|c|c|c|c|c|c|c|}
\hline Variable & $\mathrm{DF}$ & Estimate & std Err & Chisquare & $\operatorname{Pr}>\mathrm{Ch} i$ & Label/Value \\
\hline INTERCPT & 1 & 29.12 & 17.61 & 2.74 & 0.0981 & Intercept \\
\hline LPLB & 1 & 1.95 & 0.21 & 84.44 & 0.0001 & $\begin{array}{l}\text { Price Per } \\
\text { Pound }\end{array}$ \\
\hline LCLBSC & 1 & -1.22 & 0.30 & 17.16 & 0.0001 & $\begin{array}{l}\text { Stock } \\
\text { Constant } \\
\text { Harvest Cost } \\
\text { Per Pound }\end{array}$ \\
\hline LFLSZ & 1 & $-4 \cdot 34$ & 2.16 & 4.04 & 0.0444 & Fleet size \\
\hline DYRFLSZ & 1 & 0.08 & 0.04 & 4.14 & 0.0420 & $\begin{array}{l}\text { Post-67 Fleet } \\
\text { Size }\end{array}$ \\
\hline GEN & 1 & 0.18 & 0.33 & 0.31 & 0.5777 & $\begin{array}{l}\text { Generalist } \\
\text { Vessel }\end{array}$ \\
\hline LABUN & 1 & 1.49 & 0.37 & 16.49 & 0.0001 & $\begin{array}{l}\text { Shrimp } \\
\text { Abundance }\end{array}$ \\
\hline BGH & 1 & 0.93 & 0.34 & 7.53 & 0.0061 & $\begin{array}{l}\text { Vessel } \\
\text { Bought/sold }\end{array}$ \\
\hline DMOB2 & 1 & 0.29 & 0.15 & 3.46 & 0.0630 & $\begin{array}{l}\text { Vessel } \\
\text { Mobility }\end{array}$ \\
\hline $\begin{array}{l}\text { INTER . } 2 \\
\text { INTER . } 3 \\
\text { INTER. } 4\end{array}$ & $\begin{array}{l}1 \\
1 \\
1\end{array}$ & $\begin{array}{l}0.04 \\
7.23 \\
7.36\end{array}$ & $\begin{array}{l}0.02 \\
0.19 \\
0.20\end{array}$ & & & $\begin{array}{l}\text { Intercept. } 1 \\
\text { Intercept. } 2 \\
\text { Intercept. } 3\end{array}$ \\
\hline
\end{tabular}


Estimated Covariance Matrix

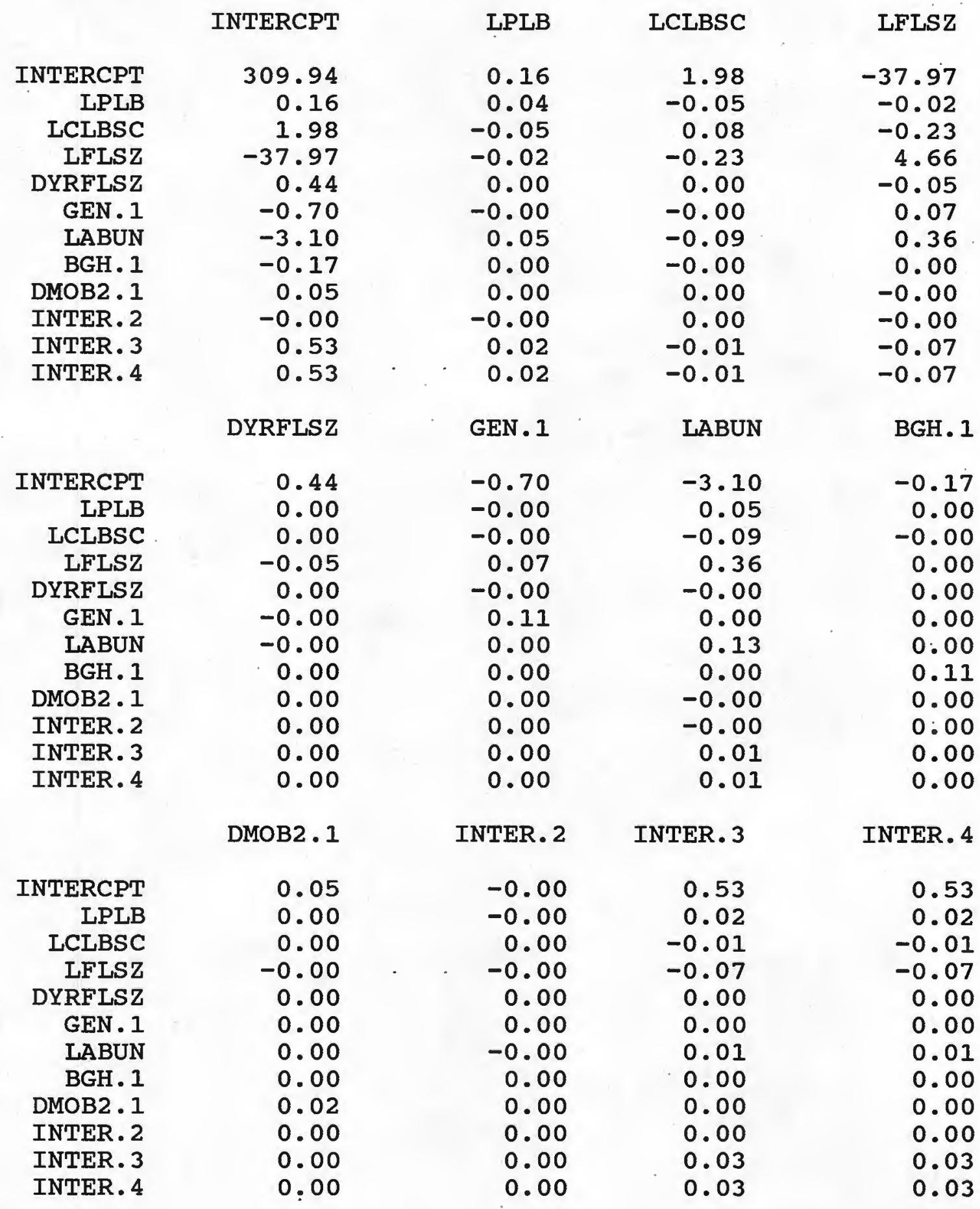




\section{Estimated Correlation Matrix}

\section{INTERCPT}

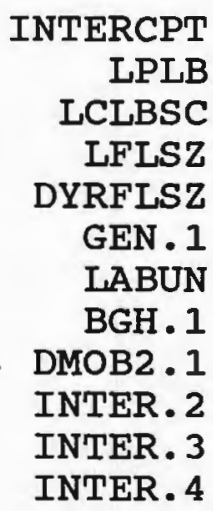

INTERCPT LPLB LCLBSC LFLSZ

DYRFLSZ

GEN. 1

IABUN

BGH .1

DMOB2 . 1

INTER. 2

INTER. 3

INTER. 4

INTERCPT

LPLB

LCLBSC

LFLSZ

DYRFLSZ

GEN . 1

LABUN

BGH. 1

DMOB2 . 1

INTER . 2

INTER. 3

INTER . 4
1.00

0.04

0.38

$-0.99$

0.62

$-0.12$

$-0.48$

$-0.02$

0.01

$-0.00$

0.15

0.15

DYRFLSZ

$$
\begin{array}{r}
0.62 \\
0.00 \\
0.20 \\
-0.64 \\
1.00 \\
-0.03 \\
-0.26 \\
0.01 \\
0.02 \\
0.00 \\
0.18 \\
0.17
\end{array}
$$

DMOB2 . 1

$$
\begin{array}{r}
0.01 \\
0.02 \\
0.00 \\
-0.02 \\
0.02 \\
0.07 \\
-0.00 \\
0.03 \\
1.00 \\
0.00 \\
0.09 \\
0.09
\end{array}
$$

LPLB

0.04

1.00

$-0.81$

$-0.05$

0.00

$-0.05$

0.76

0.03

0.02

$-0.00$

0.50

0.49

GEN . 1

$-0.12$

$-0.05$

$-0.01$

0.10

$-0.03$

1.00

0.02

0.05

0.07

0.00

0.02

0.02

INTER . 2

$-0.00$

$-0.00$

0.00

$-0.00$

0.00

0.00

$-0.00$

0.00

0.00

1.00

0.09

0.09
LCLBSC

0.38

$-0.81$

1.00

$-0.37$

0.20

$-0.01$

$-0.89$

$-0.02$

0.00

0.00

$-0.21$

$-0.21$

L.ABUN

$-0.48$

0.76

$-0.89$

0.46

$-0.26$

0.02

1.00

0.01

$-0.00$

$-0.00$

0.19

0.19

INTER . 3

$$
0.15
$$

0.50

$-0.21$

$-0.17$

0.18

0.02

0.19

0.11

0.09

0.09

1.00

0.98
LFLSZ

$-0.99$

$-0.05$

$-0.37$

1.00

$-0.64$

0.10

0.46

0.00

$-0.02$

$-0.00$

$-0.17$

$-0.16$

BGH . 1

$-0.02$

0.03

$-0.02$

0.00

0.01

0.05

0.01

1.00

0.03

0.00

0.11

0.11

INTER . 4

0.15

0.49

$-0.21$

$-0.16$

0.17

0.02

0.19

0.11

0.09

0.09

0.98

1.00 


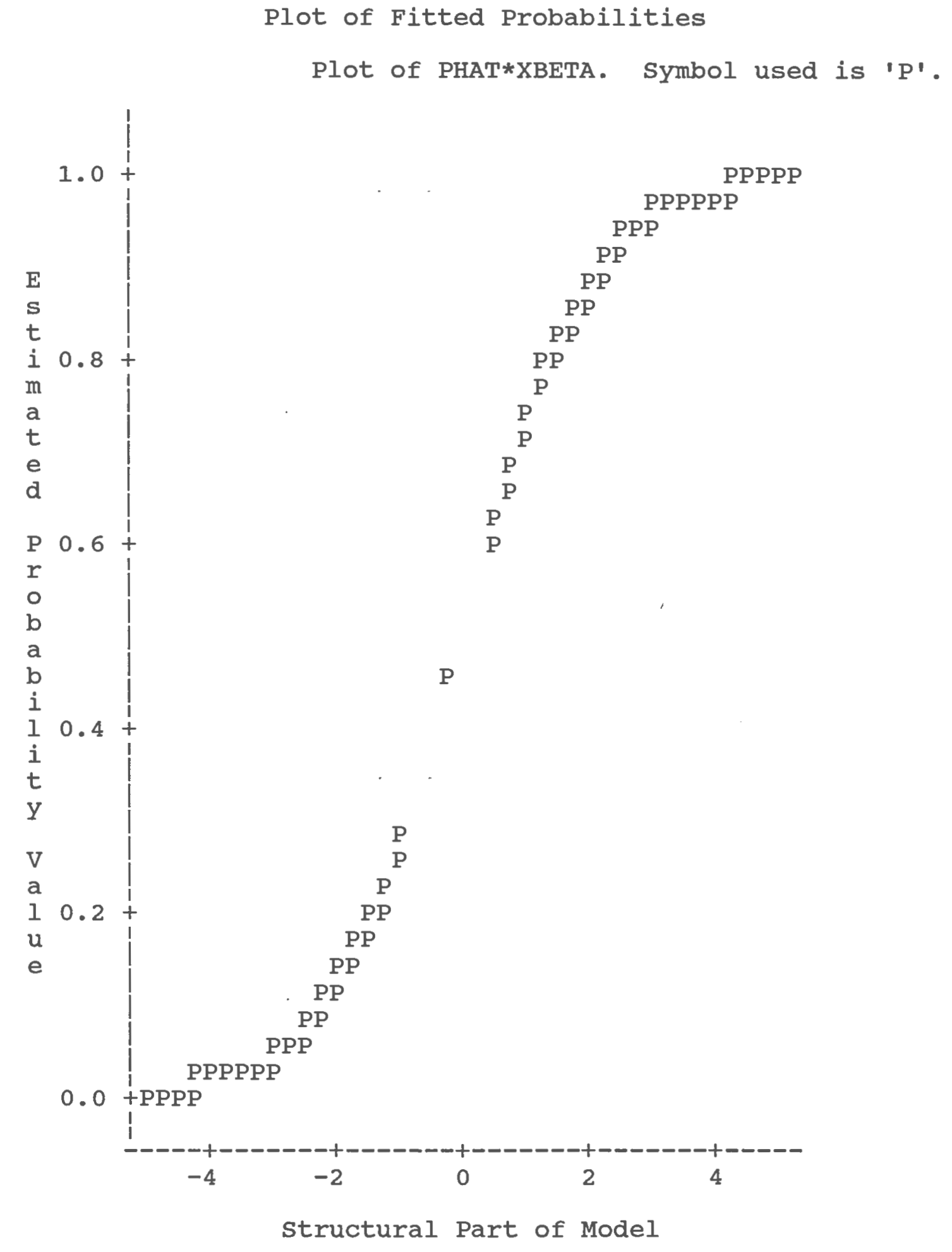

NOTE: 16 obs had missing values. 10516 obs hidden. 


\section{Statistical Results 4: Price/Cost Hypothesis Test}

The model specification is altered to test the hypothesis that the negative of the exvessel price coefficient is equal to the value of the stock constant harvesting cost coefficient. A new variable $\mathrm{Z}$ is included in the model to represent the restriction. A statistically significant difference in the value of the likelihood ratio test did not exist and the null hypothesis could not be rejected. This result implies that vessels are as likely to enter the fleet with a price increase or a cost decrease when the physical characteristics of the fleet are explicitly held constant in the model specification. 
Probit Procedure

Class Level Information

Class Levels Values

$\begin{array}{lllllll}\mathrm{PROB} & 5 & 0 & 1 & 2 & 3 & 4\end{array}$

GEN $\quad 2 \quad 0 \quad 1$

$\begin{array}{llll}\text { BGH } & 2 & 0 & 1\end{array}$

$\begin{array}{llll}\text { DMOB2 } & 2 & 0 & 1\end{array}$

Number of observations used $=2647$

Data set =WORK.TESTT

Dependent Variable $=$ PROB

Weighted Frequency Counts for the ordered Response Categories

$\begin{array}{rr}\text { Level } & \text { Count } \\ 0 & 109 \\ 1 & 4 \\ 2 & 2427 \\ 3 & 12 \\ 4 & 95\end{array}$

Observations with Missing Values $=4$

Log Likelihood for LOGISTIC -821.8394774

Goodness-of-Fit Tests

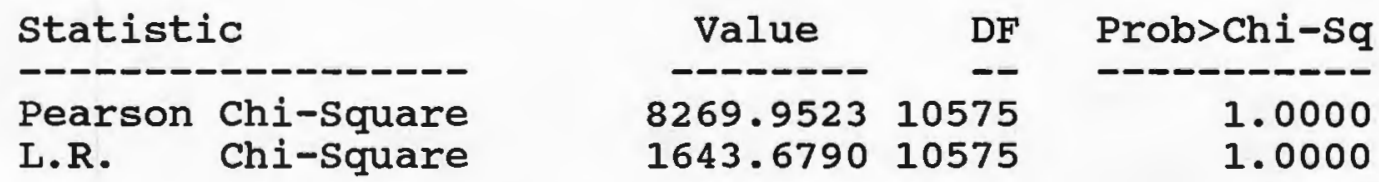

Response Levels: 5 Number of Covariate Values: 2647

NOTE: Since the chi-square is small ( $p>0.1000)$, fiducial limits will be calculated using a $t$ value of 1.96 . 


\section{Probit Procedure}

\begin{tabular}{|c|c|c|c|c|c|c|}
\hline Variable & DF & Estimate & Std Err & Chisquare & $\operatorname{Pr}>\mathrm{Ch} i$ & Label/Value \\
\hline INTERCPT & 1 & 32.75 & 15.04 & 4.74 & 0.0294 & Intercept \\
\hline $\mathrm{z}$ & 1 & -2.22 & 0.21 & 108.30 & 0.0001 & $\begin{array}{l}\text { Null } \\
\text { Hypothesis }\end{array}$ \\
\hline LFLSZ & 1 & -4.71 & 1.84 & 6.54 & 0.0106 & Fleet Size \\
\hline DYRFLSZ & 1 & 0.10 & 0.04 & 6.37 & 0.0116 & $\begin{array}{l}\text { Post-67 Fleet } \\
\text { Size }\end{array}$ \\
\hline LLEN & 1 & -1.13 & 0.16 & 48.75 & 0.0001 & Vessel Length \\
\hline LGTON & 1 & 0.74 & 0.15 & 23.45 & 0.0001 & $\begin{array}{l}\text { Vessel Gross } \\
\text { Tonnage }\end{array}$ \\
\hline GEN & 1 & 0.10 & 0.34 & 0.09 & 0.7686 & $\begin{array}{l}\text { Generalist } \\
\text { Vessel }\end{array}$ \\
\hline LABUN & 1 & 2.42 & 0.30 & 63.99 & 0.0001 & $\begin{array}{l}\text { Shrimp } \\
\text { Abundance }\end{array}$ \\
\hline BGH & 1 & 1.10 & 0.33 & 11.08 & 0.0009 & $\begin{array}{l}\text { Vessel } \\
\text { Bought/sold }\end{array}$ \\
\hline DMOB2 & 1 & 0.31 & 0.16 & 3.72 & 0.0538 & $\begin{array}{l}\text { Vessel } \\
\text { Mobility }\end{array}$ \\
\hline INTER . 2 & 1 & 0.05 & 0.02 & & & Intercept. 1 \\
\hline INTER. 3 & 1 & 7.42 & 0.20 & & & Intercept. 2 \\
\hline INTER. 4 & 1 & 7.55 & 0.20 & & & Intercept. 3 \\
\hline
\end{tabular}


Estimated Covariance Matrix

INTERCPT

INTERCPT
$Z$
LFLSZ
DYRFLSZ
LLEN
LGTON
GEN. 1
LABUN
BGH . 1
DMOB2 . 1
INTER . 2
INTER . 3
INTER . 4

INTERCPT

Z

LFLSZ

DYRFLSZ

LLEN

LGTON

GEN . 1

LABUN

BGH . 1

DMOB2 . 1

INTER. 2

INTER. 3

INTER . 4

$$
\begin{array}{r}
226.17 \\
-0.65 \\
-27.68 \\
0.39 \\
-0.44 \\
0.16 \\
-0.25 \\
-0.54 \\
-0.19 \\
-0.02 \\
0.00 \\
0.34 \\
0.34
\end{array}
$$

LLEN

$-0.44$

0.00

0.05

$-0.00$

0.02

$-0.02$

0.01

$-0.00$

$-0.00$

$-0.00$

$-0.00$

$-0.00$

$-0.00$

BGH. 1

$-0.19$

$-0.00$

0.01

0.00

$-0.00$

0.00

0.00

0.00

0.10

0.00

0.00

0.01

0.01
Z

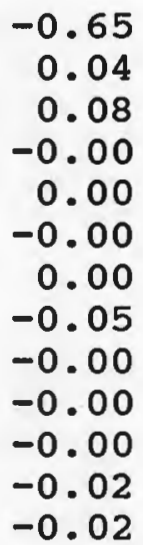

LGTON

0.16

$-0.00$

$-0.01$

$-0.00$

$-0.02$

0.02

$-0.01$

0.00

0.00

0.00

0.00

0.00

0.00

DMOB2 . 1

$-0.02$

$-0.00$

0.00

$-0.00$

$-0.00$

0.00

0.00

0.00

0.00

0.02

0.00

0.00

0.00
LFLSZ

$-27.68$

0.08

3.39

$-0.04$

0.05

$-0.01$

0.01

0.04

0.01

0.00

$-0.00$

$-0.04$

$-0.04$

GEN . 1

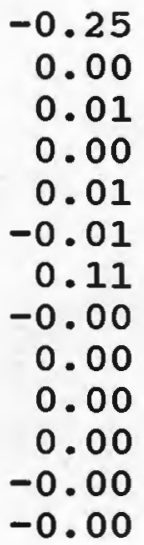

INTER . 2

0.00

$-0.00$

$-0.00$

0.00

$-0.00$

0.00

0.00

0.00

0.00

0.00

0.00

0.00

0.00
DYRFLSZ

0.39

$-0.00$

$-0.04$

0.00

$-0.00$

$-0.00$

0.00

$-0.00$

0.00

$-0.00$

0.00

0.00

0.00

LABUN

$-0.54$

$-0.05$

0.04

$-0.00$

$-0.00$

0.00

$-0.00$

0.09

0.00

0.00

0.00

0.02

0.02

INTER . 3

0.34

$-0.02$

$-0.04$

0.00

$-0.00$

0.00

$-0.00$

0.02

0.01

0.00

0.00

0.04

0.04 
Estimated Covariance Matrix

INTER . 4

$\begin{array}{rr}\text { INTERCPT } & 0.34 \\ \mathrm{Z} & -0.02 \\ \text { LFLSZ } & -0.04 \\ \text { DYRFLSZ } & 0.00 \\ \text { LLEN } & -0.00 \\ \text { IGTON } & 0.00 \\ \text { GEN.1 } & -0.00 \\ \text { IABUN } & 0.02 \\ \text { BGH.1 } & 0.01 \\ \text { DMOB2.1 } & 0.00 \\ \text { INTER.2 } & 0.00 \\ \text { INTER.3 } & 0.04 \\ \text { INTER.4 } & 0.04\end{array}$

Estimated Correlation Matrix

INTERCPT

Z

LFLSZ DYRFLSZ

INTERCPT

1.00

$-0.20$

$-0.99$

0.63

$-0.20$

1.00

0.22

$-0.07$

$-0.99$

1.00

$-0.65$

0.63

0.22

$-0.07$

$-0.65$

1.00

LLEN

$-0.18$

0.03

0.17

$-0.03$

0.07

$-0.00$

$-0.06$

$-0.03$

GEN . 1

$-0.05$

0.02

0.02

LABUN

$-0.12$

0.08

$-0.08$

$-0.03$

0.01

0.00

$-0.01$

0.00

$-0.00$

INTER. 2

0.00

$-0.00$

0.11

$-0.12$

$-0.12$

0.00

0.15

0.15

0.11

$-0.56$

$-0.56$ 
Estimated Correlation Matrix

LLEN

INTERCPT
Z
LFLSZ
DYRFLSZ
LLEN
LGTON
GEN . 1
LABUN
BGH . 1
DMOB2 . 1
INTER . 2
INTER . 3
INTER . 4

INTERCPT

LFLSZ

DYRFLSZ

LLEN

LGTON

GEN . 1

LABUN

BGH. 1

DMOB2 . 1

INTER . 2

INTER. 3

INTER . 4
$-0.18$

0.03

0.17

$-0.03$

1.00

$-0.96$

0.20

$-0.03$

$-0.04$

$-0.13$

$-0.01$

$-0.26$

$-0.26$

BGH . 1

$-0.03$

$-0.06$

0.01

0.00

$-0.04$

0.03

0.05

0.03

1.00

0.03

0.00

0.15

0.15
LGTON

0.07

$-0.00$

$-0.06$

$-0.03$

$-0.96$

1.00

$-0.22$

0.02

0.03

0.14

0.00

0.23

0.22

DMOB2 . 1

$-0.01$

$-0.04$

0.00

$-0.00$

$-0.13$

0.14

0.02

0.03

0.03

1. 00

0.00

0.11

0.11
GEN . 1

$-0.05$

0.07

0.02

0.02

0.20

$-0.22$

1.00

$-0.04$

0.05

0.02

0.00

$-0.00$

$-0.00$

INTER . 2

0.00

$-0.00$

$-0.00$

0.00

$-0.01$

0.00

0.00

0.00

0.00

0.00

1.00

0.10

0.10
LABUN

$-0.12$

$-0.83$

0.08

$-0.08$

$-0.03$

0.02

$-0.04$

1.00

0.03

0.03

0.00

0.43

0.42

INTER . 3

0.11

$-0.56$

$-0.12$

0.15

$-0.26$

0.23

$-0.00$

0.43

0.15

0.11

0.10

1.00

0.98

INTER . 4

INTERCPT

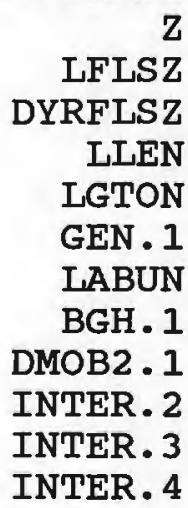

0.11

$-0.56$

$-0.12$

0.15

$-0.26$

0.22

$-0.00$

0.42

0.15

0.11

0.10

0.98

1.00 
Plot of Fitted Probabilities

Plot of PHAT*XBETA. Symbol used is 'P'.

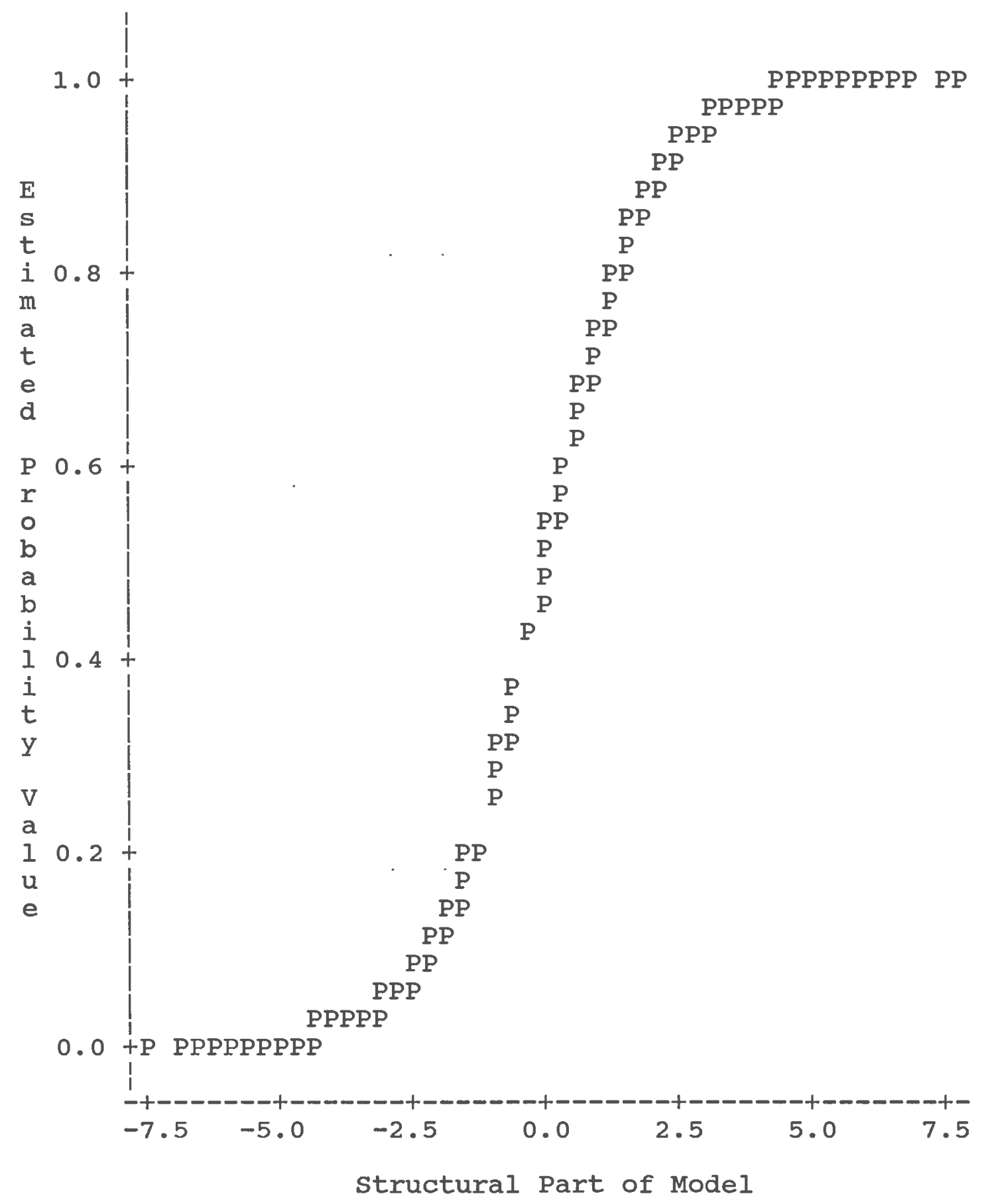

NOTE: 16 obs had missing values. 10504 obs hidden. 
Statistical Results 5: Alternative Model Hypothesis Test

The hypothesis that the negative of the exvessel price coefficient is equal to the value of the stock constant harvesting cost coefficient is tested when vessel length and gross tonnage are excluded from the model specification. The null hypothesis that the negative of the exvessel price coefficient was equal to the coefficient on unit harvesting cost is rejected at the $\alpha=0.05$ level of significance. This reflects the impact of the vessel length and gross tonnage variables on vessel behavior. 


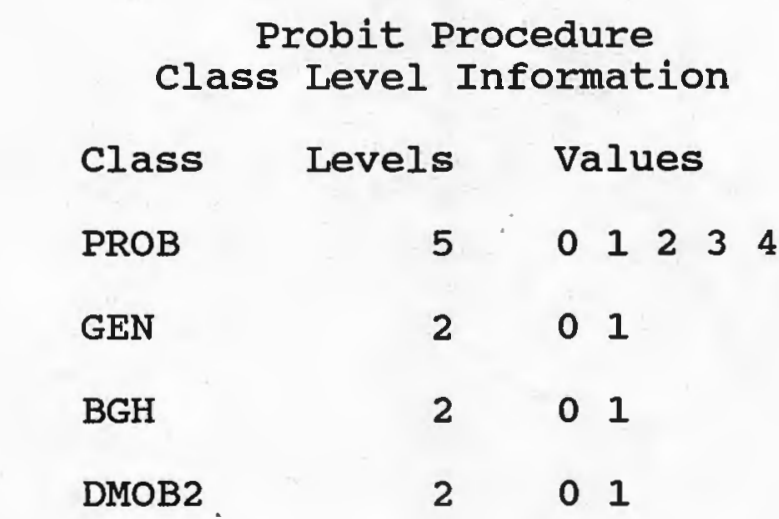

Number of observations used $=2647$

Data set =WORK.TESTT

Dependent Variable $=$ PROB

Weighted Frequency Counts for the Ordered Response Categories

$\begin{array}{cc}\text { Level } & \text { Count } \\ 0 & 109 \\ 1 & 4 \\ 2 & 2427 \\ 3 & 12 \\ 4 & 95\end{array}$

Observations with Missing Values $=\quad 4$

Log Likelihood for LOGISTIC -918.2632266

Goodness-of-Fit Tests

\begin{tabular}{l} 
Statistic \\
\hline Pearson Chi-Square \\
L.R. Chi-Square
\end{tabular}

Response Levels: 5 Number of Covariate Values: 2647

NOTE: Since the chi-square is small $(p>0.1000)$, fiducial limits will be calculated using a $t$ value of 1.96 . 


\section{Probit Procedure}

\begin{tabular}{|c|c|c|c|c|c|c|}
\hline Variable & $\mathrm{DF}$ & Estimate & Std Err & Chisquare & $\operatorname{Pr}>\mathrm{Ch} i$ & Label/Value \\
\hline INTERCPT & 1 & 22.38 & $17: 17$ & 1.70 & 0.1924 & Intercept \\
\hline $\mathrm{z}$ & 1 & 1.04 & 0.17 & 37.62 & 0.0001 & $\begin{array}{l}\text { Null } \\
\text { Hypothesis }\end{array}$ \\
\hline LFLSZ & 1 & -3.23 & 2.10 & 2.36 & 0.1243 & Fleet Size \\
\hline DYRFLSZ & 1 & 0.09 & 0.04 & 5.51 & 0.0189 & $\begin{array}{l}\text { Post-67 Fleet } \\
\text { Size }\end{array}$ \\
\hline GEN & 1 & 0.35 & 0.34 & 1.09 & 0.2959 & $\begin{array}{l}\text { Generalist } \\
\text { Vessel }\end{array}$ \\
\hline LABUN & 1 & -1.18 & 0.23 & 25.40 & 0.0001 & $\begin{array}{l}\text { Shrimp } \\
\text { Abundance }\end{array}$ \\
\hline BGH & 1 & 0.81 & 0.33 & 6.01 & 0.0143 & $\begin{array}{l}\text { Vessel } \\
\text { Bought/Sold }\end{array}$ \\
\hline DMOB2 & 1 & 0.26 & 0.15 & 3.00 & 0.0831 & $\begin{array}{l}\text { Vessel } \\
\text { Mobility }\end{array}$ \\
\hline INTER. 2 & 1 & 0.04 & 0.02. & & & Intercept. 1 \\
\hline INTER. 3 & 1 & 6.74 & 0.16 & & & Intercept. 2 \\
\hline INTER . 4 & 1 & 6.86 & 0.17 & & & Intercept. 3 \\
\hline
\end{tabular}


Estimated Covariance Matrix

INTERCPT

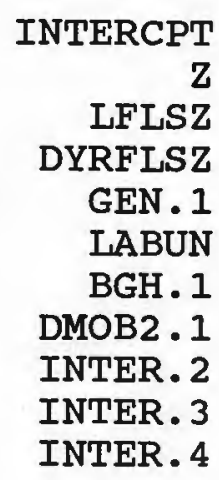

INTERCPT

LFLSZ

DYRFLSZ

GEN. 1

LABUN

BGH. 1

DMOB2 . 1

INTER. 2

INTER. 3

INTER . 4

INTERCPT

$\mathrm{Z}$

LFLSZ

DYRFLSZ

GEN. 1

LABUN

BGH. 1

DMOB2. 1

INTER. 2

INTER. 3

INTER . 4

$\begin{array}{rr}294.74 & 2.08 \\ 2.08 & 0.02 \\ -36.08 & -0.25 \\ 0.40 & 0.00 \\ -0.69 & -0.00 \\ -3.15 & -0.02 \\ -0.07 & 0.00 \\ 0.06 & 0.00 \\ 0.00 & 0.00 \\ 0.35 & 0.00 \\ 0.35 & 0.00\end{array}$

GEN . 1

$-0.69$

$-0.00$

0.07

$-0.00$

0.11

0.00

0.00

0.00

0.00

0.00

0.00

INTER. 2

INTER. 3

0.00

0.00 .

$-0.00$

0.00

0.00

$-0.00$

0.00

0.00

0.00

0.00

0.00

0.35

0.00

$-0.04$

0.00

0.00

$-0.01$

0.00

0.00

0.00

0.02

0.02
Z

LFLSZ

$-36.08$

$-0.25$

4.42

$-0.05$

0.07

0.37

$-0.00$

$-0.01$

$-0.00$

$-0.04$

$-0.04$

BGH. 1

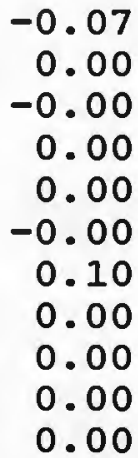

INTER . 4

$$
\begin{array}{r}
0.35 \\
0.00 \\
-0.04 \\
0.00 \\
0.00 \\
-0.01 \\
0.00 \\
0.00 \\
0.00 \\
0.02 \\
0.02
\end{array}
$$

DYRFLSZ

$$
\begin{array}{r}
0.40 \\
0.00 \\
-0.05 \\
0.00 \\
-0.00 \\
-0.00 \\
0.00 \\
0.00 \\
0.00 \\
0.00 \\
0.00
\end{array}
$$

DMOB2 . 1

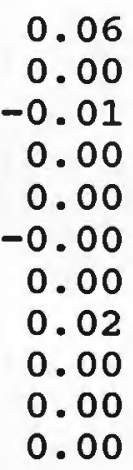

0.06

0.00

$-0.01$

0.00

0.00

$-0.00$

0.00

0.02

0.00

0.00 
Estimated Correlation Matrix INTERCPT $\mathrm{Z}$ LFLSZ

DYRFLSZ

INTERCPT
$\mathrm{Z}$
LFLSZ
DYRFLSZ
GEN . 1
LABUN
BGH . 1
DMOB2 . 1
INTER . 2
INTER . 3
INTER . 4

1.00

0.71

1.00

$-0.99$

0.61

0.71

$-0.72$

$-0.72$

0.33

$-0.99$

0.33

1.00

$-0.63$

0.61

$-0.11$

$-0.78$

$-0.70$

$-0.63$

1.00

$-0.01$

0.02

0.09

0.77

0.02

0.05

$-0.00$

$-0.03$

$-0.39$

0.01

0.00

$-0.03$

0.02

0.12

0.00

$-0.00$

0.00

0.12

0.35

$-0.13$

$-0.13$

0.16

0.16 
Estimated Correlation Matrix

INTERCPT
$\mathrm{Z}$
LFISZ
DYRFLSZ
GEN . I
IABUN
BGH. 1
DMOB2 . 1
INTER . 2
INTER . 3
INTER . 4

INTERCPT

LFLSZ

DYRFLSZ

GEN. 1

LABUN

BGH. 1

DMOB2 . 1

INTER. 2

INTER. 3

INTER. 4
GEN . 1

LABUN

$-0.11$

$-0.11$

0.09

$-0.03$

1.00

0.11

0.04

0.07

0.00

0.06

0.06

INTER. 2

0.00

0.00

$-0.00$

0.00

0.00

$-0.00$

0.00

0.00

1.00

0.11

0.11
$-0.78$

$-0.70$

0.77

$-0.39$

0.11

1.00

$-0.04$

$-0.03$

$-0.00$

$-0.31$

$-0.30$

INTER 3

0.12

0.35

$-0.13$

0.16

0.06

$-0.31$

0.12

0.09

0.11

1.00

0.97
BGH . 1

$-0.01$

0.02

$-0.00$

0.01

0.04

$-0.04$

1.00

0.02

0.00

0.12

0.12

INTER . 4

0.12

0.34

$-0.13$

0.16

0.06

$-0.30$

0.12

0.09

0.11

0.97

1.00
DMOB2 . 1

0.02

0.05

$-0.03$

0.02

0.07

$-0.03$

0.02

1.00

0.00

0.09

0.09 


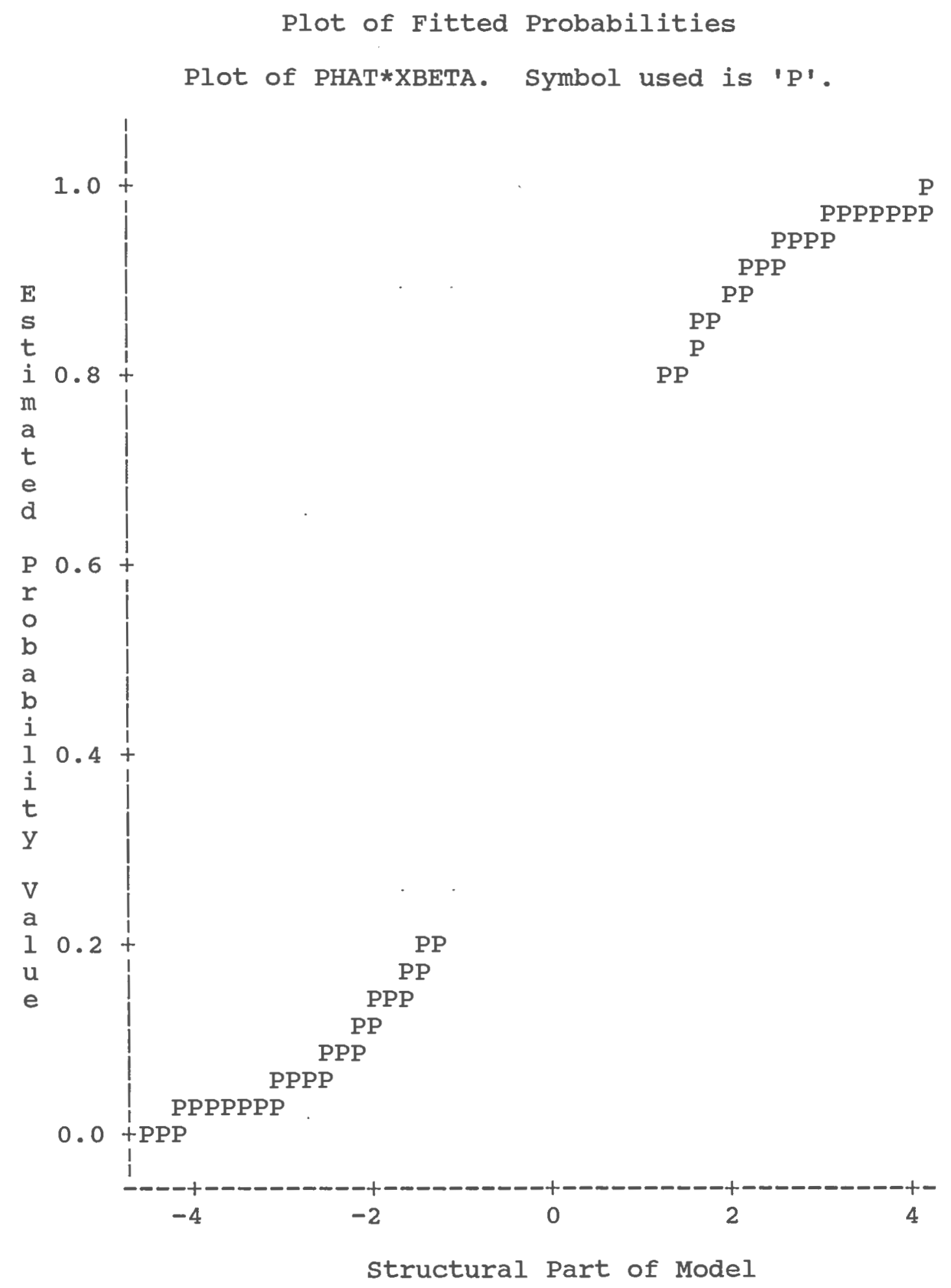

NOTE: 16 obs had missing values. 10528 obs hidden. 
statistical Results 6: Nonconstant stock Model

This model specification does not employ a stock constant unit harvesting cost as an independent variable. The stock abundance variable (LABUN) is statistically insignificant, however, the value of the likelihood function and the estimated coefficients and their level of statistical significance are the same as in the model employing a stock constant unit harvesting cost. 


\begin{tabular}{lrcrl}
\multicolumn{2}{c}{$\begin{array}{c}\text { Probit } \\
\text { Class }\end{array}$} & Procedure \\
Class & Levels & Values \\
PROB & 5 & 0 & 1234 \\
GEN & 2 & 0 & 1 \\
BGH & 2 & 0 & 1 \\
DMOB2 & 2 & 0 & 1
\end{tabular}

Number of observations used $=2647$

Data set $\quad=$ WORK.TEST

Dependent Variable $=$ PROB

Weighted Frequency Counts for the Ordered Response Categories

$\begin{array}{rr}\text { Level } & \text { Count } \\ 0 & 109 \\ 1 & 4 \\ 2 & 2427 \\ 3 & 12 \\ 4 & 95\end{array}$

Observations with Missing Values= 4

Log Likelihood for LOGISTIC -821.5801996 
Probit Procedure

\begin{tabular}{|c|c|c|c|c|c|c|}
\hline Variable & DF $\mathrm{I}$ & Estimate & Std Err & Chisquare & $\operatorname{Pr}>\mathrm{Chi}$ & Label/Value \\
\hline INTERCPT & 1 & 42.91 & 20.58 & 4.35 & 0.0371 & Intercept \\
\hline LPLB & 1 & 2.18 & 0.22 & 99.57 & 0.0001 & $\begin{array}{l}\text { Price Per } \\
\text { Pound }\end{array}$ \\
\hline LCLB & 1 & -2.03 & 0.34 & 35.64 & 0.0001 & $\begin{array}{l}\text { Stock Constant } \\
\text { Harvest Cost } \\
\text { Per Pound }\end{array}$ \\
\hline LFLSZ & 1 & -5.96 & 2.53 & 5.56 & 0.0184 & Fleet Size \\
\hline DYRFLSZ & 1 & 0.12 & 0.04 & 6.76 & 0.0093 & $\begin{array}{l}\text { Post-67 Fleet } \\
\text { Size }\end{array}$ \\
\hline LLEN & 1 & -1.05 & 0.20 & 28.38 & 0.0001 & Vessel Length \\
\hline LGTON & 1 & 0.67 & 0.19 & 12.93 & 0.0003 & $\begin{array}{l}\text { Vessel Gross } \\
\text { Tonnage }\end{array}$ \\
\hline GEN & 1 & 0.11 & 0.34 & 0.10 & 0.7529 & $\begin{array}{l}\text { Generalist } \\
\text { Vessel }\end{array}$ \\
\hline LAABUN & 1 & 0.19 & 0.17 & 1.25 & 0.2629 & $\begin{array}{l}\text { Shrimp } \\
\text { Abundance }\end{array}$ \\
\hline $\mathrm{BGH}$ & 1 & 1.10 & 0.33 & 11.04 & 0.0009 & $\begin{array}{l}\text { Vessel } \\
\text { Bought/Sold }\end{array}$ \\
\hline DMOB2 & 1 & 0.31 & 0.16 & 3.57 & 0.0587 & $\begin{array}{l}\text { Vessel } \\
\text { Mobility }\end{array}$ \\
\hline INTER. 2 & 1 & 0.05 & 0.02 & & & Intercept. 1 \\
\hline INTER. 3 & 1 & 7.43 & 0.20 & & & Intercept. 2 \\
\hline INTER . 4 & 1 & 7.56 & 0.20 & & & Intercept. 3 \\
\hline
\end{tabular}




\section{statistical Results 7: Rent Model}

The model specification is altered to test the hypothesis that rent is the determining factor in the entry exit decision. The stock constant unit harvesting cost is subtracted from the exvessel price of shrimp and the difference LNP is used in the model. Since logarithms of negative numbers do not exist, fifty cent per pound is added to the estimate of rent. This null hypothesis is rejected at the $\alpha=0.05$ level of significance using the likelihood ratio. Although statistically significant, the explanatory power of the model using the ratio of exvessel price to stock constant unit harvesting cost is greater than the model using the rent measure. 


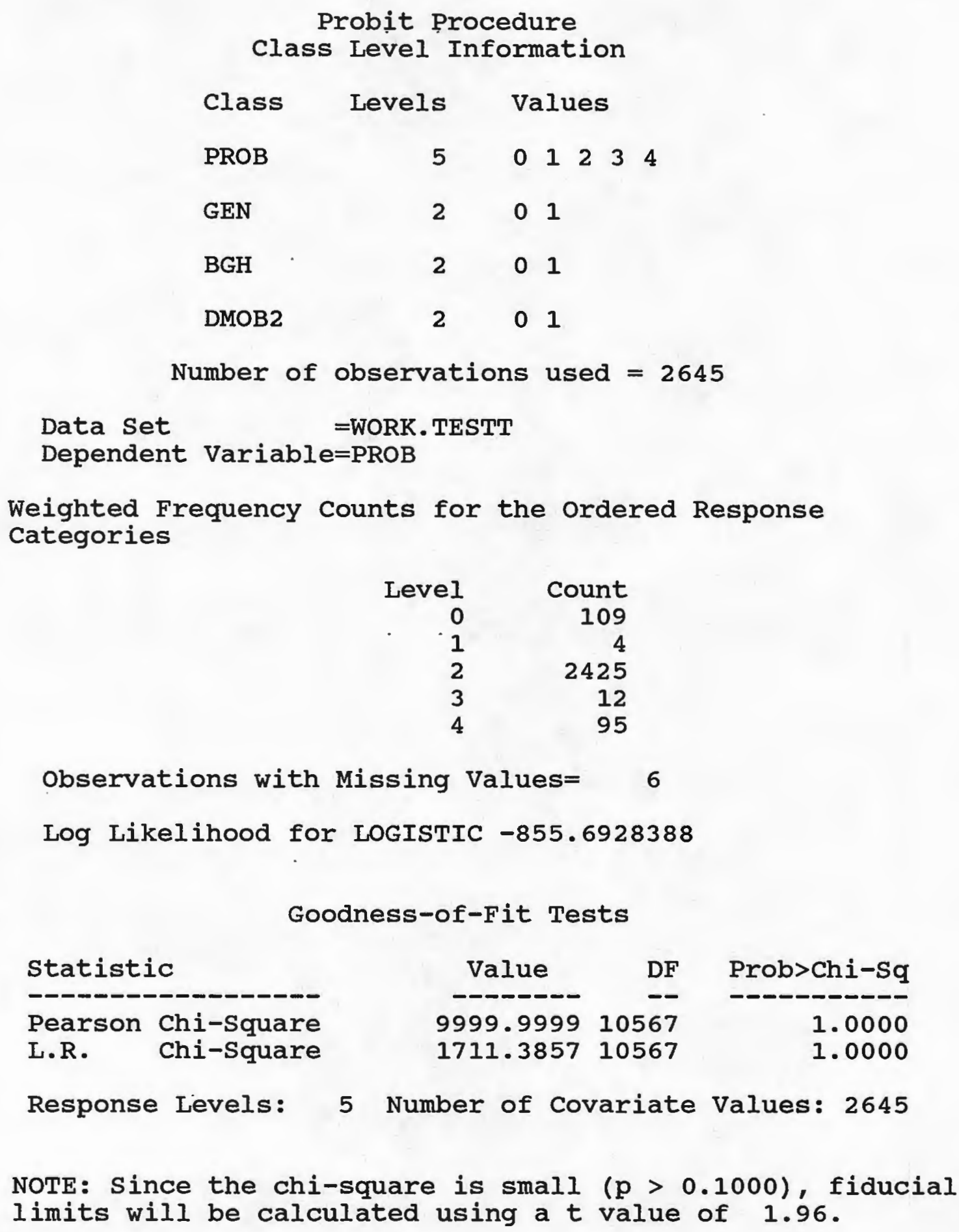

Weighted Frequency Counts for the ordered Response Categories

$\begin{array}{rr}\text { Level } & \text { Count } \\ 0 & 109 \\ 1 & 4 \\ 2 & 2425 \\ 3 & 12 \\ 4 & 95\end{array}$

Observations with Missing Values $=\quad 6$

Log Likelihood for LOGISTIC -855.6928388

Goodness-of-Fit Tests

\begin{tabular}{lcrr} 
Statistic & Value & DF & Prob>Chi-Sq \\
\hline Pearson Chi-Square & -9999.9999 & 10567 & 1.0000 \\
L.R. Chi-Square & 1711.3857 & 10567 & 1.0000
\end{tabular}

Response Levels: 5 Number of Covariate Values: 2645

NOTE: Since the chi-square is $\operatorname{small}(p>0.1000)$, fiducial limits will be calculated using a $t$ value of 1.96 . 


\section{Probit Procedure}

\begin{tabular}{|c|c|c|c|c|c|c|}
\hline ariable & DF & Estimate & std Err & Chisquare & Pr $>\mathrm{Ch} i$ & Label/Value \\
\hline INTERCPT & 1 & 69.26 & 17.20 & 16.21 & 0.0001 & Intercept \\
\hline LNP & 1 & 1.38 & 0.20 & 46.21 & 0.0001 & Rent \\
\hline LFLSZ & 1 & -9.05 & 2.11 & 18.26 & 0.0001 & Fleet Size \\
\hline DYRFLSZ & 1 & 0.19 & 0.04 & 20.15 & 0.0001 & $\begin{array}{l}\text { Post-67 Fleet } \\
\text { Size }\end{array}$ \\
\hline LLEN & 1 & -1.08 & 0.16 & 42.70 & 0.0001 & Vessel Length \\
\hline LGTON & 1 & 0.69 & 0.15 & 19.91 & 0.0001 & $\begin{array}{l}\text { Vessel Gross } \\
\text { Tonnage }\end{array}$ \\
\hline GEN & 1 & 0.36 & 0.34 & 1.07 & 0.3005 & $\begin{array}{l}\text { Generalist } \\
\text { Vessel }\end{array}$ \\
\hline LABBUN & 1 & -0.12 & 0.16 & 0.53 & 0.4647 & $\begin{array}{l}\text { Shrimp } \\
\text { Abundance }\end{array}$ \\
\hline $\mathrm{BGH}$ & 1 & 0.98 & 0.32 & 9.19 & 0.0024 & $\begin{array}{l}\text { Vessel } \\
\text { Bought/sold }\end{array}$ \\
\hline DMOB2 & 1 & 0.26 & 0.15 & 2.64 & 0.1043 & $\begin{array}{l}\text { Vessel } \\
\text { Mobility }\end{array}$ \\
\hline INTER. 2 & 1 & 0.05 & 0.02 & & & Intercept. 1 \\
\hline INTER. 3 & 1 & 7.01 & 0.17 & & & Intercept. 2 \\
\hline INTER . 4 & 1 & 7.13 & 0.17 & & & Intercept. 3 \\
\hline
\end{tabular}




\section{Appendix E \\ Directions for Future Research}

\section{Theory}

This analysis bases the discrete choice of remaining in, entering, or exiting the Gulf of Mexico shrimp fishery on the current profits generated by a vessel in the fleet or myopic expectations. Rational expectation models could be developed using these data sets for individual firms entering and exiting the Gulf of Mexico shrimp fleet. Given that the capital invested in the vessel is for the long run, the present value of the expected stream of net revenues over the life of this investment should be a good predictor of the entry-exit decision of the firm.

Most theoretical analyses are based on the change in total effort in a homogenous fishery. Additional research on the entry-exit decision needs to be done at the individual firm level and for heterogenous fishing fleets. This research could also incorporate uncertainty about the future shrimp stock levels due to environmental effects as a stochastic dynamic problem ${ }^{87}$. A dynamic model of individual firm behavior in the Gulf of Mexico shrimp fishery could be developed that incorporates the bycatch problem, growth overfishing, as well as allowing the

${ }^{87}$ Chaotic behavior could also be investigated as in R.S. sample, Transition to chaos in Multidimensional constrained Systems, Thesis, Department of Physics, University of Maine, Orono, Maine, 1990. 
investigation of various fishery management options such as individual transferable quotas, license limitations, closed areas, or fishing seasons.

\section{Applied Analysis}

One area where the present analysis could be improved is in the performance of alternative fishery exvessel price variables. The assumption that the Gulf of Mexico shrimp fishery is autonomous with vessels moving between shrimp and finfish fisheries is incorrect. Table 2 indicates that most vessels that enter or exit the fishery leave the regional data base. Unfortunately, information about vessel activity in other regions is difficult to acquire and cost information for these fisheries impossible to access. This prevents the use of relative exvessel prices and harvesting costs for alternative fisheries as variables in the model. The assumption has to be made that the economic and biological conditions in these alternative fisheries remains constant over time. In future analyses of the shrimp fishery, a sample of these vessels could be interviewed to determine what alternative fisheries they engage in and what types of fishing gear are employed. Exvessel prices and unit harvesting costs could then be developed for use in estimating this model.

The indirect cost function uses total landings by a vessel to determine their impact on vessel operating costs. Due to the growth overfishing that has occurred over the 
time period of this analysis, a better approach would be to use landings in the various size categories. If this information had been available, the estimated coefficient for pounds landed in the model might have had the correct sign.

\section{Policy}

One direct extension of this analysis is the analysis of shrimp import controls on fleet size. Dr. Walter Keithly of Louisiana State University has developed a simultaneous equation model that can be used to determine the impact of a regulation that restricts importation of shrimp or shrimp products on exvessel shrimp price. The change in exvessel price that results from a tariff or quota can be incorporated into the probability model to determine their effect on fleet size. Given the change in fleet size, the costs and benefits of the quota regulations can be determined.

An additional application of this model is in the development of management regulations to control finfish bycatch in the shrimp fishery. Modifications to the otter trawl that reduce or eliminate finfish bycatch may also reduce shrimp harvest affecting both the harvesting costs and the average exvessel price the fisherman receives by altering the size distribution of landings. Alternatively, individual transferable quotas could be imposed on the shrimp fishery resulting in an increase in the unit 
harvesting cost. Alternative management measures could include a Gulf of Mexico wide closure as was considered for the red snapper fishery, closures in areas with a high incidence of bycatch, or fishing licenses. The net benefits of these alternative regulations for the shrimp fishery should be compared with the net benefits derived in the finfish fisheries that are affected by the bycatch.

\section{Future Research}

A dynamic bycatch model of the shrimp fishery has been proposed and funded under the Marine Fisheries Initiative program. The impacts on the commercial and recreational finfish fisheries from fishery management measures designed to reduce or eliminate bycatch in the shrimp fishery will be determined using a bioeconomic model in a computer simulation based on existing data collected from secondary sources, published articles, expert opinion and arbitrarily derived parameter estimates.

This model is envisioned to have three components: a biological component, an individual firm fishing effort component, and a fleet size component. The biological component will model both shrimp and finfish species. Predator - prey and competitor effects will be incorporated into this submodel since finfish may play both roles at various stages of their life $\operatorname{cycle}^{88}$. The stochastic

\footnotetext{
${ }^{88}$ Bycatch in shrimp otter trawls consists of both adult and juvenile versions of each finfish species.
} 
effects of uncertainty on both shrimp and finfish recruitment into their respective fisheries will have to be addressed. The individual firm fishing effort component will represent both a shrimp fishing firm directly harvesting shrimp with a finfish bycatch that is discarded ${ }^{89}$ and a directed finfish fishing firm operating independently of the shrimp fishery; for example, different areas of operation. The fleet size component for the finfish and shrimp fisheries will be used to determine the entry into or exit of vessels from the fleet in response to changing biological and. economic conditions.

The model will also incorporate both intra and interseasonal components to analyze the various proposed management scenarios for correcting the shrimp bycatch problem ${ }^{90}$. The model will also be designed to incorporate additional research as it develops. For example, an individual transferable quota market where demand is proportional to the discounted net revenue generated by the fishery and supply is determined by total allowable catch could be a factor that affects fishing costs. A model of

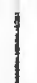

${ }^{89}$ The sale of marketable finfish is not considered in this modelling approach since it is believed to be of relatively minor impact on the effort level of the individual firm.

${ }^{90} \mathrm{~A}$ total quota for the finfish fishery, for example, would lead to shorter annual fishing seasons as the stock recovered, fishing costs declined, and the fleet size increased in response to this increased short run profitability. 
import demand and supply could be incorporated into the exvessel price that fishermen face for shrimp or finfish. Proposed management regulations that this model could analyze include area and seasonal closures of the shrimp fishing grounds to reduce bycatch, the introduction of a finfish excluder device to the shrimp otter trawl, the development of an individual transferable quota system for the shrimp fishery, the finfish fishery, or both, and other forms of limited entry such as restrictive licenses. Given the time limit on implementing bycatch regulations in the shrimp fishery, the analysis of these different options could have a substantial impact on the final rules adopted by the fishery management decision makers. 


\section{Bibliography}

Adams, C.M. "Price Dynamics in the U.S. Shrimp Market." Dissertation, Department of Agricultural Economics, University of Florida, Gainesville, FL, 1984 .

Akin, J.S., D.K. Guilkey, and R. Sickles. "A Random Coefficient Probit Model with an Application to a study of Migration." Journal of Econometrics october - December (1979): 233-46.

Aldrich, J.H. and R.D. Nelson. Linear Probability, Logit, and Probit Models. Sage University Paper Series on Quantitative Applications in the Social Sciences, 07-045. Beverly Hills and London: Sage Publications, 1984 .

Alvarey, J., C.O. Andrew, and F.J. Prochaska. "Dual structure Equilibrium in the Florida Shrimp Processing Industry." Fishery Bulletin. 74(4) (1976): 879-883.

Aldrich, John H. and Forrest D. Nelson. Linear Probability, Logit, and Probit Models. Sage University Papers, Quantitative Applications in the Social Sciences, Series/Number 07-045. Beverly Hills: Sage Publications, 1984.

Amemiya, T. "The Estimation of a Simultaneous Equation Generalized Probit Model." Econometrica, 46(5) (1978): 1193-1205.

Amemiya, T. "Qualitative Response Models: A Survey." Journal of Economic Literature 19 (December) (1981): 1483-1536.

Anderson, I.G. "Optimal and Intra- and Interseasonal Harvesting strategies When Price Varies with Individual Size." Marine Resource Economics 6(2) (1989): 145-162.

Anonymous. "Revenues, Costs, and Returns from Vessel Operations in Major U.S. Fisheries." United states Department of Commerce, National Oceanic and Atmospheric Administration, National Marine Fisheries Service, National Technical Information Service PB-265275, Washington, D.C., February, 1977 . 
Arnason, Ragnar. "Minimum Information Management with the Help of Catch Quotas," in Rights Based Fishing, ed. P.A. Neher, et al. Boston: Kluwer Academic Publishers, 1989.

Bainton, B., J. Cantena, and D. Allen. "Matching Capital to Resources." Prepared by Atlantic Offshore Fishermen's Association, Saltonstall Kennedy Grant \#NA86AA-H-SK131, National Marine Fisheries Service, National Oceanic and Atmospheric Administration, United States Department of Commerce, 1987.

Bartel, A. "The Migration Decision: What Role Does Job Mobility Play?" American Economic Review December (1979): 775-86.

Beattie, B.R. and C.R. Taylor. The Economics of Production. New York: John Wiley and Sons, 1985.

Bell, Frederick W. and Vernon R. Leeworthy. "Economic Demand for Marinas and Projected Impact on Wetlands." Land Economics 63(1) (1987): 79-91.

Ben-Porath, Y. "Fertility Response to Child Mortality: Mirco Data from Israel." Journal of Political Economy August (1976): 163-78.

Berck, P. and J.M. Perloff. "An Open-Access Fishery with Rational Expectations." Econometrica $52(2)$ (1984): 489-506.

Berkson, J. "Application of the Logistic Function to Bio-Assay." Journal of the American statistical Association 39 (1944): 357-356.

Bjorndal, Trond and Jon M. Conrad. "Capital Dynamics in the North Sea Herring Fishery." Marine Resource Economics 4 (1987): 63-74.

Bjorndal, Trond and Jon M. Conrad. "The Dynamics of an Open Access Fishery." Canadian Journal of Economics $20(1)$ (1987): 74-85.

Blomo, V. and W.L. Griffin. "Cost and Returns Data Florida Based Gulf of Mexico Shrimp Trawlers, 1977." Tex. A\&M University sea Grant Report TAMUSG-79-604, 1978 .

Blomo, V.J., J.P. Nichols, W.L. Griffin, and W.E. Grant. "Dynamic Modeling of the Eastern Gulf of 
Mexico Shrimp Fishery." American Agricultural Economics Association August (1982): 475-482.

Blomo, V., K. Stokes, W. Griffin, W. Grant, and J. Nichols. "Bioeconomic Modeling of the Gulf Shrimp Fishery: An Application to Galveston Bay and Adjacent offshore Areas." Southern Journal of Agricultural Economics July (1978): 119-125.

Bockstael, N.E. Analysis of Investment Behavior and Price Determination: Analytical Input for the Formation of Policy in the Fisheries. Dissertation, Department of Resource Economics, University of Rhode Island, Kingston, Rhode Island, 1976.

Bockstael, N.E. and J.J. Opaluch. "Discrete Modelling of Supply Response Under Uncertainty: The Case of the Fishery." Journal of Environmental Economics and Management 10 (1983): 125-137.

Boskin, M.J. "A Conditional Logit Model of occupational Choice." Journal of Political Economy March - April (1974): 389-98.

Browder, J.A. "Vessel Activity Relative to the Texas Closure, 1981 and 1982." National Oceanic and Atmospheric Administration Technical Memorandum NMFS-SEFC-118, 1983.

Brunenmeister, S.L. "Standardization of Fishing Effort and Production Models for Brown, White and Pink Shrimp Stocks Fished in U.S. Waters of the Gulf of Mexico." In Penaeid shrimps - Their Biology and Management, eds. J.A. Gulland and B.J. Rothschild. Farnham, England: Fishing News Books Limited, 1984 .

Carothers, P.E. and W.E. Grant. "Fishery Management Implications of Recruitment seasonality: Simulation of the Texas Fishery for the Brown Shrimp, Penaeus Aztecus." Ecological Modeling 36 (1987): 239-268.

Chambers, R.G. Applied Production Analysis. Cambridge, New York: Cambridge University Press, 1988.

Clark, C.w. Mathematical Bioeconomics. New York: John Wiley and Sons, 1976.

Clark, C.W. Bioeconomic Modelling and Fisheries Management. New York: John Wiley and Sons, 1985. 
Clark, C.W. and G.P. Kirkwood. "Bioeconomic Model of the Gulf of Carpentaria Prawn Fishery." Journal of the Fisheries Research Board of Canada 36 (1979): 1304-1312.

Clark, C.W., F.H. Clarke, and G.R. Munro. "The optimal Exploitation of Renewable Resource Stocks: Problems of Irreversible Investment." Econometrica 47 (1) (1979): 25-47.

Clark, Jerry E. and Richard S. Johnston. "Open Access, Market structure, Optimality, and Entrepreneurship in the Fishery." Copies from Department of Agricultural and Resource Economics, Oregon state University, Corvallis, Oregon, 1986.

Clark, Simon and Donald A.R. George. "Investment in the British Fishing Industry." Economics Research Papers, No.10, Sea Fish Industry Authority, Fisheries Economics Research Unit, Sea Fisheries House, 10 Young St., Edinburgh EH2 4JQ, 1990.

Conroy, P.D. and J.R. Poffenberger. "Estimated Impacts of Texas Closure Regulation on Ex-Vessel Prices and Value of Shrimp, 1983 and 1984." National Oceanic and Atmospheric Administration Technical Memorandum NMFS-SEFC-171, 1986.

Cragg, J.G. and R.S. Unler. "The Demand for Automobiles." Canadian Journal of Economics August (1970): 386-406.

Cramer, J.A. Econometric Applications of Maximum Likelihood Methods. Cambridge: Cambridge University Press, 1986.

crutchfield, S. "Personal computer simulation of Two New England Trawl Fisheries." Fisheries Research 4 (2) (1986): 157-165.

Daganzo,c. Multinomial Probit. New York: Academic Press, 1979.

Danville Research Associates, Inc. "Work Plan for the Development of Cost, Revenue and Income Profiles for the Gulf and South Atlantic Shrimp Fleet." Prepared for the Southeast Fisheries center, National Marine Fisheries Service, Dec., 1982.

David, J.M. and W.E. Legg. "An Application of Multivariate Probit Analysis to the Demand for Housing: A Contribution to the Improvement of the 
Predictive Performance of Demand Theory, Preliminary Results." American Statistical Association Proceedings of the Business and Economics Statistical Section August (1975) : 295300 .

Dasgupta, P.S. and G.M. Heal. Economic Theory and Exhaustible Resources. New York: Cambridge University Press, 1979.

Da Vanzo, J. "Does Unemployment Affect Migration? Evidence from Micro Data." Review of Economics and Statistics November (1978): 504-14.

Deacon, R. and P. Shapiro. "Private Preference for Collective Goods Revealed Through Voting and Referenda." American Economic Review December $(1975): 943-55$.

Debreu, G. "Review of 'Individual Choice Behavior' by R. Luce," American Economic Review December (1975): $943-55$.

Doll, John P. "Traditional Economic Models of Fishing Vessels: A Review with Discussion." Marine Resource Economics 5 (1988): 99-128.

Domencich, T.A. and D. McFadden. Urban Transportation Demand. Amsterdam: North-Holland, 1975.

Duffy, J., Jr. and D.B. Johnson. "Study of Costs and Earnings of Bay Shrimp Fishermen in Louisiana." Southeast Fisheries Center, National Marine Fisheries Service, Louisiana state University, Baton Rouge, Louisiana, 1977.

Dubin, J.A. and D. McFadden. "An Econometric Analysis of Residential Electric Appliance Holdings and Consumption." Draft Report, February, 1980.

Duncan, G.M. "Formulation and Statistical Analysis of the Mixed, Continuous/Discrete Dependent Variable Model in Classical Production Theory." Econometrica March (1980): 839-52.

Duncan, G.M. and F. Stafford. "Do Union Members Receive Compensating Wage Differentials." American Economic Review June (1980): 355-71.

Fair, R.C. "The Effect of Economic Events on Votes for President." Review of Economics and Statistics May (1978): 159-73. 
Fields, G.S. "Place To Place Migration: Some New Evidence." Review of Economics and Statistics February (1979): 21-32.

Fomby, T.B., R.C. Hill, and S.R. Johnson. Advanced Econometric Methods. New York: Springer-Verlag, 1984.

Garcia, S. "The stock-Recruitment Relationship in Penaeid Shrimp: Reality or Artefact and Misinterpretations." Oceanographie Tropical 18 (1983): 25-48.

Garcia, S. "Environmental Aspects of Penaeid Shrimp Biology and Dynamics." In Penaeid Shrimps - Their Biology and Management, eds J.A. Gulland and B.J. Rothschild. Farnham, United Kingdom: Fishing New Books, 1984 .

Garcia, S. "Reproduction, Stock Assessment Models and Population Parameters in Exploited Penaeid Shrimp Populations." In Second Australian National Prawn Seminar, eds P.C. Rothlisberg, B.J. Hill, and D.J. Staples, NPS2, Cleveland, Queensland, Australia, 1985.

Garcia, S. "Tropical Penaeid Prawns." in Fish Population Dynamics, ed. J.A. Gulland, New York: John Wiley \& Sons, 1988.

Garcia, S. and L. Le Reste. "Life Cycles, Dynamics, Exploitation and Management of Coastal Penaeid Shrimp stocks." Fisheries and Agricultural organization Fishery Technical Papers, 203, 1981.

Goldberg, L. and F.C. Nold. "Does Reporting Deter Burglars - An Empirical Analysis of Risk and Return in Crime." Review of Economics and statistics August (1980): 424-31.

Goldberger, A.S. Econometric Theory. New York: John Wiley, 1964 .

Goodman, L.A. "A Modified Multiple Regression Approach to the Analysis of Dichotomous Variables." American Sociological Review February (1975) : 2846.

Gordon, H.S. "The Economic Theory of a Common Property Resource: The Fishery." Journal of Political Economy 62 (1954): 124-142. 
Grant, W. and W.L. Griffin. "Bioeconomic Model of the Gulf of Mexico Shrimp Resources." Transactions of American Fisheries Society Annual Meeting, Vancouver, British Columbia, September, 1977.

Grant, W.E. and W.L. Griffin. "A Bioeconomic Model of the Gulf of Mexico Shrimp Fishery." Transactions of the American Fisheries Society, 108(1) (1979): $1-13$.

Grant, W., W.L. Griffin, and J.P. Warren. "A Management Model of the Northwest African Cephalopod Fishery." Marine Fisheries Review 43 (11) (1981) : 1-10.

Grant, W.E., K.G. Isakson, and W.L. Griffin. "A General Bioeconomic Simulation Model for Annual Crop Marine Fisheries." Ecological Modelling 13 (1981) : 195-219.

Green, T. The Economic Value and Policy Implications of Recreational Red Drum Success Rate in the Gulf of Mexico. Marine Fisheries Initiative Contract No. NA87WC-H-06146 prepared for Southeast Regional Office, National Marine Fisheries Service, National Oceanic and Atmospheric Administration, st. Petersburg, Florida, July, 1989.

Griffin, W.L. Fleetsim: A General Fleet Level Policy Simulation Model. Texas A\&M University, 1988.

Griffin, W.L. and B. Beattie. "Economic Impact of Mexico's 200-Mile offshore Fishing Zone on the U.S. Gulf of Mexico Shrimp Fishery. Land Economics 54 (1978): 27-38.

Griffin, W.L. and W.E. Grant. "A Bioeconomic Analysis of the Ivory Coast Shrimp Fishery." United Nations Development Programme, Food and Agricultural Organization of the United Nations, CECAF/TECH/82/41 (En), 1981.

Griffin, W.L. and W.E. Grant. "General Bioeconomic Fisheries Simulation Model." Draft report, Department of Agricultural Economics, Texas A\&M University, College Station, Texas, 1991.

Griffin, W.L., R.D. Lacewell, and W. Hayenga. "Estimate Costs and Returns and Financial Analysis: Gulf of Mexico Shrimp Vessels." Marine Fisheries Review $36(12)$ (1974) : 1-4. 
Griffin, W.L., R.D. Lacewell, and J.B. Smith. "Economic Analysis of Returns to Gulf of Mexico Shrimp Vessel Owners for the Period 1971 - 1975." Texas A\&M University Staff Paper, DIR 75-1, Sp-4, 1975.

Griffin, W.L. and J.P. Nichols. "An Analysis of Increasing Costs to Gulf of Mexico Shrimp Vessel Owners, 1971-75." Marine Fisheries Review 38(3) (1976): 8-12.

Griffin, W.L., J.P. Nichols, w.E. Grant, and J.P. Warren. "Analysis of Management Alternatives for the Texas Shrimp Fishery." DIR 81-1, Staff Paper No. 1, Department of Agricultural Economics, Texas Agricultural Experiment Station, Texas A\&M University, February, 1981.

Griffin, W.I., J.P. Nichols, and J.B. Smith. "Economic Analysis of Returns to Gulf of Mexico Shrimp Vessel Owners for the Period 1971-75." Tex. A\&M University Staff Paper, DIR 75-1, SP-4, 1975.

Griffin, W.L., N.J. Wardlaw, and J.P. Nichols. "Cost and Return Analysis by Selected Vessel

Characteristics: Gulf of Mexico Shrimp Fishery, 1971-75." Texas Agricultural Experiment Station, Texas A\&M University, Report MP-1253C, 1976.

Griffin, W.L., J.P. Warren, and W. Grant. "A Bioeconomic Model for Fish Stock Management: The Cephalopod Fishery of Northwest Africa." United Nations Development Programme, Food and Agricultural Organization of the United Nations, CECAF/TECH/79/16 (En), 1979.

Griffin, W., J. Warren, J. Nichols, W. Grant, and C. Pardy. "The Texas Shrimp Fishery: Analysis of Six Management Alternatives Using the General Bioeconomic Fishery Simulation Model (GBFSM)." TAMU-SG-84-202, Sea Grant College Program, Texas A\&M University, College Station Texas, October, 1983.

Gronau, R. "The Allocation of Time of Israeli Women." Journal of Political Economy August (1976): 20120.

Gulland, J.A. and B.J. Rothschild. Penaeid Shrimps Their Biology and Management. Norwich, Norfolk, Great Britain: Fishing News Books Limited, Page Bros. Ltd. 1984 . 
Gunderson, M. "Retention of Trainees: A study with Dichotomous Dependent Variables." Journal of Econometrics May (1974): 79-93.

Gurland, J., I. Lee, and P.A. Dahm. "Polychotomous Quantal Response in Biological Assay." Biometrics September (1960): 382-98.

Hannesson, R. "Bioeconomic Production Function in Fisheries: Theoretical and Empirical Analysis." Canadian Journal of Fisheries and Aquatic Science 40 (1983): 968-982.

Hausman, J.A. "Individual Discount Rates and the Purchase and Utilization of Energy-Using Durables." Bell Journal of Economics and Management Science Spring (1979): 33-54.

Hausman, J.A. and D, McFadden. "A Specification Test for the Independence of Irrelevant Alternatives in Logit Models." Unpublished Paper given at the European Workshop on Discrete Choice Models, 1981.

Hausman, J.A. and D.A. Wise. "A Conditional Probit Model for Qualitative Choice: Discrete Decisions Recognizing Interdependence and Heterogeneous Preferences." Econometrica March (1978): 403-26.

Heckman, J.J. "Simultaneous Equations Models with Continuous and Discrete Endogenous Variables and structural shifts." in studies in Nonlinear Estimation, eds. S.M. Goldfeld and R.E. Quandt. Cambridge, Mass: Ballinger, 1976.

Heckman, J.J. and R.J. Willis. "Estimation of a Stochastic Model of Reproduction: An Econometric Approach." In Household Production and Consumption, ed. N.E. Terleckyj, New York: NBER, 1975.

Heckman, J.J. and R.J. Willis. "A Beta-Logistic Model for the Analysis of Sequential Labor Force Participation by Married Women." Journal of Political Economy February (1977): 27-58.

Hill, C.R. "Capacities, Opportunities, and Educational Investments: The Case of the High School Dropout." Review of Economics and statistics February (1979): 9-20.

Hilborn, R. "Fleet Dynamics and Individual Variation: Why some People Catch More Fish than Others." 
Canadian Journal of Fisheries and Aquatic Science 42 (1985): 2-13.

Hill, C.R. "Capacities, Opportunities and Educational Investments: The Case of the High School Dropout." Review of Economics and Statistics February (1979): 9-20.

Hughes, G.A. "On the Estimation of Migration Equations." Draft report. Faculty of Economics, Cambridge University, 1980.

Huppert, D.D. "Implications of Multipurpose Fleets and Mixed Stocks for Control Policies.: Journal of the Fisheries Research Board of Canada 36 (1979):845-854.

Intriligator, M. Econometric Models, Techniques, and Applications. New Jersey: Prentice-Hall, 1978.

Johansen, L. Production Functions. Amsterdam: NorthHolland Publishing Co., 1972.

Judge, G.G., W.E. Griffiths, R.C. Hill, and T. Lee. The Theory and Practice of Econometrics. New York: John Wiley and Sons, 1980.

Judge, G.G., W.E. Griffiths, R.C. Hill, H. Lutkepohl, and $T$. Lee. The Theory and Practice of

Econometrics, second edition. New York: John wiley and Sons, 1985.

Judge, G.G., R.C. Hill, W.E. Griffiths, H. Lutkepohl, and $T$. Lee. Introduction to the Theory and Practice of Econometrics. New York: John Wiley and Sons, 1982 .

Kahn, L.M. and K. Morimune. "Unions and Employment Stability: A Sequential Logit Approach." International Economics Review February (1979): 217-36.

Karpoff, J.M. "Time, Capital Intensity, and the cost of Fishing Effort." Western Journal of Agricultural Economics 10(2) (1985): 254-258.

Kau, J.B. and P.H. Rubin. "Voting on Minimum Wages: A Time Series Approach." Journal of Political Economy April (1978): $337-42$.

Keithly, W.R., Jr. and Liz Baron-Mounce. "An Economic Assessment of the Louisiana Shrimp Fishery." 
Final report to National Marine Fisheries Service, NA88WC-H-MF179, October, 1990.

Keithly, W.R., Jr. and Liz Baron-Mounce. "Louisiana Shrimp Fishery: An Economic Perspective with Emphasis on the 1987 Inshore Fleet." Submitted to National Oceanic and Atmospheric Administration Technical Report, National Marine Fisheries Service, 1991.

Keithly, w.R., Jr. and K.J. Roberts. "An Economic Analysis of U.S. Shrimp Imports and Dockside Prices with Policy Implications." Draft Report, Center for Wetland Resources, Louisiana State University, Baton Rouge, Louisiana, 1991.

Kmenta, J. "On Estimation of the CES Production Function." International Economic Review 8 (1967): 180-89.

Kohn, M.G., C.F. Manski, and D.S. Mundel. "An Empirical Investigation of Factors Which Influence college-Going Behavior." Annals of Economic and Sociological Measurement Fall (1976): 391-420.

Krauthamer, J.T., W.E. Grant, and W.L. Griffin. "Characteristics of the Texas Shrimp Fleet, 197982." Marine Fisheries Review 46(2) (1984): 53-59.

Lane, D.E. "A Partially Observable Model of Decision Making by Fishermen." Working Paper 86-46. University of ottawa, Ontario, Canada, 1986.

Lane, D.E. "Investment Decision Making by Fishermen." Working Paper 87-20, University of Ottawa, Ontario, Canada, 1987.

Lave, C.A. "The Demand for Urban Mass Transportation." Review of Economics and Statistics August (1970): $320-23$.

Lee, L.F. "Estimation of a Modal Choice Model for the Work Journey with Incomplete Observations." Draft Report. Department of Economics, University of Minnesota, 1977.

Lee, L.F. "Unionism and Wage Rates: A Simultaneous Equations Model with Qualitative and Limited Dependent Variables." International Economic Review June (1978): 1081-98. 
Li, M.M. "A Logit Model of Home Ownership." Econometrica July (1977): 1081-98.

Liao, D.S. "An Economic Analysis of Mobility of Shrimp Vessels in the South Atlantic States." South Carolina Marine Research Center Technical Report No. $35,1979$.

Long, J.E. and E.B. Jones. "Labor Force Entry and Exit by Married women: A Longitudinal Analysis." Review Economics and Statistics February (1980): 1-6.

Luce, R.D. and P. Suppes. "Preference, Utility, and Subjective Probability," in Handbook of

Mathematical Psychology, Vol. 3, eds. R.D. Luce, R. Bush, and E. Galanter. New York: John Wiley, 1965 .

Kurkle, P. "Northeast Region Financial Information System." Draft Working Paper, National Marine Fisheries Service, Northeast Regional office, 1986 .

McFadden, D. "Conditional Logit Analysis of Qualitative Choice Behavior" in Frontiers in Econometrics, ed. P. Zarembka. New York: Academic Press, 1974 .

McFadden, D. "Quantal Choice Analysis: A Survey." Annals of Economic and Sociological Measurement Fall (1976a) : 363-90.

McFadden, D. "The Revealed Preferences of a Government Bureaucracy: Empirical Evidence." Bell Journal of Economics and Management Science Spring (1976b): 55-72.

McFadden, D. "Qualitative Methods for Analyzing Travel Behavior of Individuals: Some Recent

Developments." In Behavioral Travel Modeling, ed. D. Hensher and P. Stopher. London: Croom-Helm, 1979 .

McFadden, D. "Modeling the Choice of Residential Location." In Spatial Interaction Theory and Residential Location, ed. A. Karlqvist, et al. Amsterdam: North-Holland, 1978.

McFadden, D. "Qualitative Response Models." In Advances in Econometrics, Invited Papers for the Fourth World Congress of the Econometric Society at Aix-En-Provence, September, 1980, ed. W. 
Hildenbrand. Cambridge: Cambridge University Press, 1985.

McGillivray, R.G. "Binary Choice of Urban Transport Mode in the San Francisco Bay Region." Econometrica September (1972): 827-48.

McKelvey, R. "The Fishery in a Fluctuating Environment: Coexistence of Specialist and Generalist Fishing Vessels in a Multipurpose Fleet." Journal of Economics and Environmental Management 10 (1983): 287-309.

McKelvey, R.D. and W. Zavoina. "A Statistical Model for the Analysis of Ordinal Level Dependent Variables." Journal of Mathematical Sociology 4 (1975): 103-120.

Maddala, G.S. Limited-Dependent and Qualitative Variables in Econometrics. Cambridge University Press, 1983.

Mayor, T.H. "Some Theoretical Difficulties in the Estimation of the Elasticity of substitution from Cross-Sectional Data." Western Economic Journal 7 (1969) : 153-163.

Medoff, J.L. "Layoffs and Alternatives Under Trade Unions in U.S. Manufacturing." American Economic Review June (1979): 380-95.

Meuriot, Eric. "Fishing Fleet Replacement: The French Policy from 1945 - 1983." Marine Policy 10(4) $(1986)$ : 294-309.

Milon, J.W. Estimating Recreational Angler Participation and Economic Impact in the Gulf of Mexico Mackerel Fishery. Marine Fisheries Initiative Contract No. NA86WC-H-06116 prepared for Sotheast Regional office, National Marine Fisheries Service, National Oceanic and Atmospheric Administration, St. Petersburg, Fl., July, 1988 .

Montegut, R.S. "Planning to Buy a Shrimp Boat? Some Things to Consider First." Louisiana State University Sea Grant Publ. LSU-TL-79-005, 1979.

Moore, W.J., R.J. Newman, and R.W. Thomas. "Determinants of the Passage of Right-To-Work Laws: An Alternative Interpretation." Journal of Law and Economics April (1974): 197-211. 
Nance, J.M., E.F. Klima, and E.X. Martinez. "Impacts of Proposed Brown Shrimp Fishery Management

Closures in the Gulf of Mexico." Report for the Gulf of Mexico Fishery Management Council,

December, 1990.

Nance, J.M., Edward F. Klima, Peter F. Sheridan, K. Neal Baxter, Frank J. Patella, and Dennis B. Koi, Review of the 1987 Texas Closure for the shrimp Fishery off Texas and Louisiana, Presented at the Gulf of Mexico Fishery Management Council Shrimp Advisory Panel Meeting, Tampa, Florida, January, 1988 .

Nerlove, M. "Recent Empirical Studies of the CES and Related Production Functions," in The Theory and Empirical Analysis of Production, National Bureau of Economic Research, ed. M, Brown. New York: Columbia University Press, 1967.

Nickell, S. "Education and Lifetime Patterns of Unemployment." Journal of Political Economy October (1979): 117-31.

Nichols, S. "Stock Assessments for Brown, White, and Pink Shrimp in the U.S. Gulf of Mexico, 1960 1985." United States Department of Commerce, National Oceanic and Atmospheric Administration, National Marine Fisheries Service, Miami Laboratory, 1986.

Nichols, S., A. Shah, and G. Pellegrin, Jr. "Estimates of Annual Shrimp Fleet Bycatch for Thirteen Finfish Species in the offshore Waters of the Gulf of Mexico." Draft report. National Marine Fisheries Service, Southeast Fisheries Center, Mississippi Laboratory, Pascagoula Facility, 1987.

Osten, S. "Industrial Search for New Locations: An Empirical Analysis." Review of Economics and Statistics May (1979): 288-92.

Ostrom, C.W., Jr. and J.H. Aldrich. "The Relationship Between size and stability in the Major Power International System." American Journal of Political Science 22(4) (1978): 743-771.

Orth, Geoffry C. "Fishing Strategies Among Southeast Alaskan Salmon Seiners." Unpublished Masters Thesis. Department of Anthropology, University of Alaska, Fairbanks, AK, 1986. 
Parks, R.W. "Determination of Scrapping Rate for Postwar Vintage Automobiles." Econometrica July (1977): 1099-1116.

Parks, R.W. "On the Estimation of Multinomial Logit Models from Relative Frequency Data." Journal of Econometrics August (1980): 293-304.

Parsons, D.O. "The Decline in Male Labor Force Participation." Journal of Political Economy February (1980a): 117-34.

Parsons, D.O. "Racial Trends in Male Labor Force Participation." American Economic Review December $(1980 \mathrm{~b})$ : $911-20$.

Paterson, D.G. and J. Wilen. "Depletion and Diplomacy: The North Pacific Seal Hunt." Research in Economic History 2 (1977): 81-139.

Pellegrin, G.J., Jr., S.B. Drummond, and R.S. Ford, Jr. The Incidental Catch of Fish by the Northern Gulf of Mexico Shrimp Fleet. Draft Report, National Oceanic and Atmospheric Administration, National Marine Fisheries Service, Southeast Fisheries Center, Mississippi Laboratories, Pascagoula, MS, 1985.

Pencavel, J.H. "Market Work Decisions and Unemployment of Husbands and Wives in the Seattle and Denver Income Maintenance Experiments." Mimeographed, April, 1979.

Penson, John B., Jr., Ernest o. Tetty, and Wade I. Griffin. "An Econometric Analysis of Net Investment in Gulf Shrimp Fishing Vessels." Technical Article No. TA-20803 of the Texas Agricultural Experiment Station, Texas A\&M University, 1987.

Perloff, J.M. and M.L. Wachter. "The New Jobs Tax Credit: An Evaluation of the 1977-78 Wage Subsidy Program." American Economic Review May (1979): 173-79.

Poffenberger, J.R. "Estimated Impacts on Ex-Vessel Brown Shrimp Prices and Value as a Result of the Texas Closure Regulation." Marine Fisheries Review $44(9-10)$ (1982a): 38-43.

Poffenberger, J.R. "Estimated Impacts of Texas Closure Regulation on Ex-Vessel Prices and Value, 1981 and 
1982." National Oceanic and Atmospheric

Administration Technical Memorandum NMFS-SEFC-111, $1982 \mathrm{~b}$.

Poffenberger, J.R. "Economic Impacts of the Texas Closure Regulation on Ex-Vessel Prices and Value, 1984 and 1985." National Oceanic and Atmospheric Administration Technical Memorandum, NMFS-SEFC184, October, 1986a.

Poffenberger, J.R. "Economic Impacts of the Texas Closure, 1981 - 1985." Draft report prepared for the Gulf of Mexico Fishery Management Council, December, 1986b.

Poffenberger, J.R.. "Economic Impacts of the Texas Closure, 1985 - 1986." Draft report prepared for the Gulf of Mexico Fishery Management Council, 1987.

Powers, J.A., L.C. Marsh, R.R. Huckfeldt, and Johnson. "A Comparison of Logit, Probit and Discriminant Analysis in Predicting Family Size." American Statistical Association Proceedings of the Sociological Statistics Section Aug. (1978): 69397.

Prochaska, F.J. "Shrimp Mariculture and Imports: Effects on U.S. Markets and Research Needs." Presented at the Miami Economics Workshop, September, 1985.

Prochaska, F.J. and C.M. Adams. "Analysis of U.S. Shrimp Prices at Exvessel, Wholesale, and Retail Market Levels." Draft report, Department of Food and Resource Economics, University of Florida, 1987.

Prochaska, F.J. and C.O. Andrew. "Shrimp Processing in the Southeast: Supply Problems and Structural Change." Southern Journal of Agricultural Economics July (1974): 247-252.

Prochaska, F.J. and J.C. Cato. "Economic Conditions in the Gulf of Mexico Shrimp Industry: 1960 - 1981." Staff Paper 180, Food and Resource Economics Department, Institute of Food and Agricultural Sciences, University of Florida, Gainesville. April, 1981.

Prochaska, F., J. Cato, and J. Taylor. "Economic Returns in Operating Atlantic Coast Charter and 
Party Boats." University of Florida, Sea Grant, MAP-28, August, 1982.

Prochaska, F.J. and W.R. Keithly. "Market Impacts of U.S. Shrimp Imports." Draft, University of Florida, Department of Agricultural Economics, Gainesville, Fl, 1984 .

Prochaska, F.J., M. Suazo, and W.R. Keithly. "World Shrimp Production Trends and the U.S. Import Market." Tropical and Subtropical Fisheries Technical Conference Proceedings, 1983.

Quandt, R.E. "Estimation of Modal Splits." Transportation Research (1968): 41-50.

Quandt, R.E. and W.J. Baumol. "The Demand for Abstract Transport Modes: Theory and Measurement." Journal of Regulatory Science Winter (1966): 13-26.

Radner, R. and L.S. Miller. "Demand and Supply in U.S. Higher Education: A Progress Report." American Economic Review, Papers and Proceedings May $(1970): 326-34$.

Roberts, K.J. and M.E. Sass. "Financial Aspects of Louisiana Shrimp Vessels, 1978." Louisiana State University Sea Grant Report LSU-TL-79-007, 1979.

Rosen, H.S. and K.T. Rosen. "Federal Taxes and Home Ownership: Evidence from Time Series." Journal of Political Economy February (1980): 59-75.

Rothschild, B.J. and S.L. Brunenmeister. "The Dynamics and Management of Shrimp in the Northern Gulf of Mexico." In Penaeid Shrimps - Their Biology and Management, eds. J.A. Gulland and B.J. Rothschild. Farnham, England: Fishing News Books Limited, 1984 .

Schiller, B.R. and R.D. Weiss. "The Impact of Private Pensions on Firm Attachment." Review of Economics and Statistics August (1979): 369-80.

Schmidt, P. and R.P. Strauss. "The Prediction of Occupation Using Multiple Logit Models."

International Economic Review June (1975): 471-86.

Schmidt, P. and R.P. Strauss. "The Effects of Unions on Earnings and Earnings on Unions: A Mixed Logit Analysis." International Economic Review February (1976): 204-12. 
Silberman, J.I. and G.C. Durden. "Determining Legislative Preferences on the Minimum Wage: An Economic Approach." Journal of Political Economy April (1976): 317-29.

Smith, C. and R. McKelvey. "Specialist and Generalists: Roles for Coping with Variability." North American Journal of Fisheries Management 6 $(1986)$ : 88-99.

Smith, J.P. "The Distribution of Family Earnings." Journal of Political Economy October (1979): 16392 .

Smith, V.I. "Economics of Production from Natural Resources. American Economic Review 58 (1968): 409-431.

Smith, V.L. "On Models of Commercial Fishing." Journal of Political Economy 77 (1969): 181-198.

Spector, L.C. "The Effectiveness of a Personalized System of Instruction in Economics." Journal of Personalized Instruction 1(2) (1976).

Spector, L.C. and M. Mazzeo. "Probit Analysis and Economic Education." Journal of Economic Education 11 (1980): 37-44.

Squires, Dale. "Public Regulation and the structure of Production in Multiproduct Industries: An Application to the New England otter Trawl Industry." Rand Journal of Economics 18 (2) summer, (1987).

Squires, Dale. "Production Technology, Costs, and Multiproduct Industry Structure: An Application of the Long-Run Profit Function to the New England Fishing Industry." Canadian Journal of Economics, in press, 1987.

Stollery, K.R. "Monopsony Processing in an open-Access Fishery." Marine Resource Economics 3 (4) (1987): $331-351$.

Sutinen, J.G. "Seasonality in Renewable Resource Models." Presented at the annual meeting of the Allied Social Science Association, New orleans, Louisiana, December, 1986.

Swartz, A.M. and C.M. Adams. "The Economics of Rockport Bay Texas Shrimping Vessels." Report DIR 
79-1, SP-6 Department of Agricultural Economics, Texas A\&M University, 1979.

Talvitie, A. "Comparison of Probabilistic Modal Choice Models: Estimation Methods and System Inputs." National Academy of Science, National Research Council, Highway Research Board, Record 392 (1972): 111-20.

Tettey, E.O. "The Gulf of Mexico Shrimp Fishery: An Econometric Analysis of Real Net Investment in Fishing Vessels." Dissertation, Department of Agricultural Economics, Texas A\&M University, college station, 1983.

Tettey, E.O., and W.L. Griffin. "Investment in Gulf of Mexico Shrimp Vessels, 1965-77." Marine Fisheries Review $46(2)$ (1984): 49-52.

Tettey, E.O., W.L. Griffin, and J.B. Penson. "Real Net Investment in Gulf Shrimp Fishing Vessels." Technical Article, Texas Agricultural Experiment station, Department of Agricultural Economics, Texas A\&M University, College Station, 1983.

Tettey, E.O., W.L. Griffin, J.B. Penson, and J.R. stoll. "Implications of Tax Policy on Investment in a Common Property Resource." North American Journal of Fisheries Management 6 (1986): 100-104.

Tettey, E., C. Pardy, and W. Griffin. "Economic Analysis of Investment Alternatives for the Gulf of Mexico Shrimp Vessels." Draft Report, Texas A\&M University, 1982.

Theil, H. Principles of Econometrics. New York: Wiley, 1971.

Thompson, R.G., M.D. George, R.J. Callen, and L.C. Wolken. "A Stochastic Investment Model for a Survival Conscious Firm Applied to Shrimp Fishing." Epplied Economics 5 (1973): 75-87.

Tollefson, J.O. and J.A. Pichler. "A comment on RightTo-Work Laws: A Suggested Economic Rationale." Journal of Law and Economics April (1974): 19396.

Townsend, R.E.. "On 'Capital - Stuffing' in Regulated Fisheries." Land Economics 61(2) (1985): 195-197. 
Townsend, R.E. "Empirical Evidence on Limited Entry: A Survey." Draft report, Department of Economics, University of Maine, Orono, Me, 1987.

Tse, E. and A. Khilnani. "An Integrated System Model for a Fishery Management Process-I." Computers and Mathematical Applications $17(8 / 9)$ (1989a): 1329-1343.

Tse, E. and A. Khilnani. "An Integrated System Model for a Fishery Management Process-II. A Case Study." Computers and Mathematical Applications $17(6 / 7)(1989 \mathrm{~b}): 675-690$.

Uhler, R.S. "The Demand for Housing: An Inverse Probability Approach." Review of Economics and Statistics February (1968): 129-34.

Wang, D.H. and Christopher B. Kellog. "American Lobster Demand and Choice of Sizes in the United states." Mimeograph. National Oceanic and Atmospheric Administration/National Marine Fisheries Service, Northeast Region Analytical Services Branch, Gloucester, MA, 1986.

Ward, J.M. "A Synthesis of Cost and Revenue Surveys for Gulf of Mexico Shrimp Vessels." Marine Fisheries Review 50(1) (1988): 47-52.

Ward, J.M. "Modelling fleet size in the Gulf of Mexico Shrimp Fishery, 1966 - 1979." National Oceanic and Atmospheric Administration Technical Memorandum National MFS-SEFC-229, 1989.

Ward, J.M. "Feasibility Study of Vessel Entry and Exit Behavior Using the Gulf of Mexico Shrimp Fishery Data Set from 1965-80." National Oceanic and Atmospheric Administration Technical Memorandum NMFS-SEFC-231, 1989.

Ward, J.M. and S. Sinha. "Resource Value Impacts of the Texas Closure for 1986-1987." Report prepared for the Gulf of Mexico Fishery Management Council, Jan. , 1988 .

Warming, J. "Om Grundrente af Fiskegrunde," Nationaløkonomisk Tidssdift 49 (1911): 499-505.

Warner, S.L. Stochastic Choice of Node in Urban Travel-A Study in Binary Choice. Evanston, Ill.: Northwestern University Press, 1962. 
Warren, J.P., and W.L. Griffin. "Cost and Return Trends for Gulf of Mexico Shrimp Vessels." Texas A\&M University, Staff Paper Series, Dir 78-1, SP4,1978 .

Warren, J.P., W.L. Griffin, and R.D. Lacewell. "Applying an Index of Fishing Effort to Estimated 1971 Costs and Returns for Gulf of Mexico Shrimp Vessels." Department of Agricultural Economics, Texas A\&M University, Sea Grant Report TAMU-SG-74217,1974 .

Warren, R.S. and R.P. Strauss. "A Mixed Logit Model of the Relationship Between Unionization and RightTo-Work Legislation." Journal of Political Economy June (1979): 648-55.

Waters, J. and J. Platt. "Economic Analyses of Alternative Management options for the Red snapper Fishery in the Gulf of Mexico." Report prepared for the Gulf of Mexico Fishery Management council. Southeast Regional office, National Marine Fisheries Service. July, 1990.

Watson, P.L. and R.B. Westin. "Transferability of Disaggregate Mode Choice Models." Regulatory Science and Urban Economics May (1975): 227-49.

Weisberg, H.F. "Evaluating Theories of Congressional Roll-Call Voting." American Journal of Political Science 22(3) (1978): 554-577.

Westin, R.B. "Predictions from Binary Choice Models." Journal of Econometrics May (1974): 1-16.

Wilensky, G.R. and L.F. Rossiter. "OLS and Logit Estimation in a Physician Location Study." American Statistical Association Proceedings of the Sociological statistics Section August (1978): $260-265$.

Willis, R.J. and S. Rosen. "Education and SelfSelection." Journal of Political Economy October (1979) : 7-36.

Witte, A.D. and P. Schmidt. "An Analysis of the Type of Criminal Activity Using the Logit Model." Journal of Research in Crime and Delinquency January (1979): 164-79. 
Wu, D.M. "An Empirical Analysis of Household Durable Goods Expenditure." Econometrica October (1965): 761-80. 